Final Report

FHWA/IN/JTRP-2002/20

\title{
EFFECTS OF HEAVIER TRUCK LOADINGS AND SUPER-SINGLE TIRES ON SUBGRADES
}

\author{
By \\ Rodrigo Salgado \\ Principal Investigator \\ Associate Professor of Civil Engineering \\ Daehyeon Kim \\ Graduate Research Assistant \\ Joint Transportation Research Program \\ Project No: C-36-52R \\ File No: 6-20-17 \\ SPR-2402 \\ Conducted in Cooperation with the \\ Indiana Department of Transportation \\ and the U.S. Department of Transportation \\ Federal Highway Administration
}

The contents of this report reflect the views of the authors who are responsible for the facts and accuracy of the data presented herein. The contents do not necessarily reflect the official views or policies of the Indiana Department of Transportation and Federal Highway Administration. This report does not constitute a standard, specification, or regulation.

Purdue University

West Lafayette, Indiana

November 2002 
TECHNICAL REPORT STANDARD TITLE PAGE

\begin{tabular}{|c|c|c|}
\hline $\begin{array}{l}\text { 1. Report No. } \\
\text { FHWA/IN/JTRP-2002/20 }\end{array}$ & 2. Government Accession No. & 3. Recipient's Catalog No. \\
\hline \multirow{2}{*}{\multicolumn{2}{|c|}{$\begin{array}{l}\text { 4. Title and Subtitle } \\
\text { Effects of Heavier Truck Loadings and Super-Single Tires on Subgrades }\end{array}$}} & 5. $\quad$ Report Date \\
\hline & & 6. Performing Organization Code \\
\hline \multicolumn{2}{|l|}{$\begin{array}{l}\text { 9. Performing Organization Name and Address } \\
\text { Joint Transportation Research Program } \\
\text { 1284 Civil Engineering Building } \\
\text { Purdue University } \\
\text { West Lafayette, IN 47907-1284 }\end{array}$} & 10. Work Unit No. \\
\hline \multirow{2}{*}{\multicolumn{2}{|c|}{$\begin{array}{l}\text { 12. Sponsoring Agency Name and Address } \\
\text { Indiana Department of Transportation } \\
\text { State Office Building } \\
100 \text { North Senate Avenue } \\
\text { Indianapolis, IN } 46204\end{array}$}} & $\begin{array}{l}\text { 13. Type of Report and Period Covered } \\
\text { Final Report }\end{array}$ \\
\hline & & 14. Sponsoring Agency Code \\
\hline \multicolumn{3}{|l|}{ 15. Supplementary Notes } \\
\hline
\end{tabular}

\section{Abstract}

Due to their efficiency and economy, super-single tires have gradually been replacing conventional dual tires in the trucking industry. According to recent studies, super-single tires generate much higher vertical contact stresses than do conventional dual tires, resulting in larger deformations and more severe damage to the subgrade. In order to better assess the higher stresses generated by super-single tires and their effect on the subgrade, analyses are done taking into account soil plasticity rather than simple elastic analysis. In this study, the effects of super-single tires on subgrades for typical road cross-sections are investigated using plane-strain (2D) and 3D static and dynamic finite element analyses. The analyses focus on the sand and clay subgrades rather than on asphalt and base layers. The subgrades are modeled as saturated in order to investigate the effects of porewater pressures under the most severe conditions. The analyses suggest that current flexible pavement design methods are unconservative for the increased loads imposed by super-single tires on the pavement system. Load Equivalent Factors (LEF) and damage factors for super-single tires are suggested for use of those values in design practice. The effects of overlay and subgrade improvement are investigated in order to mitigate the higher strains generated by super-single tire loadings in the subgrade. Subgrade improvement allows decreasing the adverse effects of super-single tires on the subgrades. FE analyses are also done in order to assess the performance of the Indiana typical pavements for the super-heavy loads (occurred in Texas during 1990s). This investigation is to evaluate how much plastic strain by super-heavy loads occurs in the subgrade and asphalt layers as compared with the super-single tire loadings.

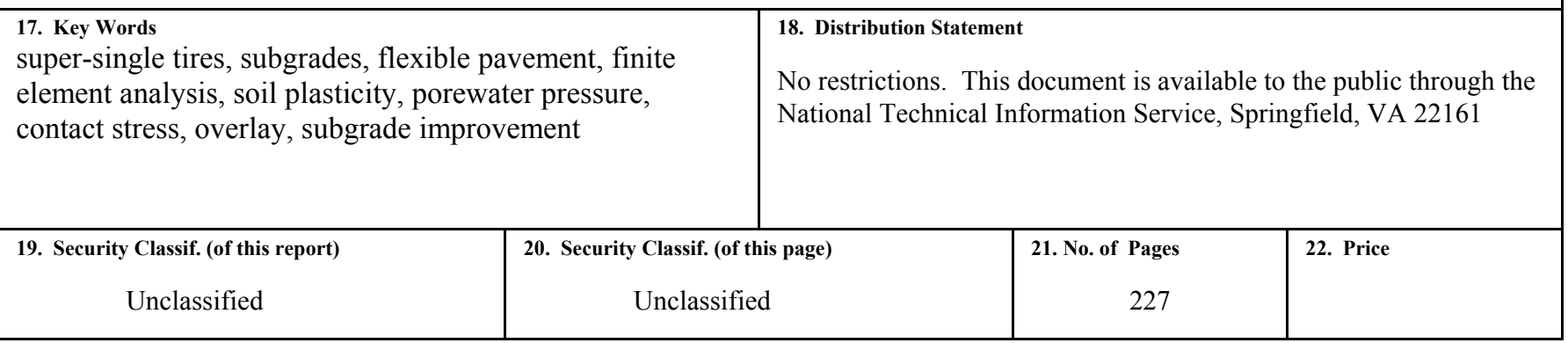




\section{TECHNICAL Summary}

INDOT Research

Technology Transfer and Project Implementation Information

TRB Subject Code:62-7 Soil Foundation Subgrades

Publication No.: FHWA/IN/JTRP-2002/20, SPR-2402

November 2002

Final Report

\section{Effects of Heavier Truck Loadings and Super-Single Tires on Subgrades}

\section{Introduction}

In the last two decades, use of supersingle tires has slightly increased, with the aim of improving efficiency and economy. Since the contact stresses generated by super-single tires are higher than those of conventional dual tires, this change has caused concern about possible damage to pavements designed based on the current design methods. The higher the contact stresses on the pavement surface, the larger the subgrade deformation, and the more severe the damage to the subgrade.
In order to investigate the effects of super-single tire loadings on subgrades for typical Indiana road cross-sections, static and dynamic finite element analyses were performed taking into account the realistic shape of the contact area and the increased vertical contact stress. Subgrade soils were modeled as saturated to consider the most severe conditions possibly occurring during the pavement design life.

\section{Findings}

It was found that the direction of the maximum tensile stress is dependent on the shape of the contact area and stress distribution. Supersingle tires generate larger transverse tensile strain than longitudinal tensile strain at the bottom of the asphalt layer.

The analyses showed that super-single tires induce larger permanent strains in the pavement layers than conventional tires. Therefore, design of a pavement using Load Equivalency Factors (LEF) for dual tires may lead to overestimation of the pavement design life. Single axle loadings with super-single tires induce the largest vertical plastic strains on top of the subgrade rutting of all the axle configurations considered.

Analysis results also show that the higher the speed of the truck, the less the load on the subgrade. Since repeated super-single tire loadings increase vertical permanent strains in the subgrade for existing roads, either mitigation of permanent strains in the subgrade may be pursued or the number of passages of supersingle tires could be limited by appropriate regulation.

For clay subgrades, the higher the Over Consolidation Ratio (OCR), the less the deformation. Positive pore pressures are generated in normally consolidated clay subgrades, while negative pore pressures are typically generated within heavily overconsolidated clays and dense sands. Therefore, in a Normally Consolidated (NC) clayey subgrade, the shear strength is reduced as a result of traffic loadings due to the pore pressure build-up.

Vertical strains induced by supersingle tires can be mitigated either by subgrade modification or by adding a structural overlay.

\section{Implementation}

The research results can be helpful for designing for super-single heavier traffic loads. It would be necessary to indicate that information regarding the extent of super-single tires on INDOT highways need to be collected. This is essential in order to use the analysis 
presented in this report for pavement design including factor of super-single tire loads. In addition, information regarding subgrade type, classification and strength characteristics need to be also present. With the presence of these pieces of information, the study provides two options for the design; to mitigate the effect of super-single tires, 1) improving subgrade strength or 2) adding an adequate structural overlay.

\section{Contacts}

For more information:

Prof. Rodrigo Salgado

Principal Investigator

School of Civil Engineering

Purdue University

West Lafayette IN 47907

Phone: (765) 494-5030

Fax: (765) 496-1364
Indiana Department of Transportation

Division of Research

1205 Montgomery Street

P.O. Box 2279

West Lafayette, IN 47906

Phone: (765) 463-1521

Fax: (765) 497-1665

\section{Purdue University}

Joint Transportation Research Program

School of Civil Engineering

West Lafayette, IN 47907-1284

Phone: (765) 494-9310

Fax: (765) 496-1105 


\section{Introduction}

In the last two decades, use of super-single tires has slightly increased, with the aim of improving efficiency and economy. Since the contact stresses generated by supersingle tires are higher than those of conventional dual tires, this change has caused concern about possible damage to pavements designed based on the current design methods. The higher the contact stresses on the pavement surface, the larger the subgrade deformation, and the more severe the damage to the subgrade.

In order to investigate the effects of super-single tire loadings on subgrades for typical Indiana road cross-sections, static and dynamic finite element analyses were performed taking into account the realistic shape of the contact area and the increased vertical contact stress. Subgrade soils were modeled as saturated to consider the most severe conditions possibly occurring during the pavement design life.

\section{Findings}

It was found that the direction of the maximum tensile stress is dependent on the shape of the contact area and stress distribution. Super-single tires generate larger transverse tensile strain than longitudinal tensile strain at the bottom of the asphalt layer.

The analyses showed that super-single tires induce larger permanent strains in the pavement layers than conventional tires. Therefore, design of a pavement using Load Equivalency Factors (LEF) for dual tires may lead to overestimation of the pavement design life. Single axle loadings with super-single tires induce the largest vertical plastic strains on top of the subgrade rutting of all the axle configurations considered. 
Analysis results also show that the higher the speed of the truck, the less the load on the subgrade. Since repeated super-single tire loadings increase vertical permanent strains in the subgrade for existing roads, either mitigation of permanent strains in the subgrade may be pursued or the number of passages of super-single tires could be limited by appropriate regulation.

For clay subgrades, the higher the Over Consolidation Ratio (OCR), the less the deformation. Positive pore pressures are generated in normally consolidated clay subgrades, while negative pore pressures are typically generated within heavily overconsolidated clays and dense sands. Therefore, in a Normally Consolidated (NC) clayey subgrade, the shear strength is reduced as a result of traffic loadings due to the pore pressure build-up.

Vertical strains induced by super-single tires can be mitigated either by subgrade modification or by adding a structural overlay.

\section{Implementation}

The research results can be helpful for designing for super-single heavier traffic loads. It would be necessary to indicate that information regarding the extent of supersingle tires on INDOT highways need to be collected. This is essential in order to use the analysis presented in this report for pavement design including factor of super-single tire loads. In addition, information regarding subgrade type, classification and strength characteristics need to be also present. With the presence of these pieces of information, the study provides two options for the design; to mitigate the effect of super-single tires, 1) improving subgrade strength or 2) adding an adequate structural overlay. 


\section{Implementation Report}

The use of super-single tires in highways has been cause of concern. These tire loadings impose much higher contact stresses on the pavement surface, resulting in more damage to the subgrade layers as well as the asphalt and base layers. The main objective of this study was to investigate the effects of super-single tire loadings on subgrades and to provide guidelines for admissibility of super-single tire loadings for typical Indiana road cross-sections.

The research results can be helpful for designing for super-single heavier traffic loads. It would be necessary to indicate that information regarding the extent of super-single tires on INDOT highways need to be collected. This is essential in order to use the analysis presented in this report for pavement design including factor of super-single tire loads. In addition, information regarding subgrade type, classification and strength characteristics need to be also present. 


\section{Implementation Report}

The use of super-single tires in highways has been cause of concern. These tire loadings impose much higher contact stresses on the pavement surface, resulting in more damage to the subgrade layers as well as the asphalt and base layers. The main objective of this study was to investigate the effects of super-single tire loadings on subgrades and to provide guidelines for admissibility of super-single tire loadings for typical Indiana road cross-sections.

The research results can be helpful for designing for super-single heavier traffic loads. It would be necessary to indicate that information regarding the extent of super-single tires on INDOT highways need to be collected. This is essential in order to use the analysis presented in this report for pavement design including factor of super-single tire loads. In addition, information regarding subgrade type, classification and strength characteristics need to be also present. 
TABLE OF CONTENTS

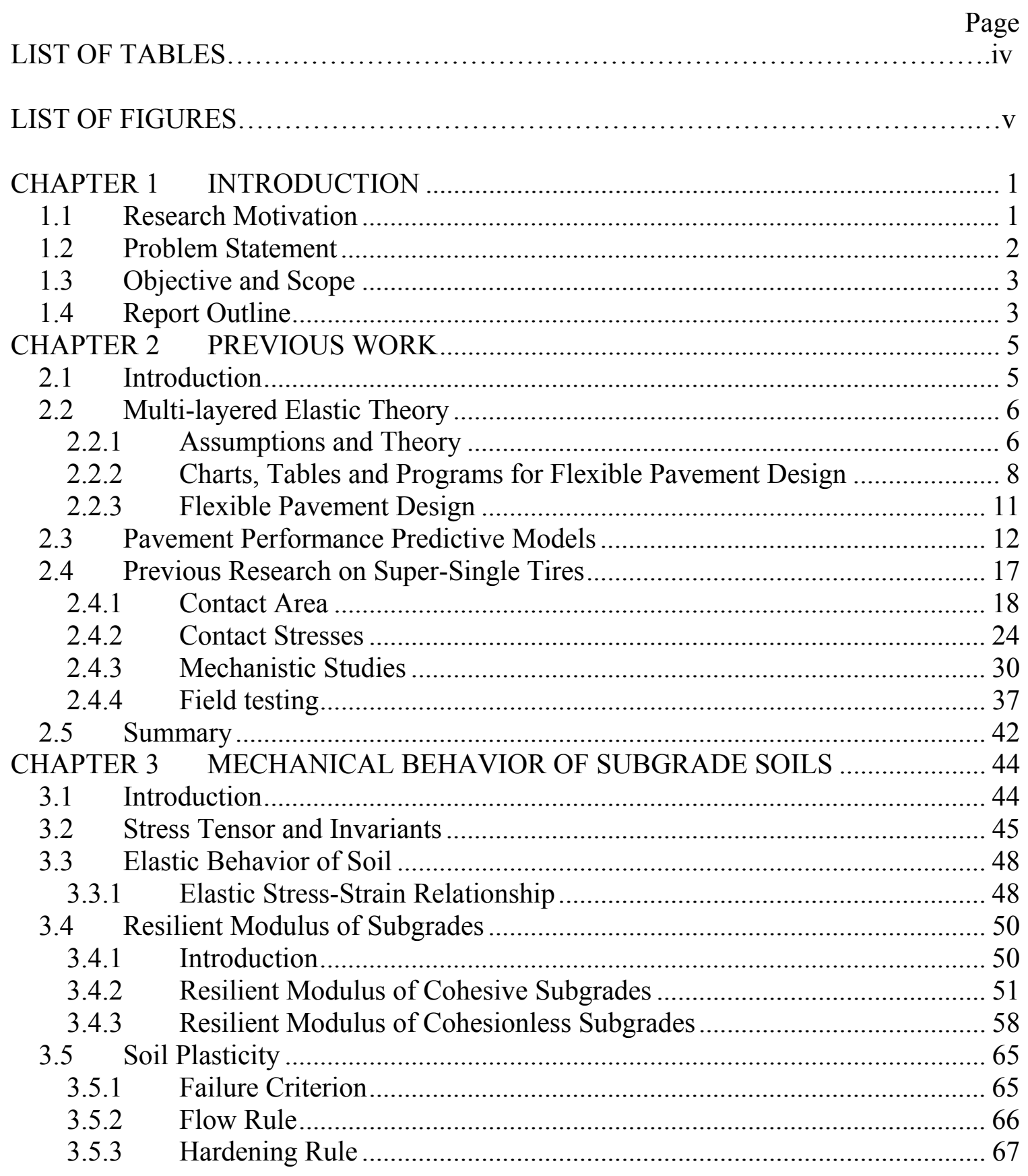




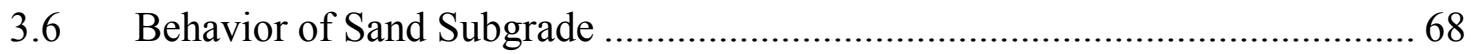

3.6.1 General Behavior of Sand Subgrade........................................................... 68

3.6.2 Permanent Deformations of Cohesionless Subgrades ............................. 72

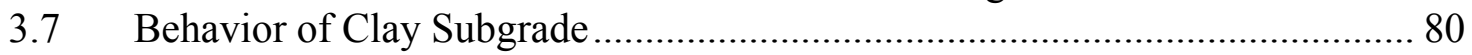

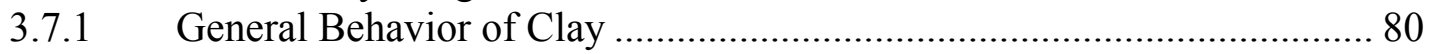

3.7.2 Permanent Deformations of Cohesive Subgrades..................................... 83

3.8 Development of Pore Water Pressure During Repeated Loading .................... 96

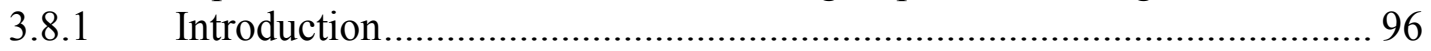

3.8.2 Development of Pore Water Pressures ................................................. 97

3.9 Constitutive Models for Subgrade Soils .................................................... 102

3.9.1 Drucker-Prager Model without Cap....................................................... 102

3.9.2 Drucker-Prager Model with Cap........................................................... 104

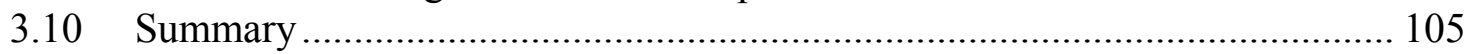

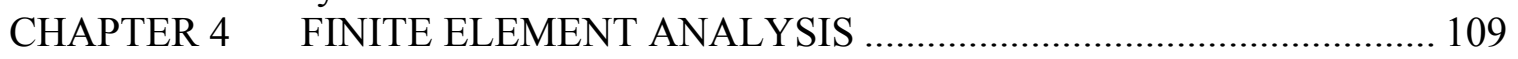

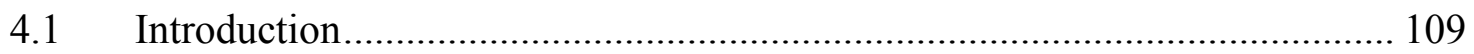

4.2 Modeling of Pavement System ........................................................... 110

4.2.1 Typical Cross-sections …………………….................................... 110

4.2.2 Geometry and Boundary Conditions .................................................... 113

4.2.3 Implication of the Nonuniform Contact Stresses Observed for Super-

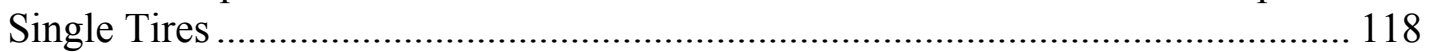

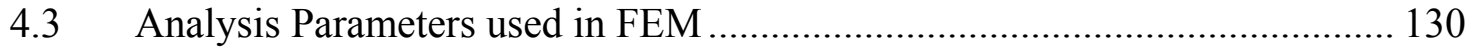

4.4 Static Finite Element Analysis............................................................... 134

4.4.1 Plane-Strain (2D), Elastic, Static Analysis ............................................ 134

4.4.2 3D Elastic, Static Analysis.................................................................. 139

4.4.3 Comparison of Plane-Strain (2D) and 3D Elastic Results...................... 141

4.4.4 Comparison of 3D and Multi-Layered Elastic Results ........................... 144

4.4.5 3D Elastic-Plastic, Static Analysis....................................................... 146

4.4.6 Static Load Equivalency Factors using 3D Elastic, Static Analysis....... 157

4.5 3D Dynamic Finite Element Analyses......................................................... 161

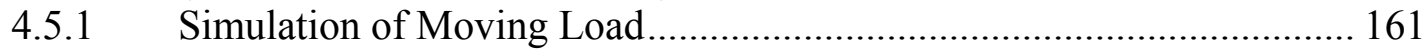

4.5.2 Determination of Appropriate Number of Moving Load Elements........ 163

4.5.3 Effects of Moving Load Speed ............................................................. 164

4.5.4 Effects of Repeated Moving Loads..................................................... 165

4.6 Dynamic Load Equivalency Factors ............................................................... 168

4.7 Comparison of Damage Factor between Linear-elastic and Elastic-plastic Dynamic Analyses for Dual and Super-Single Tires .............................................. 169

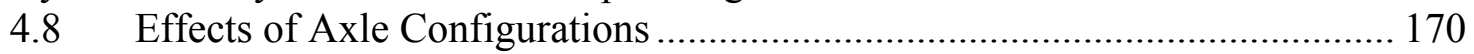

$4.9 \quad$ Comparison of the subgrade type ………................................................ 173

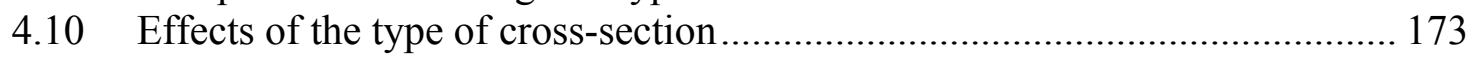

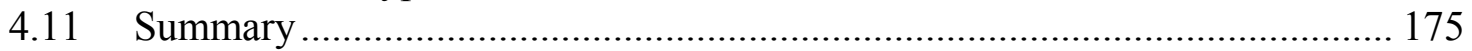

CHAPTER 5 OVERLAY AND SUBGRADE IMPROVEMENT ………………..... 177

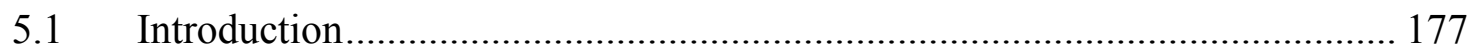

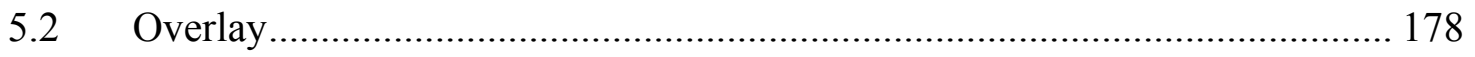

5.2.1 Overview of Overlay Methods.......................................................... 178

5.2.2 Effects of Overlay ............................................................................ 180 


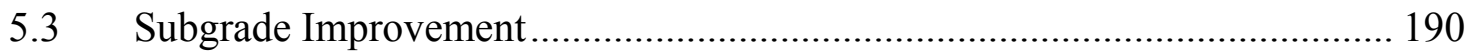

5.3.1 Overview of Subgrade Improvement Methods..................................... 190

5.3.2 Effects of Subgrade Improvement ...................................................... 193

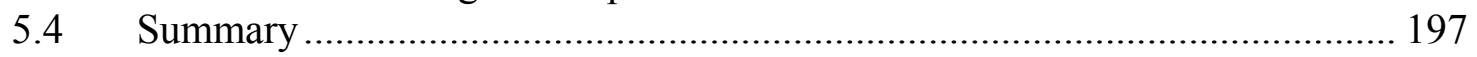

CHAPTER 6 SUPER-HEAVY LOAD MOVE IN TEXAS ...................................... 198

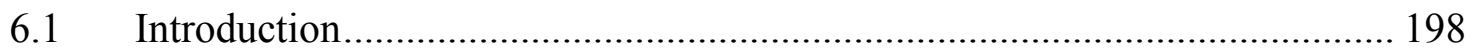

6.2 Typical Super Heavy Loads in Texas ....................................................... 198

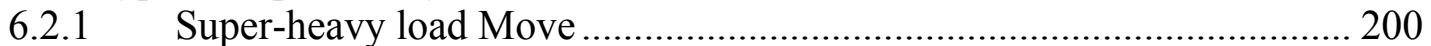

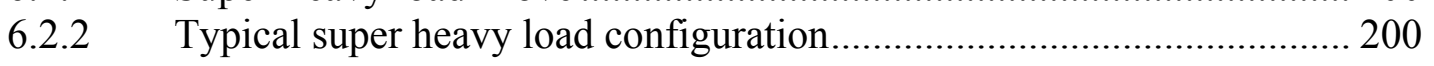

6.2.3 Modeling of the super heavy loads ..................................................... 206

6.3 Effects of Typical Heavier Truck Move in Indiana ………….......................... 211

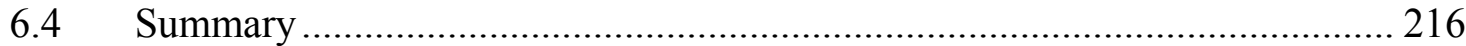

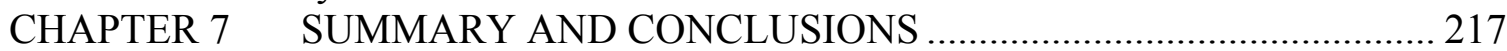

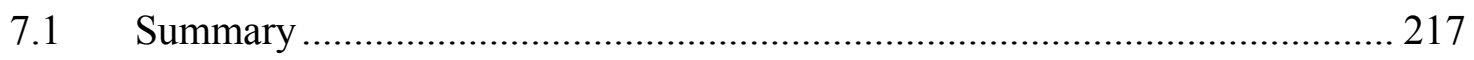

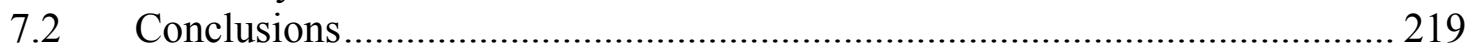

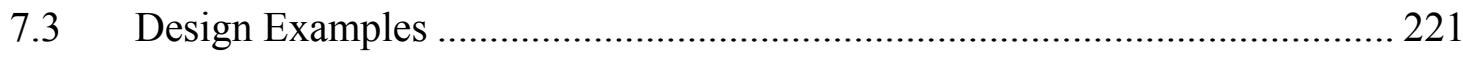

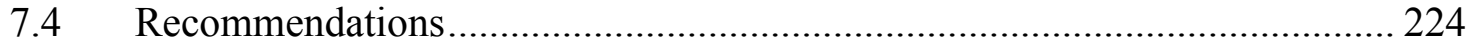




\section{LIST OF TABLES}

Table

Page

Table 2.1 Subgrade strain criteria used by various organizations (Huang 1993) ............ 15

Table 2.2 Contact area of wide base tires manufactured by Goodyear (after Goodyear). 23

Table 2.3 Contact area of wide base tires manufactures by Michelin (Michelin Inc. 1997)

Table 2.4 Allowable single axle load in the State of Indiana based on tire load limits .... 24

Table 2.5 Mechanistic research related to super-single tires ......................................... 37

Table 4.1 Material parameters for asphalt and base layers ...................................... 132

Table 4.2 Material parameters for sand and clay layers ........................................... 133

Table 4.3 Number of fatigue and rutting failure using empirical equations ................... 159

Table 4.4 Load equivalency factors by linear elastic FE results for cross-section 1 ...... 160

Table 4.5 Dynamic load equivalent factors using elastic-plastic, dynamic analysis ...... 168

Table 4.6 Comparison of damage factors between linear-elastic and elastic plastic,

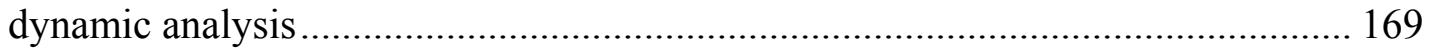

Table 4. 7 Effects of types of cross-sections and nature of subgrade on response to supersingle tires loadings................................................................................... 174

Table 5.1 Effect of overlay on the number of repetitions needed to fatigue and rutting failure (cross-section 1).

Table 5.2 Effect of overlay on the number of repetitions needed to fatigue and rutting

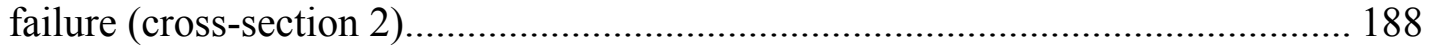

Table 5.3 Effect of increase in Young's modulus of the asphalt layer on the number of repetitions to fatigue and rutting failure (cross-section 1) ................................. 189

Table 6.1 Details of ten superheavy loads monitored in Texas (Jooste and Fernando 1995)

199

Table 6.2 Approximate axle and wheel spacings used on superheavy load vehicle (Jooste

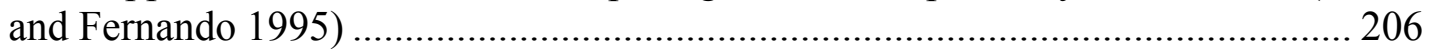




\section{LIST OF FIGURES}

Figure

Figure 2.1 Vertical surface displacement (after Burmister 1943).................................... 9

Figure 2.2 Vertical interface displacement (after Huang 1969) ..................................... 10

Figure 2.3 Imprints for a Goodyear bias-ply (left side) and a Goodyear radial tire (right side) (Weissman 1999)

Figure 2.4 Video image footprints of (a) a conventional and (b) a wide base truck tire

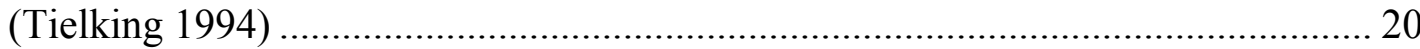

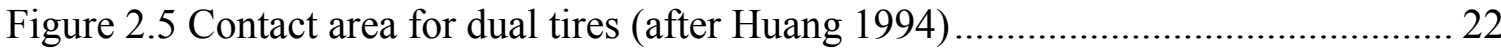

Figure 2.6 Direction of lateral contact stresses (Ford and Yap 1990) ............................ 25

Figure 2.7 Distribution of vertical contact stresses (Myers et al. 1999) ........................ 27

Figure 2.8 Distribution of transverse contact stresses (Myers et al, 1999) ....................... 28

Figure 2.9 Influence of vehicle speed on shear strain induced in the AC layer

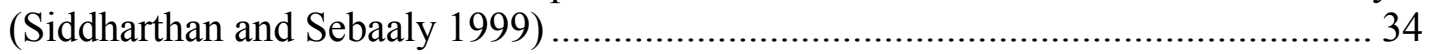

Figure 2.10 Effect of axle load and tire types on tensile strain at the bottom of the layer

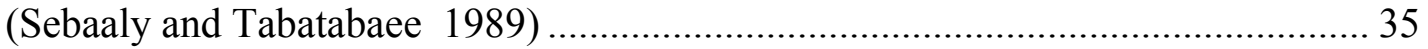

Figure 2.11 Effect of axle load and tire types on the compressive stress at the asphalt

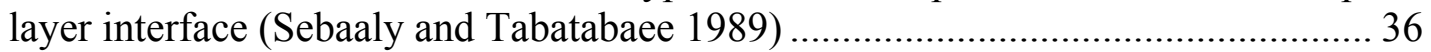

Figure 2.12 Effect of speed on vertical strain on top of the subgrade (Akram et al. 1992)

Figure 2.13 Effect of speed on vertical strain on top of the subgrade (Akram et al. 1992)

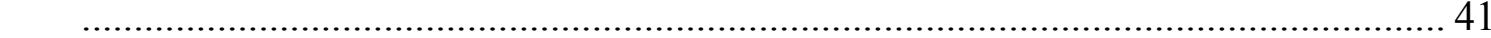

Figure 3.1 Effect of deviator stress on a A-7-6 subgrade soil (Wilson et al. 1990) ......... 52

Figure 3.2 Effect of compaction water content and moisture density on a cohesive

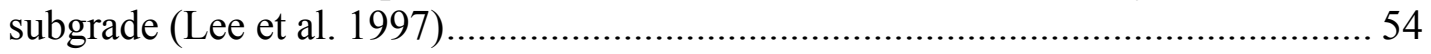

Figure 3.3 Effect of post-compaction saturation on resilient modulus of an A-7-5 subgrade soil (Drumm et al. 1997) ..................................................................... 55

Figure 3.4 Effect of deviator stress on the resilient modulus of an A-1 subgrade soil

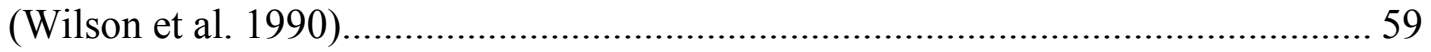

Figure 3.5 Influence of dry density on the resilient modulus of granular subgrades (Hicks

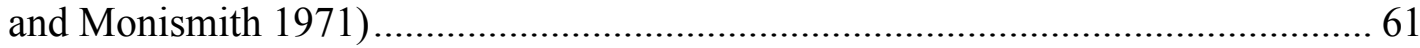

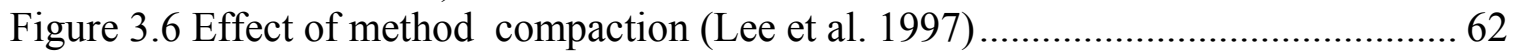

Figure 3.7 Typical behavior of loose and dense sands under drained condition ............. 70

Figure 3.8 Behavior of loose and dense sands under undrained condition.................... 71

Figure 3.9 Permanent axial strains for Sydenham sand (Gaskin et al. 1979) .................. 73

Figure 3.10 Plastic axial strains for Coteau Balast (Diyaljee and Raymond 1983)......... 74 
Figure

Page

Figure 3.11 Effect of confining stress on permanent strain at $\mathrm{N}=10,000$ for the Florida subgrade sand (Pumphrey and Lentz 1986) 76

Figure 3.12 Effect of dry unit weight and moisture content on permanent strainat

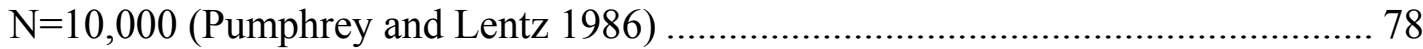

Figure 3.13 Typical behaviors of $\mathrm{NC}$ and $\mathrm{OC}$ clays under drained condition................. 81

Figure 3.14 Behavior of NC and OC clays under undrained condition......................... 82

Figure 3.15 Results from tests on compacted at dry of optimum A-6 subgrade soil (Muhanna et al. 1998) ................................................................................... 84

Figure 3.16 Results from tests on compacted at optimum A-6 subgrade soil (Muhanna et al. 1998) 84

Figure 3.17 Results from tests on compacted at wet of optimum A-6 subgrade soil (Muhanna et al. 1998). 85

Figure 3. 18 Results from tests on silty clay; left: $\sigma_{3}=0 \mathrm{psi}, \gamma_{\mathrm{d}}=129.5 \mathrm{lb} / \mathrm{ft}^{3}, \mathrm{~m}=7 \%$ right: $\sigma_{3}=14.5 \mathrm{psi}, \gamma_{\mathrm{d}}=129.5 \mathrm{lb} / \mathrm{ft}^{3}, \mathrm{~m}=7 \%($ Raad and Zeid 1990) 86

Figure 3. 19 Results from tests on silty clay; left: $\sigma_{3}=0 \mathrm{psi}, \gamma_{\mathrm{d}}=129.5 \mathrm{lb} / \mathrm{ft}^{3}, \mathrm{~m}=10 \%$ right: $\sigma_{3}=14.5 \mathrm{psi}, \gamma_{\mathrm{d}}=129.5 \mathrm{lb} / \mathrm{ft}^{3}, \mathrm{~m}=10 \%$ (Raad and Zeid 1990). 87

Figure 3.20 Influence of stress history on permanent strains (Monismith et al. 1975) .... 88

Figure 3.21 Effect of period of rest on deformation under repeated loading of silty clay with high degree of saturation (Seed and Chan 1958) .......................................... 90

Figure 3.22 Effect of period of rest on deformation under repeated loading of silty clay with low degree of saturation (Seed and Chan, 1958)

Figure 3.23 Effect of frequency of stress application on deformation of silty clay with high degree of saturation (Seed and Chan 1958) ................................................... 92

Figure 3. 24 Effect of frequency of stress application on deformation of silty clay with low degree of saturation (Seed and Chan 1958) .................................................... 93

Figure 3.25 Development of pore pressure and various stress levels (Wilson and

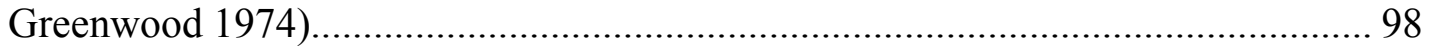

Figure 3.26 Relationship between pore pressure and axial strain (Wilson and Greenwood 1974) 101

Figure 3.27 Variation of pore pressure parameter A (Hyde 1974) ................................ 101

Figure 3.28 Drucker-Prager Model without Cap in the $I_{1}-\sqrt{J_{2}}$ plane ..................... 103

Figure 3.29 Drucker-Prager and Mohr-Coulomb failure criteria in the principal plane. 104

Figure 3.30 Drucker-Prager Model with Cap in the $I_{1}-\sqrt{J_{2}}$ plane.......................... 105

Figure 4.1 Typical flexible pavement cross-sections (after the Indiana Department of Transportation)....

Figure 4.2 The effect of boundary depth and width in plane-strain (2D) analysis ........ 115

Figure 4.3 (a) plane-strain (2D) geometry with the cross-section width and typical (b) plane-strain (2D) and (c) 3D finite element geometries ..................................... 117

Figure 4.4 Uniform vertical contact stress in one 2D element .................................. 120

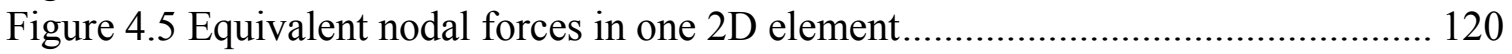

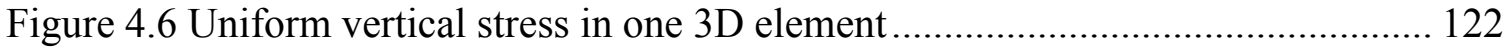

Figure 4.7 Equivalent nodal force in one 3D element .............................................. 122

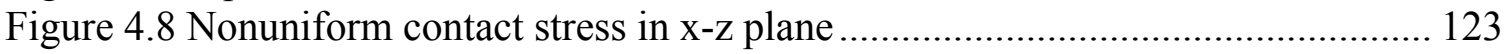


Figure Page

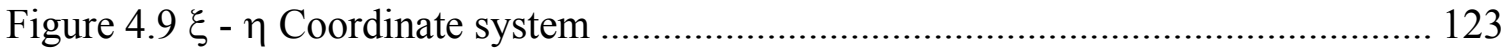

Figure 4.10 Equivalent nodal forces corresponding to nonuniform vertical stresses in

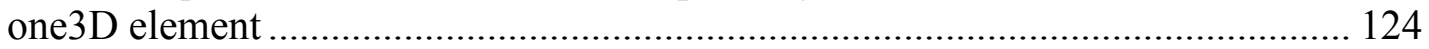

Figure 4.11 Vertical displacements of various contact stresses.................................. 128

Figure 4.12 Vertical strains of various contact stresses on top of the subgrade layer ... 129

Figure 4.13 Horizontal strains of various contact stresses at the bottom of the asphalt layer. 129

Figure 4.14 (a) 18,000 lb. single axle and (b) 22,800 lb. single axle with dual tires and

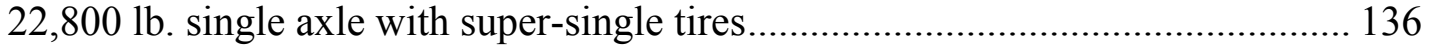

Figure 4.15 Horizontal stresses at the bottom of the asphalt layer .............................. 137

Figure 4.16 Vertical stresses on the top of the subgrade layer ................................... 137

Figure 4.17 Comparison of stresses depending on the configurations of tires ............... 138

Figure 4.18 Comparison of strains depending on the configurations of tires ................ 138

Figure 4.19 Comparison of vertical displacements depending on the configuration of tires

Figure 4.20 Comparison of stresses depending on the configurations of tires .140

Figure 4.21 Comparison of strains depending on the configurations of tires ................. 140

Figure 4.22 Comparison of vertical displacements depending on the configurations of

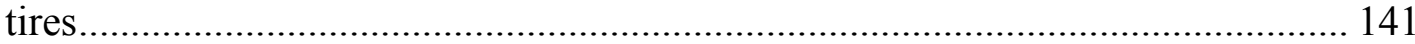

Figure 4.23 Comparison of plane-strain (2D) and 3D stresses................................. 142

Figure 4.24 Comparison of plane-strain (2D) and 3D strains..................................... 143

Figure 4.25 Comparison of plane-strain (2D) and 3D displacements .......................... 143

Figure 4.26 Comparison of stresses (3DFEM and ELSYM5) .................................... 144

Figure 4.27 Comparison of strains (3DFEM and ELSYM5) ....................................... 145

Figure 4.28 Comparison of vertical displacements (3DFEM and ELSYM5) ................ 145

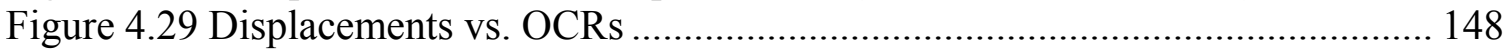

Figure 4.30 Vertical strains vs. OCRs ..................................................................... 148

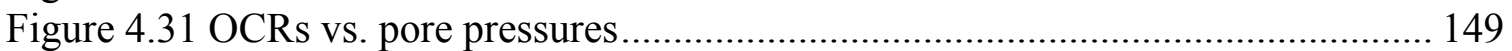

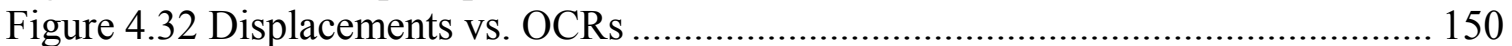

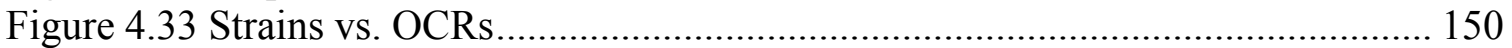

Figure 4.34 Strains vs. elastic moduli depending on OCRs ........................................ 151

Figure 4.35 Displacements vs. elastic moduli depending on OCRs ............................ 151

Figure 4.36 Pore pressures in sand subgrade analyzed by linear-elasticity................... 154

Figure 4.37 Pore pressures in sand subgrade analyzed by elastic-plasticity.................. 155

Figure 4.38 Pore pressures in normally consolidated subgrade analyzed by elastic-

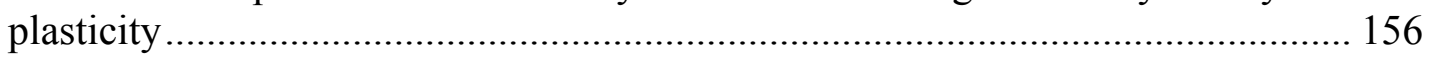

Figure 4.39 Simulation of moving load ................................................................ 162

Figure 4.40 Determination of appropriate element number of moving tire loads ......... 163

Figure 4.41 Vertical deformations on top of subgrade with various speeds.................. 164

Figure 4.42 Permanent vertical deformations of each layer ...................................... 166

Figure 4.43 Permanent strains due to the repeated moving loads................................ 167

Figure 4.44 Load Repetitions vs. vertical permanent strains ...................................... 167

Figure 4.45 Axle configurations vs. vertical plastic strains........................................ 170

Figure 4.46 (a) Single axle (b) Tandem axle (c) Tridem axle with super-single tires.... 172 
Figure Page

Figure 5.1 Effect of overlay on vertical strain on top of subgrade for cross-section 1

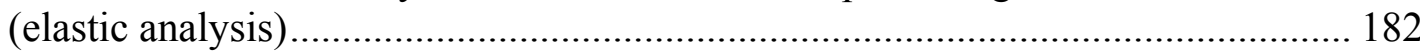

Figure 5.2 Effect of overlay on vertical strain in subgrade for cross-section 2 (elastic

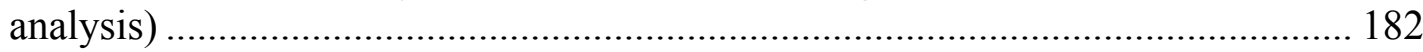

Figure 5.3 Effect of overlay on vertical plastic strain in subgrade for cross-section 1 (elastic-plastic analysis) ............................................................................ 183

Figure 5.4 Effect of overlay on vertical plastic strain in subgrade for cross-section 2 (elastic-plastic analysis) ............................................................................ 184

Figure 5.5 Effect of overlay on horizontal strain at the bottom of asphalt layer for crosssection 1 (elastic analysis) ................................................................. 185

Figure 5.6 Effect of overlay on horizontal strain at the bottom of asphalt layer for crosssection 1 (elastic-plastic analysis)............................................................ 185

Figure 5.7 Effect of increase in Young's modulus of asphalt layer on horizontal strainSubgrade for cross-section1 (elastic-plastic analysis) ................................ 186

Figure 5.8 Effect of increase in Young's modulus of subgrade on vertical plastic strainfor cross-section 1 (elastic analysis) ..................................................................... 194

Figure 5.9 Effect of increase Young's modulus of subgrade on vertical plastic strainfor cross-section 1 (elastic-plastic analysis) ........................................................... 195

Figure 5.10 Effect of increase in cohesion of subgrade on vertical plastic strainfor cross-

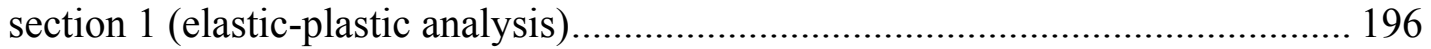

Figure 5.11 Effect of increase in friction angle of subgrade on vertical plastic strainfor cross-section 1 (elastic-plastic analysis) ............................................................ 196

Figure 6.1 Example of a conventional truck and trailer combination (Jooste and Fernado $1995)$ 202

Figure 6.2 Example of a specialized tractor-trailer combination (Jooste and Fernando 1995) 203

Figure 6.3 Example of a self-propelled multiple axle tirailer (Jooste and Fernando 1995)

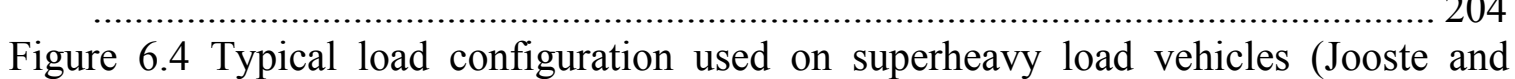

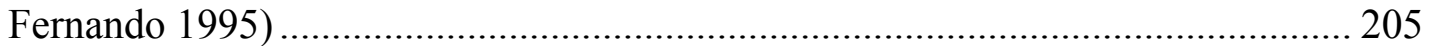

Figure 6.5 Triple axle load used in analysis (Jooste and Fernando 1995) ..................... 208

Figure 6.6 single axle load used in analysis (Jooste and Fernando 1995) ..................... 209

Figure 6.7 Dual wheel load used in analysis (Jooste and Fernando 1995) .................... 210

Figure 6.8 Pavement section in analysis (Jooste and Fernando 1995) .......................... 211

Figure 6.9 FE Mesh for tridem axle configuration for super-heavy load in Texas ........ 212

Figure 6.10 Vertical plastic strains on top of the subgrade by super-heavy load (cross-

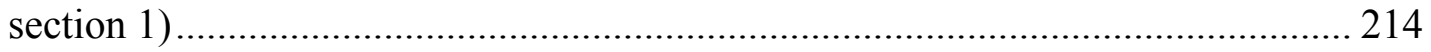

Figure 6.11Vertical plastic strains on top of the subgrade by super-heavy load (cross-

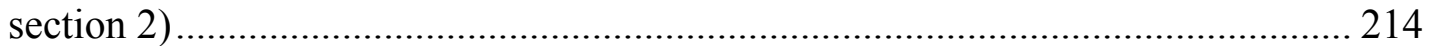

Figure 6.12 Horizontal strains at the bottom of the asphalt layer by super-heavy load(cross-section 1) ................................................................................ 215

Figure 6.13 Horizontal strains at the bottom of the asphalt layer by super-heavy

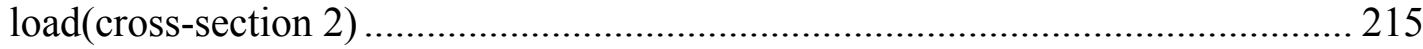




\section{CHAPTER 1 INTRODUCTION}

\subsection{Research Motivation}

The pursuit of increased efficiency and economy by the trucking industry has led to increasing use of wide-base ("Super-Single") tires and heavier truck loadings (Mrad et al. 1998). Studies by De Beer et al. (1997), Odermat et al. (1999), Meyers et al. (1999), and Siddharthan and Sebaaly (1999) have indicated that these tires create higher vertical and transverse contact stresses across larger contact areas with the pavement. These studies indicated that vertical contact stresses as large as 2.5 times the tire inflation pressures are created when these tires are used, especially at high loads and inflation pressures. The increased tendency toward larger truck loads, higher tire inflation pressures, and the use of wide-base tires has caused concern about pavement integrity. As both the area of contact between the tires and the pavement and the contact stresses increase, the subgrade may also be affected.

Excessive deformation of the subgrade has always been recognized as a major problem. The larger loads, larger tire contact pressures, and larger tire contact areas send significant stress pulses deeper into the pavement system. The larger stresses may lead to larger permanent deformations. However, in modeling a road structure, most of the studies found in the literature focus on the asphalt and base layers rather than on the 
subgrade layer, with the implied assumption that the asphalt layer and base layer would take most of the tire loadings, and the subgrade would be in an elastic state. These studies also assume that the contact stresses induced by tire loadings are the same as the inflation pressures. The results of these studies are probably acceptable for lower inflation pressures and conventional dual tires, but they would be unconservative for increased inflation pressures and contact stresses (De Beer et al. 1997, Siddharthan and Sebaaly et al. 1999). In order to ascertain the severity of the potential effects of the use of wide-base tires on the subgrades, more advanced analyses taking into account increased contact stresses and wider contact areas are required. These analyses and the lessons they offer are the main focus of the present study.

\subsection{Problem Statement}

Pavement design and analysis are generally performed based on the load equivalency factors obtained from conventional dual tires, and use the contact stress equal to the tire inflation pressure. However, super-single tires produce much higher contact stresses than the inflation pressure, and have a different contact area shape from that of conventional tires. In order to assess the increased contact stress by super-single tires, the results of the contact stress distribution measured by De Beer et al. (1997) are used. A reasonable contact area ratio (1:0.85) for super-single tires is determined. Finite element analyses for typical flexible pavements are done to evaluate the effects of the super-single tires on the subgrades. 


\subsection{Objective and Scope}

The main objective of this study addresses the question of whether the subgrades in typical flexible pavement cross-sections will potentially have problems if wide-base tires (and consequently larger truck loads and higher tire contact stresses) become part of truck traffic. Through plane-strain (2D) and 3D finite element analyses, this study will shed light on

a) How severe damage super-single tires are to pavements compared with conventional dual tires (an observation that can be quantified using load equivalent factors or damage factors);

b) How much porewater pressure is generated within the subgrade soil by the supersingle tire loading and what the consequences of this are;

c) How much deformation will be generated;

d) How the repetitions of super-single tire loadings affect the subgrades;

e) Whether overlay and subgrade improvement is sufficient measures to enable the pavement section to sustain the loadings.

\subsection{Report Outline}

This report consists of seven chapters, including this introduction.

Chapter 2 reviews multi-layered elastic theory and the previous work on supersingle tires. In this chapter, the contact area, the maximum tire load and contact stress for super-single tires are determined for FE analysis. 
Chapter 3 describes the mechanical behavior of subgrade soils in order to reasonably model subgrades. This chapter covers stress invariants, soil plasticity, subgrade resilient modulus, generation of porewater pressures, and constitutive models such as the Drucker-Prager model.

Chapter 4 presents the effects of super-single tires on subgrades for typical road cross-sections investigated using plane-strain (2D) and 3D static and dynamic finite element analyses.

Chapter 5 reviews the methods of overlay and subgrade improvement, and investigates how much overlay and subgrade improvement is needed for super-single tire loadings.

Chapter 6 reviews the super-heavy load moves, which occurred in Texas during the 1990s, and evaluates the effects of super-heavy load on typical road cross-sections and compares these results with the effects of super-single tires.

Chapter 7 presents the conclusions drawn from this study. 


\section{CHAPTER 2 PREVIOUS WORK}

\subsection{Introduction}

Historically, elastic analysis formed the foundation for work analyzing pavements under tire loadings. Since Burmister (1943) presented an elastic solution for a two-layer system, researchers have made a number of efforts to apply his solution in pavement analysis. Efforts were made to improve upon and simplify the complicated process of obtaining Burmister's solution so that engineers could use the solution in a straightforward way. The multi-layered elastic solution of Burmister (1943) still occupies a very important role in pavement engineering.

The two main concerns with flexible pavements are rutting and fatigue cracking. Rutting (vertical permanent deformation) is generally known to be induced by the accumulation of vertical compressive strains on top of the subgrade due to the repetition of traffic loadings. Fatigue cracking is largely caused by the accumulation of horizontal strains at the bottom of the asphalt layer. Most design methods focus on limiting excessive vertical strains and horizontal strains in order for a pavement structure to perform its function over a design period. 
A critical consideration in the design of flexible pavements is the tire loads of trucks. Generally, trucks have been equipped with conventional dual tires. However, as the tire industry seeks to improve efficiencies, the tire inflation pressures have been increasing and super-single tires have been replacing the conventional dual tires.

In this chapter, multi-layered elastic theory and several empirical predictive models will be reviewed. Also, previous research on super-single tires concerning contact area, contact stress, and field testing will be reviewed.

\subsection{Multi-layered Elastic Theory}

\subsubsection{Assumptions and Theory}

The Boussinesq (1885) solution for a point load applied on the surface of a semiinfinite elastic medium assumes that the soil mass is homogeneous, isotropic and linear elastic. Numerous researchers have expanded the Boussinesq (1885) solution for pavement analysis.

Burmister (1943) suggested a closed-formed solution to a two-layered elastic halfspace problem and extended it to a three-layer system in 1945. This solution plays a very significant role in pavement engineering. Since Burmister derived his solution based on linear elasticity, multiple wheel load analysis became possible under the principle of superposition. He used the stress and displacement equations of elasticity for the threedimensional problem in his solution. The assumptions made for a two-layer system were the following: 
a. The two-layer system consists of a surface layer of pavement of a certain thickness $h_{1}$, which rests continuously upon and reinforces a weaker subgrade layer.

b. A uniformly distributed, circular surface load with radius $r$ is considered.

c. The two layers are homogenous, isotropic and elastic materials, for which Hooke's law is valid.

d. The surface-reinforcing layer is assumed to be weightless and to be infinite in extent in the horizontal direction, but of finite thickness $h_{1}$. The subgrade layer is an elastic halfspace.

e. The solution of the problem must satisfy certain necessary boundary conditions: (1) the surface of layer 1 must be free of normal and shearing stresses outside the limits of the loaded area, and (2) the stresses and displacements in the subgrade layer must be equal to zero at infinite depth.

f. The solution for the two-layer system satisfies certain essential continuity conditions of stress and displacement across the interface between layer 1 and 2 . It is assumed that the two layers area continuously in contact and act together.

Burmister's equation for stress under tire loading is given as:

$$
\phi=J_{0}(m r)\left[A e^{m z}+B e^{-m z}+z C e^{m z}+z D e^{-m z}\right]
$$

This equation gives a stress function $\phi$ composed of Bessel and exponential functions that satisfy bi-harmonic equations.

where $\mathrm{r}$ is the radial and $\mathrm{z}$ is the depth (vertical coordinate of the coordinate system), $\mathrm{m}$ is a parameter, and A, B, C, and D are four constants. For multi-layered elastic systems, 
four constants should be determined for each layer using boundary and compatibility conditions. For example, for a two-layered pavement system, eight constants must be determined from two stress functions for two layers. Four constants will be determined from conditions encompassing normal stress, shear stress, vertical displacement, and radial displacement over the interface. Two additional constants will be obtained from the two surface traction boundary conditions concerning normal and shear tractions at the surface. The two final constants will be determined from two displacement boundary conditions at infinite depth, where both vertical and radial displacements are zero. After determination of these eight constants, stress, strain and displacement can be calculated by the traditional linear elasticity formulation.

\subsubsection{Charts, Tables and Programs for Flexible Pavement Design}

After Burmister (1943) derived a closed form solution for multi-layered systems, researchers made significant efforts to develop two and three layered pavement systems because his solution demanded complicated numerical computations. Thus, the primary objective of the following charts was to provide a more straightforward calculation of stresses, strains, and displacements in practical analysis. For example, Figure 2.1 can be used to calculate the surface deflections for a two-layer system once the values of $E_{1}, E_{2}$ (Elastic modulus for the first and second layer), inflation pressure, and contact area are known. Figure 2.2 can be used to determine the vertical interface displacement in a twolayer system. One of the drawbacks of these charts is that an engineer has to interpolate. 
In order to compute various output quantities, multiple charts are also needed to obtain vertical stress, vertical strain and tensile strain.

A table for a three-layered asphalt pavement system was presented by Jones (1962) to determine stress components. However, the interpolation from the tables is impractical and requires a large amount of time and effort. Peattie (1962) presented a chart based on Jones's table. He made the interpolation more straightforward than was possible with Jones's table, but the solutions obtained from the charts are not as accurate as those from the table (Huang 1973).

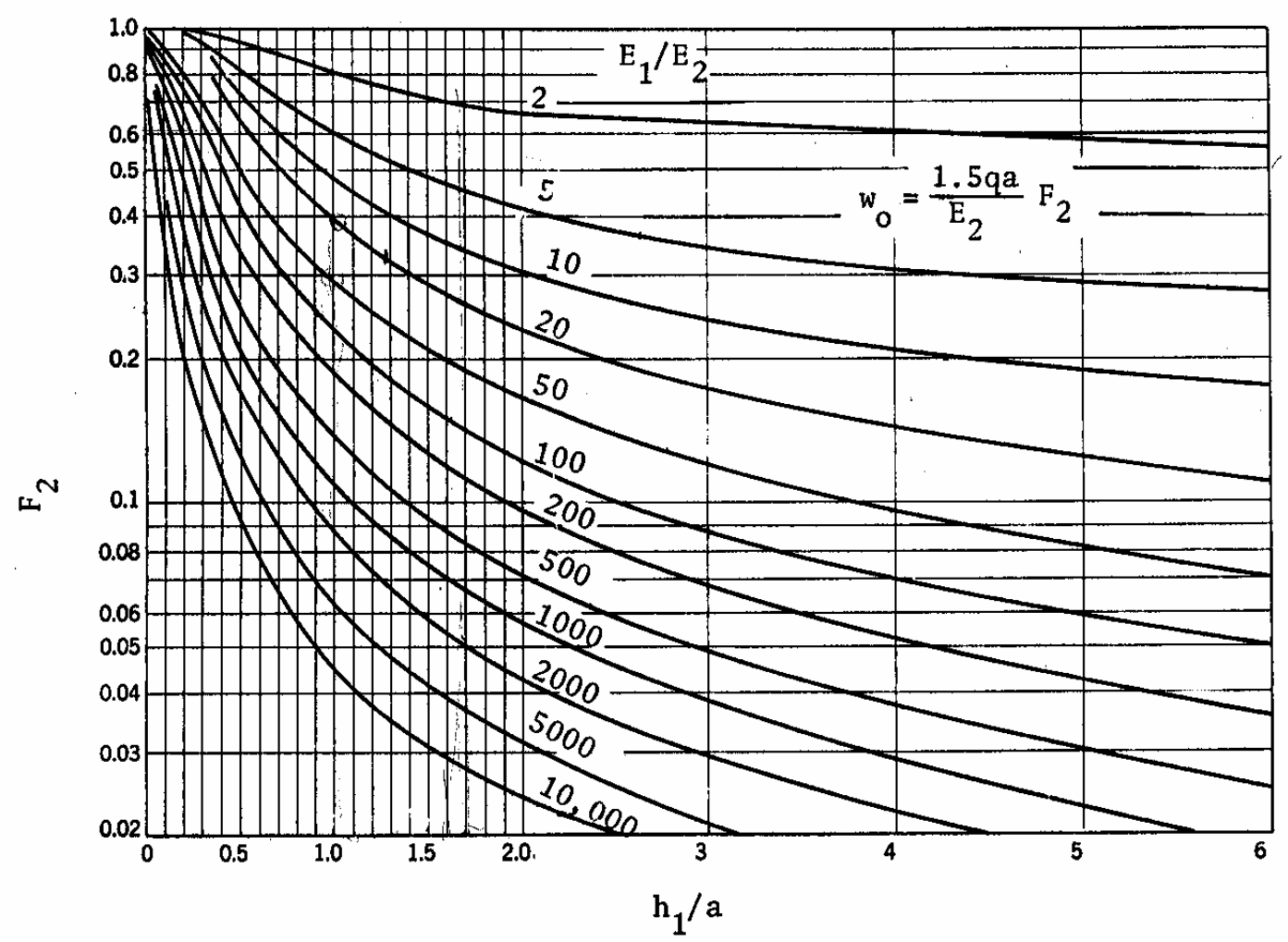

Figure 2.1 Vertical surface displacement (after Burmister 1943) 


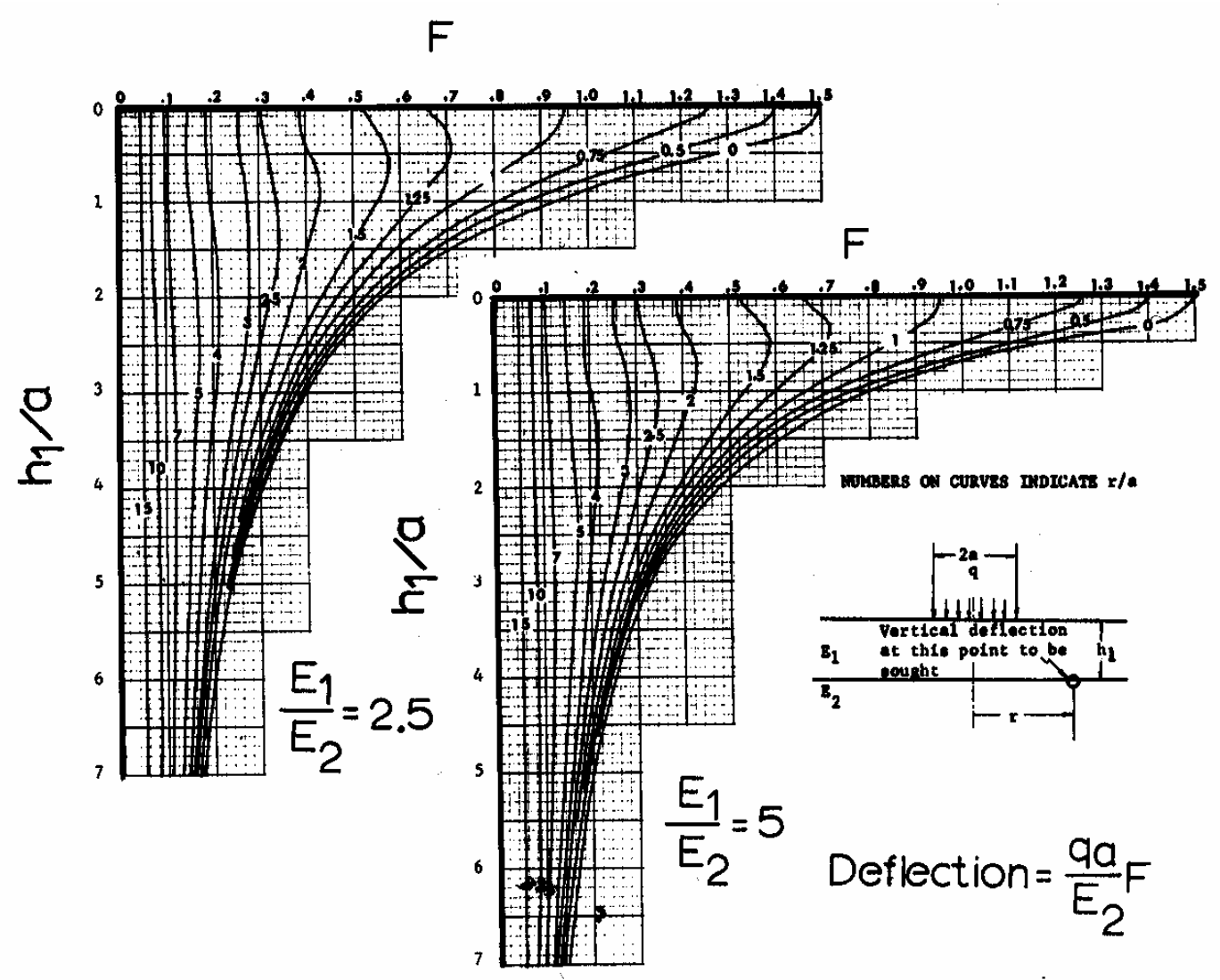

Figure 2.2 Vertical interface displacement (after Huang 1969)

With the appearance of computers after the late 1950's, researchers made a significant effort to utilize numerical computations based on Burmister's solution. The major objective of these programs was to simplify the process of obtaining stress, strain, and displacement using the Burmister's solution. As seen in Figure 2.2, tables and charts require an inevitable interpolation between adjacent lines in the charts and values presented in the tables. The first computer program to address this issue was the ILLI-AC (Metha and Veletos 1959), which performs the numerical computation for Burmister's 
solution. This program was not widely used among pavement engineers. BISAR, developed in the Shell Laboratory in Amsterdam (1978), became the first widely used program because it was written in Fortran and could be used in personal computers (Kim 1999). Many different programs (WELSEA, ELSYM5, ILLIPAVE, KENLAYER) and others have been developed to evaluate Burmister's solution using different algorithms.

\subsubsection{Flexible Pavement Design}

There are many methods for flexible pavement design. The most widely used methods are the AASHTO (American Association of Highway Transportation Officials) and the AI (Asphalt Institute) methods. In this section, the general design procedure will be briefly reviewed.

The Asphalt Institute has published eight editions of the flexible design method from 1954 to 1969. Those editions were based on data from the AASHO Road Test, WASHO Road Test, many British test roads, and some state practices (Huang 1993). Unlike the first eight editions, the ninth edition in 1981 was based on the multi-layered elastic theory in conjunction with empirical failure criteria (based on pavement thicknesses), and was revised in 1991. The DAMA Program was used to determine the minimum thickness required to satisfy both fatigue cracking and rutting criteria. The following steps are followed when designing with the AI method:

a. Step 1: Determine Design ESAL (Equivalent Single Axle Load);

b. Step 2: Select potential structural layer materials (subgrade soils, untreated granular material, Hot Mix Asphalt (HMA), Emulsified Asphalt Mixtures); 
c. Step 3: Determine $M_{R}$ (Resilient Modulus) for each layer;

d. Step 4: Determine thickness requirements from charts;

e. Step 5: Determine HMA surface mix thickness if not full depth;

f. Step 6: Verify minimum HMA surface mix thickness requirement.

The AASHTO method is based on the results of the AASHO Road tests conducted in Ottawa, Illinois, in the late 1950s and early 1960s. The design guide has been revised several times. The current guide was published in 1993. The following are the design steps for the AASHTO method:

a. Step 1: Estimate expected ESAL for the design period;

b. Step 2: Establish allowable serviceability loss;

c. Step 3: Select reliability level and overall standard deviation;

d. Step 4: Determine effective roadbed modulus value $\left(M_{R}\right)$, layer and drainage modifier coefficient values;

e. Step 5: Determine SN (structure number) from design chart using individual layer modulus as roadbed modulus;

f. Step 6: Determine thickness and verify layer thickness.

\subsection{Pavement Performance Predictive Models}

The prediction of flexible pavement failure has been empirically developed by correlating the multi-layered elastic theory results with the results of field tests such as the AASHO road test. In flexible pavements, the two major concerns are fatigue failure 
resulting from the accumulation of the horizontal strains at the bottom of the asphalt layer, and rutting resulting from the accumulation of the vertical strains on top of the subgrade.

Finn et al. (1986) presented a set of equations to predict the number of load repetitions needed to reach fatigue failure and to develop $10 \%$ and $45 \%$ fatigue class-2 cracking of wheel tracks (“AASHO Road", 1962). The study was done based on data from the AASHO road test and laboratory tests on material from the road test. The equations are as follows.

$$
\begin{aligned}
& \log N_{f}(10 \%)=15.947-3.291 \log \left(\frac{\varepsilon_{t}}{10^{-6}}\right)-0.854 \log \left(\frac{E}{6.895 \times 10^{3}}\right) \\
& \log N_{f}(45 \%)=16.086-3.291 \log \left(\frac{\varepsilon_{t}}{10^{-6}}\right)-0.854 \log \left(\frac{E}{6.895 \times 10^{3}}\right)
\end{aligned}
$$

where:

$\varepsilon_{t}=$ tensile strain at the bottom of the asphalt concrete layer $E=$ resilient modulus (repeated deviator stress/ recoverable axial strain) of asphalt concrete layer $(\mathrm{kPa})$

$N_{f}=$ number of load applications required to cause $10 \%$ or $45 \%$ class- 2 cracking of the wheel tracks

In a similar manner, the laboratory fatigue equations developed by the Asphalt Institute (1982, 1992) are as follows:

$$
N_{f}=0.00432 C\left(\varepsilon_{t}\right)^{-3.291}(E)^{-0.854}
$$

where: 
$C=10^{M}, M=4.84\left(\frac{V_{b}}{V_{a}+V_{b}}-0.69\right)$

$\mathrm{V}_{\mathrm{a}}, \mathrm{V}_{\mathrm{a}}=$ percent air and asphalt volume in AC mixture

For a standard AC (Asphalt Cement) mix with an air void volume of 5 percent and an asphalt volume of 11 percent, $\mathrm{C}$ is equal to 1 . According to the assumption of the Asphalt Institute, the actual pavement's fatigue is 18.4 times greater than the fatigue test's. Accordingly, equation (2.4) can be simplified as follows.

$$
N_{f}=0.0796\left(\varepsilon_{t}\right)^{-3.291}(E)^{-0.854}
$$

Rutting typically results from the permanent deformation of one or more of the pavement layers in an AC pavement system, including the subgrade. Rutting may also be caused by plastic movement of an $\mathrm{AC}$ mixture in hot weather or by inadequate $\mathrm{AC}$ compaction during construction (Huang 1993). For pavement rutting models, most studies employ correlations between strains and load repetitions. The correlations between the vertical strain on the surface of the subgrade and the number of equivalent single axle load (ESAL) repetitions are widely used. These types of models assume that rutting can be minimized by limiting the amount of vertical compressive strains on top of the subgrade. Rutting prediction models that are based on limiting the vertical compressive strain on top of the subgrade include the Asphalt Institute, Shell, TRRL, and Belgian Road Research Center models. These models calculate the allowable number of load repetitions before rutting becomes unacceptable through the use of a basic equation of the following form:

$$
N_{d}=f_{4}\left(\varepsilon_{v}\right)^{-f_{5}}
$$

where: 
$N_{d}=$ number of allowable load applications

$f_{4}, f_{5}=$ constants determined from road tests or field performance studies

$\varepsilon_{v}=$ vertical compressive strain on top of the subgrade

The rutting models used by the four organizations listed below differ only in the definitions of allowable rut depth and the values assigned to the constants $f_{4}$ and $f_{5}$. The constants $f_{4}$ and $f_{5}$ are obtained by data from road tests and from field performance studies performed at various geographical locations, and thus are expected to vary. The allowable rut depths and the values of $\mathrm{f}_{4}$ and $\mathrm{f}_{5}$ used by the four afore mentioned organizations are presented in Table 2.1.

Table 2.1 Subgrade strain criteria used by various organizations (Huang 1993)

\begin{tabular}{|l|l|l|l|}
\hline Organization & $\mathrm{f}_{4}$ & $\mathrm{f}_{5}$ & $\begin{array}{l}\text { Allowable Rut } \\
\text { Depth, mm (in) }\end{array}$ \\
\hline Asphalt Institute & $1.365 \times 10^{-9}$ & 4.477 & $13(0.5)$ \\
\hline $\begin{array}{l}\text { Shell (revised 1985) } \\
50 \% \text { Reliability }\end{array}$ & $6.15 \times 10^{-7}$ & 4.0 & \\
$85 \%$ Reliability & $1.94 \times 10^{-7}$ & 4.0 & $13(0.5)$ \\
$95 \%$ Reliability & $1.05 \times 10^{-7}$ & 4.0 & $10(0.4)$ \\
\hline $\begin{array}{l}\text { U.K Transport and Road Research } \\
\text { Laboratory- (85 \% Reliability) }\end{array}$ & $6.18 \times 10^{-8}$ & 3.95 & $10(0.4)$ \\
\hline Belgian Road Research Center & $3.05 \times 10^{-9}$ & 4.35 & \\
\hline
\end{tabular}


Numerous researchers have suggested permanent deformation models. Among those models, the Diylayee and Raymond (1983) model is widely used. The equation is as follows.

$$
\varepsilon_{P}(N)=I N^{s}
$$

where:

I = permanent strain that occurs during the first cycle of load;

$\mathrm{S}=$ slope of the plot between permanent strain and number of load cycles $(\mathrm{N})$.

The NCHRP 1-26 study (Barenberg et al. 1992) indicated that those models that relate the $\log$ of permanent strain to the $\log$ of load repetitions appear to be the most appropriate and versatile for practical use at this time. These relationships can be expressed in either of the following forms.

$$
\begin{aligned}
\log \varepsilon_{p} & =a+b(\log N) \\
\varepsilon_{p} & =A N^{b}
\end{aligned}
$$

$\varepsilon_{p}=$ permanent strain;

$a=$ experimental parameter dependent on material and stress state conditions;

$b=$ experimental parameter;

$A=\operatorname{antilog}$ of "a";

$N=$ number of repeated load applications.

Other rutting criteria correlate the rate of permanent strain to the elastic vertical strain and the number of load repetitions. One of these, the Asphalt Institute rutting criterion, is among the most widely used in pavement design (Sebaaly et al. 1992).

A rutting prediction criterion recommended by Finn et al. (1986) is as follows. 
For an asphalt concrete layer less than $152.4 \mathrm{~mm}(6 \mathrm{in})$ :

$$
\log R R=-5.617+4.343 \log d-0.16 \log \left(N_{18}\right)-1.118 \log \sigma_{c}
$$

For an asphalt concrete layer greater than $152.4 \mathrm{~mm}$ (6 in):

$$
\log R R=-1.173+0.717 \log d-0.658\left(N_{18}\right)+0.666 \log \sigma_{c}
$$

where:

$R R=$ rate of rutting, micro inches per axle-load repetition $\left(1 \mu \mathrm{in}=10^{-6} \mathrm{in}\right)$;

$d=$ surface deflection $\times 10^{3}$ in $\left(25.4 \times 10^{3} \mathrm{~mm}\right)$;

$\sigma_{c}=$ vertical compression stress at interface with asphalt concrete (psi);

$N_{18}=$ equivalent number of $18 \mathrm{kip}(80 \mathrm{kN})$ single axle load $\times 10^{5}(\mathrm{ESAL})$.

\subsection{Previous Research on Super-Single Tires}

In this section, previous research on super-single tires is examined. One of the most popular super-single tires used in the trucking industry is the $425 / 65 \mathrm{R} 22.5$ tire and the equivalent dual tire, the 11R 22.5 Radial tire (Bonaquist 1993, Tielking 1994, Akram 1992). A single axle with dual tires has been generally defined as consisting of four tires, two tires in each side of a truck. However, a single axle with super-single tires is defined as consisting of two tires (see Figure 4.14). Previous studies on super-single tires indicated that any type of axles such as tandem and tridem axles could be replaced with super-single tires. This tendency has also been identified in Indiana. The typical weights of super-single tires range from 100 to $120 \mathrm{lbs}$, as shown in Table 2.4. The super-single 
tire parameters to be discussed are contact area and contact stress. We will review both mechanistic studies and field testing.

\subsubsection{Contact Area}

Although the contact area of a truck tire is assumed to be circular in multi-layered elastic theory, the contact area of a truck tire is in reality closer to a rectangle than to a circle. Weissman (1999) used an array of pins to measure the dimensions of the contact area for a Goodyear 10.00 x 20 bias-ply tire and for a Goodyear G159A 11R22.5 radial tire. The range of the load was $13 \sim 28 \mathrm{kN}$ and the tire inflation pressure ranged from 220 $\sim 920 \mathrm{kPa}$. The results presented in Figure 2.3 are for a load of $23 \mathrm{kN}$ and a pressure of $690 \mathrm{kPa}$. It is evident that both contact areas are much closer to having a rectangular shape rather than a circular shape. Weissman also stated that for the tires tested, when the pressure was above $420 \mathrm{kPa}$, the length of the contact area depended primarily on the applied load, while the width remained almost constant. 

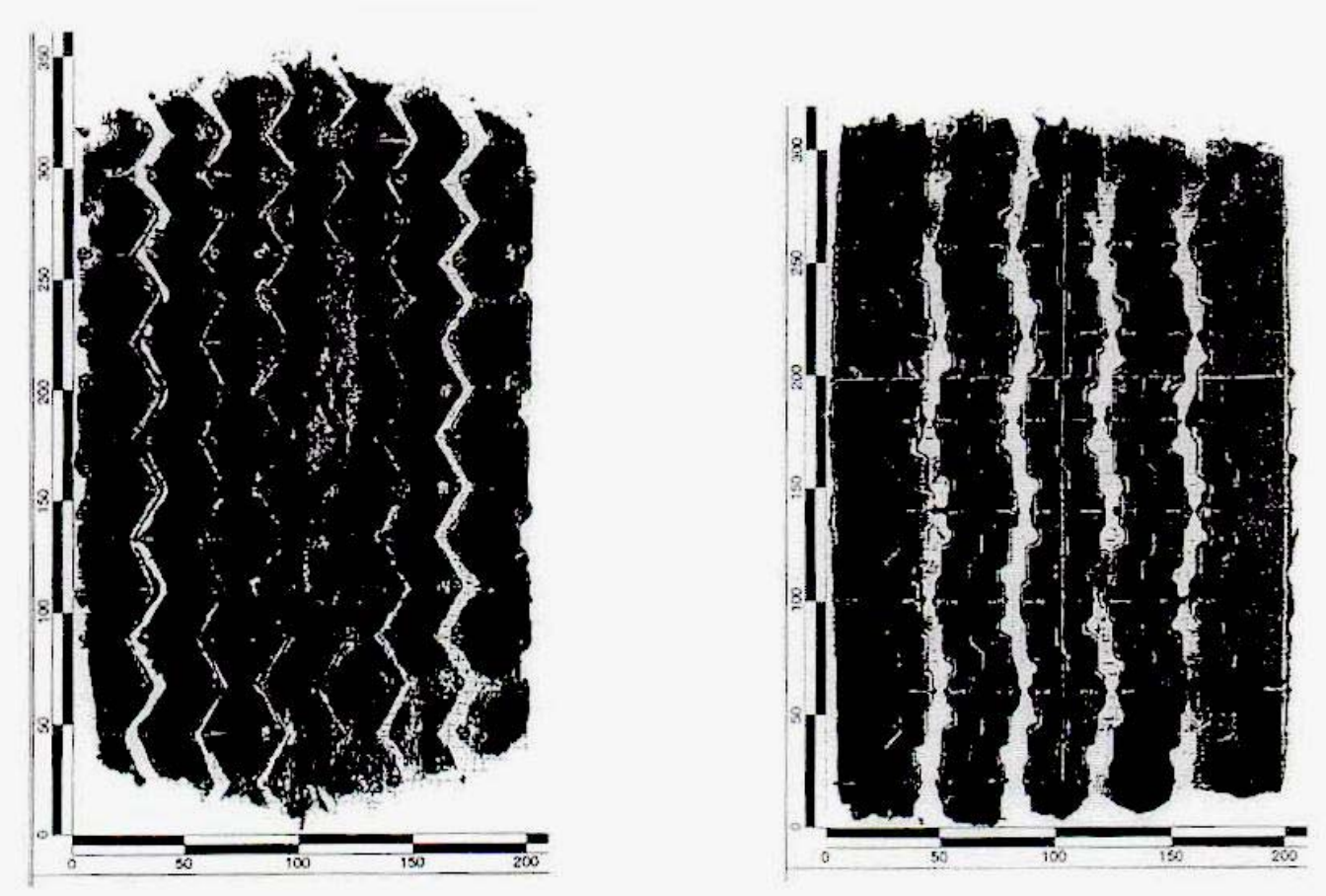

(a)

(b)

Figure 2.3 Imprints for (a) a Goodyear bias-ply and (b) a Goodyear radial tire (Weissman 1999)

Tielking (1994) made similar observations. As part of a study to create a model of a heavy vehicle, he used a MTS servo-hydraulic testing machine to make measurements of the contact area of a conventional $11 \mathrm{R} 22.5 / \mathrm{G}$ radial tire and a $425 / 65 \mathrm{R} 22.5 / \mathrm{J}$ wide base tire. The range of loads and inflation pressures were $590-860 \mathrm{kPa}$ and $12-33 \mathrm{kN}$ for the radial tire and $550-830 \mathrm{kPa}$ and $18-54 \mathrm{kN}$ for the wide base tire. Figure 2.4 illustrates the video image of the contact area of both tires. The contact areas in this case are also rather rectangular in shape. Tielking examined the effect of the inflation pressure 
and the load on the contact area. He concluded that the gross contact area increased as the tire load increased. The effect of the inflation pressure was not so significant. However, an increase of the gross contact area was noticed as the tire load increased.

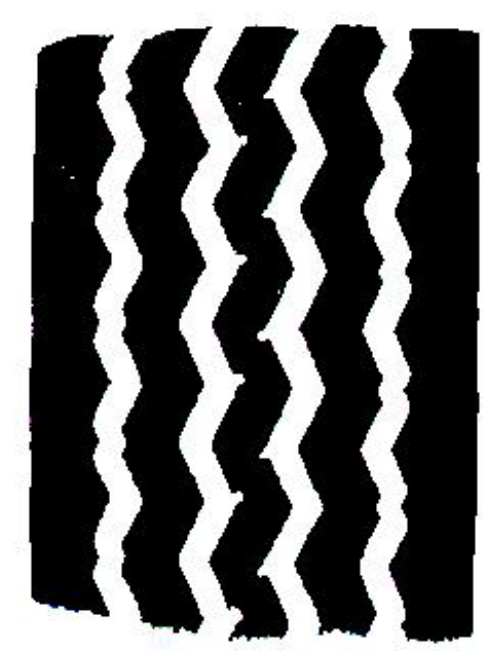

(a)

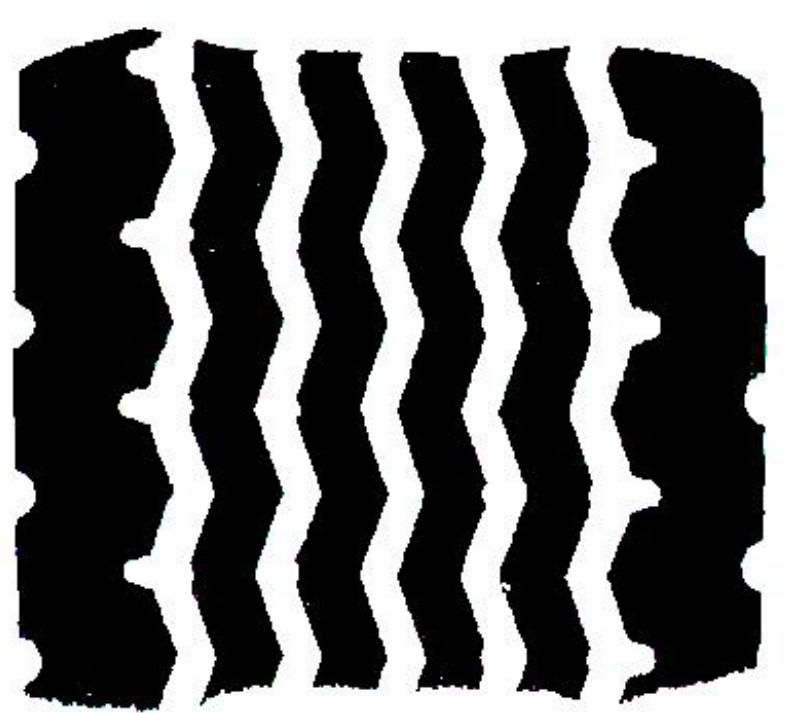

(b)

Figure 2.4 Video image footprints of (a) a conventional and (b) a wide base truck tire (Tielking 1994)

As shown in Tables 2.2 and 2.3, some data regarding the dimensions of the contact area of wide base tires for certain values of the inflation pressure and the tire load were collected from Goodyear and Michelin (tire manufacturing companies). As seen in Tables 2.2 and 2.3 , it is noticed that the dimensions of the contact area depend on the tire type, load and inflation pressure. As identified in the study by Tielking (1994) and evidenced by data collected from tire manufactures (shown in Table 2.3), the contact area of a super-single tire is larger in the transverse than in the longitudinal direction, as opposed 
to the contact area of a conventional dual tire. The contact area of a truck tire is primarily dependent upon axle load, inflation pressure, and tire type.

Unfortunately, there are not many published data on contact areas of super-single tires and dual tires. Most researchers have either assumed that the contact area is circular or used the equivalent rectangular contact area shown in Figure 2.5(b) when doing analysis of pavement loading. The equivalent contact area is commonly used in finite element analysis for dual conventional tires. The equivalent contact area approximates the shape of the contact area of dual tires (shown in Figure 2.5(left)) composed of two semicircles and a rectangle by assuming a length $\mathrm{L}$ and a width equal to $0.6 \mathrm{~L}$ (Huang 1993). The contact area is calculated for a dual tire using the following equation:

$$
A_{c}=\pi(0.3 L)^{2}+(0.4 L)(0.6 L)=0.5227 L^{2}
$$

or

$$
L=\sqrt{\frac{A_{c}}{0.5227}}
$$

where $A_{c}=$ equivalent contact area. As can be seen in Figure 2.5(a), (2.12) is the sum of the areas of the two semicircles and the area of rectangle.

In the Finite Element (FE) analysis we will discuss in a later chapter, equation (2.12) was used to calculate the value of the contact area for conventional dual tires. An equivalent rectangular contact area was used, shown in Figure 2.5(b). As the 425/65R22.5 super-single tire is most typically used (Bonaquist 1992, Tielking 1994, Akram 1992), the ratio of width to length (shown in Figure 2.5(b) (dotted line)) 
appropriate for the typical super-single tire (1:0.85, as shown in Table 2.3 for 425/65R22.5) was used for super-single tires in order to model them more realistically.

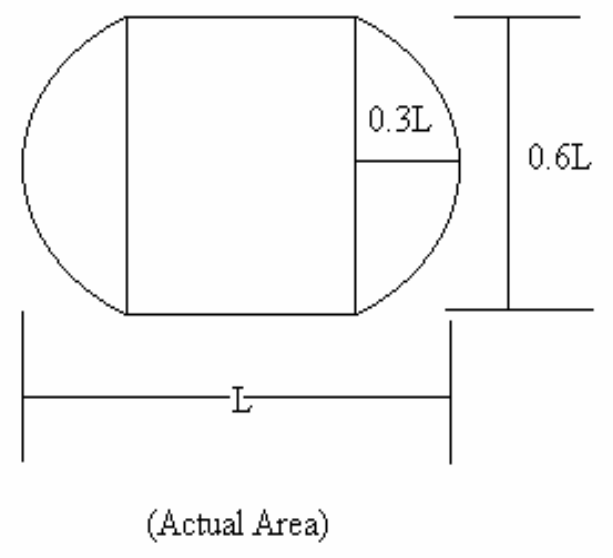

(a)

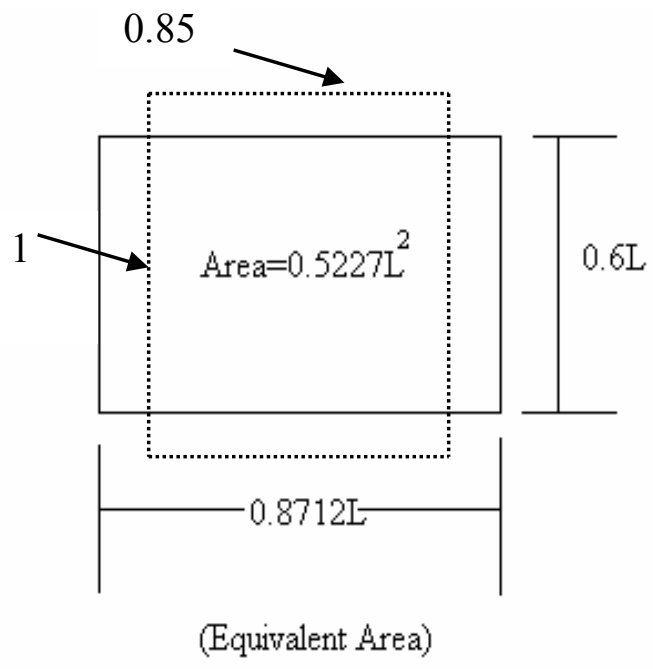

(b)

Figure 2.5 Contact area for dual tires (after Huang 1994) 
Table 2.2 Contact area of wide base tires manufactured by Goodyear (after Goodyear)

\begin{tabular}{|l|l|l|l|l|l|}
\hline Tire & $\begin{array}{l}\text { Maximum } \\
\text { width } \\
\text { (in) }\end{array}$ & $\begin{array}{l}\text { Inflation } \\
\text { pressure } \\
(\mathrm{psi})\end{array}$ & $\begin{array}{l}\text { Maximum } \\
\text { load } \\
(\mathrm{lbs})\end{array}$ & $\begin{array}{l}\text { Net contact } \\
\text { area } \\
\left(\mathrm{in}^{2}\right)\end{array}$ & $\begin{array}{l}\text { Average } \\
\text { vertical contact } \\
\text { pressure (psi) }\end{array}$ \\
\hline $385 / 65 \mathrm{R} 22.5$ & 15.3 & 120 & 9,370 & 66.3 & 128 \\
\hline $425 / 65 \mathrm{R} 22.5$ & 16.6 & 120 & 11,000 & 71.4 & 119 \\
\hline $445 / 65 \mathrm{R} 22.5$ & 17.5 & 120 & 12,300 & & \\
\hline
\end{tabular}

Table 2.3 Contact area of wide base tires manufactured by Michelin (Michelin Inc. 1997)

\begin{tabular}{|c|c|c|c|c|c|c|}
\hline Tire & $\begin{array}{c}\text { Width } \\
\text { (in) }\end{array}$ & $\begin{array}{c}\text { Length } \\
\text { (in) }\end{array}$ & $\begin{array}{c}\text { Ratio } \\
\text { (width:length) }\end{array}$ & $\begin{array}{c}\text { Net contact } \\
\text { area }\left(\mathrm{in}^{2}\right)\end{array}$ & $\begin{array}{c}\text { Maximum } \\
\text { load (lbs) }\end{array}$ & $\begin{array}{c}\text { Inflation } \\
\text { pressure } \\
\text { (psi) }\end{array}$ \\
\hline 445/65R19.5 & 13.1 & 10.2 & $1: 0.78$ & 81.0 & 10,250 & 110 \\
\hline $385 / 65 \mathrm{R} 22.5$ & 11.1 & 9.4 & $1: 0.85$ & 65.9 & 9,370 & 125 \\
\hline $425 / 65 \mathrm{R} 22.5$ & 12.0 & 10.2 & $1: 0.85$ & 71.3 & 11,400 & 125 \\
\hline 445/65R22.5 & 15.0 & 11.3 & $1: 0.75$ & 85.3 & 12,300 & 120 \\
\hline 445/65R22.5 & 13.1 & 10.8 & $1: 0.82$ & 81.7 & 12,300 & 125 \\
\hline
\end{tabular}

According to Perdomo and Nokes (1993) and Sebbaaly (1994), regulations limiting the weight per inch of tire width for steering and regular axles have been adopted in 28 states around the nation (as of 1990). The allowable single axle loads in the State of Indiana are shown in Table 2.4. 
Table 2.4 Allowable single axle load in the State of Indiana based on tire load limits

\begin{tabular}{|c|c|c|c|}
\hline Tire Load & $\begin{array}{c}\text { Dual } \\
11 \mathrm{R} 22.5\end{array}$ & $\begin{array}{c}\text { Super-Single } \\
425 / 65 \mathrm{R} 22.5\end{array}$ & $\begin{array}{c}\text { Super-Single } \\
385 / 65 \mathrm{R} 22.5 \\
\mathrm{~N} / \mathrm{mm}(\mathrm{lbs})\end{array}$ \\
$\mathrm{kN}(\mathrm{lbs})$ & $\mathrm{kN}(\mathrm{lbs})$ & $\mathrm{kN}(\mathrm{lbs})$ \\
\hline 140.1 & 156 & 119 & 108 \\
$(800)$ & $(35,070)$ & $(26,752)$ & $(24,279)$ \\
\hline
\end{tabular}

\subsubsection{Contact Stresses}

When a tire loading is applied to the pavement surface, three contact stress components are generated: vertical, transverse, and longitudinal. The vertical contact stress is a direct function of the tire's loading and inflation pressure, and the transverse and longitudinal shear stresses are associated with the bending of the tire as it is deformed from its normally toroidal shape at the tire/road interface (Yap 1988). The measurement of contact stresses started for super-single tires in the 1980's. Marshek et al. (1986) first attempted to measure the distribution of the vertical contact stresses of a biasply tire for inflation pressures of 75, 90 and 110 psi and for loads of 4,500 lbs and 5,400 lbs using pressure-sensitive films prints. They found the distributions were not uniform, and the vertical pressures exceeded the inflation pressure in some areas.

Ford and Yap (1990) measured the contact stresses for a slow-rolling tire over a strain gage transducer embedded in the flat road-bed with the use of a speciallyinstrumented flat bed machine. A schematic representation of the direction of the lateral contact stresses is given in Figure 2.6. Of note is that in the " $\mathrm{X}$ " direction (longitudinal 
direction) there is a change in the direction of stresses at about the center of the contact area, whereas in the "Y" direction (transverse direction) there is a continuous alteration. Ford and Yap also examined the effect of inflation pressure and tire load on the distribution of the vertical contact stresses.

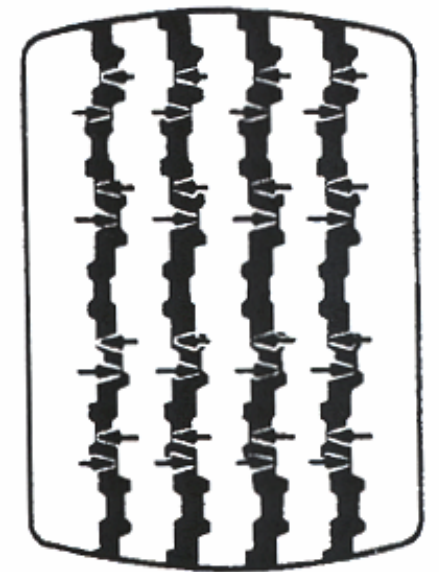

"Y" DIRECTION

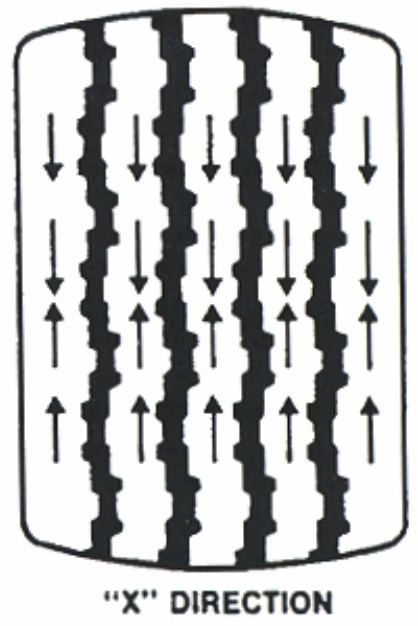

" $\mathrm{X}$ " DIRECTION

Figure 2.6 Direction of lateral contact stresses (Ford and Yap 1990)

For two Goodyear super-single tires (385/65R22.5 and 425/65R22.5) at a constant load, the tire inflation pressure variation primarily affected the contact stresses in the central region of the contact area; the higher the inflation pressure, the greater the contact pressures in this central region. The contact pressures in outer portions of the tires were 
essentially not affected. In contrast, at a constant inflation pressure, the tire load variation explicitly influenced the contact stresses in the outer regions of the contact area; the higher the load, the higher those stresses. The maximum contact stress was still located at the center of the contact area, as Yap (1988) reported in a similar study. Yap (1988) compared the tire load increase due first to an inflation pressure increase and then to a tire load increase for a 11-24.5 radial tire, a 11R24.5 radial tire and a 385/65R22.5 wide base tire (all manufactured by Goodyear). The wide base tires exhibited higher increase in the contact stresses in the case of the increase of the inflation pressure, but they had the lowest increase as the tire load increased. Despite this fact, in both cases wide base tires had higher vertical contact stresses.

Myers et al. (1999) measured the three components of the contact stresses under various truck tires using a device composed of 16 coaxial load and displacement transducers, developed and operated by Smithers Scientific Services, Inc. (Ravenna, Ohio). Results are presented for the vertical and transverse contact stresses for a bias ply tire (load $25 \mathrm{kN}$ and inflation pressure $793 \mathrm{kPa}$ ), a Bridgestone R299 radial tire (load 25 $\mathrm{kN}$ and inflation pressure $793 \mathrm{kPa}$ ) and a Bridgestone M844 wide base radial tire (load $41.7 \mathrm{kN}$ and inflation pressure $793 \mathrm{kPa}$ ). As seen in Figures 2.7 and 2.8, a comparison of radial tires with wide base tires showed that the vertical and transverse contact stresses are higher for wide base tires because wide base tires have a higher load per tire ratio than any other type of tire. The distribution of the vertical contact stresses was also not uniform. The maximum value was found to occur at the center of the contact area and equal to approximately 2.3 times the inflation pressure. Also, it is observed that the 
maximum vertical stresses of the wide base tire are about 1.5 times greater than those of the bias ply and radial tires.

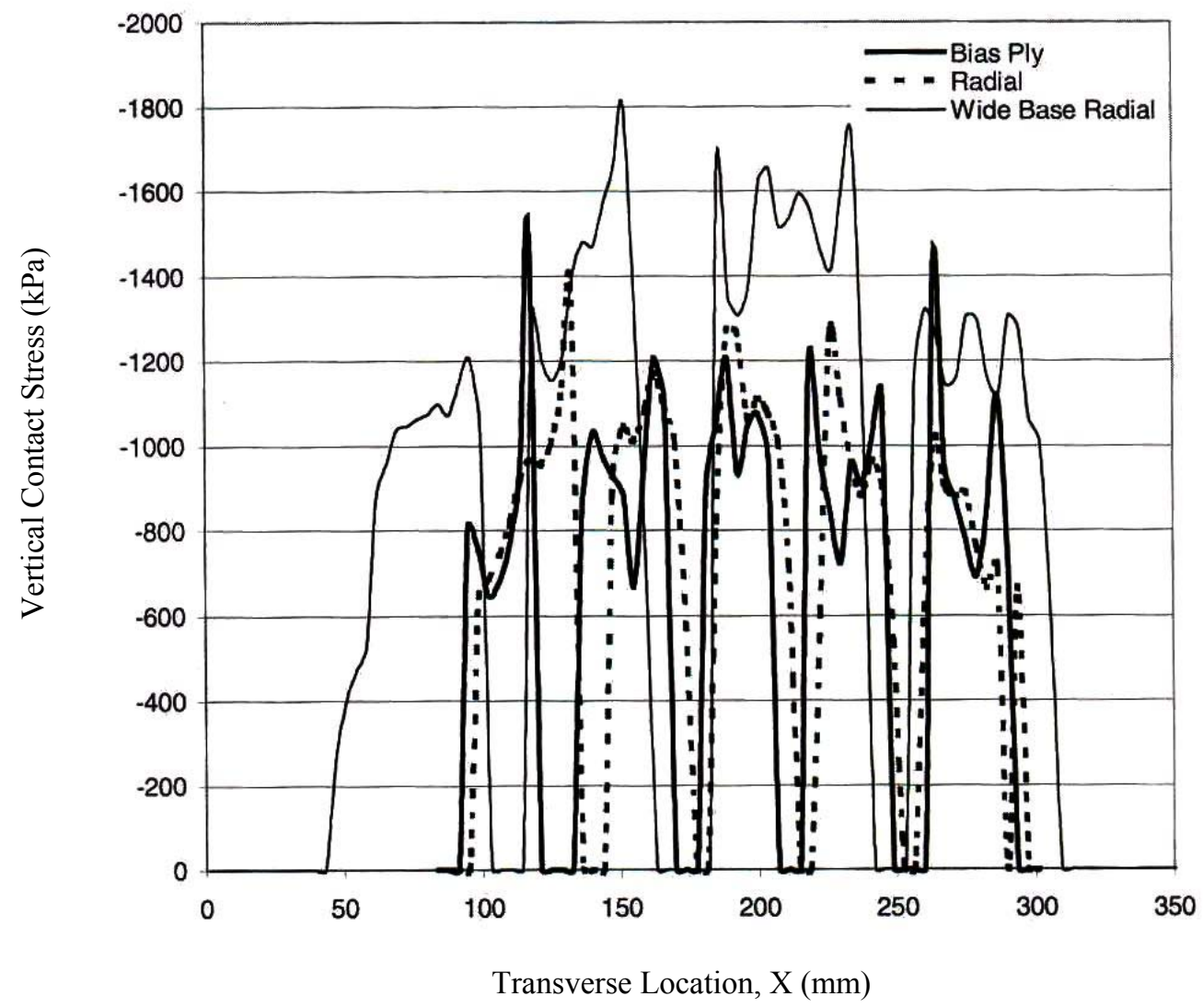

Figure 2.7 Distribution of vertical contact stresses (Myers et al. 1999)

With respect to the transverse stresses, again the wide base tires exhibit higher values in the central region of the contact area. Maximum transverse stress (of the wide base tire) is about one third of the maximum vertical contact stress. Finally, Myers et al. examined the influence of load and inflation pressure on transverse contact stresses for the radial 
tire. It was concluded that the inflation pressure increased the stresses at the center of the tire, but did not affect the shoulder regions. In contrast, higher loads increased the transverse stresses over the entire width of the radial tire.

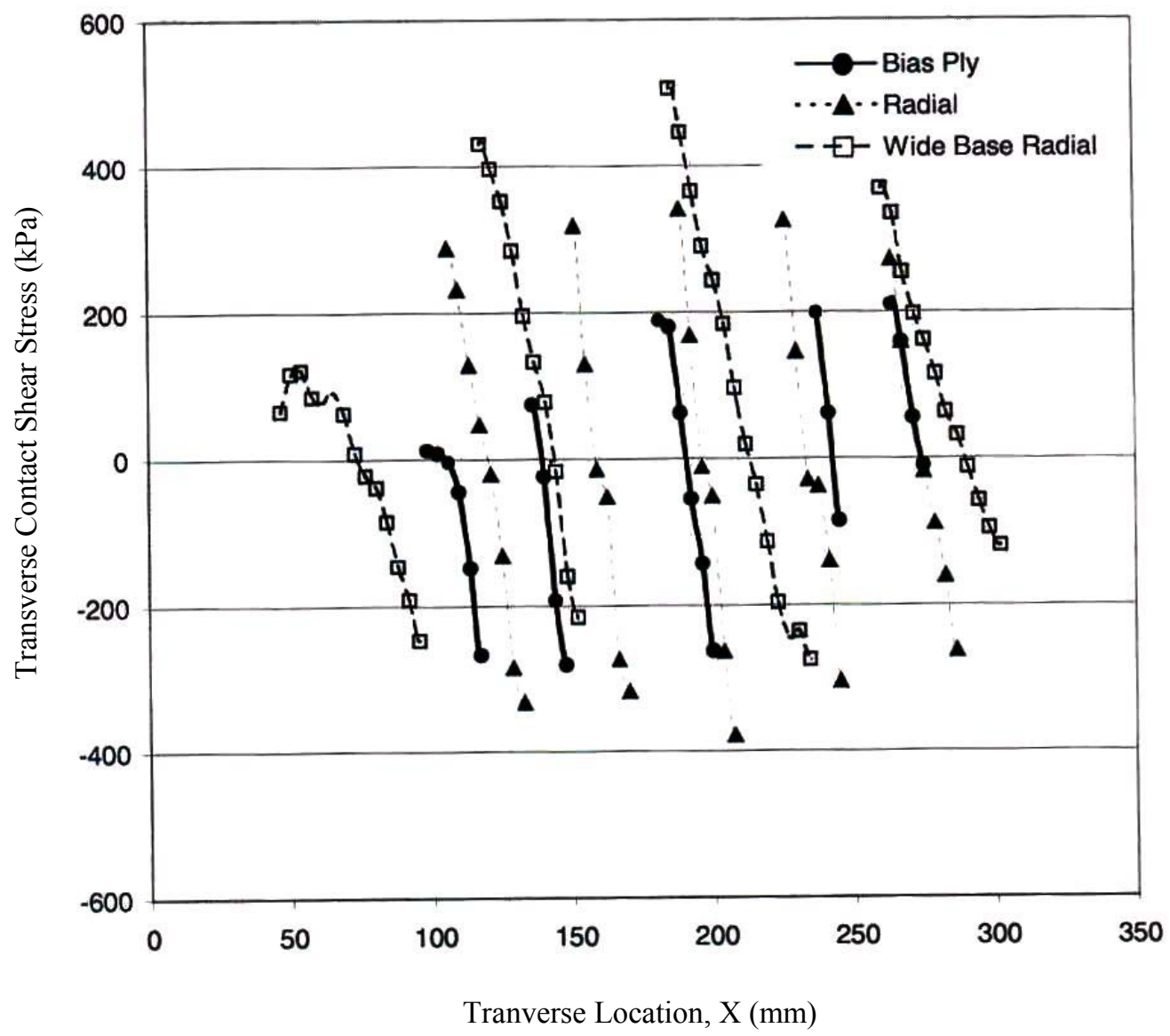

Figure 2.8 Distribution of transverse contact stresses (Myers et al, 1999) 
De Beer et al. (1997) did the most extensive research on tire tact stresses. They invented the Vehicle-Road Surface Pressure Transducer Array (VRSPTA). It consists mainly of an array of triaxial strain gauged steel pins fixed to a steel base plate, together with additional non-instrumented supporting pins, fixed flush with the road surface. This system is automatically triggered by a moving wheel and is designed to measure at wheel speeds from $1 \mathrm{~km} / \mathrm{h}$ up to $25 \mathrm{~km} / \mathrm{h}$, and loads up to $200 \mathrm{kN}$ (vertical) and $20 \mathrm{kN}$ (horizontal). The surface that VRSPTA represents is an "average equivalent dry road surface" and is assumed to be acceptable for this kind of measurement. The stresses were measured simultaneously with the Vehicle-Road Surface Pressure Transducer Array (VRSPTA). The influence of the increase of tire loads and inflation pressures on the contact stresses was examined. The following general equation was proposed to estimate three components of the contact stresses:

$$
\text { Contact stress }=\mathrm{K}_{1}+\mathrm{K}_{2} \times(\text { inflation pressure })+\mathrm{K}_{3} \times(\text { load })
$$

where $\mathrm{K}_{1}, \mathrm{~K}_{2}$ and $\mathrm{K}_{3}$ are regression coefficients that are always positive numbers.

In the FE analysis covered in later chapters of this report, the maximum contact stresses of the three components for the Michelin 425/65R22.5 wide base tire were obtained for an inflation pressure of $125 \mathrm{psi}$ and for a tire load of $11,400 \mathrm{lbs}$, which are the maximum inflation pressure and tire load recommended by the tire company for this tire. Based on the above regression equation, an increase in either the load or the inflation pressure increases the maximum vertical and transverse contact stresses. It is intuitive that vertical contact stresses are more sensitive to changes either of the inflation pressure or of the tire load than are the other two components. Moreover, the ratio of the maximum vertical contact stress to the lateral and longitudinal stress is approximately 
10:1.6:0.8 (Siddharthan et al. 1998). This means that vertical contact stress is the most significant component. Siddharthan et al. (1998) reported that the impact of contact shear stresses on tensile strains at the bottom of asphalt were insignificant. Accordingly, in our FE analysis, transverse and longitudinal shear stress components were neglected.

\subsubsection{Mechanistic Studies}

Rutting and fatigue cracking are two major concerns associated with pavement structures. Rutting is generally known to be induced by the accumulation of vertical compressive strains on top of the subgrade due to the repetitive traffic loadings, while fatigue cracking is mainly known to be caused by the accumulation of horizontal strains at the bottom of an asphalt layer. The design of a pavement structure concentrates on limiting these strains in order to achieve satisfactory pavement performance over a certain design period. Most analyses of pavements subjected to the super-single tire loadings rely on either the multi-layered elastic theory (Perdomo et al. 1993, Hallin et al. 1983, Bell et al. 1992, Gillipsie et al. 1993, Sebaaly et al. 1992) or the FEM (Hallin et al. 1983) to assess the relative damage caused on the pavement structure by single tires as compared with dual tires. Generally, using multi-layered elastic theory and FEM, tensile and compressive strains are calculated, and the difference of these strains between supersingle tires and dual tires are evaluated.

Deacon (1969) initiated research on single tires that are different from current super-single tires in terms of tire width. He derived theoretical equivalency factors based on the strain at the bottom of the AC layer using multi-layered elastic theory. $\mathrm{He}$ 
analyzed pavement structures with circular tire contact area and uniform contact pressure and derived load equivalency factors as a function of the exponential strain ratios. The equivalency factors were obtained as follows.

$$
F_{i}=\left(\varepsilon_{i} / \varepsilon_{b}\right)^{5.5}
$$

where $\varepsilon_{\mathrm{i}}$ and $\varepsilon_{\mathrm{b}}$ are the calculated tensile strains at the bottom of the $\mathrm{AC}$ layer under the load in question and the reference load of $80 \mathrm{kN}(18,000 \mathrm{lbs})$ on a single axle with dual tires, respectively. He indicated an $80 \mathrm{kN}(18,000 \mathrm{lbs})$ single axle load with dual tires is equivalent to a single axle load of $52 \mathrm{kN}(11,700 \mathrm{lbs})-64 \mathrm{kN}(14,400 \mathrm{lbs})$ with single tires.

Perdomo et al. (1993) used the multi-layered elastic theory with surface shear stresses to evaluate the influence of super-single tires on flexible pavements for the purpose of coping with the trend of replacing conventional tires with wide-base tires in California. Two cases of non-uniform vertical stress and non-uniform vertical stress with inward surface shear stress were analyzed using the CIRCLY program based on multilayered elastic theory. Their study indicated that ignoring the shear stress effects could lead to overestimation of the life of the surface layers under actual conditions of contact stresses.

Hallin et al. (1983) evaluated the effects of axles with single and dual tires on pavement performance. For rigid pavements, load-related stresses in concrete pavements were determined by using the ILLI-SLAB finite-element computer program. For flexible pavements, the maximum horizontal strain at the bottom of the asphalt concrete layer was calculated for various sizes and axle load using the Elastic Theory Iterative Method-Dual 
Wheel Option (PSAD2A). The relative damage equivalency factors were calculated by the following equation:

$$
\text { Equivalency Factor }=\mathrm{N}_{18} / \mathrm{N}_{\mathrm{i}}
$$

where $\mathrm{N}_{18}$ is the load repetitions to fatigue failure for $80 \mathrm{kN}$ (18kips) single axle load with dual tires and $\mathrm{N}_{\mathrm{i}}$ is the number of load repetitions to fatigue failure for the axle load and tire configuration being evaluated. Fatigue analysis was done using the method developed by Finn et al. (1986) to evaluate the number of repetitions resulting in fatigue cracking equal to or less than $10 \%$ of the wheel path. Their study showed that, for the same axle load, as the width of the single tire decreases, the equivalency factor increases, implying more damage.

Bell et al. (1992) used Deacon's approach to estimate equivalency factors. Since Deacon's approach does not consider all axle configurations, in order to extend the LEF Bell et al. used ELSYM5 based on multi-layered elastic theory for both the thick and thin pavements. The analyses determined the maximum tensile strain at the bottom of the asphalt layer and the maximum compressive strain on the top of the subgrade. These two response parameters are commonly associated with load-induced fatigue cracking and surface rutting, respectively. The equation of Shook et. al (1982) used by the Asphalt Institute was used to estimate the number of load applications to fatigue failure associated with each level of calculated tensile strain.

Gillespie et al. (1993) used analytical methods to investigate the mechanistic vehicle-pavement interaction and to evaluate pavement damage. This study used VESYSDYN to compute the primary responses of flexible pavement structures to applied loads. 
Tensile strain at the bottom of asphalt layer and vertical strains on top of each layer were also used to obtain the relative damage.

Siddharthan and Sebaaly (1999) examined asphalt concrete layer strains for two pavement sections using viscoelasticity without observations of the subgrade. They used a typical tandem axle, with a total load of $180 \mathrm{kN}$, assuming either wide base or radial tires. They utilized the three components of the contact stresses that De Beer et al. reported for a 425/65R22.5 wide base tire. The stress distribution was obtained for a load of $45 \mathrm{kN}$ per tire and inflation pressures ranging from 850 to $900 \mathrm{kPa}$. Figure 2.9 shows the variation of the longitudinal and transverse strains for the wide base tires with respect to the vehicle speed. The strains decrease as the speed of the vehicle increases. However, it is noticed that the transverse strain is slightly greater than the longitudinal strain for the thick pavement. Siddharthan and Sebaaly observed that the current pavement designs typically use the normal longitudinal strain components as a critical input, implying that the fatigue cracks initiate in the transverse direction. However, in the thick pavement, the tensile strain would be larger in the transverse direction than in longitudinal direction. 


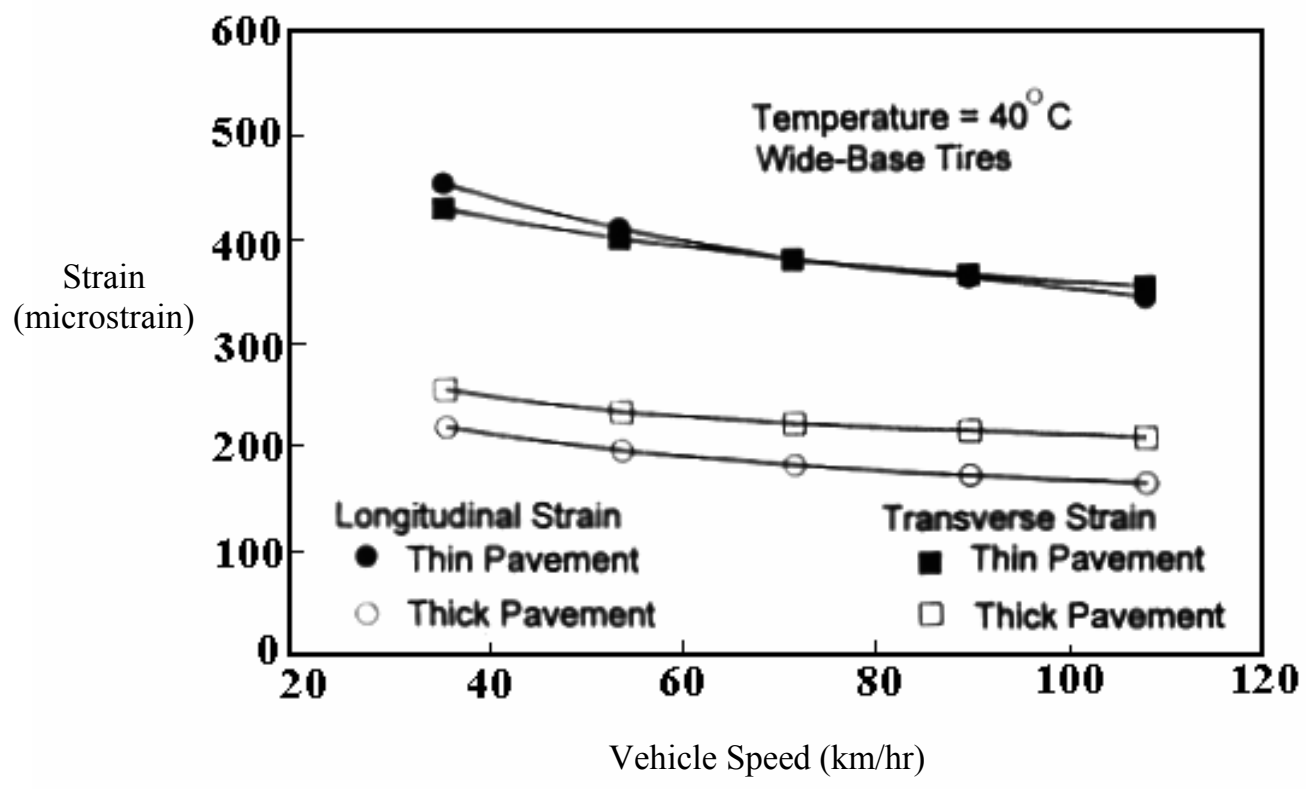

Figure 2.9 Influence of vehicle speed on shear strain induced in the AC layer (Siddharthan and Sebaaly 1999)

Sebaaly and Tabatabaee (1989) tested three types of tires in the laboratory and applied the results in their analyses. The tires tested were a dual 11-22.5 bias, dual 11R22.5 radial and a 385/65R22.5 wide base tire. The ranges of load and inflation pressure per tire were 2500 - $5500 \mathrm{lbs}$ and 80 - $130 \mathrm{psi}, 2500-5500 \mathrm{lbs}$ and $75-125 \mathrm{psi}$, and $5500-10000 \mathrm{lbs}$ and $105-145 \mathrm{psi}$, respectively. From analyses performed with the program BISAR, they evaluated the tensile strain at the bottom of the asphalt layer for various thicknesses of the $\mathrm{AC}$ layer. This strain is an indication of the fatigue failure of a pavement. Results are presented in Figures 2.10 and 2.11 for a 2-inch AC layer. For the case of the tensile strains at the bottom of the AC layer, it is apparent that the wide base 
tires generate the higher strain values and are approximately 50 percent higher than the values of the radial tires. Similarly, the compressive stresses under the wide base tire are 25 and 50 percent higher, respectively, than stresses under the radial tires. These observations were expected because the wide base tire has a higher load per tire than both radial and bias tires.

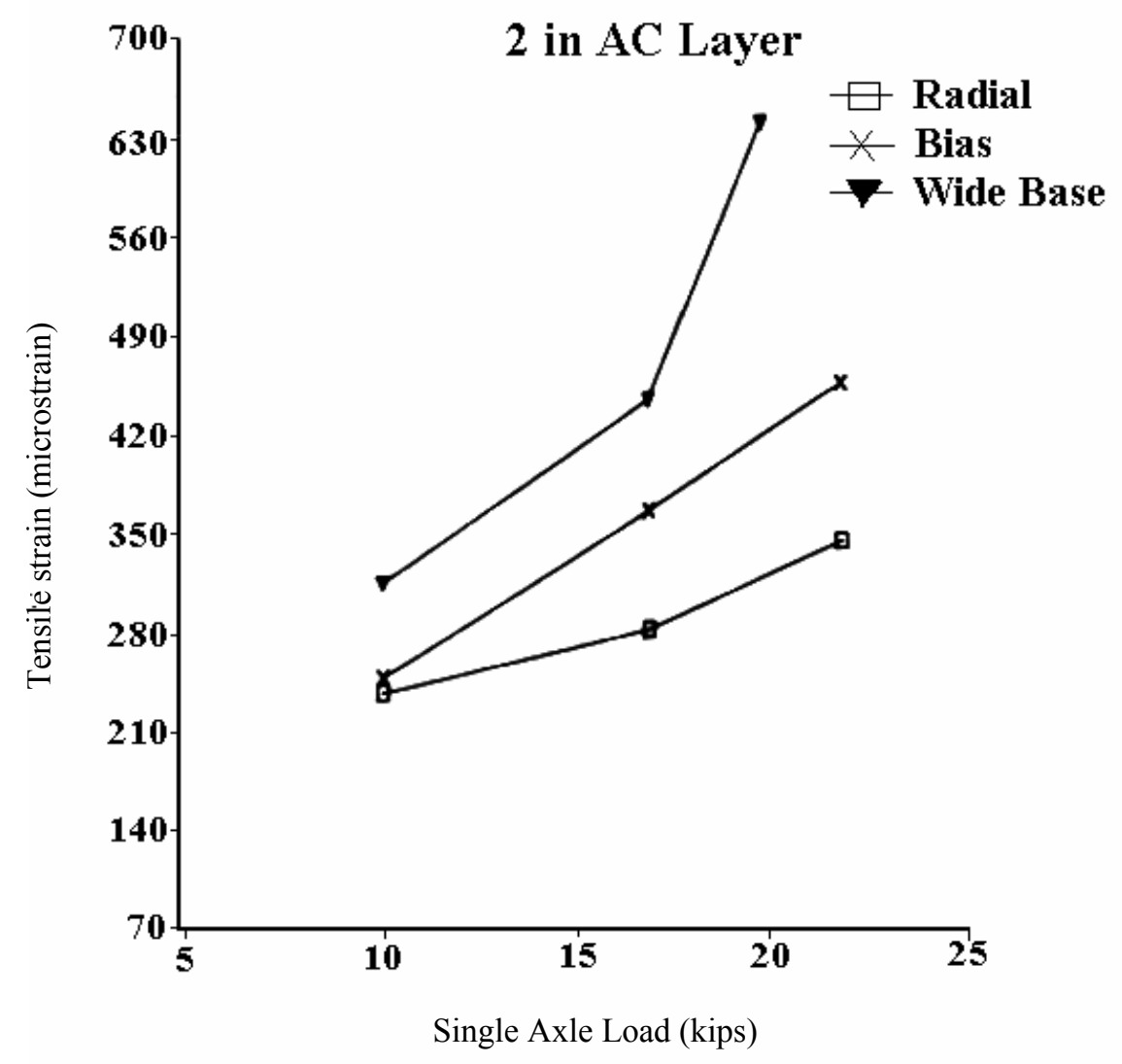

Figure 2.10 Effect of axle load and tire types on tensile strain at the bottom of the layer (Sebaaly and Tabatabaee 1989) 


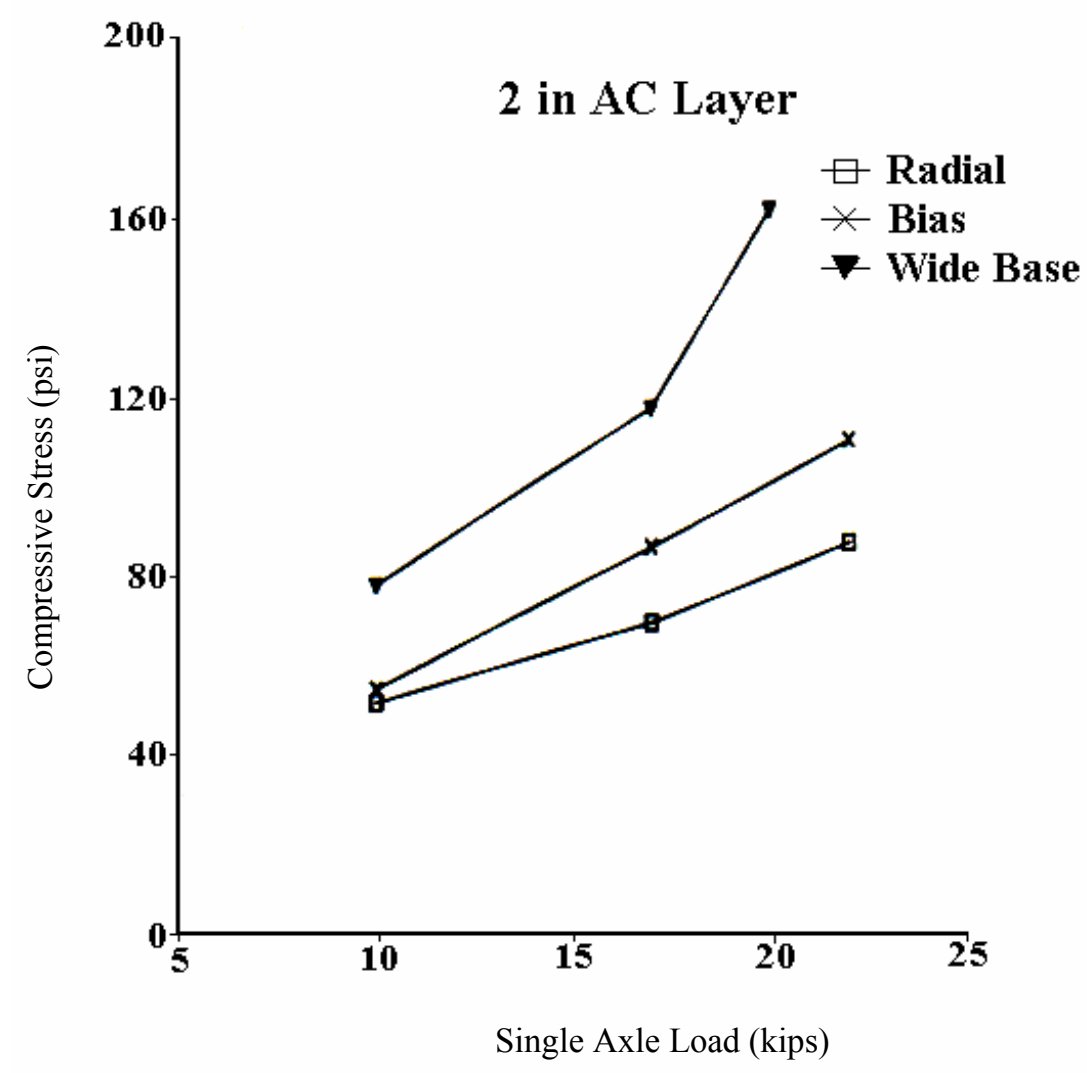

Figure 2.11 Effect of axle load and tire types on the compressive stress at the asphalt layer interface (Sebaaly and Tabatabaee 1989)

In summary, although the approaches have been different, previous research on super-single tires basically used multi-layered elastic theory and compared relative damage between conventional dual tires and single tires. A comparison is illustrated in Table 2.5 to present an outline of research trends. It should be noted that most of the previous research assumed the contact stress to be equal to the inflation pressure, which is unconservative according to recent studies. In addition, it should also be noted that plastic behavior of pavement materials, especially the subgrade has not been significantly 
observed in the previous research with the implied assumption that the subgrade would be elastic.

Table 2.5 Mechanistic research related to super-single tires

\begin{tabular}{|c|c|c|c|c|c|c|}
\hline Author & Analysis & Tool & $\begin{array}{l}\text { Contact } \\
\text { stress }\end{array}$ & Loading & Axle type & Results \\
\hline $\begin{array}{l}\text { Deacon } \\
\text { (1969) }\end{array}$ & MLE & MLE & $\begin{array}{l}\text { Uniform } \\
\text { Circular }\end{array}$ & Static & $\begin{array}{l}\text { Single } \\
\text { Tandem } \\
\text { Tridem }\end{array}$ & LEF \\
\hline $\begin{array}{l}\text { Perdomo } \\
\text { et al. } \\
(1993)\end{array}$ & MLE & CIRCLY & $\begin{array}{l}\text { Nonuniform } \\
\text { Shear stress }\end{array}$ & Static & $\begin{array}{l}\text { Single } \\
\text { Tandem } \\
\text { Tridem }\end{array}$ & N/A \\
\hline $\begin{array}{l}\text { Hallin et al. } \\
\text { (1983) }\end{array}$ & $\begin{array}{l}\text { MLE } \\
\text { FEM }\end{array}$ & $\begin{array}{l}\text { ILLISLAB } \\
\text { PSA2DA }\end{array}$ & Uniform & Static & $\begin{array}{l}\text { Single } \\
\text { Tandem }\end{array}$ & LEF \\
\hline $\begin{array}{l}\text { Bell et al. } \\
\text { (1992) }\end{array}$ & MLE & ELSYM5 & $\begin{array}{l}\text { Uniform } \\
\text { Circular }\end{array}$ & Static & $\begin{array}{l}\text { Single } \\
\text { Tandem } \\
\text { Tridem }\end{array}$ & LEF \\
\hline $\begin{array}{l}\text { Gillespie et } \\
\text { al. } \\
\text { (1993) }\end{array}$ & MLE & $\begin{array}{l}\text { VESYS- } \\
\text { DYN }\end{array}$ & $\begin{array}{l}\text { Uniform } \\
\text { Circular }\end{array}$ & Static & $\begin{array}{l}\text { Single } \\
\text { Tandem } \\
\text { Tridem }\end{array}$ & LEF \\
\hline
\end{tabular}

Note: MLE represents multi-layered elastic theory

\subsubsection{Field testing}

Field testing (Bonaquist 1992, Akram et al. 1992, Huhtala et al. 1997) involving trucks equipped with super-single tires has rarely been performed since it is very expensive. This is the main reason why the research on the super-single tires has been mainly done analytically or numerically.

Bonaquist (1992) assessed the impact of single tires on the response and performance of thin and thick flexible pavement sections using an Accelerated Loading 
Facility (ALF) to simulate traffic loading. Pavement response and performance data were collected for comparable dual and wide based single tires. This machine assembly traveled $19 \mathrm{~km} / \mathrm{h}$ on rails attached to the frame and in contact with the pavement for $12 \mathrm{~m}$. During acceleration testing, approximately 8,500 load repetitions were performed a day. Comparisons of the response and performance data for the two types of tires, 11R22.5 dual tires, 425/65R22.5 super-single tires, were then used to assess the relative damage potential of the wide based singles. They performed tests for axle loads varying from 41 $75 \mathrm{kN}(9,200$ - 16,600 lbs) and tire inflation pressures varying from 520 - $920 \mathrm{kPa}(75$ 139 psi). Horizontal strain gauges were installed at the interface between the crushed aggregate base and the lower lift of the asphalt binder. Vertical strain gauges were embedded in each layer and relative displacements were measured using a linear variable differential transformer (LVDT) between a plate bonded in the surface of the asphalt concrete and a reference plate placed at the desired depth during pavement construction. Average vertical strains were obtained by dividing the gauge length between the two plates. Their testing indicated that the thick pavement would decrease the significant effects of super-single tires as compared with thin pavement. They concluded that, for the same load and tire pressure, super-single tires induced higher vertical compressive strains in all layers, higher tensile strains at the bottom of the asphalt concrete layer, and around two times more rutting than dual tires. The fatigue life of the pavement was cut down to one fourth of that of dual tires.

Akram et al. (1992) used a Multiple Depth Deflectometer (MDD) to compare the response of two pavement sections in Texas under dual and wide base single tires on tandem axles for different speeds of a water tanker. The average vertical compressive 
strains within the pavement layers were calculated by subtracting the maximum deflection between two consecutive MDDs and dividing that by the spacing between them. The Asphalt Institute subgrade limiting strain criterion was used to estimate the reduction in pavement life that will occur by using single tires in place of dual tires. The dual tires were 11R22.5, inflated to 120 psi and the wide base tires were 425/65R22.5, inflated to 130 psi and the load was common for both cases at 33 kips. It should be noted that it would have been a better comparison if they had used the same inflation pressures in the two types of tires to evaluate the effects of those different tires. Figures 2.12 and 2.13 present the vertical strains at top of the sandy clay subgrade. For both sections and both types of axles (drive, or trailer axle), the wide base tire assembly induced larger vertical compressive strains to the subgrade. Wide base tires were found to be approximately 2.8 times more damaging to the thin pavement and 2.5 times more damaging to the thick pavement based on a design equation using vertical compressive strain. A common observation is that for both assemblies (dual and wide base), vertical strains decrease as the speed of the tanker increases. 


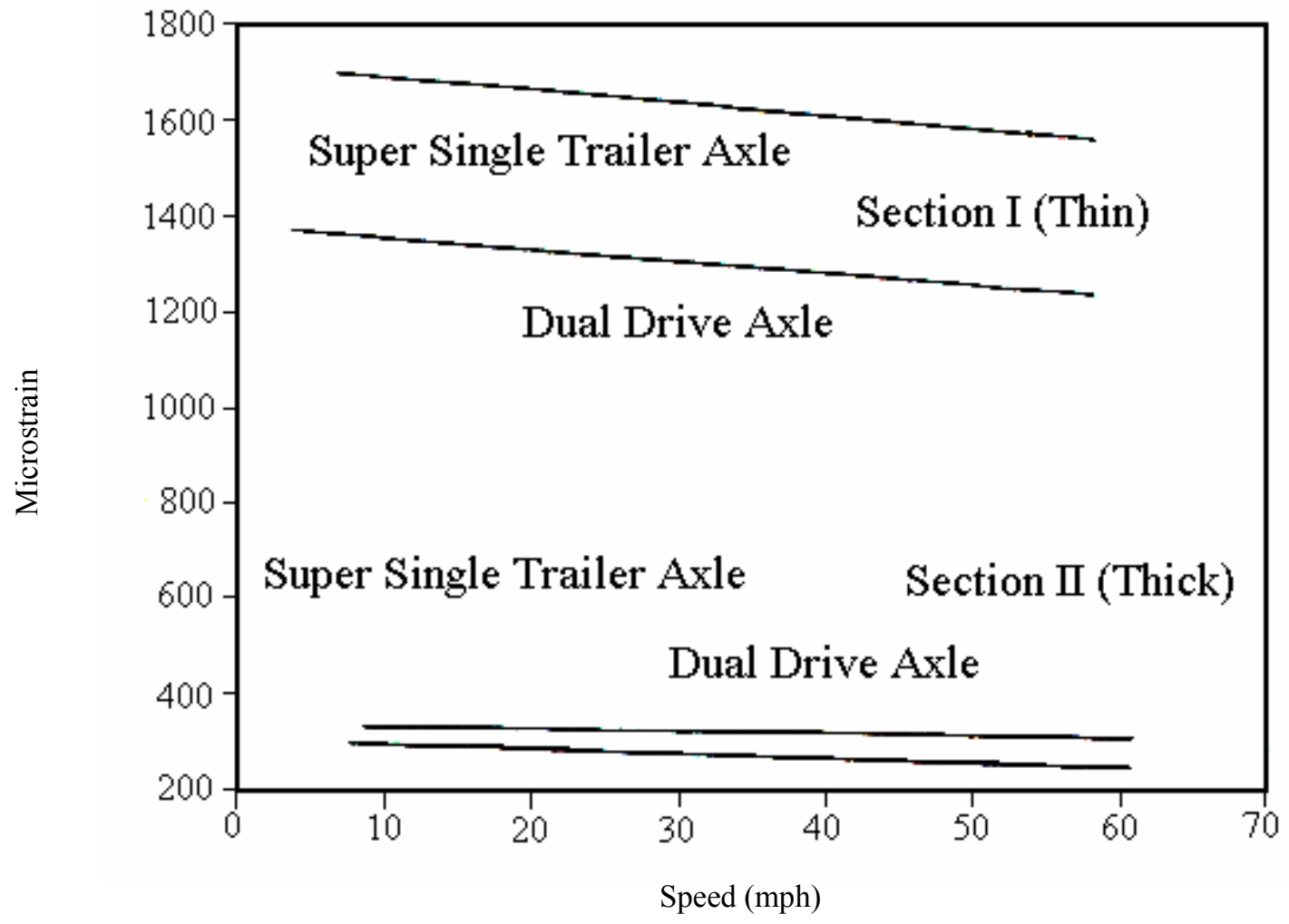

Figure 2.12 Effect of speed on vertical strain on top of the subgrade (Akram et al. 1992) 


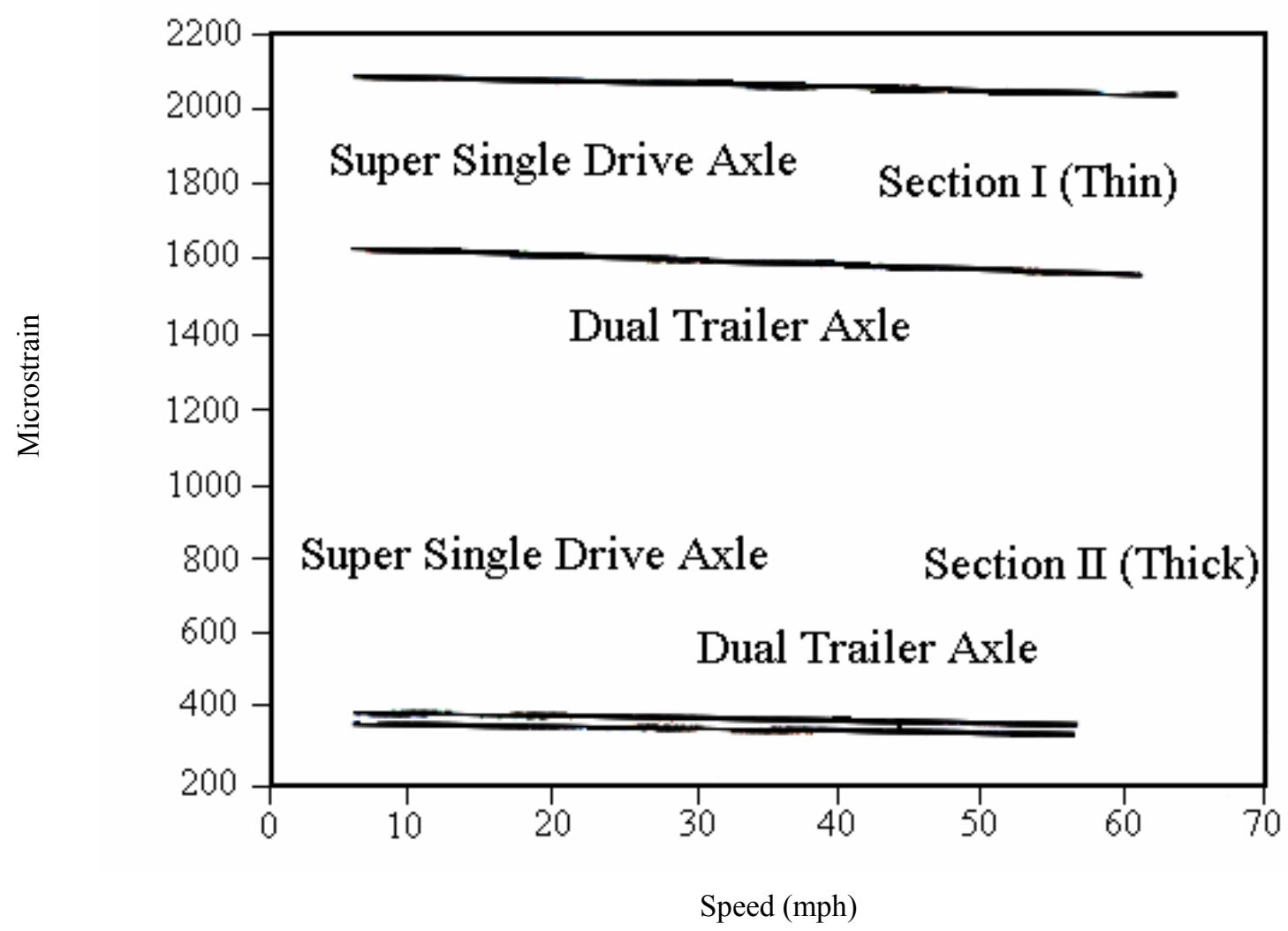

Figure 2.13 Effect of speed on vertical strain on top of the subgrade (Akram et al. 1992)

Huhtala et al. (1989) performed field testing at the Virttaa test section in Finland for thin and thick pavement sections in order to investigate the effects of different types of tires. They performed the testing for axle loads varying from $71-107 \mathrm{kN}(16,000$ 24,600 lbs) and tire inflation pressures varying from $480-1080 \mathrm{kPa}(70-157 \mathrm{psi})$. The dual tires were 12R22.5, 265/65R19.5 and singe tires were 445 65R22.5, 385/65R22.5 and 350 75R22.5. Strain gauges were placed in longitudinal or transverse positions at the bottom of the asphalt layer for each section. Longitudinal gauges at the bottom of the asphalt layer were used to compare the effects of different axles or tires. Equivalent 
numbers were compared to those of a standard axle with dual tires 12R22.5 inflated with $700 \mathrm{kPa}$. They indicated that super-single tires are more damaging than dual tires by a factor of 2.3 to 4.0 in ideal conditions for dual tires. It was also observed that when the tire inflation pressure was increased by $20 \%$, the damage in terms of the load equivalency factor (the number of equivalent standard axle load applications causing the same amount of damage by one passage of an axle) increased by 10 to $40 \%$.

\subsection{Summary}

Multi-layered elastic theory assumes that the contact stress is equal to the inflation pressure and the contact area is circular. According to recent studies, these assumptions fail to appropriately represent the real contact stresses induced by increased inflation pressures, especially for the super-single tires.

Super-single tires are replacing conventional dual tires in the trucking industry due to the efficiency in fuel consumption and the smaller total contact area compared to conventional dual tires. The contact area of super-single tires is in reality almost rectangular and larger in the transverse direction as opposed to conventional dual tires. Super-single tires, however, induce higher contact stresses, which are more adverse to all pavement layers. The contact stress might be 1.8 times the inflation pressure, and the higher contact stress may induce damage to the pavement structure well into the subgrade layer. In this study, in order to reasonably model the vertical contact stress generated by typical super-single tires, the maximum vertical contact stress for the recommended tire load was determined using De Beer et al.'s equation (2.12). The reasonable contact area 
ratio (1:0.85) for super-single tires was also determined.

Most of the studies found in the literature focus on the asphalt and base layers rather than on the subgrade layer, with the implied assumption that the asphalt layer and base layer would take most of the tire loadings and the subgrade would be in an elastic state. These studies also assume that the contact stresses induced by tire loadings are the same as the inflation pressures. The results of these studies may be acceptable for lower inflation pressures and conventional dual tires, but they would be unconservative for the higher inflation pressures and contact stresses associated with super-single tires (De Beer et al. 1997, Sebaaly et al. 1999). In order to ascertain the severity of the potential effects of the use of wide-base tires on the subgrades, more advanced analyses taking into account increased contact stresses and wider contact areas are required. These analyses are carried out in a later chapter of this report. 


\section{CHAPTER 3 MECHANICAL BEHAVIOR OF SUBGRADE SOILS}

\subsection{Introduction}

Before an analysis of the subgrade in pavements is possible, the mechanical behavior of the subgrade soil must be defined. In a road structure subjected to repeated traffic loadings, subgrade soils play a role in supporting the asphalt and base layers and traffic loadings. Due to this important role, the subgrade should have enough bearing capacity to perform its function appropriately. If the subgrade soils respond primarily in an elastic mode, the rutting problem typical in weak subgrades may not occur. However, rutting problems are observed in many roads, resulting in expensive rehabilitation efforts. Therefore, the assumption that subgrade soils are elastic is not consistent with most observation mode in practice. It is more realistic to treat the subgrade soils as elasticplastic materials.

Subgrade soils can be largely distinguished as sands or clays. Sand and clay subgrades show quite different mechanical behavior. Soils show elastic behavior at small strains, nonlinear behavior at larger strains and plastic behavior beyond the yield strength. In general, the mechanical behavior of sand and clay subgrades depends on the density, stress state, overconsolidation ratio, and drainage conditions. 
In this chapter, to facilitate the understanding of the mechanical behavior of subgrade soils, the following topics will be extensively reviewed: stress tensors and invariants, elastic stress-strain relationship, subgrade resilient modulus, failure criterion and soil plasticity, the behavior of subgrade under drained and undrained conditions, development of pore pressure during repeated loading, and constitutive models for subgrade soils.

\subsection{Stress Tensor and Invariants}

In order to look into the behavior of soils, stress-strain analysis is needed. In a Cartesian coordinate system, the stress tensor $\sigma_{\mathrm{ij}}$ of a soil element is composed of nine stress components:

$$
\sigma_{i j}=\left[\begin{array}{lll}
\sigma_{11} & \sigma_{12} & \sigma_{13} \\
\sigma_{21} & \sigma_{22} & \sigma_{23} \\
\sigma_{31} & \sigma_{32} & \sigma_{33}
\end{array}\right] \equiv\left[\begin{array}{ccc}
\sigma_{x x} & \sigma_{x y} & \sigma_{x z} \\
\sigma_{y z} & \sigma_{y y} & \sigma_{y z} \\
\sigma_{z x} & \sigma_{z y} & \sigma_{z z}
\end{array}\right] \equiv\left[\begin{array}{ccc}
\sigma_{x} & \tau_{x y} & \tau_{x z} \\
\tau_{y z} & \sigma_{y} & \tau_{y z} \\
\tau_{z x} & \tau_{z y} & \sigma_{z}
\end{array}\right]
$$

where $\sigma$ and $\tau$ represent normal and shear stress state components, respectively. Applying the moment equation of motion in the absence of body moments allows the stress tensor to be symmetric.

Thus, $\sigma_{i j}=\sigma_{j i}$ or $\sigma_{12}=\sigma_{21}, \sigma_{13}=\sigma_{31}$, and $\sigma_{23}=\sigma_{32}$.

According to the Cayley-Hamilton theorem (Desai and Siriwardane 1984), for the $3 \times 3$ square matrix given in (3.1), the characteristic equation is written as follows.

$$
\sigma^{3}-I_{1} \sigma^{2}+I_{2} \sigma-I_{3}=0
$$


The coefficients $I_{1}, I_{2}$ and $I_{3}$ of the characteristic equation, the invariants of the stress tensor, can now be obtained as follows.

$$
\begin{gathered}
I_{1}=\sigma_{11}+\sigma_{22}+\sigma_{33}=\text { sum of the diagonal terms of } \sigma_{\mathrm{ij}} \\
I_{2}=\left|\begin{array}{ll}
\sigma_{11} & \sigma_{12} \\
\sigma_{21} & \sigma_{22}
\end{array}\right|+\left|\begin{array}{ll}
\sigma_{22} & \sigma_{23} \\
\sigma_{23} & \sigma_{33}
\end{array}\right|+\left|\begin{array}{ll}
\sigma_{11} & \sigma_{13} \\
\sigma_{13} & \sigma_{33}
\end{array}\right| \\
=\text { sum of the cofactors of the diagonal terms of } \sigma_{\mathrm{ij}} \\
I_{3}=\left|\begin{array}{lll}
\sigma_{11} & \sigma_{12} & \sigma_{13} \\
\sigma_{21} & \sigma_{22} & \sigma_{23} \\
\sigma_{31} & \sigma_{32} & \sigma_{33}
\end{array}\right| \text { determinant of } \sigma_{\mathrm{ij}}
\end{gathered}
$$

$\mathrm{I}_{1}, \mathrm{I}_{2}$ and $\mathrm{I}_{3}$ are called invariants because they do not change when the coordinate axes are rotated. Although there is a change of coordinates, the principal stresses and principal axes remain the same.

In order to express the stress state for a soil in 3D space, principal stresses are generally used because the principal stresses are also invariants regardless of rotation of axes. Now expressing the stress tensor in terms of principal stresses, (3.1) becomes

$$
\sigma_{i j}=\left[\begin{array}{ccc}
\sigma_{1} & 0 & 0 \\
0 & \sigma_{2} & 0 \\
0 & 0 & \sigma_{3}
\end{array}\right]
$$

when $\sigma_{1}>\sigma_{2}>\sigma_{3}, \sigma_{1}, \sigma_{2}$, and $\sigma_{3}$ are major, intermediate and minor pricipal stresses, respectively.

A more accessible formulation results by decomposing a stress tensor into a deviatoric tensor and a hydrostatic tensor, because the characteristics of shear and mean stresses for a soil become more evident. Equation 3.7 illustrates this relationship. 


$$
\sigma_{i j}=S_{i j}+\frac{1}{3} \sigma_{n n} \delta_{i j}
$$

where $S_{\mathrm{ij}}=$ deviatoric tensor, $\sigma_{\mathrm{nn}}=$ hydrostatic stress $=\sigma_{11}+\sigma_{22}+\sigma_{33}, \delta_{\mathrm{ij}}=$ Kronecker delta.

Substitution of (3.7) into equation (3.1) leads to:

$$
\left[\begin{array}{lll}
\sigma_{11} & \sigma_{12} & \sigma_{13} \\
\sigma_{21} & \sigma_{22} & \sigma_{23} \\
\sigma_{31} & \sigma_{32} & \sigma_{33}
\end{array}\right]=\left[\begin{array}{lll}
S_{11} & S_{12} & S_{13} \\
S_{21} & S_{22} & S_{23} \\
S_{31} & S_{32} & S_{33}
\end{array}\right]+\left[\begin{array}{ccc}
\frac{\sigma_{n n}}{3} & 0 & 0 \\
0 & \frac{\sigma_{n n}}{3} & 0 \\
0 & 0 & \frac{\sigma_{n n}}{3}
\end{array}\right]
$$

Thus,

$$
S_{i j}=\sigma_{i j}-\frac{1}{3} \sigma_{n n} \delta_{i j}=\sigma_{i j}-p \delta_{i j}
$$

where $\mathrm{p}=$ mean stress $=\sigma_{\mathrm{nn}} / 3$

Because the deviatoric stress tensor is also a symmetric tensor, the deviatoric stress invariants are obtained as follows.

$$
\begin{gathered}
J_{1}=S_{i i}=S_{11}+S_{22}+S=0 \\
J_{2}=\frac{1}{2} S_{i j} S_{i j}=\frac{1}{2}\left[S_{11}^{2}+S_{12}^{2}+S_{13}^{2}+S_{12}^{2}+S_{22}^{2}+S_{23}^{2}+S_{13}^{2}+S_{23}^{2}+S_{33}^{2}\right] \\
=\frac{1}{6}\left[\left(\sigma_{1}-\sigma_{2}\right)^{2}+\left(\sigma_{2}-\sigma_{3}\right)^{2}+\left(\sigma_{1}-\sigma_{3}\right)^{2}\right] \\
J_{3}=\frac{1}{3} S_{i j} S_{j m} S_{m i}=I_{3}-\frac{2}{3} I_{1} I_{2}+\frac{2}{27} I_{1}^{3}=0
\end{gathered}
$$




\subsection{Elastic Behavior of Soil}

\subsubsection{Elastic Stress-Strain Relationship}

This first step in describing elastic-plastic behavior is to define elastic behavior. A solid is called elastic if it completely recovers its original configuration when the forces applied on it are removed. According to the generalized form of Hooke's law, the linear elastic relationship between the stress tensor and strain tensor can be written as follows (Chen and Saleeb 1994).

$$
\sigma_{i j}=C_{i j k l} \varepsilon_{k l}
$$

Here $\mathrm{C}_{\mathrm{ijk}}$ is a fourth-order elastic stiffness tensor and has 81 constants. By using the symmetry of stress, strain and elastic stiffness tensors, 81 constants reduce to 21 constants (Chen and Saleeb 1994). Now (3.14) can be expressed in matrix form as:

$$
\left\{\begin{array}{l}
\sigma_{11} \\
\sigma_{22} \\
\sigma_{33} \\
\sigma_{23} \\
\sigma_{13} \\
\sigma_{12}
\end{array}\right\}=\left[\begin{array}{llllll}
C_{1111} & C_{1122} & C_{1133} & C_{1123} & C_{1113} & C_{1112} \\
C_{2211} & C_{2222} & C_{2233} & C_{2223} & C_{2213} & C_{2212} \\
C_{3311} & C_{3322} & C_{3333} & C_{3323} & C_{3313} & C_{3312} \\
C_{2311} & C_{2322} & C_{2333} & C_{2323} & C_{2313} & C_{2312} \\
C_{1311} & C_{1322} & C_{1333} & C_{1323} & C_{1313} & C_{1312} \\
C_{1211} & C_{1222} & C_{1233} & C_{1223} & C_{1213} & C_{1212}
\end{array}\right]\left\{\begin{array}{l}
\varepsilon_{11} \\
\varepsilon_{22} \\
\varepsilon_{33} \\
\gamma_{12} \\
\gamma_{23} \\
\gamma_{13}
\end{array}\right\}
$$

where $\varepsilon_{11}, \varepsilon_{22}$, and $\varepsilon_{33}$ are normal strains, and $\gamma_{12}, \gamma_{23}$, and $\gamma_{13}$ are shear strains, respectively.

In the most general form, an isotropic, fourth-order tensor can be given by:

$$
C_{i j k l}=\lambda \delta_{i j} \delta_{k l}+\mu \delta_{i k} \delta_{j l}+v \delta_{i l} \delta_{j k}
$$

Since $\mathrm{C}_{\mathrm{ijkl}}$ is symmetric and hence $\mu=v$, taking (3.15) into (3.14) leads to:

$$
\sigma_{i j}=\lambda \delta_{i j} \varepsilon_{k k}+2 \mu \varepsilon_{i j}
$$


where $\lambda$ and $\mu$ are Lame's constants. Here $\mu$ is the shear modulus, also known as G.

In order to express $\varepsilon$ in terms of $\sigma$, rewriting (3.16) leads to:

$$
\varepsilon_{i j}=\frac{1}{2 \mu} \sigma_{i j}-\frac{\lambda \delta_{i j}}{2 \mu(3 \lambda+2 \mu)} \sigma_{k k}
$$

Matrix $\mathrm{C}^{-1}$ becomes

$$
C^{-1}=\frac{1}{\mu(3+2 \mu)}\left[\begin{array}{cccccc}
\lambda+\mu & -\frac{\lambda}{2} & \frac{-\lambda}{2} & 0 & 0 & 0 \\
-\frac{\lambda}{2} & \lambda+\mu & -\frac{\lambda}{2} & 0 & 0 & 0 \\
-\frac{\lambda}{2} & -\frac{\lambda}{2} & \lambda+\mu & 0 & 0 & 0 \\
0 & 0 & 0 & 3 \lambda+2 \mu & 0 & 0 \\
0 & 0 & 0 & 0 & 3 \lambda+2 \mu & 0 \\
0 & 0 & 0 & 0 & 0 & 3 \lambda+2 \mu
\end{array}\right]
$$

Young's modulus E, Poisson's ratio $v$, shear modulus G, and bulk modulus $\mathrm{K}$ can be defined as:

$$
\begin{gathered}
E=\frac{\mu(3 \lambda+2 \mu)}{(\lambda+\mu)} \\
v=\frac{\lambda}{2(\lambda+\mu)} \\
G=\mu=\frac{E}{2(1+v)} \\
K=\frac{\sigma_{k k}}{3 \varepsilon_{k k}}=\frac{E}{3(1-2 v)}
\end{gathered}
$$




\subsection{Resilient Modulus of Subgrades}

\subsubsection{Introduction}

It is well known that subgrade soils show a nonlinear and time dependent elasticplastic response under traffic loading. As mentioned earlier, in the traditional theories of elasticity, the elastic properties of a material are defined by the elastic modulus $\mathrm{E}$ and Poisson's ratio v. A similar approach has been widely used in dealing with base material and subgrade soils. In this approach, the elastic modulus is replaced with the resilient modulus to represent the nonlinearity with respect to stress level (Lekarp et al. 2000). This resilient modulus is generally used as an input parameter for multi-layered elastic analysis.

From 1986, AASHTO requires the use of the subgrade resilient modulus for the design of flexible pavements. Resilient modulus is an important material property, similar in concept to the modulus of elasticity. It differs from the modulus of elasticity in the fact that it is obtained by a repeated-load triaxial test and is based only on the recoverable strains. Resilient modulus is defined as:

$$
M_{R}=\frac{\sigma_{d}}{\varepsilon_{r}}
$$

where $M_{R}$ is the resilient modulus; $\sigma_{d}$ is the repeated deviator stress; and $\varepsilon_{r}$ is the recoverable axial strain.

The standard test method to determine the resilient modulus is described by AASHTO T-274. In this method, field conditions are simulated by sample preparation, conditioning and testing. Traffic conditions are simulated by applying a series of repeated 
deviator stresses, separated by rest periods. Unfortunately, this test is time consuming and requires undisturbed sampling.

The resilient modulus is very meaningful to a pavement's life. To illustrate this condition, Elliott and Thornton (1988) reported the results of analyses using the ILLIPAVE algorithms on a flexible pavement subjected to a 9,000-pound wheel load. As the resilient modulus increased, the asphalt layer strain decreased and the subgrade stress ratio (load-induced deviator stress in subgrade divided by the unconfined compressive strength of the soil) also decreased.

\subsubsection{Resilient Modulus of Cohesive Subgrades}

In general, the resilient modulus of cohesive subgrades is affected by the following factors: a) Deviator stress; b) Method of compaction; c) Compaction water content and dry density; d) Thixotropy; e) Degree of saturation; and f) Freeze-thaw cycles. Deviator stress, compaction water content and dry density, and freeze-thaw cycles are the factors that most influence the resilient modulus of cohesive subgrades. Another factor that affects the resilient modulus is seasonal variations. Seasonal variations, however, can be accounted for by variations in the degree of saturation. Therefore, seasonal variations will not be discussed further here.

\subsubsection{Deviator stress}

Results from several studies have shown that the resilient modulus of cohesive soils is greatly affected by the magnitude of the deviator stress. Wilson et al. (1990), Drumm et al. (1990) and Thompson and Robnett (1979) reported that at low levels of 
repeated deviator stress, the resilient modulus decreases significantly as the deviator stress increases. On the other hand, as shown in Figure 3.1, at greater levels of deviator stress, the resilient modulus either decreases slightly or reaches constant values. Figure 3.1 presents a subset of the tests that Wilson et al. (1990) performed on an A-6a cohesive subgrade, located in Jackson County, Ohio. In a different study, Thompson and Robnett, after thorough testing performed on Illinois soils, reported the existence of a breakpoint resilient modulus corresponding to the resilient modulus at a deviator stress of 6 psi. This breakpoint characterizes the behavior of these soils under repeated loads.

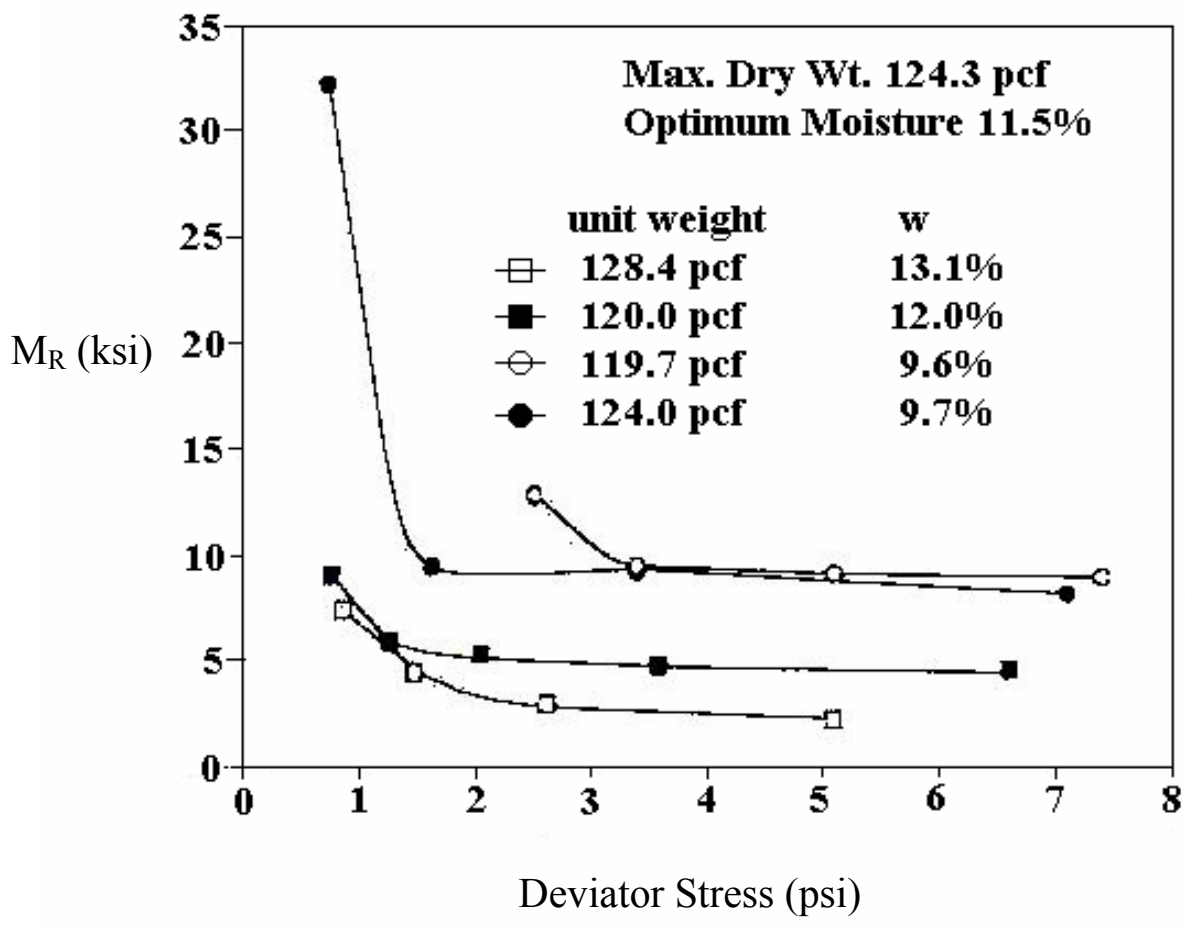

Figure 3.1 Effect of deviator stress on a A-7-6 subgrade soil (Wilson et al. 1990) 


\subsubsection{Method of compaction}

Lee (1993) reported the influence of the method of compaction on the resilient modulus of cohesive subgrades, based on the results of past studies. For samples compacted at low degrees of saturation, the method of compaction had little effect on the resilient modulus due to the flocculated arrangement of the clay particles. In contrast, when samples are compacted above optimum water content, the method of compaction caused large changes, which was attributed to the dispersed arrangement of the clay particles. Seed and Chan (1959) concluded that the kneading and impact methods of compaction usually produce a flocculated particle arrangement for water contents dry of optimum and a dispersed arrangement at wet of optimum, while static compaction, at any level of moisture content generates a flocculated arrangement. They also reported that for clays compacted dry of optimum, the recoverable strains for samples prepared by kneading and static compaction were the same. However, for specimens compacted wet of optimum, the kneading compacted specimens experienced significantly larger recoverable strains.

\subsubsection{Compaction water content and dry density}

It is expected that as the compaction moisture content of a cohesive soil increases, the stiffness of the soil tends to decrease. As seen from Figures 3.1 and 3.2, the same trend has been observed for the resilient modulus. Figure 3.2 is from results of tests on cohesive subgrades conducted in Indiana by Lee et al. (1997). Figures 3.1 and 3.2 clearly show that as the moisture content increases, the resilient modulus decreases. It was noticed that specimens compacted wet of optimum exhibit significantly lower values of 
the resilient modulus. This observation agrees well with the aforementioned effect of the method of compaction. As seen from Figure 3.2, it is also observed that the resilient modulus increases as the dry density increases. As the density of any soil increases, less volume is occupied by the voids, and this consequently results in the increase of the strength of the soil.

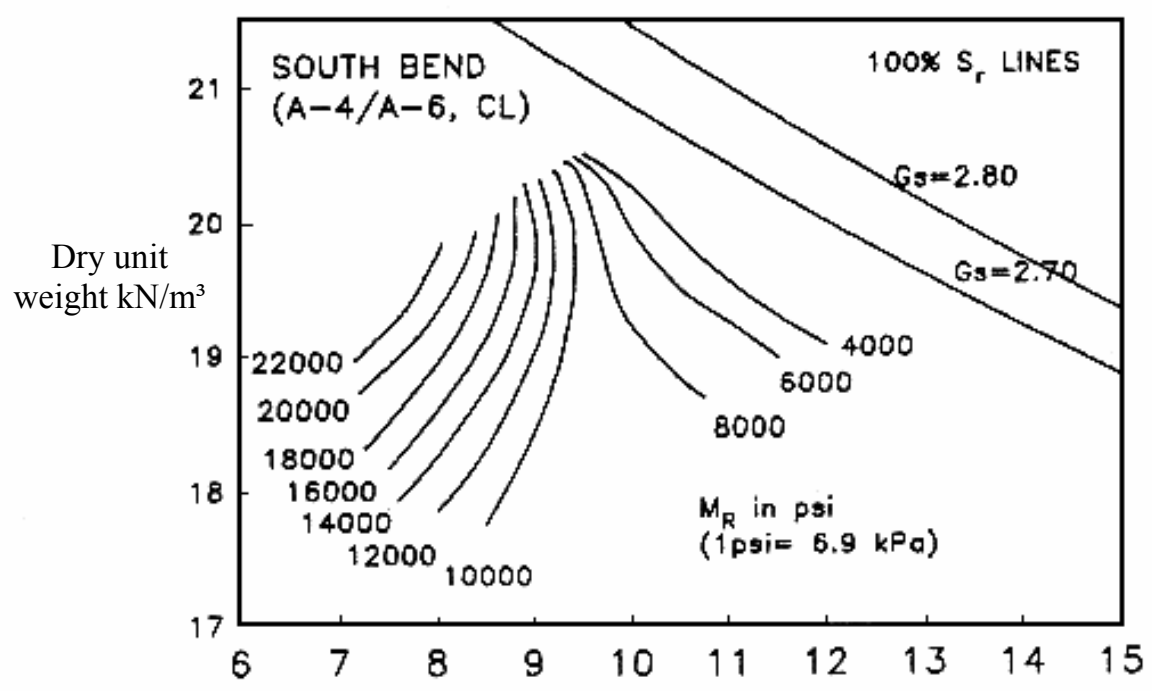

Moisture content (\%)

Figure 3.2 Effect of compaction water content and moisture density on a cohesive subgrade (Lee et al. 1997)

\subsubsection{Thixotropy}

Seed and Chan (1957) showed that when samples are compacted at a high degree of saturation, they exhibit a significant increase in strength if they are allowed to rest before testing. Seed and Chan also reported that after a certain number of repeated loads (about 40,000 repetitions), thixotropy no longer affected the recoverable deformations. 
This situation could be attributed to the fact that the induced deformations were so large that they overcame the thixotropic strength of the samples.

\subsubsection{Degree of saturation}

The effect of the degree of saturation is similar to the effect of the water content on the resilient modulus. Figure 3.3 presents the variation of the resilient modulus with the degree of saturation of an A-7-5 subgrade soil, compacted wet of optimum. The results are from research that Drumm et al. (1997) carried out on Tennessee soils. A decrease in the resilient modulus is observed as the degree of saturation increases.

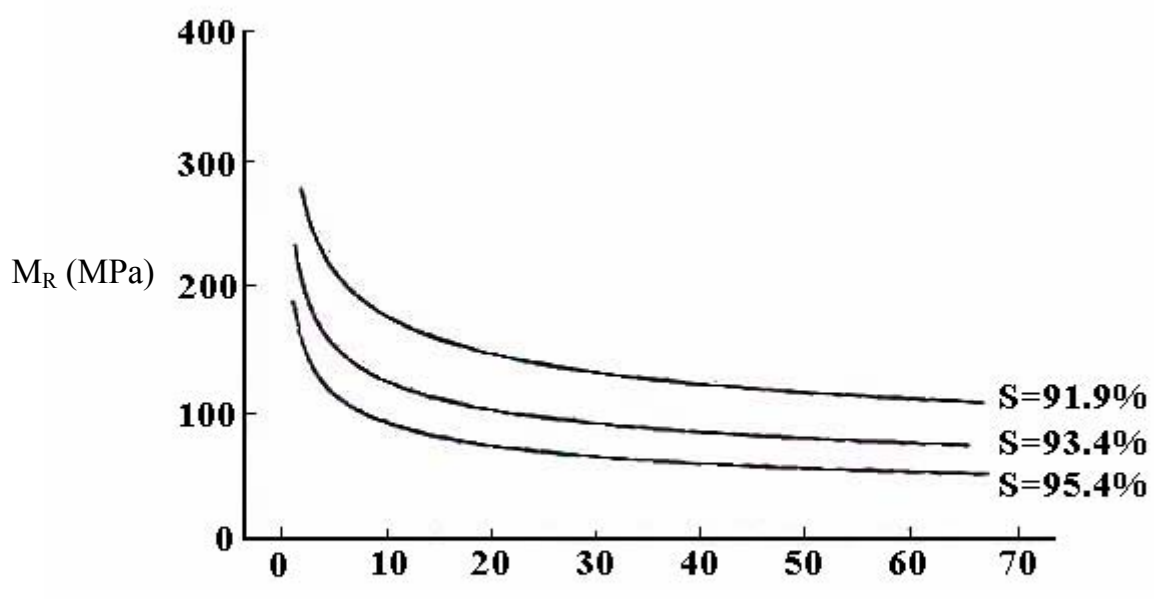

Deviator Stress $(\mathrm{kPa})$

Figure 3.3 Effect of post-compaction saturation on resilient modulus of an A-7-5 subgrade soil (Drumm et al. 1997) 


\subsubsection{Freeze-thaw}

The effect of freeze-thaw on the resilient modulus of cohesive subgrades is significant. Elliott and Thornton (1988) mentioned a dramatic reduction in the resilient modulus following only one freeze-thaw cycle. In some Arkansas soils, this reduction was estimated to be about 50 percent. Lee (1993) also reported that Micleborough in 1970 examined the effect of freeze-thaw on the resilient properties of highly plastic glacial lake clay. After two and four freeze-thaw cycles, the results showed a reduction of the resilient modulus by 63 and 74 percent, respectively.

\subsubsection{Models for the resilient modulus of cohesive subgrades}

During the last twenty years, many models have been proposed to predict the resilient modulus of cohesive subgrades. Some of them are stress-dependent and others are dependent on physical properties. There are also models that considered both physical and stress conditions of the subgrades. However, all these models seem to apply only to the subgrades that were used to develop these models. In most of the cases when the models were applied to other types of cohesive subgrades, the deviation was significant. This deviation is expected given the nature of the models. These models were developed for certain soils and then were examined to see if they were applicable to others. The results were not satisfactory because these soils had different physical and stress conditions. Therefore, it is worth noting that when using one of the models presented next, one must proceed with caution.

a. Pezo and Hudson (1994) suggested the following model for the resilient modulus. 


$$
M_{R}=F_{0} \cdot F_{1} \cdot F_{2} \cdot F_{3} \cdot F_{4} \cdot F_{5} \cdot F_{6}, R^{2}=0.803
$$

Factors $\mathrm{F}_{0} \sim \mathrm{F}_{6}$ depend on physical properties and the stress condition of the soil.

b. Thompson and Robnett (1979) introduced the following model.

$$
\begin{aligned}
& M_{R}=k_{2}+k_{3} \cdot\left(k_{1}-\sigma_{d}\right), \text { if } \mathrm{k}_{1}>\sigma_{\mathrm{d}} \\
& M_{R}=k_{2}+k_{4} \cdot\left(\sigma_{d}-k_{1}\right), \text { if } \mathrm{k}_{1}<\sigma_{\mathrm{d}}
\end{aligned}
$$

$\mathrm{k}_{1}-\mathrm{k}_{4}=$ material and physical property parameters.

c. Hall and Thompson (1994) proposed the model:

$$
M_{R}(O P T)=6.90+0.0064 \cdot C+0.216 \cdot P I-1.970 \cdot C, R^{2}=0.76
$$

$\mathrm{M}_{\mathrm{R}}(\mathrm{OPT})$ : subgrade resilient modulus (ksi) at AASHTO T-99 optimum moisture content and 95 percent compaction

C: percent clay $(<2 \mu \mathrm{m})$

PI: plasticity index (percent)

OC: percent organic carbon

$\mathrm{R}^{2}$ : coefficient of determination

d. Lee et al. (1979) suggested the following model.

$$
M_{R}=695.4 \cdot\left(S_{u 1.0 \%}\right)-5.93 \cdot\left(S_{u 1.0 \%}\right)^{2}, R^{2}=0.97
$$

$\mathrm{M}_{\mathrm{R}}$ : resilient modulus (psi) at maximum axial stress of $6 \mathrm{psi}$, confining stress is $3 p s i$ $\mathrm{S}_{\mathrm{u} 1.0 \%}$ : stress (psi) causing 1\% strain in conventional unconfined compressive test e. Mohammad et al. (1999) performed CPT tests in two types of clay and suggested the model below.

$$
M_{R}=a \cdot q_{c}^{n}+b \cdot f_{s}+c \cdot w+d \cdot \gamma_{d}+e, R^{2}=0.91-0.95
$$

$\mathrm{M}_{\mathrm{R}}$ : resilient modulus (in $\mathrm{MPa}$ ) 
a, b, c, d, e: constants from regression analyses

$\mathrm{n}$ : integer $(1,2$, or 3$)$

$\mathrm{q}_{\mathrm{c}}$ : tip resistance $(\mathrm{MPa})$

$\mathrm{f}_{\mathrm{s}}$ : sleeve friction $(\mathrm{MPa})$

W:moisture content $(\%)$

$\gamma_{\mathrm{d}}$ : dry unit weight $\left(\mathrm{kN} / \mathrm{m}^{3}\right)$

f. Drumm et al. (1997) modeled the change of the resilient modulus with respect to postcompaction saturation and presented the following model.

$$
M_{R(w e t)}=M_{R(o p t)}+\frac{d M_{R}}{d S} \cdot \Delta S
$$

$\mathrm{M}_{\mathrm{R}(\text { wet) }}$ : resilient modulus (MPa) at increased post-compaction saturation

$\mathrm{M}_{\mathrm{R}(\mathrm{opt})}$ : resilient modulus ( $\left.\mathrm{MPa}\right)$ at optimum moisture content

$\mathrm{dM}_{\mathrm{R}} / \mathrm{dS}$ : gradient of resilient modulus ( $\left.\mathrm{MPa}\right)$, function of type of soil

$\Delta \mathrm{S}$ : change in post-compaction degree of saturation (decimal)

\subsubsection{Resilient Modulus of Cohesionless Subgrades}

In the case of cohesionless subgrades, the factors that influence the resilient modulus the most are, in approximate order of importance, the following: a) Dry density; b) Degree of saturation; c) Confining pressure; d) Aggregate gradation; e) Compaction method; f) Deviator stress. 


\subsubsection{Deviator stress}

The influence of the deviator stress on the resilient modulus of cohesionless subgrades is similar to that of cohesive subgrades. Wilson et al. (1990) and Mohammad et al. (1995) reported a decrease of the resilient modulus as the deviator stress increased. Figure 3.4 illustrates that for an A-1 subgrade, there is a significant decrease of the resilient modulus with respect to the deviator stress for specimens compacted dry of the optimum water content. It can also be noticed that the resilient modulus of specimens compacted wet of optimum is smaller compared to the compacted dry of optimum specimens and decreases significantly with increasing deviator stress.

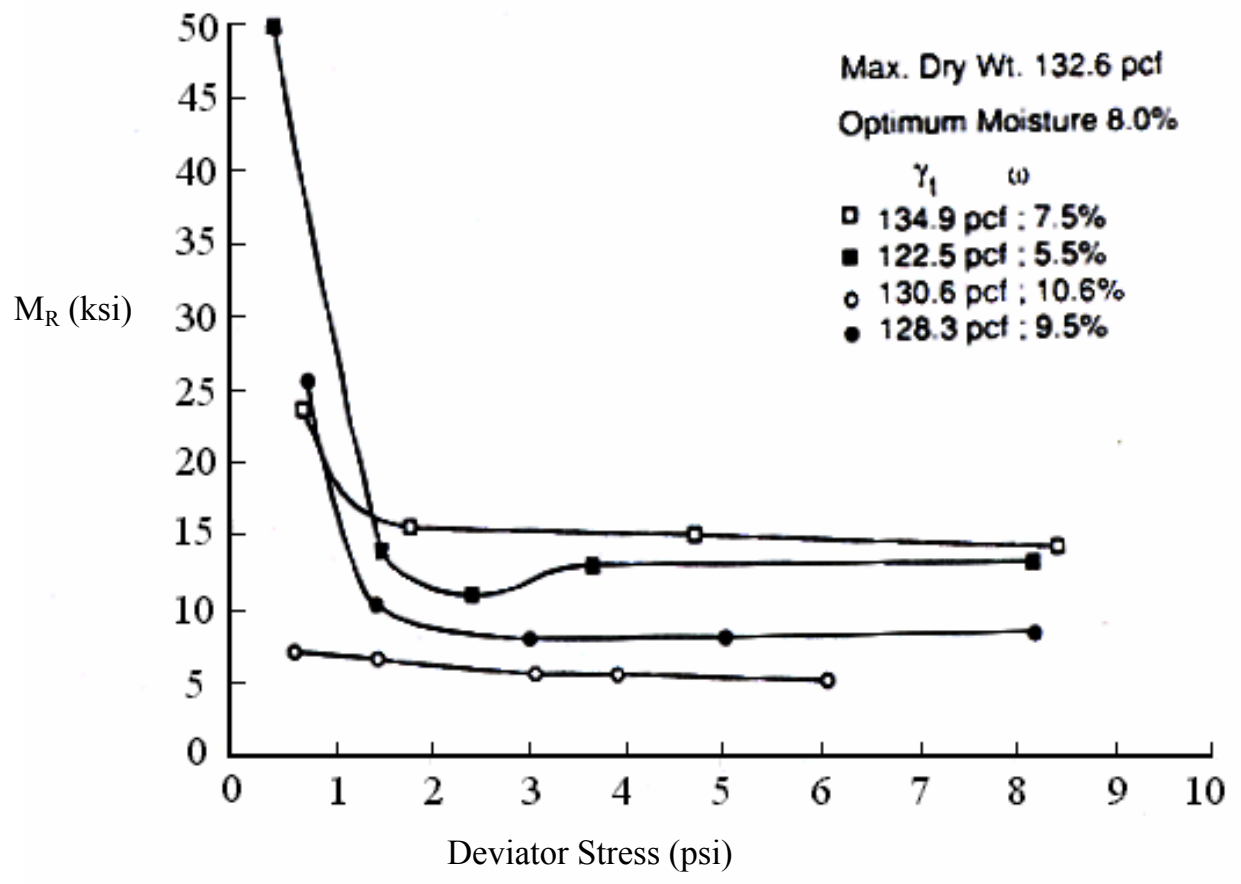

Figure 3.4 Effect of deviator stress on the resilient modulus of an A-1 subgrade soil (Wilson et al. 1990) 


\subsubsection{Confining pressure}

The effect of confining pressure on granular subgrades is more pronounced than the effect of the deviator stress. Mohammad et al. (1995) and Hicks and Monismith (1971) reported that the resilient modulus of granular subgrades increases as the confining pressure increases.

\subsubsection{Dry density}

Dry density has a significant role in the resilient modulus of cohesionless subgrades. Lee et al. (1995) reported that specimens of dune sand exhibited higher values of resilient modulus as the dry density increased. Moreover, Hicks and Monismith (1971) concluded from tests performed on a granular subgrade (shown in Figure 3.5) that the resilient modulus increased as the relative dry density increased for both coarse-graded and fine-grading subgrade. This conclusion is certainly due to the fact that increasing the dry density consequently decreases the volume of voids and as a result increases the strength properties of a granular subgrade. 

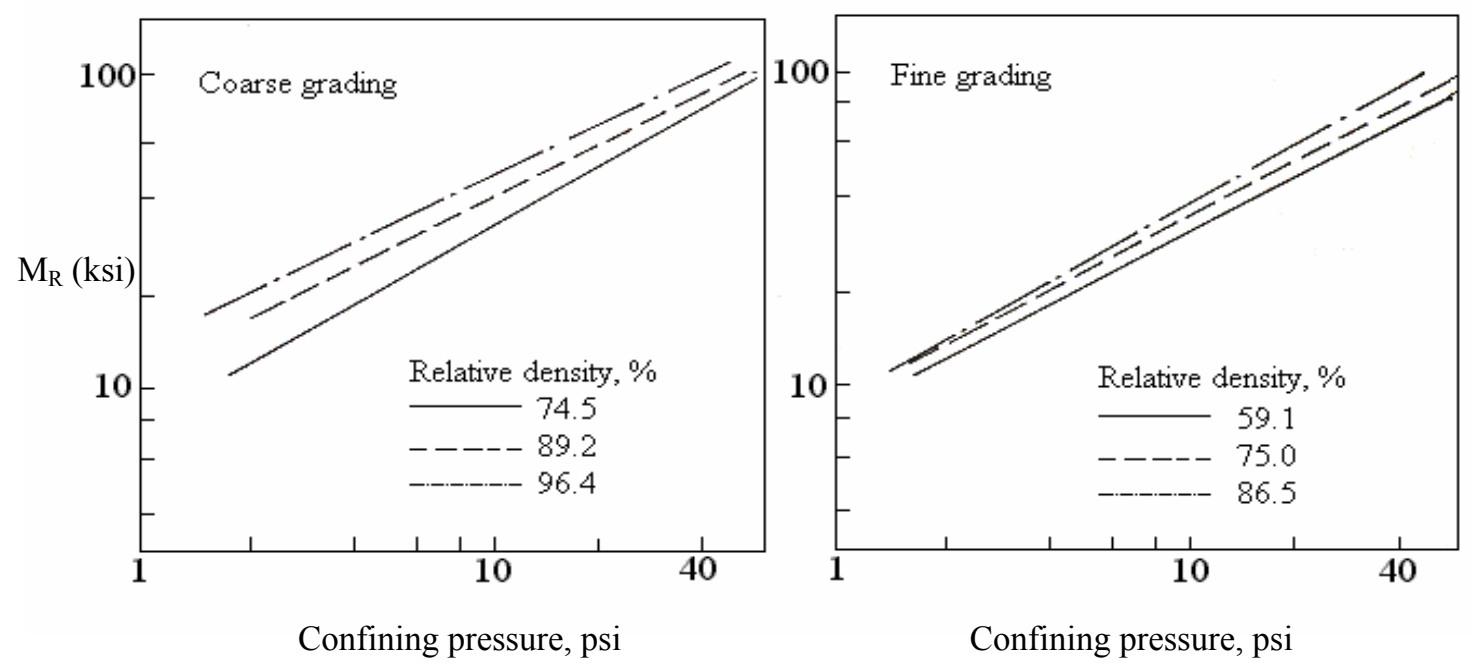

Figure 3.5 Influence of dry density on the resilient modulus of granular subgrades (Hicks and Monismith 1971)

\subsubsection{Degree of saturation}

The degree of saturation significantly affects the resilient modulus. As Lee (1993) reported, Haynes and Yoder, from tests conducted on both gravel and crushed stone base course material, found that the resilient modulus of the gravel at a degree of saturation of 97 percent was one half of that at a degree of saturation of 70 percent. In addition, Hicks and Monismith (1971) also found a decrease in the resilient modulus as the degree of saturation increased.

\subsubsection{Aggregate gradation}

Hicks and Monismith (1971) examined the effect of aggregate gradation. As presented in Figure 3.5, as the percentage of fines increased in a granular subgrade, for the same level of confining pressure, a decrease of the resilient modulus was observed. 
As the percentage of fines increases in a granular soil, the degree of interlocking decreases which results in the decrease of the strength of the soil.

\subsubsection{Method of compaction}

Lee et al. (1995) from their testing on dune sand found that, as seen in Figure 3.6, the resilient modulus of an impact-compacted specimen is lower than that of a vibratorycompacted one; despite the fact that the impact compacted specimen has slightly higher density and lower water content.

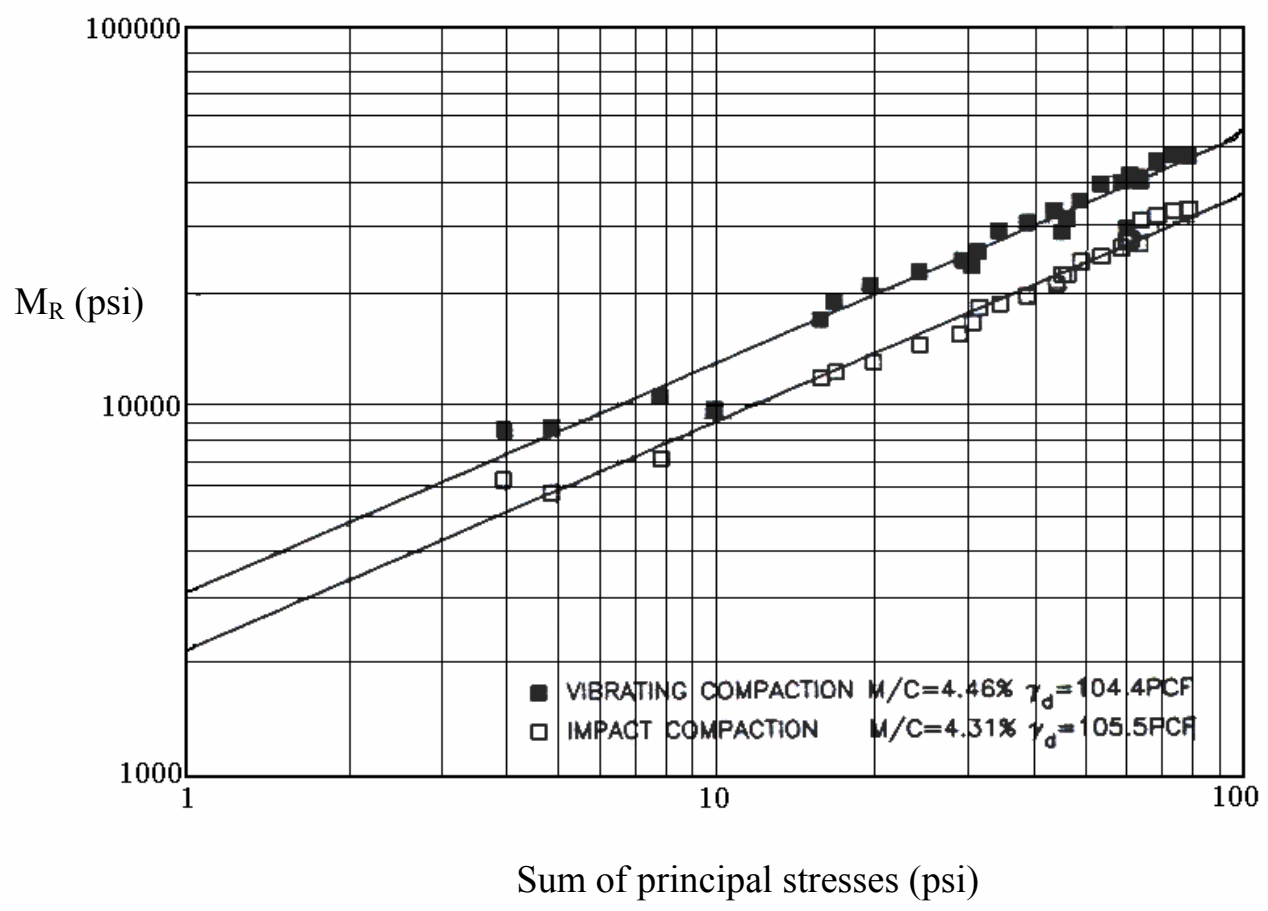

Figure 3.6 Effect of method compaction (Lee et al. 1997) 


\subsubsection{Models for the resilient modulus of cohesionless subgrades}

The models proposed to predict the resilient modulus of granular subgrades do not fit well to soils other than those for which the models were developed. One example is the case of Puppala et al. (1996) who used three models to predict the resilient modulus of sand. Among those three models, the triaxial model provided predictions closer to the measured data. The other two models deviated significantly from the measured data. The following are some examples of models used to predict the resilient modulus of granular subgrade.

a. Lee et al. (1995) from their tests on dune sand proposed the following model.

$$
M_{R}=(-20,163+232.886 \cdot R C) \cdot \theta^{0.595}
$$

$\mathrm{M}_{\mathrm{R}}$ : resilient modulus $(\mathrm{kPa})$

$\mathrm{RC}$ : relative compaction $=$ dry density $/ 17.17 \mathrm{kN} / \mathrm{m}^{3}$

$\theta$ : sum of principal stresses $(\mathrm{kPa})$

b. Puppala et al. (1996), in their study to predict the resilient modulus of a sand, used the following three equations.

(Bulk stress model)

$$
\begin{gathered}
M_{R}=a \cdot \theta^{b} \\
\log a=-0.85+0.06 \cdot \gamma_{d}-0.27 \cdot w, R^{2}=0.98 \\
b=-1.23+0.002 \cdot \gamma_{d}+0.11 \cdot w, R^{2}=0.96
\end{gathered}
$$


(Octahedral stress model)

$$
\begin{gathered}
\frac{M_{R}}{\sigma_{a t m}}=k_{1} \cdot\left(\frac{\sigma_{o c t}}{\sigma_{a t m}}\right)^{k_{2}} \cdot\left(\frac{\tau_{o c t}}{\sigma_{a t m}}\right)^{k_{3}} \\
\log k_{1}=2.56+0.013 \cdot \gamma_{d}-0.08 \cdot w, R^{2}=0.96 \\
k_{2}=-34.9+0.31 \cdot \gamma_{d}-0.003 \cdot w, R^{2}=0.72 \\
k_{3}=28.1-0.25 \cdot \gamma_{d}+0.07 \cdot w, R^{2}=0.68
\end{gathered}
$$

(Triaxial stress model)

$$
\begin{gathered}
\frac{M_{R}}{\sigma_{a t m}}=k_{4} \cdot\left(\frac{\sigma_{3}}{\sigma_{a t m}}\right)^{k_{5}} \cdot\left(\frac{\sigma_{d}}{\sigma_{a t m}}\right)^{k_{6}} \\
\log k_{4}=-9.61+0.12 \cdot \gamma_{d}-0.08 \cdot w, R^{2}=0.69 \\
k_{5}=-19.6+0.17 \cdot \gamma_{d}-0.05 \cdot w, R^{2}=0.69 \\
k_{6}=15.2-0.14 \cdot \gamma_{d}+0.06 \cdot \mathrm{w}, R^{2}=0.68
\end{gathered}
$$

$\mathrm{M}_{\mathrm{R}}$ : resilient modulus $(\mathrm{kPa})$

$\sigma_{\text {oct }}$ octahedral normal stress $(\mathrm{kPa})$

$\tau_{\text {oct }}$ octahedral shear stress $(\mathrm{kPa})$

$\sigma_{\text {atm }}:$ atmospheric pressure $(\mathrm{kPa})$

$\gamma_{d}$ : dry unit weight (pcf)

w: moisture content 


\subsection{Soil Plasticity}

\subsubsection{Failure Criterion}

In order to do analysis of the elastic-plastic behavior of subgrades, a failure criterion must be defined. In terms of principal stresses, a failure criterion can be mathematically represented as:

$$
\mathrm{F}\left(\sigma_{1}, \sigma_{2}, \sigma_{3}\right)=0
$$

or

$$
\mathrm{F}\left(\mathrm{I}_{1}, \mathrm{~J}_{2}, \mathrm{~J}_{3}\right)=0
$$

In the failure criterion shown in (3.35), since soil shear strength is generally dependent on the hydrostatic stress (except in the case of undrained loading of clay), the hydrostatic stress (or $I_{1}$ ) is included in the yield criterion. In the case of materials whose shear strength is independent of the hydrostatic stress, such as metals, $I_{1}$ is excluded from the failure criterion. A failure criterion physically determines if a soil element is in an elastic or plastic state by using a failure surface or yield surface. It is impossible for the stress state to be outside of the yield surface. If a point of stress for a soil element is inside the yield surface, the soil is said to be elastic. If it is on the yield surface, the soil is said to be in a plastic state.

So, mathematically, $\mathrm{F}<0$ : elastic state $\mathrm{F}=0:$ plastic state Here, $\mathrm{F}$ is called the yield function, which defines the yield surface in the stress space. 
The relationship of a small stress increment $d \sigma_{i j}$ and current stress $\sigma_{i j}$ can be of three types: loading, neutral loading and unloading for a work hardening material. The gradient vector $\partial \mathrm{F} / \partial \sigma_{\mathrm{ij}}$ is the outward normal to the yield surface. Loading, neutral loading and unloading can be written as:

$$
\begin{gathered}
\mathrm{F}=0 \text { and } \frac{\partial F}{\partial \sigma_{i j}} d \sigma_{i j}>0: \text { loading } \\
\mathrm{F}=0 \text { and } \frac{\partial F}{\partial \sigma_{i j}} d \sigma_{i j}=0: \text { neutral loading } \\
\mathrm{F}=0 \text { and } \frac{\partial F}{\partial \sigma_{i j}} d \sigma_{i j}<0: \text { unloading }
\end{gathered}
$$

In the loading process, because the stress state attempts to move out of the yield surface, the current yield surface expands in order for the stress state to remain on it. In the unloading process, the stress state moves from its position on the yield surface towards the elastic region, and the loading surface is not changed, which results only in elastic deformation. In the neutral loading process, the stress point moves along the current yield surface.

\subsubsection{Flow Rule}

Once soil reaches a plastic state beyond the elastic state, Hooke's law is no longer applicable to the stress-strain relationship for a perfectly plastic material. The flow rule becomes involved in the subsequent stress-strain relationships for elastic-plastic 
deformation. The flow rule defines the direction and the magnitude of the plastic strain increment vector $\mathrm{d} \varepsilon_{\mathrm{ij}}^{\mathrm{p}}$, and can be expressed as:

$$
d \varepsilon_{i j}^{p}=d \lambda \frac{\partial G}{\partial \sigma_{i j}}
$$

where $\mathrm{d} \lambda$ is a non-negative scalar function, and $\mathrm{G}$ is a plastic potential function.

The direction of the plastic strain increment vector, which is normal to the potential surface $\mathrm{G}=0$, is determined by $\partial \mathrm{G} / \partial \sigma_{\mathrm{ij}}$ in the function. When the plastic potential function $G$ is the same as the yield function $F$, the flow rule is called associated, otherwise nonassociated.

\subsubsection{Hardening Rule}

For a hardening material, the yield surface changes continuously during the loading process in order for the stress state to lie on a subsequent yield surface. In the loading process, the hardening rule governs the change of yield surface. Depending on the plastic behavior of materials, the hardening rule can be caterigorized into three types: isotropic hardening, kinematic hardening and mixed hardening. These hardening rules can be expressed as:

$$
\mathrm{F}(\sigma, \mathrm{k})=\mathrm{f}(\sigma)-\mathrm{k}(\kappa) \text { : Isotropic hardening }
$$

where $\kappa$ is an isotropic hardening variable

$$
F(\sigma, \rho)=f(\sigma-\rho)-\mathrm{k}: \text { kinematic hardening }
$$

where $\mathrm{k}$ is a constant, and $\rho$ is back stress

$$
F(\sigma, \rho, k)=f(\sigma-k)-k(\kappa): \text { mixed hardening }
$$


Isotropic hardening assumes that the shape of yield surface remains the same and only the size of yield surface increases, while kinematic hardening rule assumes that the yield surface translates as a rigid body in stress space with the size, shape and orientation of the original yield surface unchanged. Mixed hardening is a combination of isotropic hardening and kinematic hardening.

\subsection{Behavior of Sand Subgrade}

\subsubsection{General Behavior of Sand Subgrade}

The behavior of sand is quite different depending on whether the sand is loose or dense. Generally, because of its high permeability, consolidated drained (CD) triaxial tests are used to characterize the behavior of sand. The behavior of loose and dense sands under the drained and undrained conditions can be explained graphically as shown in Figure (3.7). In drained testing, the loose sand progressively reduces its volume during deformation because the loose sand does not have much interlocking between particles. Once large strains are reached, deformation can occur without any further changes of volume or effective stress ratio. In contrast, in dense sand it is observed that deformations occur initially with an increase of volume. After a sample reaches a peak value of stress ratio, deformations occur with appreciable softening. Since in dense sand there is a considerable degree of interlocking between particles, prior to the occurrence of the shear failure the interlocking and the frictional resistance at the points of contact must be overcome. A higher degree of interlocking is observed in denser, angular, and well graded sands. As characterized by the relationship between volumetric strain and axial 
strain, shown in Figure 3.7, a gradual reduction of interlocking would induce an increase in the volume of the dense sand during shearing. As a result, the sand would become loose so that the sand particles can move over and around their neighboring particles without any further volume change and reach critical state.

One characteristic of a dense sand is dilatancy. Dilatancy is used to explain the increase in volume of a dense sand during shearing. The rate of dilation can be defined as the gradient of volumetric strain and axial strain. For a dense sand the maximum angle of friction $\left(\phi_{\text {peak }}^{\prime}\right)$ is significantly greater than the critical angle of friction $\left(\phi_{\text {critical }}^{\prime}\right)$. The critical angle of friction results from an overcoming of interlocking and rearranging of particles. It is known that irrespective of initial void ratio, at large deformations, both the loose sand and dense reach the same critical void ratio. 

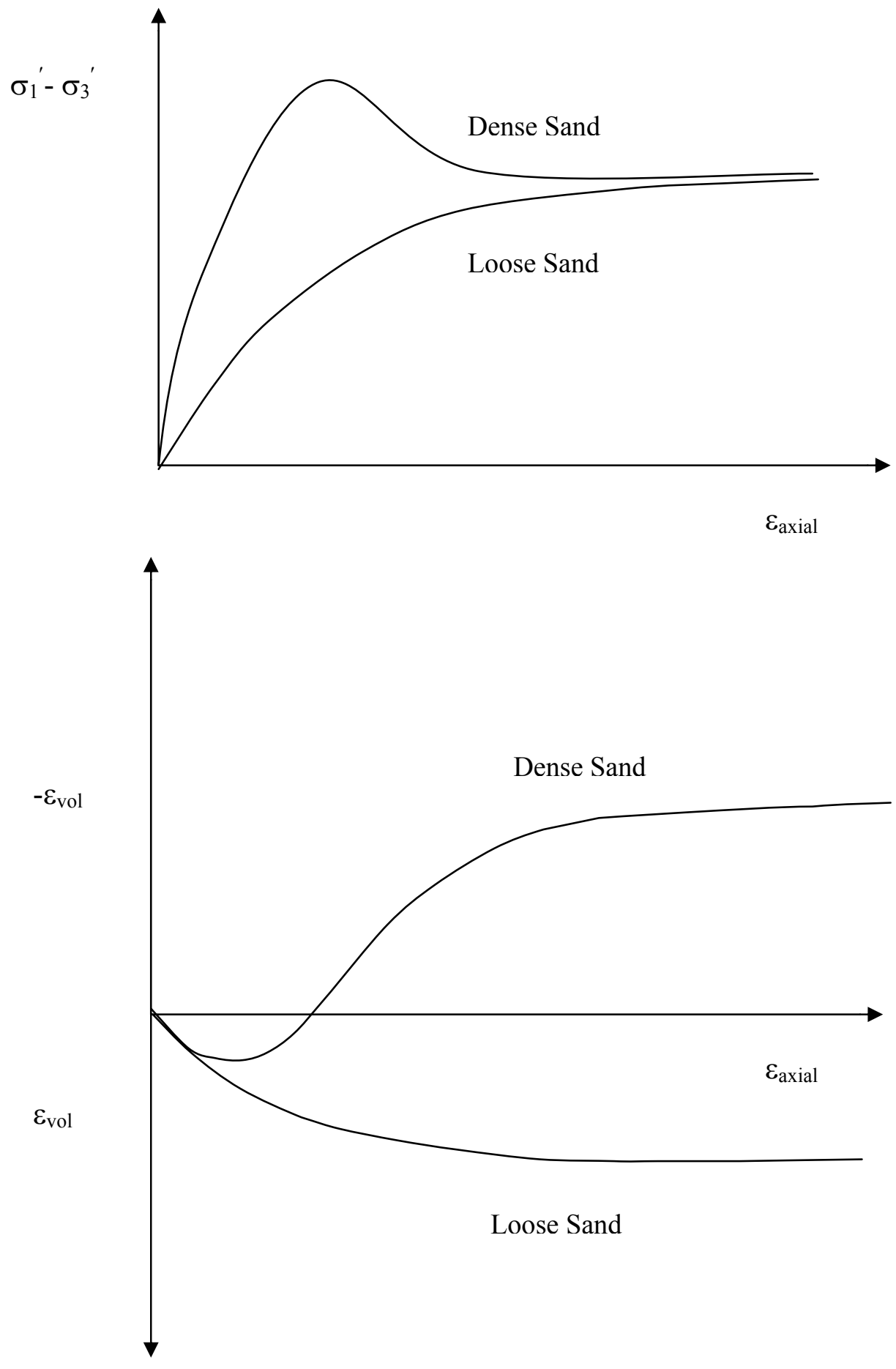

Figure 3.7 Typical behavior of loose and dense sands under drained conditions 

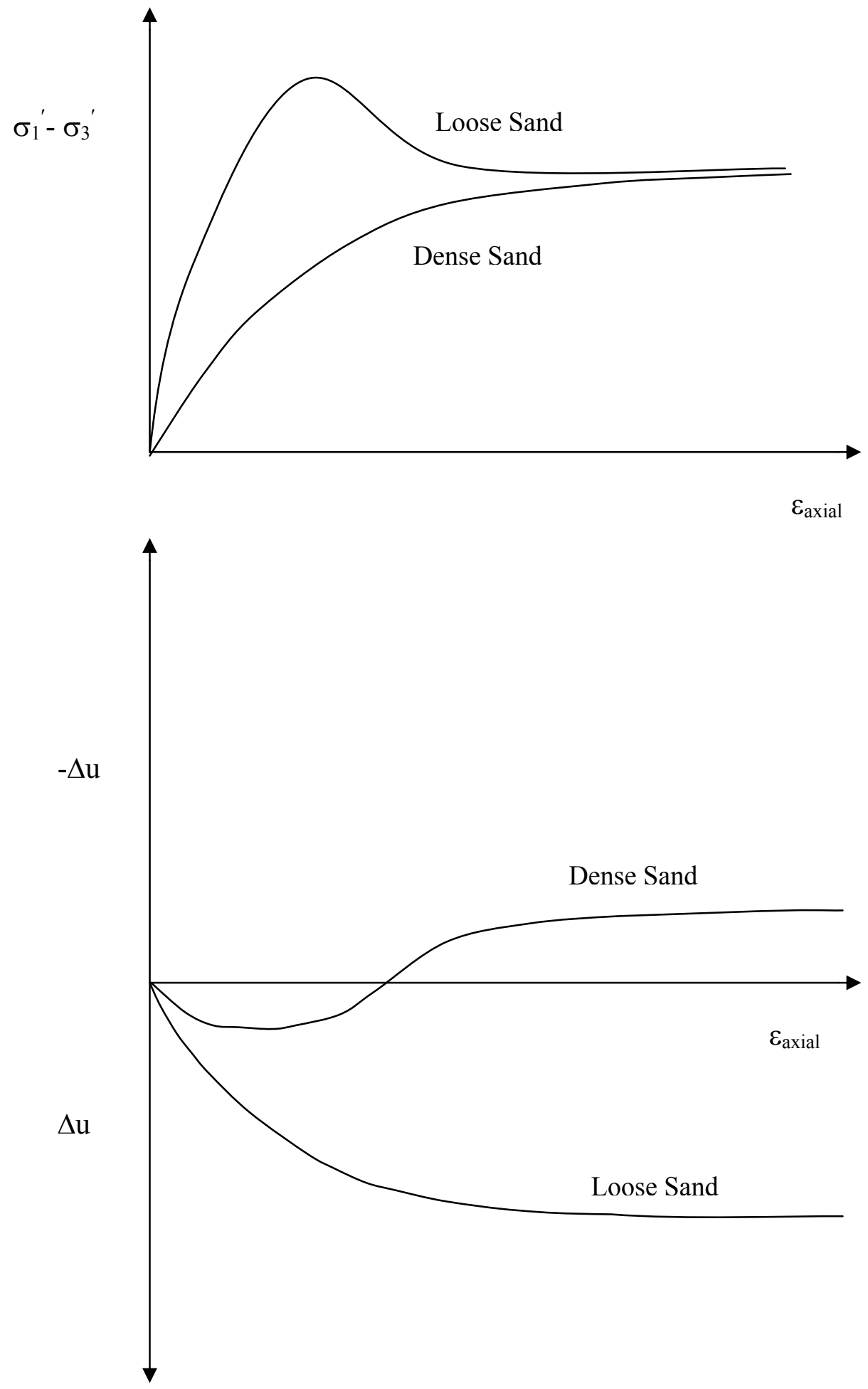

Figure 3.8 Behavior of loose and dense sands under undrained conditions 


\subsubsection{Permanent Deformations of Cohesionless Subgrades}

Pavements are considered to have failed when the permanent deformations (irrecoverable deformations) of their components are so large that they cause an intolerably uneven riding surface, or the recoverable strains induce cracking of the surfacing material. Thus, the objective of a pavement design should focus on how to limit the stresses and strains induced by the traffic on the pavement's materials, so that rutting (accumulation of permanent deformations) and fatigue failure do not occur. Since subgrade soils may contribute greatly to the rutting of a pavement, permanent deformations of subgrade soils under repeated loads are important. Traffic is simulated by triaxial tests, and suitable devices measure permanent deformations. The permanent deformations of cohesive and cohesionless subgrades will be described in different sections, due to their differing behaviors.

The factors affecting most permanent deformations of cohesionless subgrades are the following: a) Stress level; b) Dry unit weight; and c) Moisture content.

\subsubsection{Stress level}

The level of the deviator stress and confining pressure of repeated triaxial tests has a significant role in the accumulation of permanent strains under repeated loads. Gaskin et al. (1979) conducted repeated stress tests on a Sydenham sand, which had a Standard Proctor maximum dry density of $17.7 \mathrm{kN} / \mathrm{m}^{3}$. The confining pressure was kept constant at $35 \mathrm{kPa}$ (5 psi). As seen in Figure 3.9, the repeated stress was expressed as the ratio $\mathrm{X}$ of the applied stress to the shear strength obtained by a standard triaxial test. For a dry density of $15.8 \mathrm{kN} / \mathrm{m}^{3}$, this shear strength was $130 \mathrm{kPa}$. Permanent strains for any stress 
level increased until $10^{4}$ cycles, and at high values of $\mathrm{X}$, permanent strains continued to increase. In particular, the sample with $X=0.90$ failed in shear at about the $500,000^{\text {th }}$ cycle. The other samples were considered to approach this failure by excessive deformation. For values of X less than 0.50 , permanent strains leveled off and reached a constant value. At this state, the sand had reached an equilibrium and behaved almost elastically. As seen in the case of the cohesive subgrades, the existence of a "threshold stress level" was observed. For the case of the Sydenham sand, this level is approximately at a value of $\mathrm{X}=0.50$.

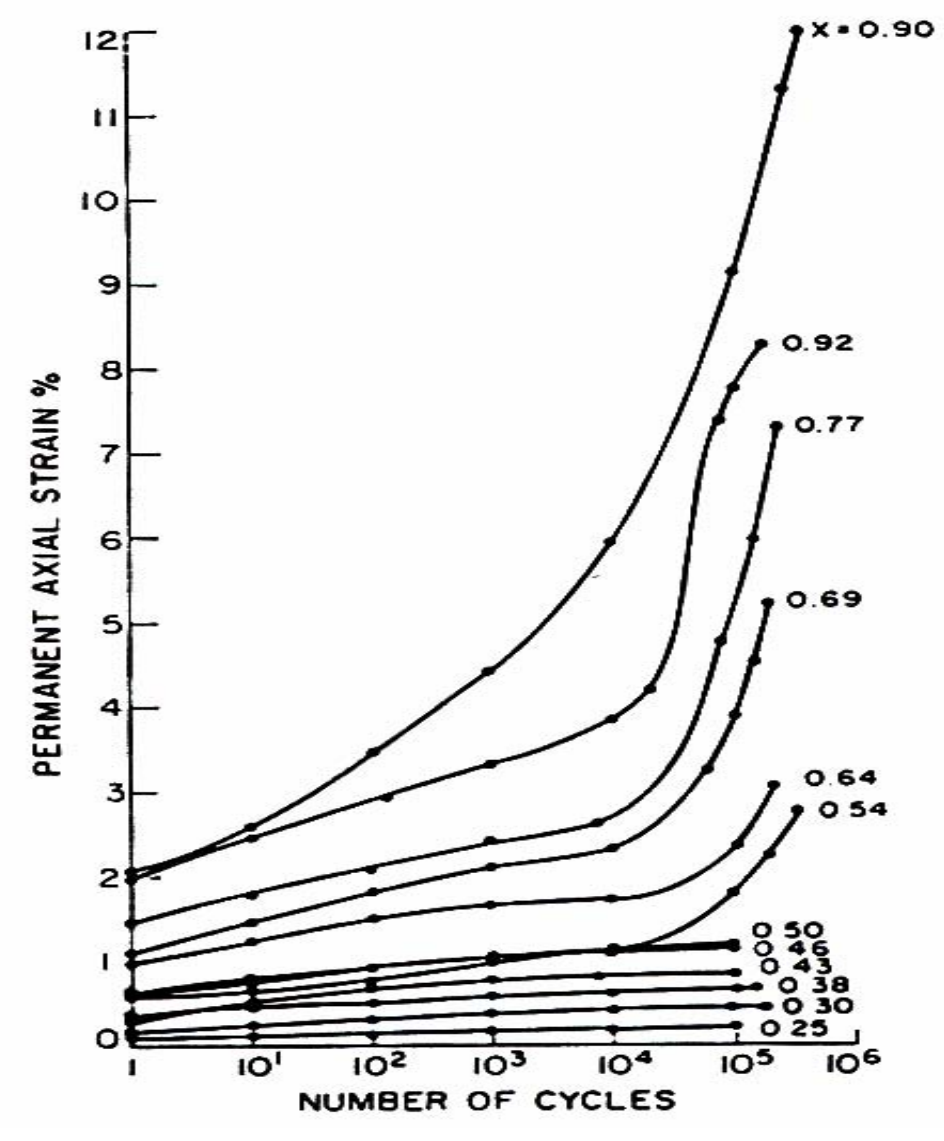

Figure 3.9 Permanent axial strains for Sydenham sand (Gaskin et al. 1979) 
Diyaljee and Raymond (1983) performed repeated load tests on a Coteau Balast. The confining pressure was kept constant at 5 psi. The repeated deviator stress was again expressed as the ratio $\mathrm{X}$ of the repeated deviator stress to the failure deviator stress under static loading. The results are presented in Figure 3.10. At any stress level, it is noteworthy that permanent strains increase. However, it seems that for values of $\mathrm{X}$ up to 0.70 , permanent strains tend to reach a constant value, while for $\mathrm{X}=0.82$ permanent strains continue to increase. Thus, in this case, the "threshold stress level" is estimated at a value of $\mathrm{X}$ between 0.70 and 0.82 .

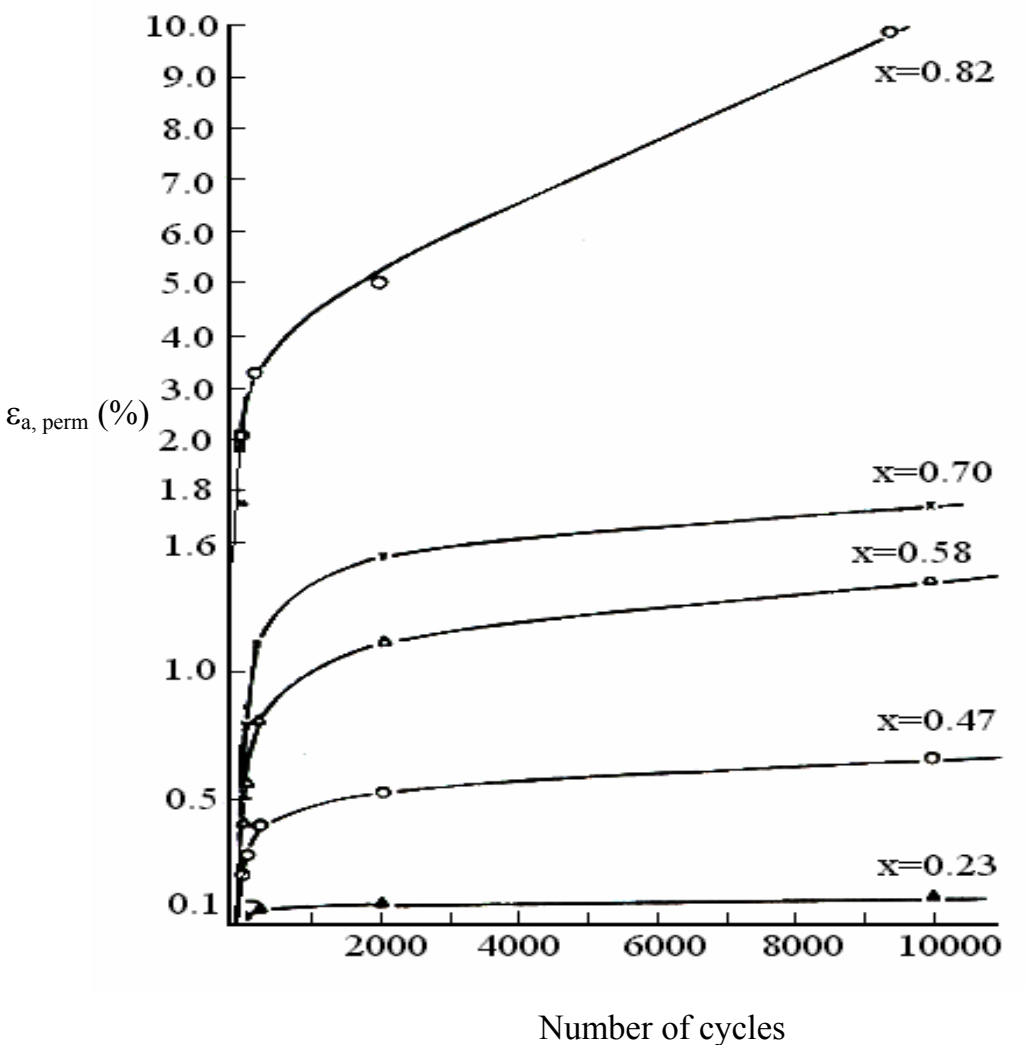

Figure 3.10 Plastic axial strains for Coteau Balast (Diyaljee and Raymond 1983) 
Pumphrey and Lentz (1986) carried out tests on a Florida subgrade sand with a maximum dry unit weight of 110 pcf and optimum water content of 11 percent (AASHTO T-180). The repeated deviator stress was a percentage of the peak static soil strength determined from samples tested at similar dry unit weight and moisture content. For tests where the confining pressure was constant at 50 psi, they reported (for any of the tested stress levels) a continuous increase of the permanent strain as the number of cycles increased. Thus, they did not report a "threshold stress level" for this sand. They also examined the influence of the confining pressure on the permanent strain as shown in Figure 3.11. It was observed that for low stress levels, the effect of the confining pressure was minor. For the highest stress level, however, permanent strain decreased with increasing confining pressure. This observation might be the result of aggregate interlock since the degree of interlock exceeded that observed for the other stress levels. Notice that for high levels of confining pressure, the difference in the permanent strain between stress ratios of 0.40 and 0.75 was not significant. This may be explained by the fact that higher confining pressures led to increasing inter-particle friction, resulting in less movement, for any stress level. 


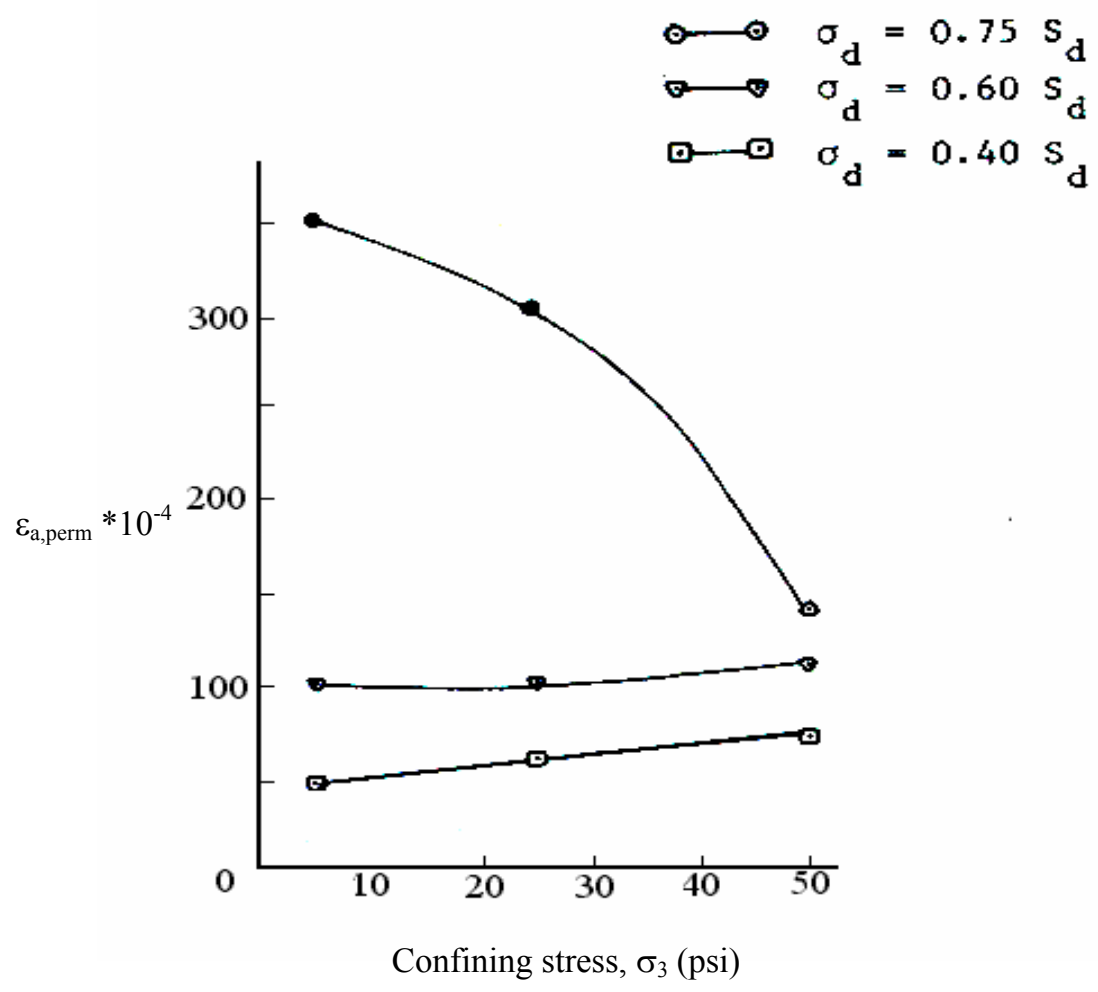

Figure 3.11 Effect of confining stress on permanent strain at $\mathrm{N}=10,000$ for the Florida subgrade sand (Pumphrey and Lentz 1986)

In both cohesive and cohesionless subgrades, there exists a "threshold stress level". Below this level, subgrades reach an equilibrium state and their behavior becomes almost elastic. Above this level, the behavior of subgrades under repeated loads is unstable and, as a consequence, shear failure occurs due to excessive deformations. Therefore, it is essential to subgrade stability to keep the stresses induced by the traffic below this level. Unfortunately, this level is not unique and it depends on the soil type. In general, the "threshold stress level" is greater than $50 \sim 60$ percent of the principal stress difference at failure obtained from static triaxial tests. 


\subsubsection{Dry unit weight}

Pumphrey and Lentz (1986) examined the influence of the dry unit weight on permanet strain. For samples compacted below and at optimum moisture content, Figure 3.12 shows the variation of the permanent strain for the $10,000^{\text {th }}$ cycle with the dry unit weight. As expected, permanent strain decreased as the dry unit weight increased. This result is reasonable, because with higher dry unit weight the volume of voids becomes less, resulting in more particle contacts and greater aggregate interlock.

\subsubsection{Moisture content}

As shown in Figure 3.12, Pumphrey and Lentz (1986) investigated the effects of moisture content on permanent strain. For samples compacted at optimum moisture content, permanent strains at the $10,000^{\text {th }}$ cycle are greater than for samples compacted below optimum. Generally, this is attributed to the fact that less water volume during compaction allows for a denser soil structure. 


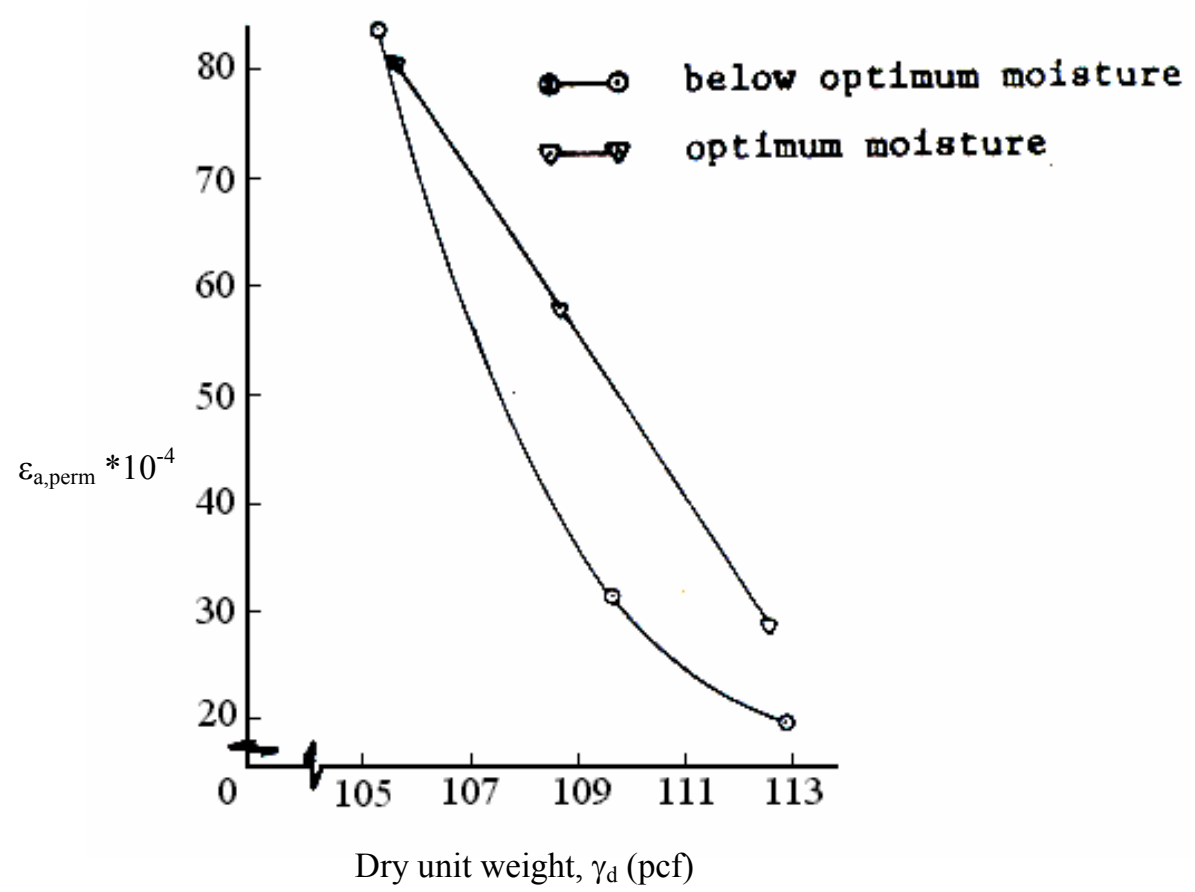

Figure 3.12 Effect of dry unit weight and moisture content on permanent strainat $\mathrm{N}=10,000$ (Pumphrey and Lentz 1986)

\subsubsection{Models for the permanent strains of cohesionless subgrades}

For cohesionless subgrades, some models have been developed to predict permanent strains under repeated loads. These models were found to reasonably predict the permanent strains of the soils that were developed, but for the reasons stated earlier, failed to predict the accumulation of permanent strains for different cohesionless subgrades. The following are some examples of models that have been suggested.

a. Lentz and Baladi (1981) performed tests on a uniform, medium sand and developed the following model, which was based on results from static triaxial tests. 


$$
\begin{gathered}
\varepsilon_{p}=\left[\varepsilon_{0.95 S_{d}} \cdot \ln \left(1-\frac{\sigma_{d}}{S_{d}}\right)^{-0.15}\right]+\left[\frac{\left(\frac{\sigma_{d}}{S_{d}}\right) \cdot n}{1-m \cdot\left(\frac{\sigma_{d}}{S_{d}}\right)}\right] \cdot \ln N \\
n=\left(0.809399+0.003769 \cdot \sigma_{3}\right) \cdot 10^{-4} \\
m=0.856355+0.049650 \cdot \ln \sigma_{3}
\end{gathered}
$$

$\varepsilon_{\mathrm{p}}:$ permanent strain

$\varepsilon_{0.95 \mathrm{Sd}}:$ static strain at 95 percent of static strength

$\sigma_{\mathrm{d}}:$ repeated deviator stress $(\mathrm{psi})$

$\mathrm{S}_{\mathrm{d}}:$ static strength $(\mathrm{psi})$

$\mathrm{n}, \mathrm{m}$ : regression constants

$\sigma_{3}$ : confining pressure $(\mathrm{psi})$

$\mathrm{N}$ : number of cycle

Lekarp and Dawson (1998) mentioned that Sweere used this model for both sands and granular base course materials and the results were not satisfactory.

b. Diyaljee and Raymond (1983) developed the following general model for the permanent strain of cohesionless subgrades.

$$
\varepsilon_{p}=B \cdot e^{n \cdot X} \cdot N^{m}
$$

$B$ : value of strain at $X=0$ for the first cycle

$\mathrm{n}, \mathrm{m}$ : experimentally derived parameters

$\mathrm{N}$ : number of cycles

$\mathrm{X}$ : repeated deviator stress level 
c. Other models can be found in the paper by Lekarp and Dawson (1998). However, most of these models were developed for base materials.

\subsection{Behavior of Clay Subgrade}

\subsubsection{General Behavior of Clay}

An important clay characteristic is the dependence on the stress history in determination of the relationship between void ratio and effective stress. As a result, the response of a clay is dependent on the overconsolidation ratio (OCR). The overconsolidation ratio is defined as the maximum effective stress in the past divided by the current effective stress. The clay is called normally consolidated (NC) if the current effective stress is the maximum effective stress that the clay has ever been subjected to. The clay is called overconsolidated (OC) if the clay has ever been subjected to a greater effective stress than the current effective stress.

In general, a normally consolidated clay shows a very similar behavior to that of a loose sand while an overconsolidated clay shows a similar behavior to dense sand. Thus, as shown in Figures 3.13 and 3.14, the typical behaviors of $\mathrm{NC}$ and $\mathrm{OC}$ clays can be explained graphically in a similar manner to that used to discuss the behavior of sands. In normally consolidated clays, during the process of shearing, clay particles tend to contract, thereby compressing the pore water between clay particles, resulting in steady increase in porewater pressure. In contrast, in overconsolidated clays, clay particles tend to initially contract and then expand, thereby generating suction in the pore water. This process results in an initial increase then gradual decrease in porewater pressure. 
Therefore, the pore water pressure for heavily overconsolidated clay may become negative during loading.

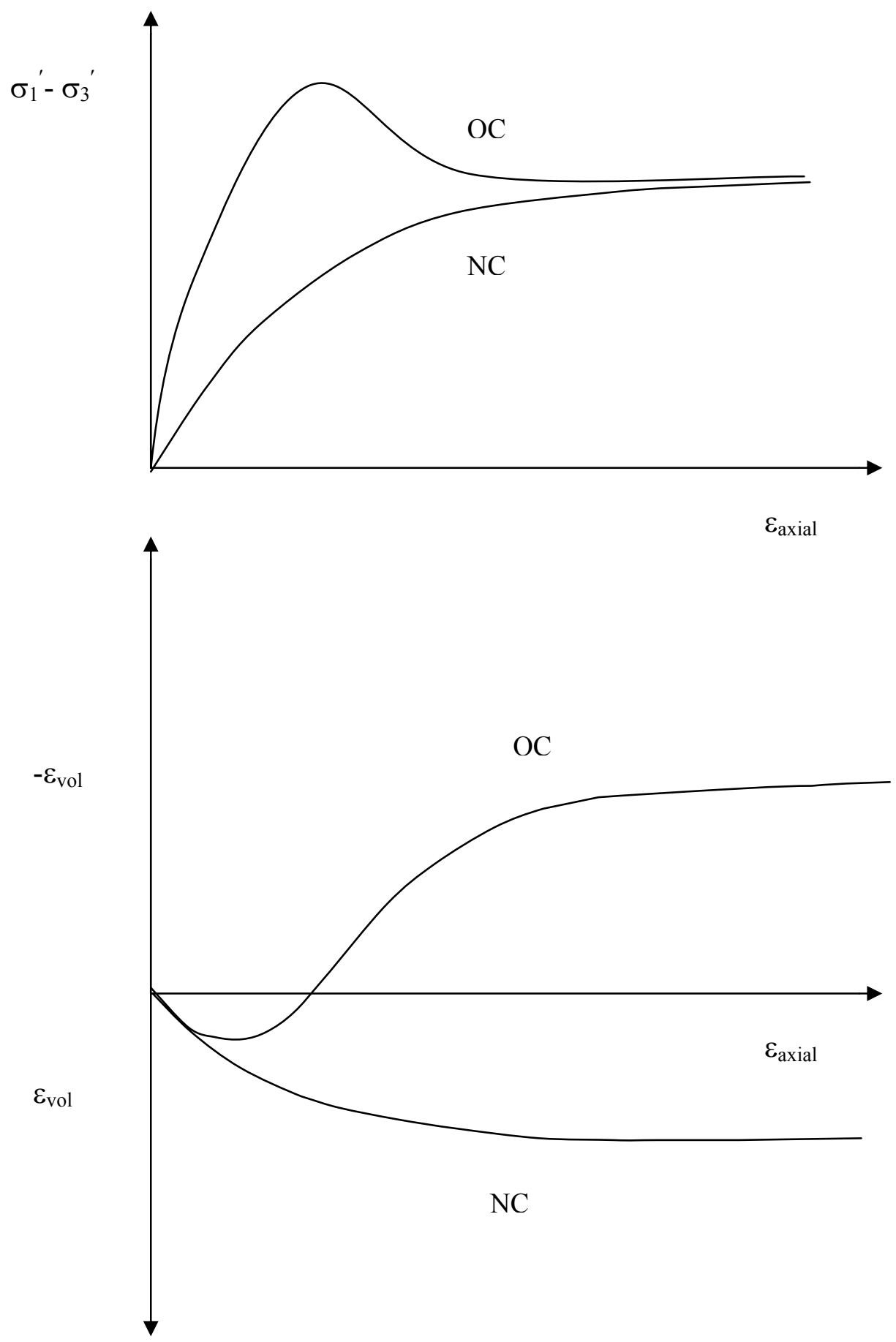

Figure 3.13 Typical behaviors of NC and OC clays under drained condition 

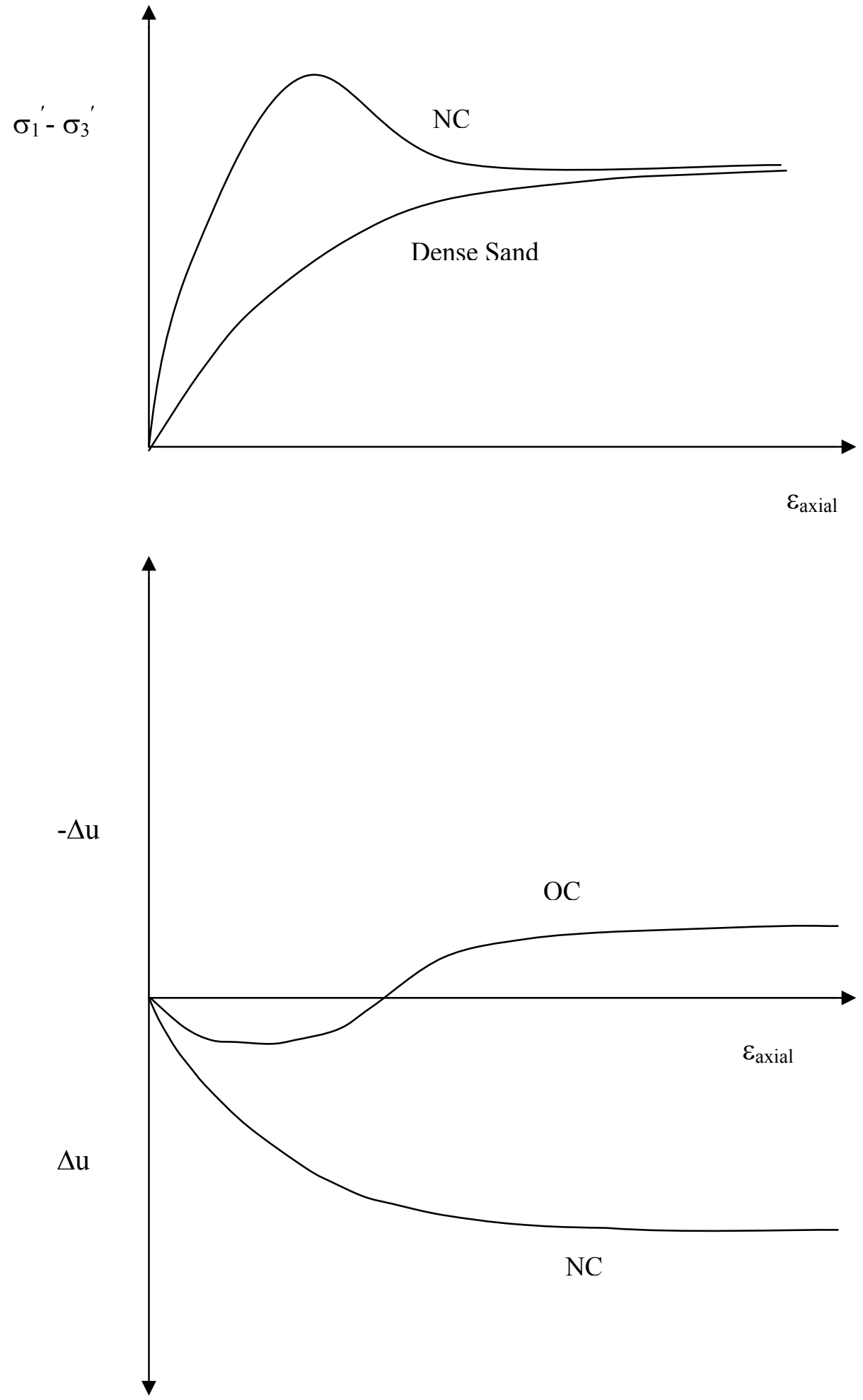

Figure 3.14 Behavior of NC and OC clays under undrained condition 


\subsubsection{Permanent Deformations of Cohesive Subgrades}

The factors that most affect the permanent deformation of cohesive subgrades are a) Stress level; b) Stress history; c) Thixotropy; d) Frequency of load; e) Moisture content; f) Freeze-thaw cycles and; g) Overconsolidation ratio.

\subsubsection{Shear Stress level}

The stress level is the most influential factor on the development of permanent deformations in cohesive subgrades. Muhanna et al. (1998) tested an A-6 subgrade soil under repeated load tests. This soil had a maximum dry density of $17.52 \mathrm{kN} / \mathrm{m}^{3}$ at optimum water content of 15.7 percent. The stress levels (SL) were expressed as a percentage of the deviator stress at failure from unconsolidated undrained (UU) tests, while the confining pressure was kept constant. Results are presented in Figures 3.15 3.17 and are for specimens compacted at 2.5 percent below optimum moiture content, optimum, and 2.5 percent above optimum respectively. It is evident that at any stress level, as the number of load repetitions increases, permanent deformations increase. Also, permanent deformations increase significantly when the stress level increases. For specimens compacted dry of optimum, permanent deformations become constant as the number of cycles increase. Only in the case of specimens compacted above optimum water content, for $\mathrm{SL}=75 \%$, are permanent deformations very large, and do not reach a constant value as the number of cycles increase. Shear failure occurs in these cases. 


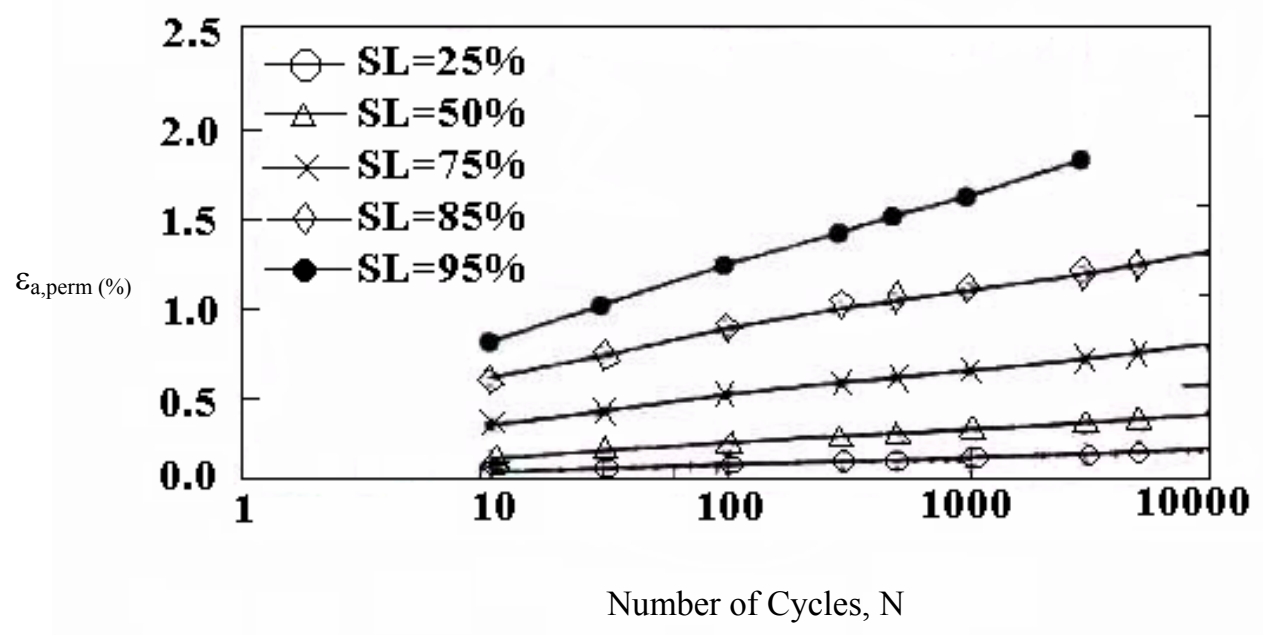

Figure 3.15 Results from tests on compacted at dry of optimum A-6 subgrade soil (Muhanna et al. 1998)

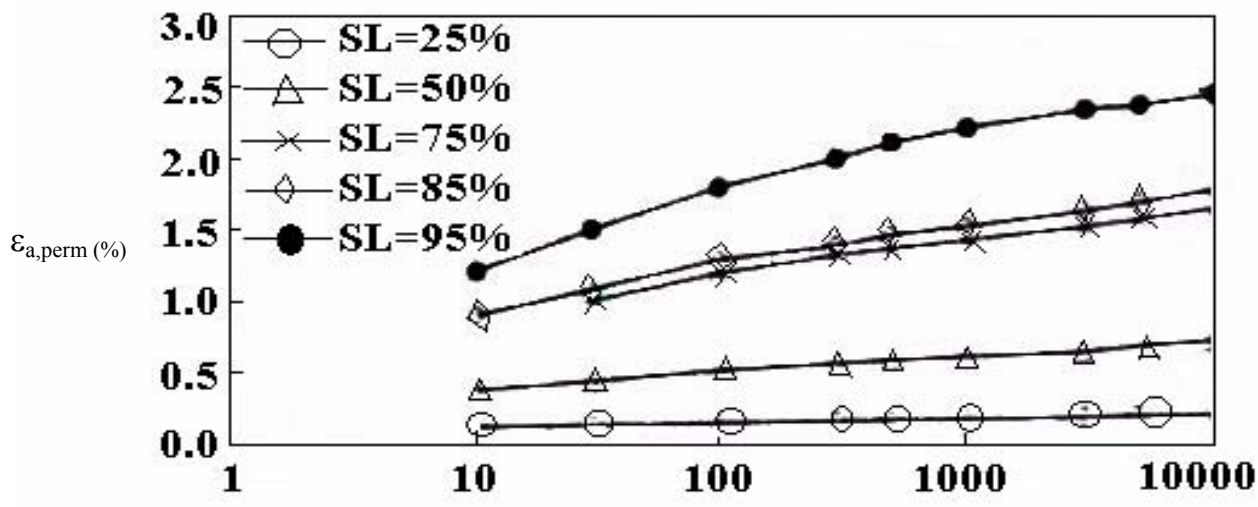

Number of Cycles, $\mathrm{N}$

Figure 3.16 Results from tests on compacted at optimum A-6 subgrade soil (Muhanna et al. 1998) 


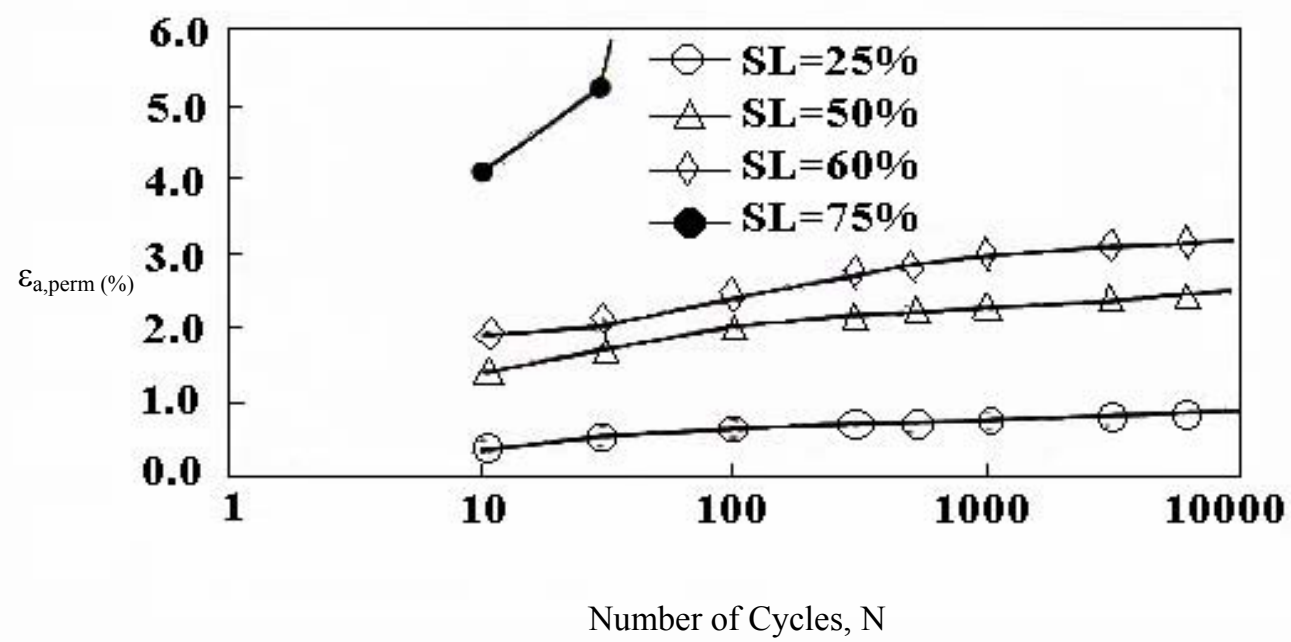

Figure 3.17 Results from tests on compacted at wet of optimum A-6 subgrade soil (Muhanna et al. 1998)

Raad and Zeid (1990) developed a model of permanent strains under repeated loads for an A-6 silty clay subgrade. The maximum dry density and optimum moisture content given by modified AASHTO compaction were $131.5 \mathrm{lb} / \mathrm{ft}^{3}$ and 8.5 percent. The ratio $\mathrm{q}_{\mathrm{r}}$ is the ratio of repeated deviator stress to the strength obtained from a standard triaxial test at a strain rate of $0.5 \% / \mathrm{min}$. Results are illustrated in Figures 3.18 and 3.19. Permanent strains were measured at two levels of confining pressure (0 and $14.5 \mathrm{psi})$ and water content ( 7 and 10 percent). For stress levels of $\mathrm{q}$ up to 0.80 , permanent deformations initially increase, but eventually stabilize with an increasing number of repetitions. In contrast, for $\mathrm{q} \geq 0.90$ permanent strains continuously increase. Therefore, it can be concluded that there exists a "threshold stress level", below which the accumulation of permanent axial strains stops, leading to a stable response, and above which progressive accumulation of axial strains occurs and causes unstable response and ultimately failure. 
In the case of Raad and Zeid, the "threshold stress level" was between 0.80 and 0.90 . For the tests of Muhanna et al. (1998), the "threshold stress level" appeared only for specimens compacted wet of optimum and it was for values of SL between 60 and 75 percent.

The effect of the confining pressure on the tests that Raad and Zeid performed is very significant. As confining pressure was increased, a stiffening of the soil was observed, consequently resulting in lower axial strains.

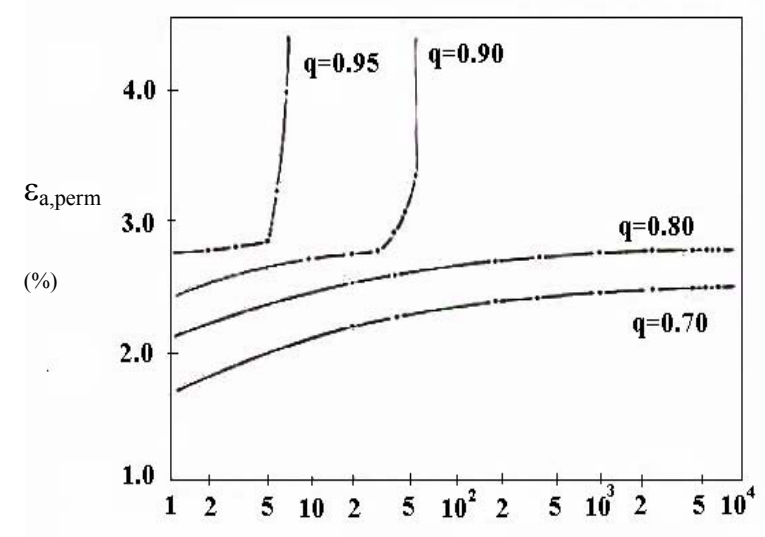

Number of stress repetitions $\mathrm{N}$

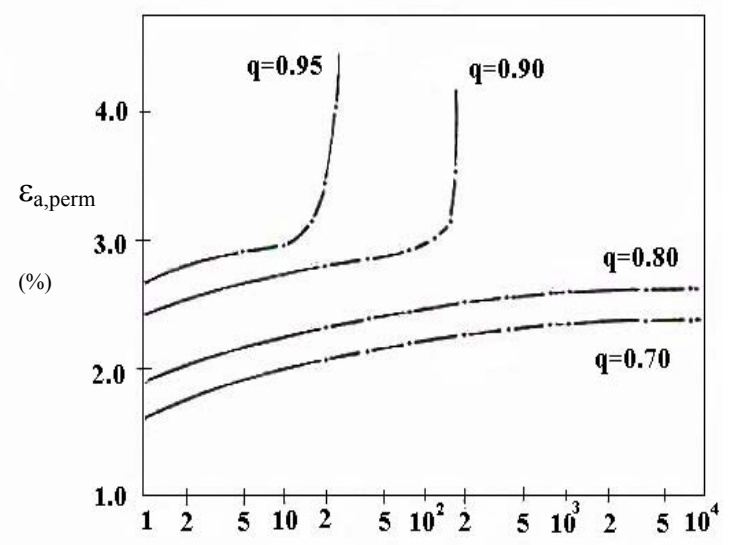

Number of stress repetitions $\mathrm{N}$

Figure 3.18 Results from tests on silty clay; left: $\sigma_{3}=0 \mathrm{psi}, \gamma_{\mathrm{d}}=129.5 \mathrm{lb} / \mathrm{ft}^{3}, \mathrm{~m}=7 \%$ right: $\sigma_{3}=14.5 \mathrm{psi}, \gamma_{\mathrm{d}}=129.5 \mathrm{lb} / \mathrm{ft}^{3}, \mathrm{~m}=7 \%(\operatorname{Raad}$ and Zeid 1990) 

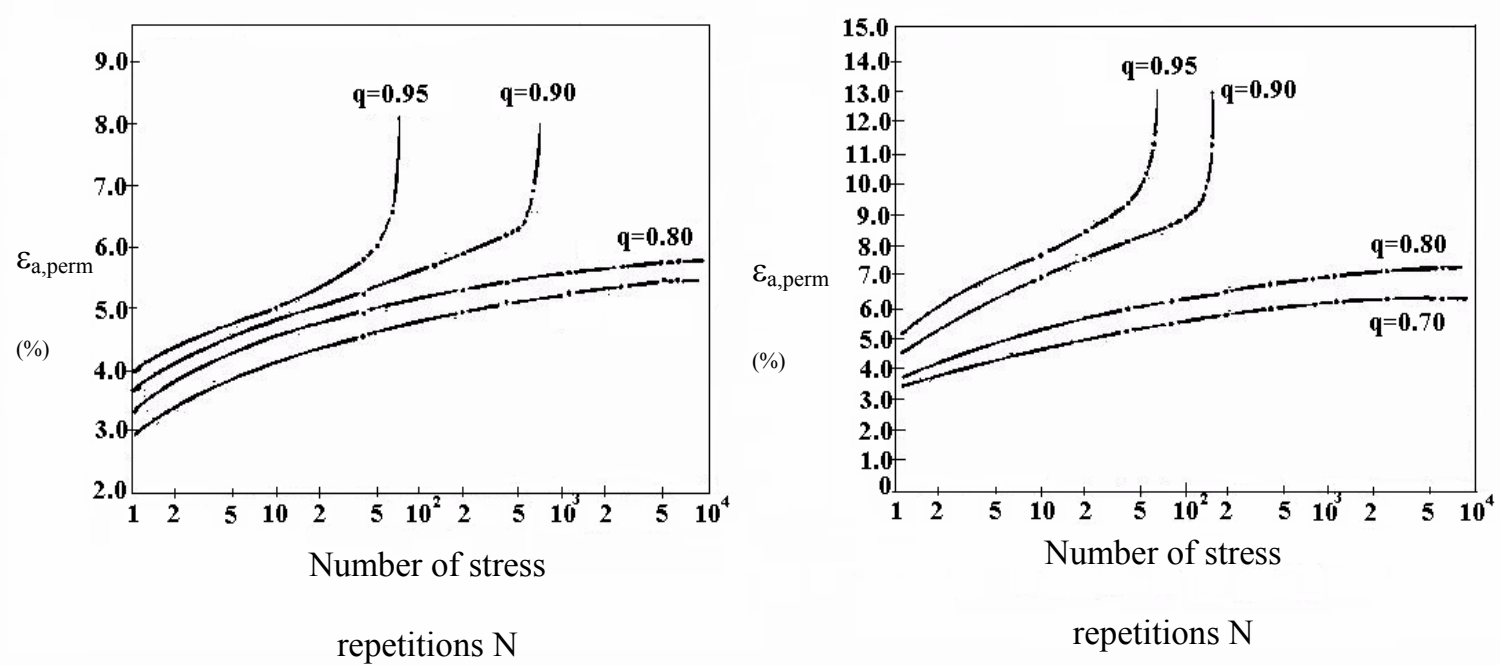

Figure 3.19 Results from tests on silty clay; left: $\sigma_{3}=0 \mathrm{psi}, \gamma_{\mathrm{d}}=129.5 \mathrm{lb} / \mathrm{ft}^{3}, \mathrm{~m}=10 \%$ right: $\sigma_{3}=14.5 \mathrm{psi}, \gamma_{\mathrm{d}}=129.5 \mathrm{lb} / \mathrm{ft}^{3}, \mathrm{~m}=10 \%($ Raad and Zeid 1990)

Raymond et al. (1979) reported the existence of the "threshold stress level" for Leda clay. This clay is very sensitive and saturated, having a natural water content of $91 \%$, a liquid limit of $66 \%$ and a plastic limit of $20 \%$. Drained triaxial tests were performed under a constant confining pressure of $35 \mathrm{kPa}$ to simulate a typical subgrade stress. The repeated deviator stress was a percentage of the principal stress difference at failure, $66 \mathrm{kPa}$, from drained triaxial tests (at $35 \mathrm{kPa}$ confining pressure). Here, the "threshold stress level" was about 54 to 60 percent of the deviator stress at failure.

\subsubsection{Stress history}

Monismith et al. (1975) performed a series of undrained triaxial compression tests on a silty clay (liquid limit $=35$, plasticity index $=15$ ). Specimens were prepared at dry densities from 90 to 95 percent of the maximum value obtained in the modified 
AASHTO compaction test and at water contents from 16 to 20 percent. The effect of stress history on permanent strain accumulation is presented in Figure 3.20. These are the results of repeated load tests of specimens at a constant confining pressure of 5 psi and at repeated deviator stresses of 10 and 20 psi. In two of the cases, the specimens were subjected to 10,000 applications of these stresses, followed by an unloading and a reload to the same number and level of stress applications. The data shows that specimens with previous stress applications exhibited lower axial permanent strains than specimens that were not previously subjected to stress applications. This result is attributed to a considerable stiffening and a consequent increase in resistance to deformation that is generated by the previous stress applications.

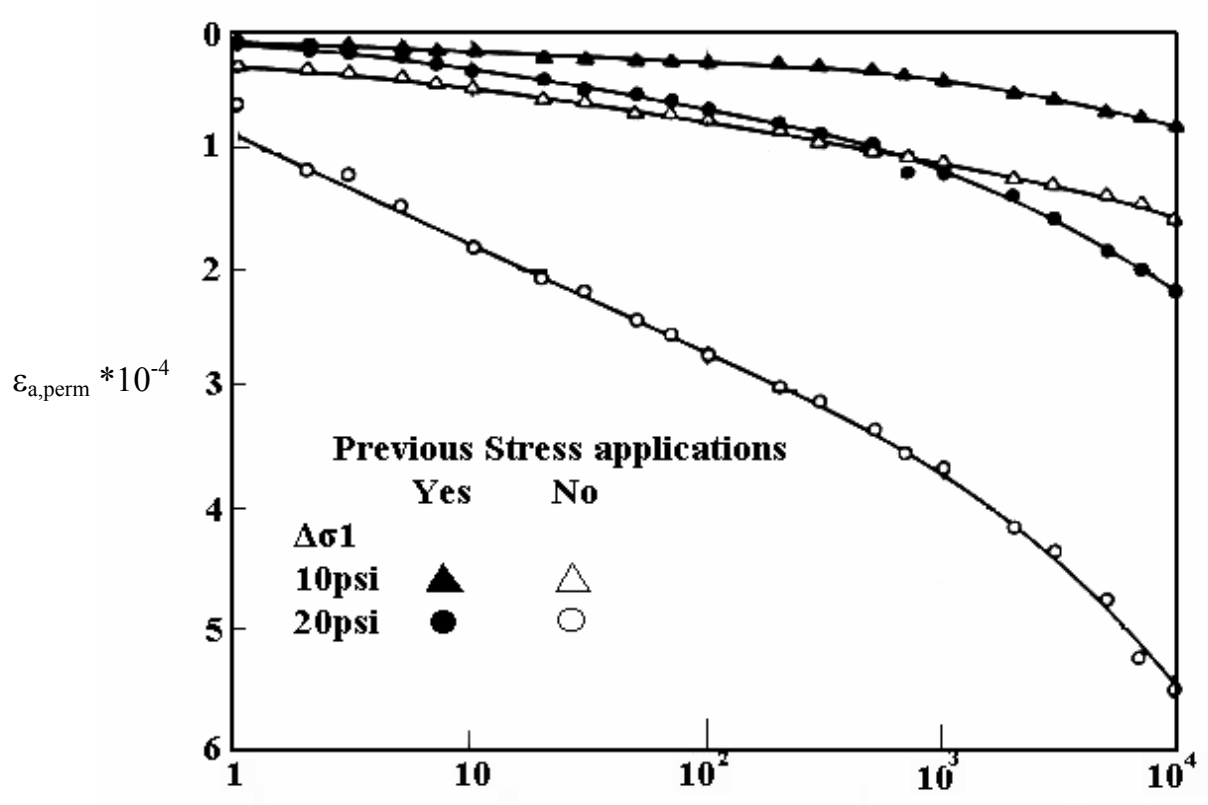

Number of Stress Applications

Figure 3.20 Influence of stress history on permanent strains (Monismith et al. 1975) 
Seed and Chan (1958) made similar observations when they tested a silty clay (liquid limit 37 and plastic limit 23). They concluded that this stress stiffening was probably due to changes in the structural arrangements of the clay particles that compressed as water dissipated under repeated loads.

\subsubsection{Thixotropy}

Seed and Chan (1958) investigated the effects of thixotropy (strength gain with time in saturated clays) on axial strain. This investigation was accomplished by testing specimens six weeks after compaction, thereby allowing the specimens to gain considerable thixotropic strength. Figure 3.21 presents the results for specimens with an initial degree of saturation of 95 percent. For specimens tested six weeks after compaction, axial strains were significantly lower than for samples tested immediately after they were compacted. In contrast, Figure 3.22 shows the results for specimens at an initial degree of saturation of 70 percent. The period of rest did not influence the accumulation of axial strains. Therefore, saturated clay subgrades are affected significantly by the period of rest. In particular, between long intervals of load applications, saturated clays regain more thixotropic strength than at short intervals (high frequencies). 
Number of stress applications

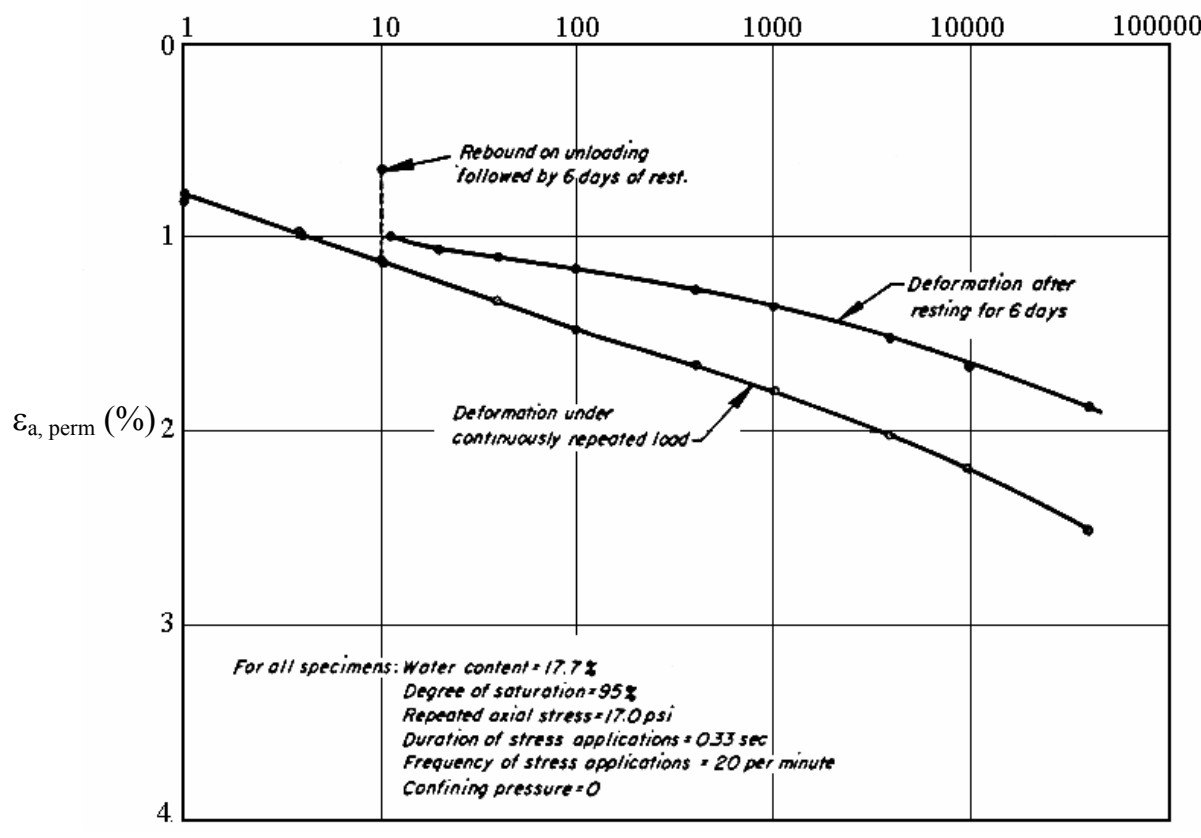

Number of stress applications

Figure 3.21 Effect of period of rest on deformation under repeated loading of silty clay with high degree of saturation (Seed and Chan 1958) 


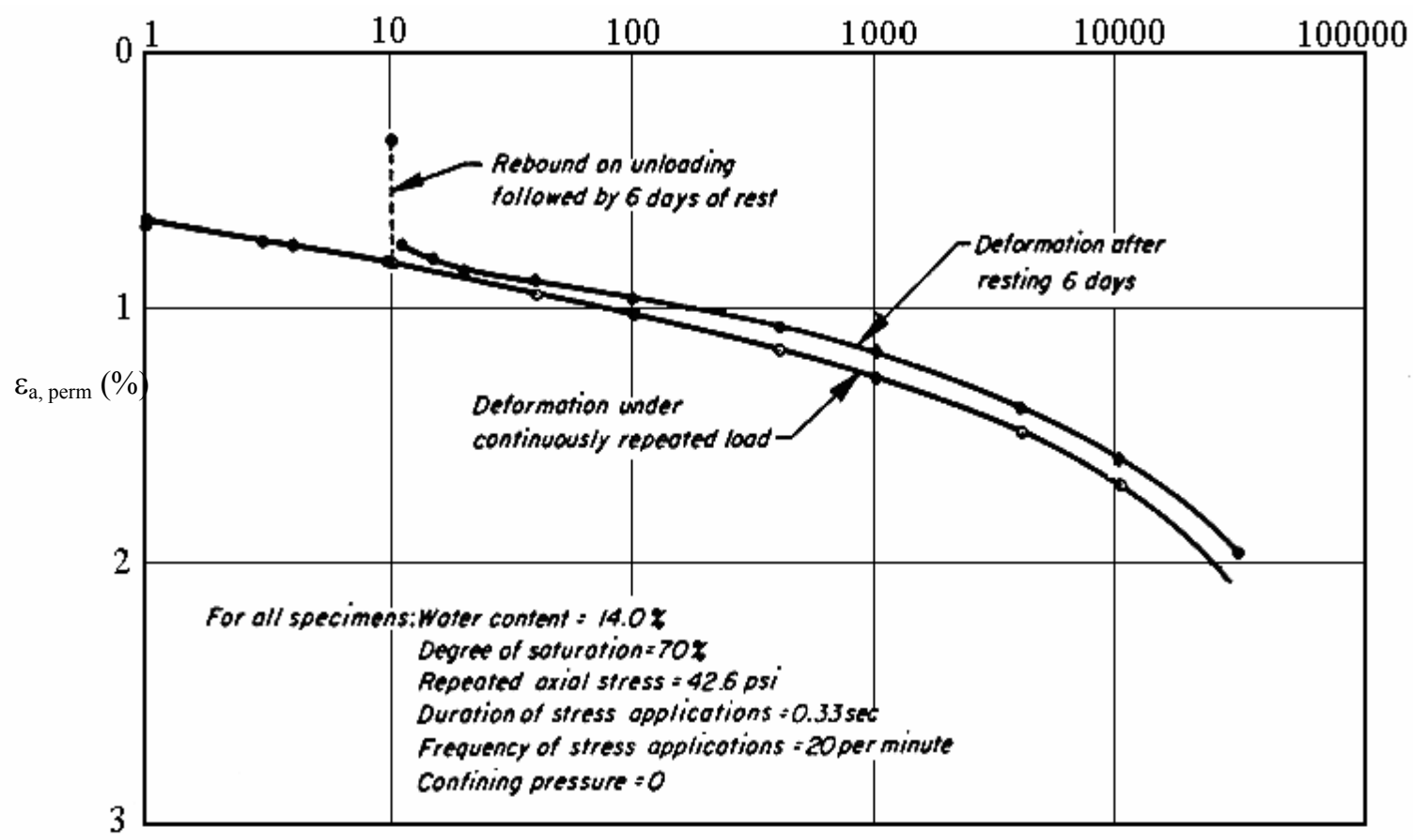

Figure 3.22 Effect of period of rest on deformation under repeated loading of silty clay with low degree of saturation (Seed and Chan, 1958)

\subsubsection{Frequency of load}

Seed and Chan (1958) thoroughly examined this matter. They found that the influence of the frequency of load was significant on clays with high degrees of saturation, which are very thixotropic. Clays with low degrees of saturation (less thixotropic) were not influenced at all. Figure 3.23 presents the effect of the load frequency using stress controlled tests for identical silty clay specimens compacted to an initial degree of saturation of 95 percent and subjected to repeated stress applications of the same magnitude and duration, but with varying frequencies. There is large difference in the number of applications required to cause a certain amount of strain. Specimens 
subjected to high load frequencies developed a certain amount of axial strain sooner than specimens subjected to low load frequencies.

Figure 3.24 shows that for specimens compacted at an initial degree of saturation of 63 percent and tested at a wide range of frequencies, the accumulation of axial strains was the same and the frequency had no influence at all. This difference was due to the thixotropic behavior of clays with high degree of saturation as mentioned earlier.

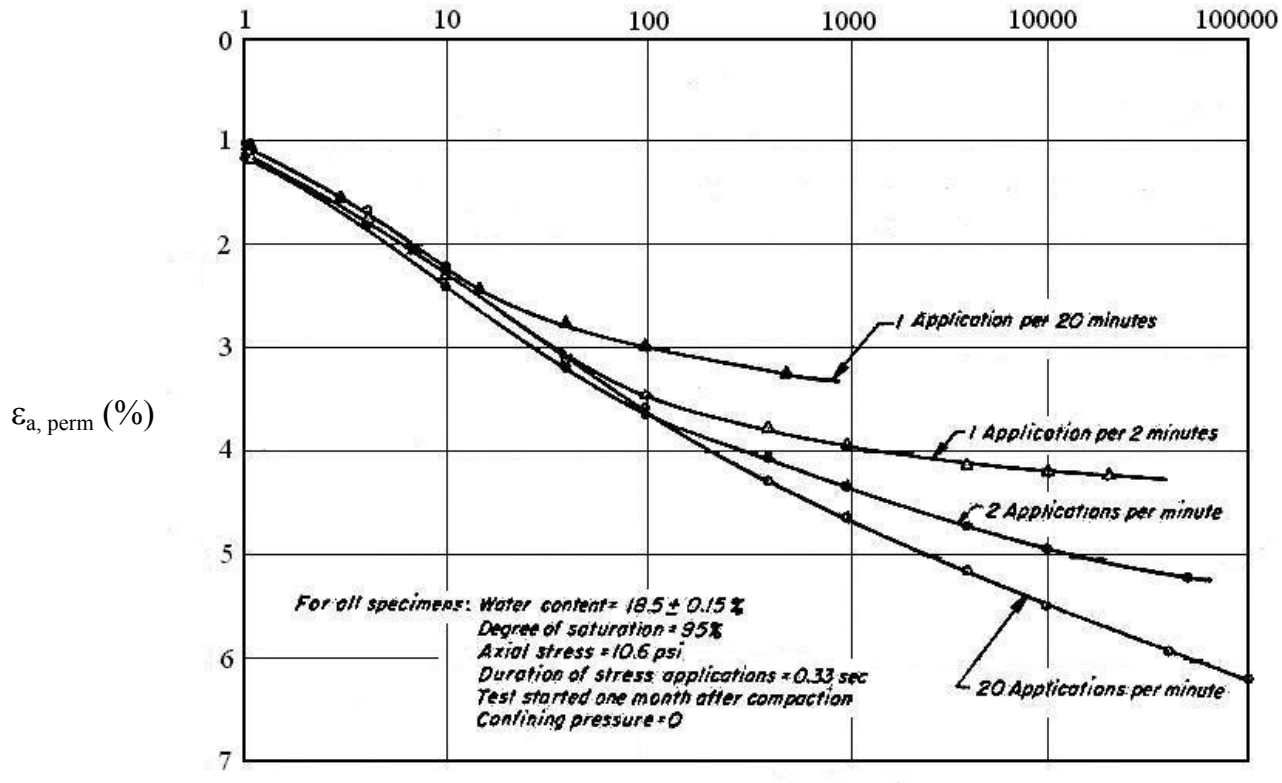

Number of stress applications

Figure 3.23 Effect of frequency of stress application on deformation of silty clay with high degree of saturation (Seed and Chan 1958) 


\subsubsection{Moisture content}

The influence of moisture content is illustrated in Figures 3.1 - 3.5. In all of these figures, it is apparent that as the moisture content increases, the permanent strains also increase. Elliott et al. (1999) examined the influence of moisture content on the permanent deformations of four representative Arkansas cohesive subgrade soils and found that as moisture content increased (especially for specimens compacted above optimum), for the same deviator stress, permanent strains increased. This result is expected since the presence of water results in a decrease of the resistance to deformation and therefore strains (recoverable, or permanent) consequently increase.

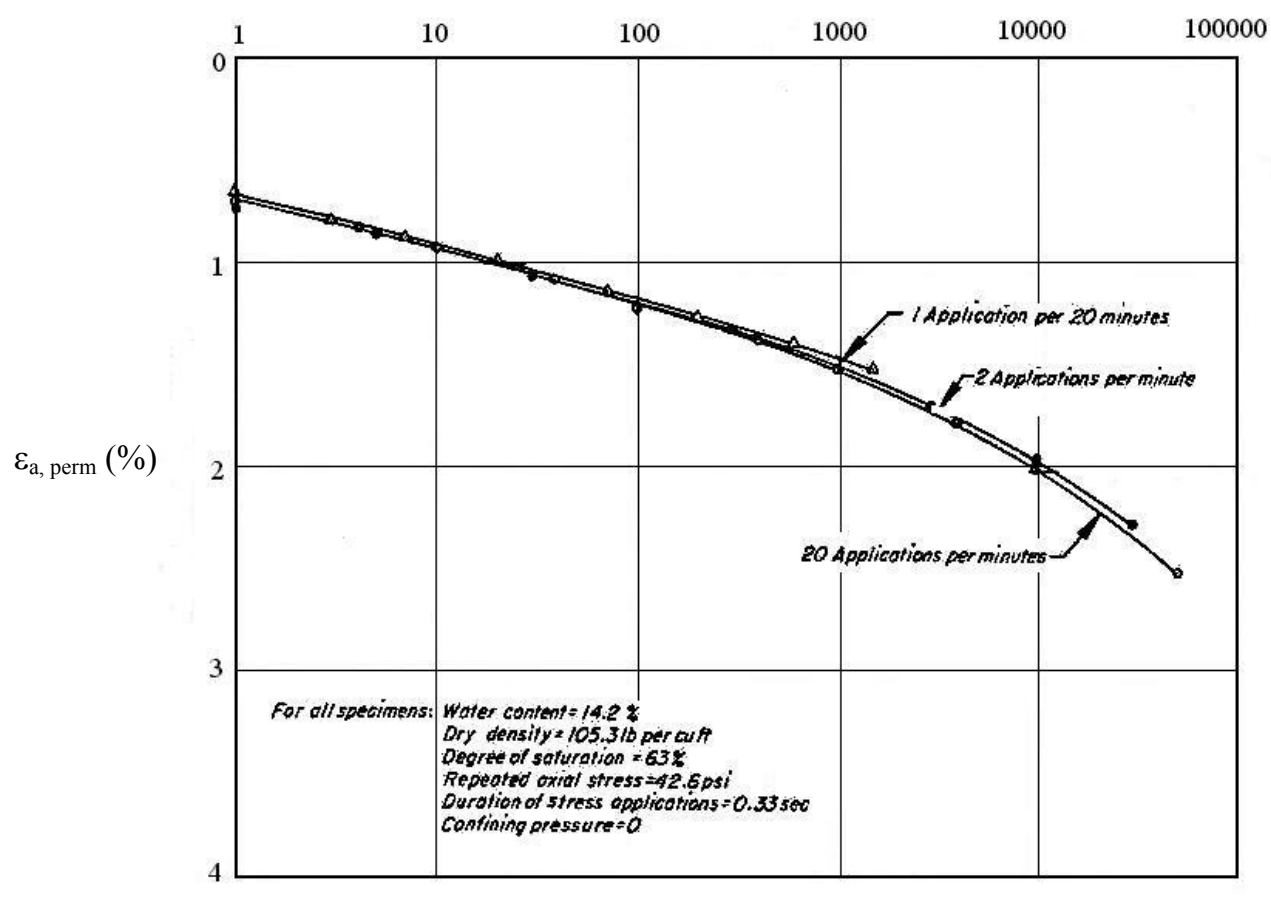

Number of stress applications

Figure 3. 24 Effect of frequency of stress application on deformation of silty clay with low degree of saturation (Seed and Chan 1958) 


\subsubsection{Freeze-thaw}

Elliott et al. (1999) investigated the effect of freeze-thaw cycles on the permanent strains. The effect of freeze-thaw was significant, even for one cycle. They reported that for one freeze-thaw cycle, permanent strains increased up to 100 percent, depending on the type of subgrade tested.

\subsubsection{Overconsolidation ratio}

Hyde (1974) examined the effect of overconsolidation ratio (OCR) on Keuper Marl soil. This soil had a liquid limit of $32 \%$, plastic limit of $18 \%$ and plasticity index of $14 \%$. The percentage of clay was found to be $18 \%$. Keuper Marl was subjected to repeated load tests at a constant confining pressure of $40 \mathrm{kN} / \mathrm{m}^{2}$. The results of these tests for values of OCR $=4,10$, and 20 , showed that as the overconsolidation ratio increased, permanent strain decreases (for a certain deviator stress). This result is expected since an increasing OCR leads to an increase in the strength of clays.

\subsubsection{Models for the permanent strains of cohesive subgrades}

Not many models have been suggested to predict the accumulation of permanent strains in cohesive subgrades under repeated loads. The few models found appear to reasonably predict the permanent strains for the soil used for the models, but fail to predict the permanents strains of other soils. These models consider, in general, the number of load repetitions, physical properties and the stress conditions. Several major models found in the literature are presented.

a. Monismith et al. (1975) proposed the following model 


$$
\varepsilon_{p}=A \cdot N^{b}
$$

$\varepsilon_{\mathrm{p}}$ : permanent strain

$\mathrm{N}$ : number of stress applications

A, b: experimentally determined coefficients.

Poulsen and Stubstad (1987) used this model to predict the permanent strains of the subgrades in six countries and they concluded that it did not represent adequately the behavior of the investigated soils.

b. Muhanna et al. (1998) proposed the following model

$$
\log \left[\sum \varepsilon_{p}^{*} /\left(S L^{7 / 4} \cdot e^{3}\right)\right]=1.3+2.476 \cdot\left(w-w_{0}\right) / w_{0}
$$

$\Sigma \varepsilon_{\mathrm{p}}{ }^{*}:$ accumulated plastic strain (\%) at the state of apparent shakedown (shake down can be defined as the switch of material response from plastic to purely elastic behavior after a few cycles of loading)

SL: stress level

e: void ratio obtained by $\mathrm{T}-99$ compaction at $\mathrm{w}$

w: molding water content $(\%)$

$\mathrm{w}_{0}$ : T-99 optimum moisture content (\%)

c. Raad and Zeid (1990) suggested the following models for stress levels lower than the "threshold stress level".

$$
q=\frac{\varepsilon_{a}}{a_{L}+s_{L} \cdot \log N}
$$

q: stress level 
$\varepsilon_{\mathrm{a}}$ : permanent axial strain $(\%)$

$\alpha_{\mathrm{L}}, \mathrm{s}_{\mathrm{L}}:$ material parameters

For stress levels above the "threshold stress level"

$$
\begin{gathered}
q_{r}=\frac{\varepsilon_{a}}{a_{h}+b_{h} \cdot \varepsilon_{a}} \\
b_{h}=B_{h}+S_{h} \cdot \log N
\end{gathered}
$$

$\mathrm{q}_{\mathrm{r}}$ : stress level

$\varepsilon_{\mathrm{a}}:$ permanent axial strain $(\%)$

$\alpha_{\mathrm{h}}, \mathrm{B}_{\mathrm{h}}, \mathrm{S}_{\mathrm{h}}:$ material parameters

\subsection{Development of Pore Water Pressure During Repeated Loading}

\subsubsection{Introduction}

The development of pore water pressures under repeated loading is very significant in saturated clays. Because undrained shear strength for clays is affected by pore pressure, the study of this development is important. Despite the importance of this process, it has not been frequently addressed. Pore pressures are caused by displacements at the grain-to-grain contacts when stresses are applied. Immediately following the stress application, deformation occurs in the soil skeleton. This deformation in turn produces elastic pore pressures $\left(\Delta \mathrm{u}_{\mathrm{e}}\right)$ (related to recoverable deformations), while sliding at grain contacts produces non-recoverable deformations. As a result, as contact stresses increase, these contacts between grains fail, permanent deformations occur, and part of the stress initially carried by these contacts is transferred to the pore water pressure and to the 
neighboring contacts which have not failed. As stresses are continuously applied, deformations and pore pressures increase with time.

The total pore pressure $(\Delta \mathrm{u})$ consists of an elastic component $\left(\Delta \mathrm{u}_{\mathrm{e}}\right)$ and a plastic non-recoverable component $\left(\Delta \mathrm{u}_{\mathrm{p}}\right)$ due to failure of the bonds at contacts between the soil particles.

$$
\Delta u=\Delta u_{e}+\Delta u_{p}
$$

In the following section, results from two studies will be presented. Both studies examined the pore water pressure development during the repeated loading of cohesive subgrades.

\subsubsection{Development of Pore Water Pressures}

Wilson and Greenwood (1974) performed repeated undrained triaxial tests on a normally consolidated lacustrine clay from Hamilton, Ontario. The natural water content was between 25 and $27 \%$, the liquid limit was $34 \%$, and the plastic limit was $20 \%$. All samples were isotropically consolidated under a cell pressure of 70 psi against a backpressure of $20 \mathrm{psi}$. The samples were allowed to consolidate for 4 days in order to behave in the same way during the testing program. The applied stress levels were a percentage of the compressive strength $\sigma_{\mathrm{s}} \quad\left(\sigma_{\mathrm{s}}=34 \mathrm{psi}\right)$ obtained from a standard consolidated undrained test.

Figure 3.25 presents the development of pore pressures for different stress levels. In all cases, pore pressures increased with time according to the general mechanism described in the introduction. However, for stress levels below the "threshold stress level" of this clay, which was between 0.36 and 0.40 of $\sigma_{\mathrm{s}}$, pore pressures were small and 
recoverable. For higher stress levels, the deformations that occurred in this clay were so large that sliding occurred along grain contacts, strains became irrecoverable and the pore pressures carried the greatest part of the repeated stress. That is why a significant increase in pore pressure is observed.

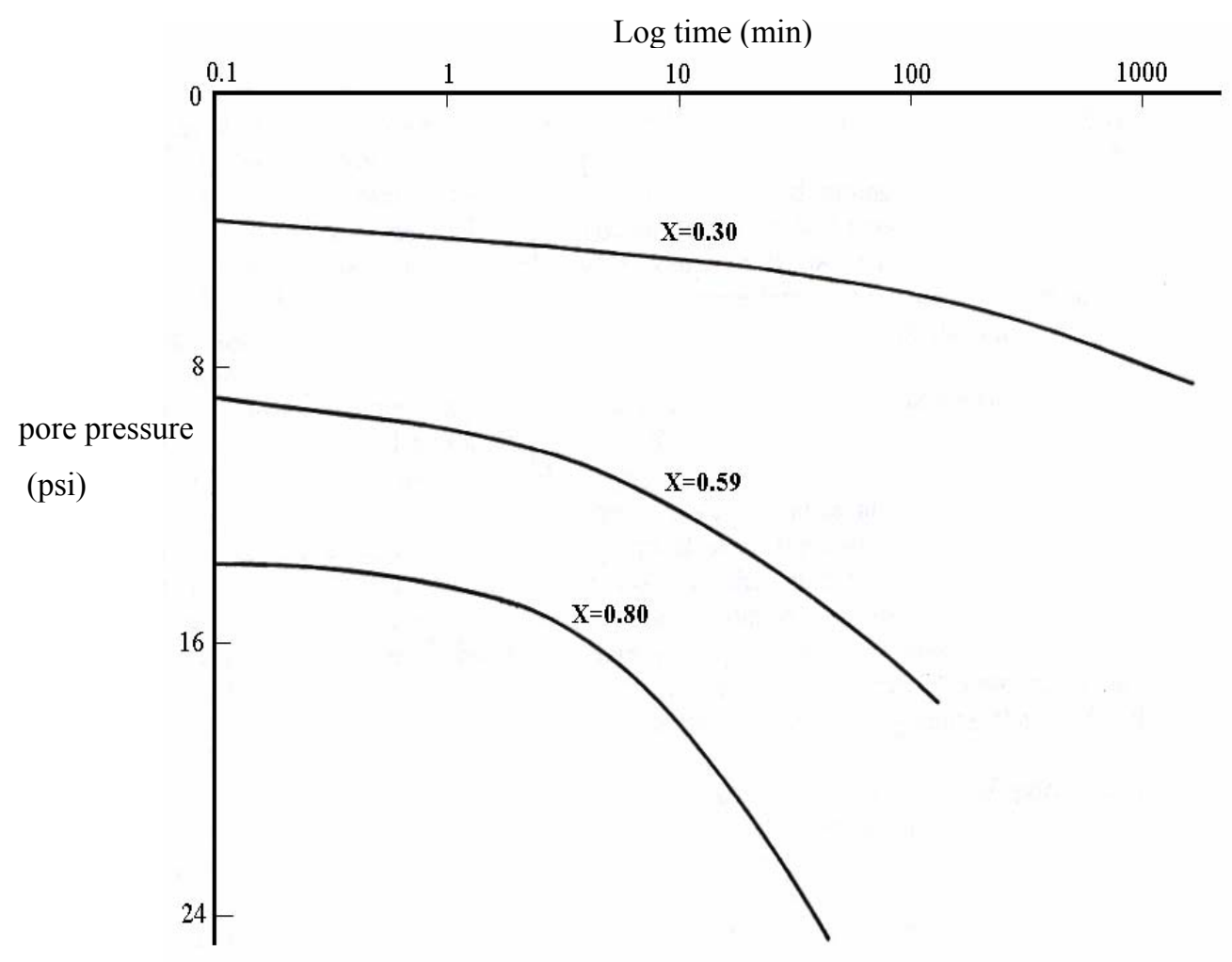

Figure 3.25 Development of pore pressure and various stress levels (Wilson and Greenwood 1974)

Next, Wilson and Greenwood examined the relationship between pore water pressure and strain. Figure 3.26 presents the results for the repeated load of $0.3 \sigma_{\mathrm{s}}$, where the clay was in the elastic range. The elastic components (dissipated pore pressure) are 
represented by the lines joining the load off (unloading) and load on (loading) points. The plastic components (non-dissipated pore pressure) are represented by the line joining the load off points. It appears that the elastic component of the pore pressure $\left(\Delta u_{e}\right)$ is analogous to the recoverable $\left(\Delta \mathrm{e}_{\mathrm{e}}\right)$ and the non-recoverable $\left(\Delta \mathrm{u}_{\mathrm{p}}\right)$ is analogous to the nonrecoverable component of strain $\left(\Delta \mathrm{e}_{\mathrm{p}}\right)$, but with a different constant of proportionality. As reported, the relationship for stress levels below the "threshold stress level" was found in other studies as well. When the stress levels exceeded the "threshold stress level", the plastic components of strain and pore water increased significantly and did not have a linear relationship.

Ghazzaly and Ha (1975) argued these results. They performed undrained triaxial tests on normally consolidated and overconsolidated samples $(\mathrm{OCR}=2)$ of Beaumont clay (water content 38\%, liquid limit $61 \%$ and plastic limit 37\%). The confining pressure was 40 psi and the repeated deviator stress levels were lower than the confining pressure. They observed that the non-recoverable $\left(\Delta \mathrm{u}_{\mathrm{p}}\right)$ pore pressure was almost constant and the non-recoverable strain $\left(\Delta \mathrm{e}_{\mathrm{p}}\right)$ increased with time. Although it is apparent that they reported a totally different behavior, an important consideration is the fact that the tests they performed were not the same as those performed by Wilson and Greenwood completed.

Hyde (1974) examined the development of pore pressures during repeated loading on Keuper Marl. The Keuper Marl was subjected to repeated undrained triaxial load tests, at a constant confining pressure of $40 \mathrm{kN} / \mathrm{m}^{2}$. Figure 3.27 shows the variation of the pore pressure parameter A with the number of cycles for different levels of deviator stress $\mathrm{q}_{\max }$ and two values of the overconsolidation ratio. For slightly overconsolidated samples, A 
increased significantly with the number of cycles and reached a constant (positive) value at about $10^{5}$ cycles. Of note is that for higher stress levels, $\mathrm{A}$ is also higher. This result means that pore pressures increased more than stress levels due to the more pronounced plastic deformations that occurred in the structure of Keuper Marl, leading to consequently larger stresses transferred from the soil to the water.

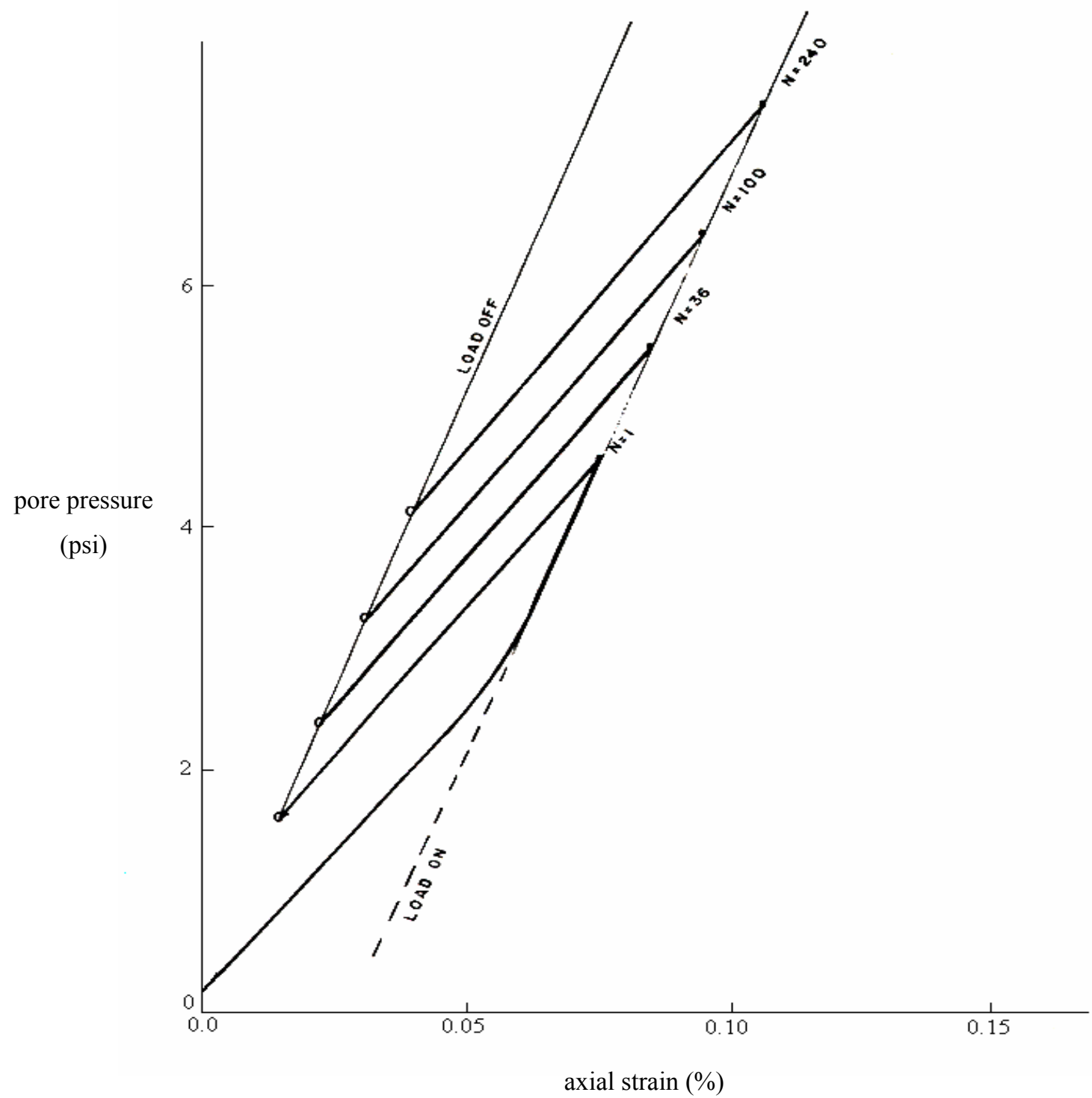


Figure 3.26 Relationship between pore pressure and axial strain (Wilson and Greenwood 1974)

Heavily overconsolidated samples showed a decrease in A as the number of cycles increased. In fact, A reached negative values after $10^{4}$ cycles. This behavior is expected for typical overconsolidated clays.

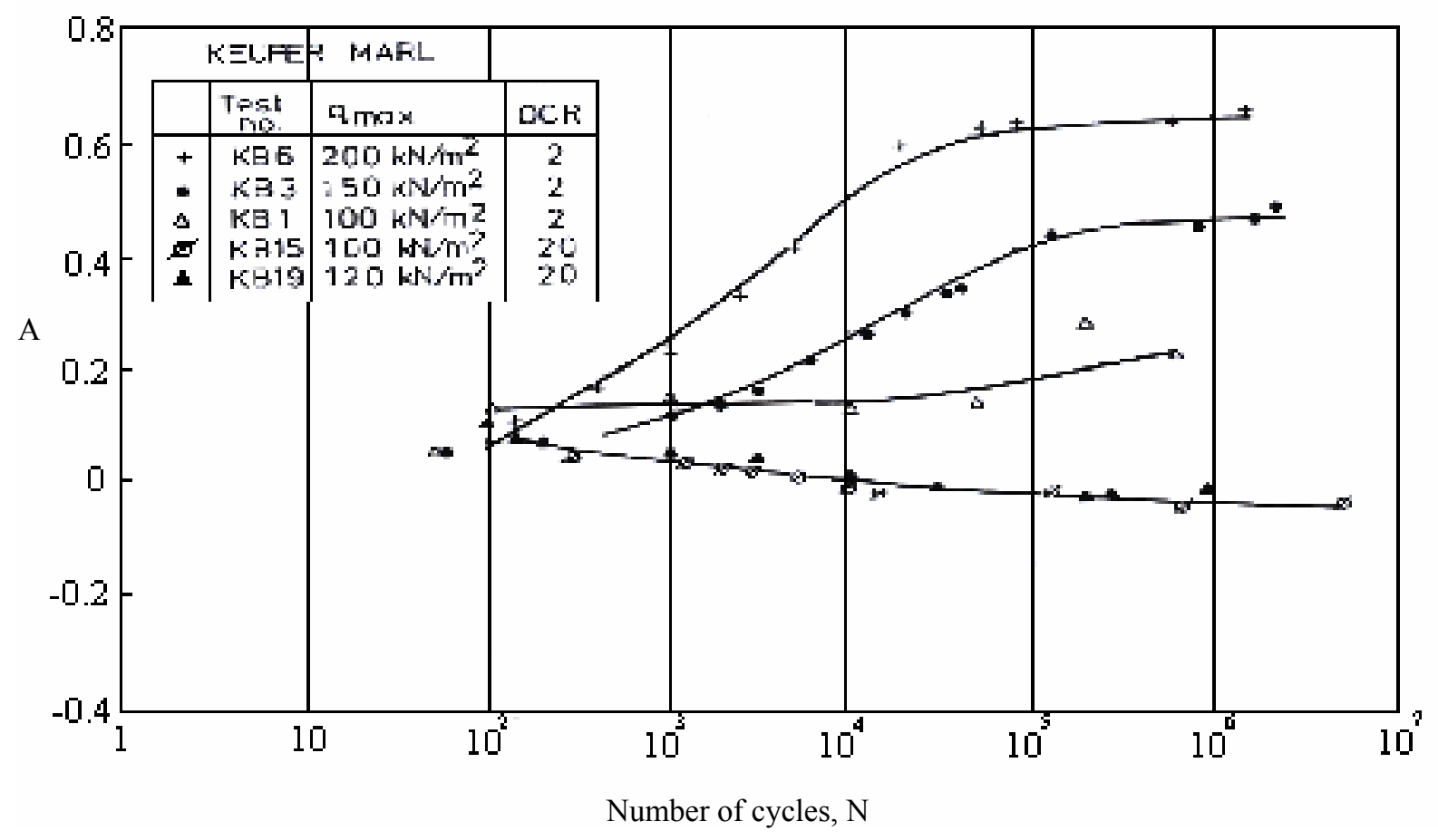

Figure 3.27 Variation of pore pressure parameter A (Hyde 1974) 


\subsection{Constitutive Models for Subgrade Soils}

The models to estimate resilient modulus and permanent strain have limitations that apply to all types of subgrades since these models are based on specific soils for each model. For further analysis, the Drucker-Prager model will be reviewed.

\subsubsection{Drucker-Prager Model without Cap}

Drucker and Prager modified the Von Mises yield criterion developed for metal plasticity in order to describe the hydrostatic pressure-dependent behavior of friction materials. Unlike the Mohr-Coulomb criterion, the Drucker-Prager model considers the influence of the intermediate principal stress (Desai and Siriwardane 1984). In addition, the Drucker-Prager model is mathematically convenient to use in three-dimensional applications due to its smooth failure surface (Chen and Saleeb 1994). In terms of the stress invariants $\mathrm{I}_{1}$ and $\mathrm{J}_{2}$, the Drucker-Prager model without cap can be written as:

$$
f\left(I_{1}, J_{2}\right)=\sqrt{J_{2}}-\alpha I_{1}-k=0
$$

where $I_{1}$ and $J_{2}$ are the first invariant of the stress tensor and the second invariant of the deviator stress tensor, respectively, and $\alpha$ and $\mathrm{k}$ are model parameters that can be related to the Mohr-Coulomb strength parameters $\mathrm{c}$ and $\phi$ for triaxial conditions by the following equations:

$$
\begin{aligned}
& \alpha=\frac{2 \sin \phi}{\sqrt{3}(3-\sin \phi)} \\
& k=\frac{6 c \cos \phi}{\sqrt{3}(3-\sin \phi)}
\end{aligned}
$$

In addition, for plane strain conditions, 


$$
\begin{gathered}
\alpha=\frac{\tan \phi}{\left(9+12 \tan ^{2} \phi\right)^{1 / 2}} \\
k=\frac{3 c}{\left(9+12 \tan ^{2} \phi\right)^{1 / 2}}
\end{gathered}
$$

Figure 3.28 illustrates the Drucker-Prager model without cap failure surface in the $I_{1}-\sqrt{J_{2}}$ plane, and Figure 3.29 describes the Drucker-Prager and Mohr-Coulomb failure criteria in principal plane.

\section{Failure Criterion}

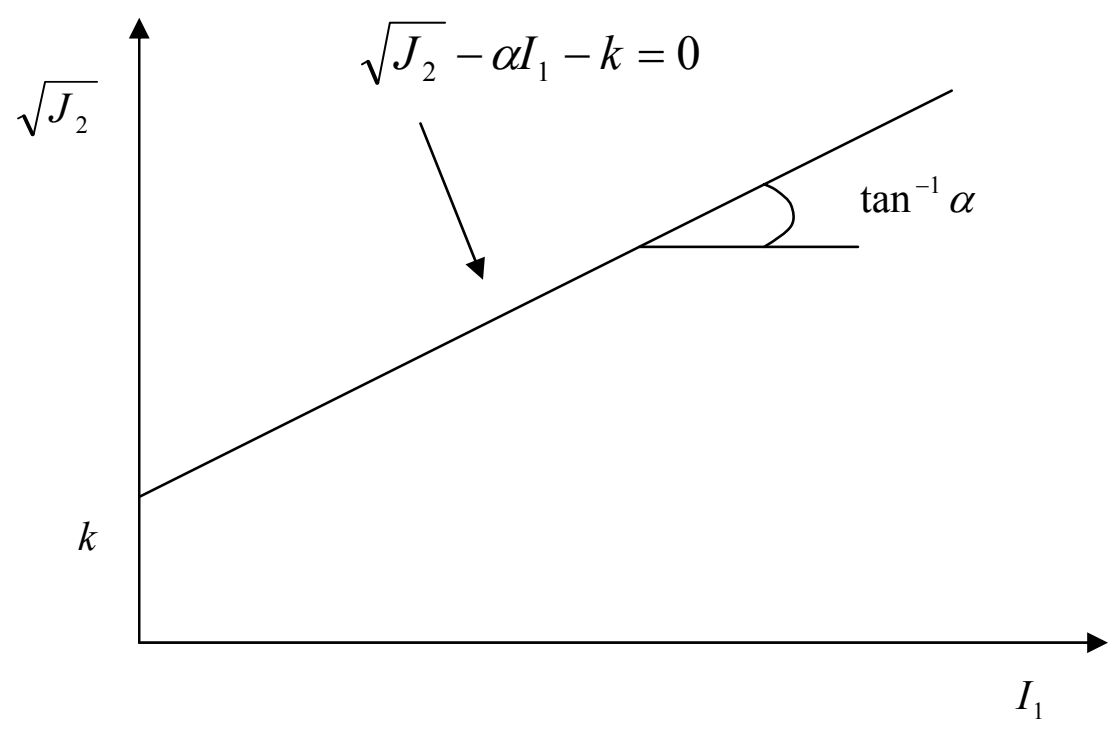

Figure 3.28 Drucker-Prager Model without Cap in the $I_{1}-\sqrt{J_{2}}$ plane 


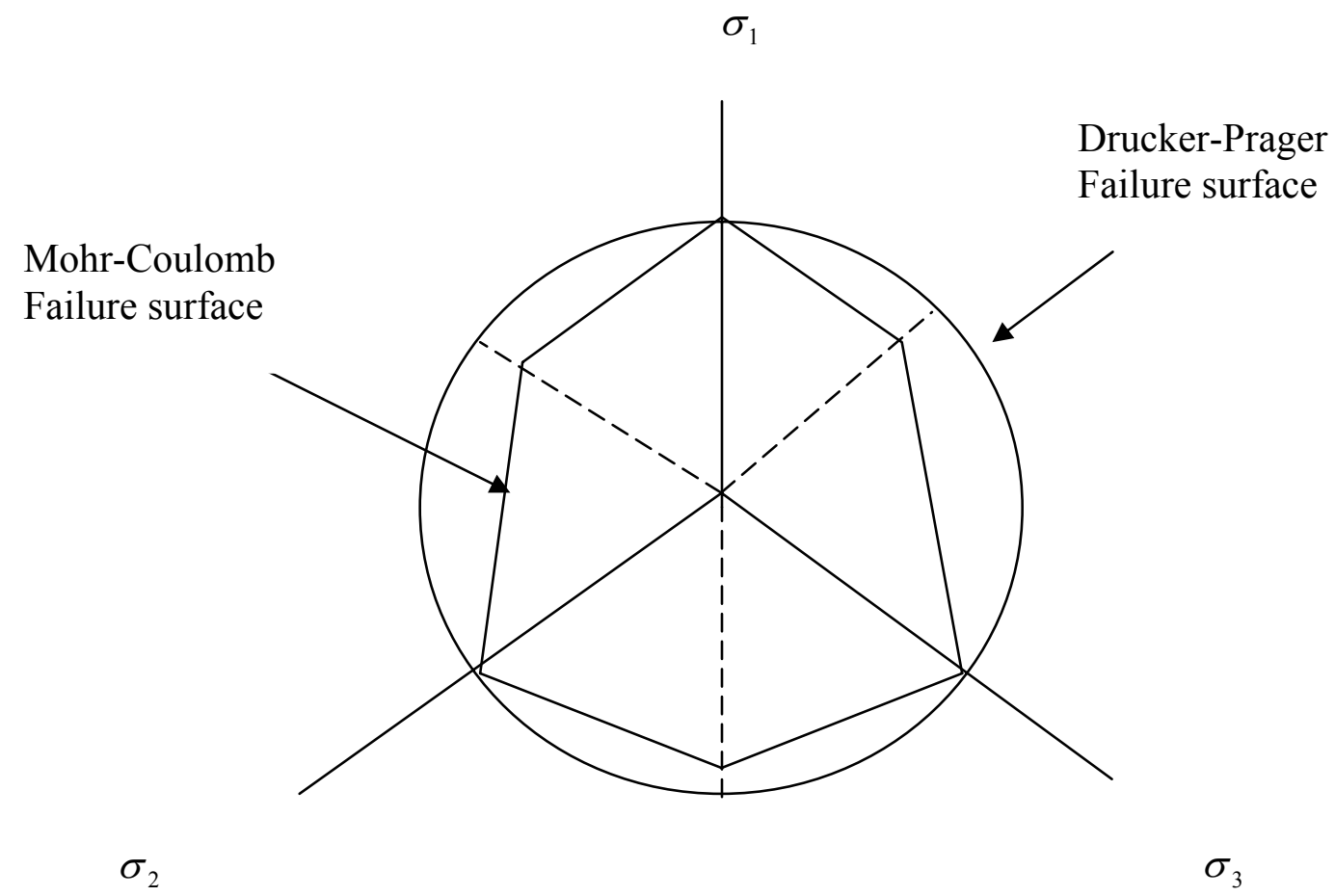

Figure 3.29 Drucker-Prager and Mohr-Coulomb failure criteria in the principal plane

\subsubsection{Drucker-Prager Model with Cap}

The Drucker-Prager Model with Cap consists of a Drucker-Prager shear surface and an elliptical cap positioned symmetrically about the hydrostatic axis at the open end. The cap used with the Drucker-Prager model is elliptical, with equation:

$$
F_{2}=\left(I_{1}-l\right)^{2}+R^{2} J_{2}-(x-l)^{2}=0
$$

where $\mathrm{R}$ is the aspect ratio of the ellipse (ratio of horizontal to vertical axes), $\mathrm{x}$ is a hardening parameter dependent on the plastic volumetric strain, and 1 is the location of the intersection of the Drucker-Prager surface and the cap. In this cap model, the 
intersection point of the shear failure surface and cap plays a role in limiting the shear surface. All loadings with a component normal to the cap will result in plastic contraction, and the cap will expand according to the hardening rule. The cap plays a role related to the role of the preconsolidation pressure in clays. That is why this model was adopted as a constitutive model for representing cohesive soils in this study. Figure 3.30 illustrates the Drucker-Prager model with Cap in the $I_{1}-\sqrt{J_{2}}$ plane.

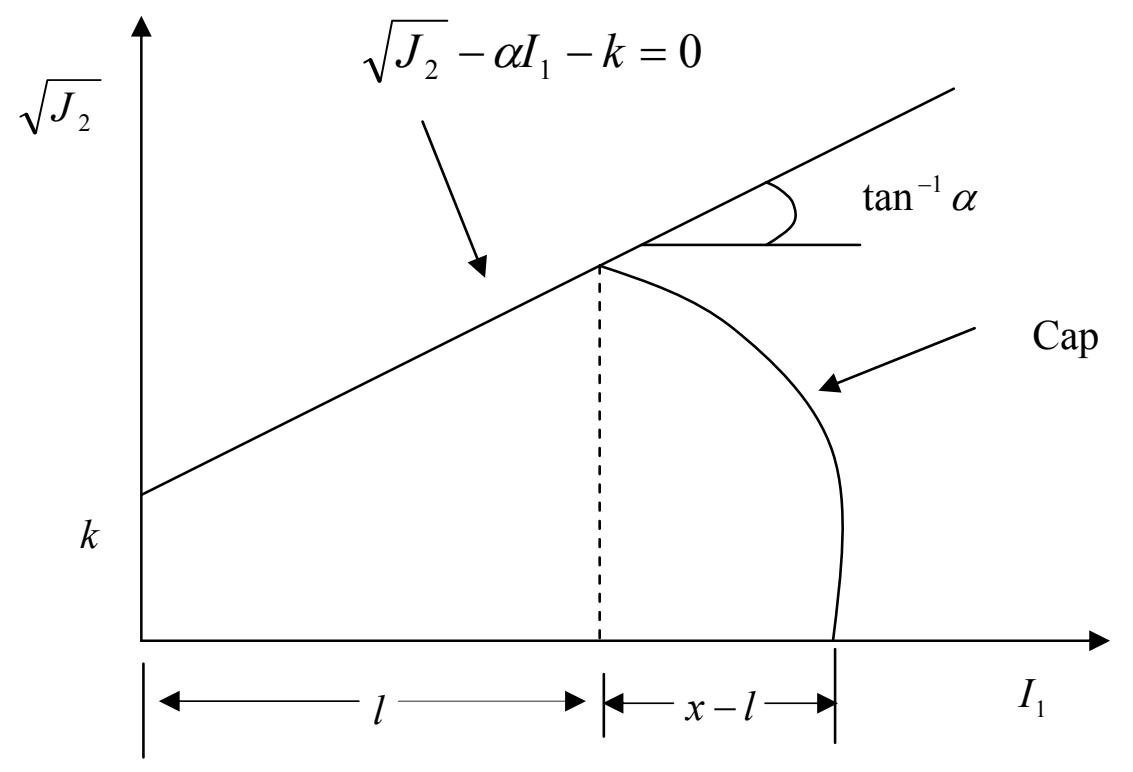

Figure 3.30 Drucker-Prager Model with Cap in the $I_{1}-\sqrt{J_{2}}$ plane

\subsection{Summary}

This chapter discussed the mechanical behavior of subgrade soils in order to reasonably model subgrade soils in the following FE analysis addressed in later chapters. 
The stress tensor of a soil element consists of nine stress components. The invariants can be found using characteristic equations. The linear elastic relationship between the stress tensor and the strain tensor was explained according to the generalized Hooke's law. The definitions of Young's modulus E, Poisson's ratio v, shear modulus G, and bulk modulus $\mathrm{K}$ were reviewed.

The resilient modulus of a cohesive subgrade is affected by all of the following: deviator stress, method of compaction, compaction water content, dry density, thixotropy, degree of saturation, and freeze-thaw. At low levels of repeated deviator stress, the resilient modulus decreases significantly as the deviator stress increases. At greater levels of deviator stress, there is either a smaller decrease, or the resilient modulus reaches constant values. Kneading and impact methods of compaction usually produce a flocculated particle arrangement when compacted dry of optimum and a dispersed arrangement when compacted wet of optimum, while static compaction, at any level of moisture content, generates a flocculated arrangement. The higher the water content and the saturation, the lower the resilient modulus. As the dry density increases, the resilient modulus increases. If highly saturated clays are allowed to rest before tested, they exhibit a significant increase in strength. Several models for the resilient modulus of cohesive subgrade were reviewed.

The resilient modulus of a cohesionless subgrade is related to the following factors: deviator stress, confining pressure, dry density, degree of saturation, aggregate gradation, and method of compaction. As the deviator stress increases, there is a significant decrease of the resilient modulus for specimens compacted below optimum, but not for specimens compacted above optimum. The effect of confining pressure on granular subgrades is 
more pronounced than the effect of the deviator stress. As the confining stress and dry density increase, the resilient modulus increases. For the same level of confining pressure, as the percentage of fines increases, the resilient modulus decreases. The resilient modulus of an impact-compacted specimen is lower than that of a vibratorycompacted one. In addition, some models of the resilient modulus of cohesionless subgrades were presented.

Permanent deformations of cohesionless subgrades are affected by the following factors: stress level, dry unit weight, and moisture content. The level of the deviator stress and the confining pressure of repeated triaxial tests play a significant role in the accumulation of permanent strains under repeated loads. If the stress ratio of the deviator stress to shear strength is high, excessive permanent deformation takes place. As the dry unit weight increases, the permanent strain goes down. Permanent strains are larger for samples compacted above optimum than below optimum. Several models for the permanent strains of cohesionless subgrade were presented.

Permanent deformations of cohesive subgrades are concerned with the following; stress level, stress history, thixotropy, load frequency, moisture content, freeze-thaw, and overconsolidation ratio. The stress level is the most influential factor in the development of permanent deformations of cohesive subgrades. Similar to cohesionless subgrades, if the stress ratio of the deviator stress to shear strength is high, excessive permanent deformation takes place in cohesive subgrades. Specimens with previous stress applications exhibit lower axial permanent strains than specimens that were not previously subjected to stress applications. Permanent strains are significantly lower for samples with a resting period than for samples without it. The higher the frequency of the 
load, the larger the permanent strain is. The higher the OCR, the smaller the strain. Some models to estimate the permanent strains of cohesive subgrade were reviewed.

A failure criterion physically determines if a soil element is in an elastic or plastic state by using a failure or yield surface. If a point representing a stress state of a soil element is inside the yield surface, the soil is said to be elastic and strains are fully recoverable. In contrast, if the point is on the yield surface, the soil is said to be in the plastic state and in part irrecoverable. The flow rule defines the direction and the magnitude of the plastic strain increment vector. The hardening rule can be categorized into isotropic hardening, kinematic hardening and mixed hardening depending on the plastic behavior of the materials. The Drucker-Prager model considers the influence of the intermediate principal stress and is mathematically convenient to use in threedimensional applications due to its smooth failure surface. The cap plays a role related to the role of the preconsolidation pressure in clays.

The mechanical behavior of subgrade soils is influenced by various factors. It might be difficult to represent the behavior of subgrades completely due to such factors. The models to estimate resilient modulus and permanent strain have limitations that apply to all types of subgrades since each of these models is based on a specific soil. Therefore, in the FE analysis that we do later, the the Drucker-Prager model will be used. 


\section{CHAPTER 4 FINITE ELEMENT ANALYSIS}

\subsection{Introduction}

Based on the previous studies on super-single tires and mechanical behavior of subgrades discussed in earlier chapters, the effects of super-single tires on subgrades for typical road cross-sections are investigated using plane-strain (2D) and 3D static and dynamic finite element analysis. Subgrades are treated as both elastic and elastic-plastic materials. Subgrades are modeled as saturated in order to investigate the effects of porewater pressure under the most severe conditions. The analysis focuses on the sand and clay subgrades rather than on asphalt and base layers. In this chapter, the objectives of FE analysis are to evaluate how severe super-single tires are to pavements as compared with conventional dual tires, how much porewater pressure is generated within the subgrade soil by the super-single tire loading and what the consequences of this are, how much permanent deformation is generated, and how the repetitions of super-single tire loadings affect the subgrades. 


\subsection{Modeling of Pavement System}

In this research, a commercial finite element program (ABAQUS) was used to analyze flexible pavement cross-sections subjected to wide base tire loadings. Eightnoded and 20-node quadratic solid elements were used for the plane-strain (2D) and 3D analysis, respectively.

\subsubsection{Typical Cross-sections}

A number of typical cross-sections for Indiana roads were obtained from the Indiana Department of Transportation. As shown in Figure 4.1, four flexible pavement cross-sections were adopted for the analysis. Cross-Section 1 is composed of a Hot Mixed Asphalt Concrete layer (HMA), an aggregate base layer and a subgrade layer from top to bottom. Cross-Section 2 has a HMA base layer instead of the aggregate base layer of cross-section 1 and is a full depth pavement for rural and urban highways. CrossSection 3 consists of a thin asphalt concrete pavement over an aggregate base layer and a subgrade layer. Cross-Section 4 is composed of a thin HMA, a HMA base, an aggregate base and a subgrade layer. All the cross-sections are composed of two traffic lanes and are $13.3 \mathrm{~m}$ wide. The analyses are presented in their entirety for cross-section 1 . Where unique results exist for the other cross-sections, these results are presented as well. 


\section{Cross-Section 1}

\begin{tabular}{c}
\hline HMA (6") \\
\hline Compacted Granular BASE (6.5”) \\
SUBGRADE (24") \\
\hline
\end{tabular}

Cross-Section 2

\begin{tabular}{c}
\hline HMA (6") \\
\hline HMA BASE (6.5") \\
SUBGRADE (24") \\
\hline
\end{tabular}

Figure 4.1 Typical flexible pavement cross-sections (after the Indiana Department of Transportation) 


\section{Cross-Section 3}

\begin{tabular}{c}
\hline HMA (4”) \\
\hline BASE (8.5”) \\
\hline
\end{tabular}

SUBGRADE (24”)

\section{Cross-Section 4}

\begin{tabular}{c}
\hline $\operatorname{HMA}(4 ")$ \\
\hline HMA BASE (2.5”) \\
BASE (6") \\
SUBGRADE (24") \\
\hline
\end{tabular}

Figure 4.1 (continued) Typical flexible pavement cross-sections (after the Indiana Department of Transportation) 


\subsubsection{Geometry and Boundary Conditions}

In finite element analysis, the selection of boundary conditions and mesh size and fineness are important factors for obtaining reasonable results. In the analyses, the effects of these factors were thoroughly investigated both in the plane-strain (2D) and 3D analyses to determine a reasonable depth and width for the Finite Element (FE) model. Model dimensions were chosen such that the vertical displacements on the asphalt surface for either roller or fixed conditions were not affected significantly by increasing the size of the mesh.

As seen in Figure 4.2, it is observed that the deeper the FE model, the larger the vertical displacement, which is an expected consequence due to the accumulation of vertical strains in every element located in vertical direction. This trend was also observed by the study done by Zaghloul and White (1994). They investigated the effects of boundary depths on the vertical displacement of asphalt surfaces. In this investigation, the bottom of the pavement geometry was considered as a bedrock layer in the pavement structure. The deeper the bedrock was, the larger the vertical displacement was in their analysis.

In the $2 \mathrm{D}$ analysis, referring to Figure 4.2 , when the width of the FEM model shown in Figure 4.3(a) was chosen as $13.3 \mathrm{~m}$ (equal to the pavement cross-section width), plane-strain analyses produce displacements of the asphalt surface below the super-single tire that are very different for roller and fixed conditions. An investigation of boundary effects, varying both width and depth of the mesh, showed that when the width of the plane-strain (2D) model shown in Figure 4.3(b) is $53.3 \mathrm{~m}$ (i.e., the pavement crosssection width plus $20 \mathrm{~m}$ on each side) and the depth is $25 \mathrm{~m}$, the effects of boundary 
conditions in the model become quite small, as shown in Figure 4.2. Bedrock was assumed to be $25 \mathrm{~m}$ below the pavement surface.

In the 3D analysis, a model was first made with the $53.3 \mathrm{~m}$ width and $25 \mathrm{~m}$ depth obtained from the plane-strain (2D) boundary investigation using infinite elements. Several trials suggested that the model with $13.3 \mathrm{~m}$ width (i.e., width equal to the pavement cross-section width) and $7 \mathrm{~m}$ depth produced almost identical results to the model, so long as infinite elements are used. Analyses varying both the width and the depth of the mesh indicate that the results are much more affected by boundary proximity for plane-strain (2D) conditions than for 3D conditions. Figures 4.3(b) and 4.3(c) show typical plane-strain (2D) and 3D finite element geometries used in the FE analyses. 


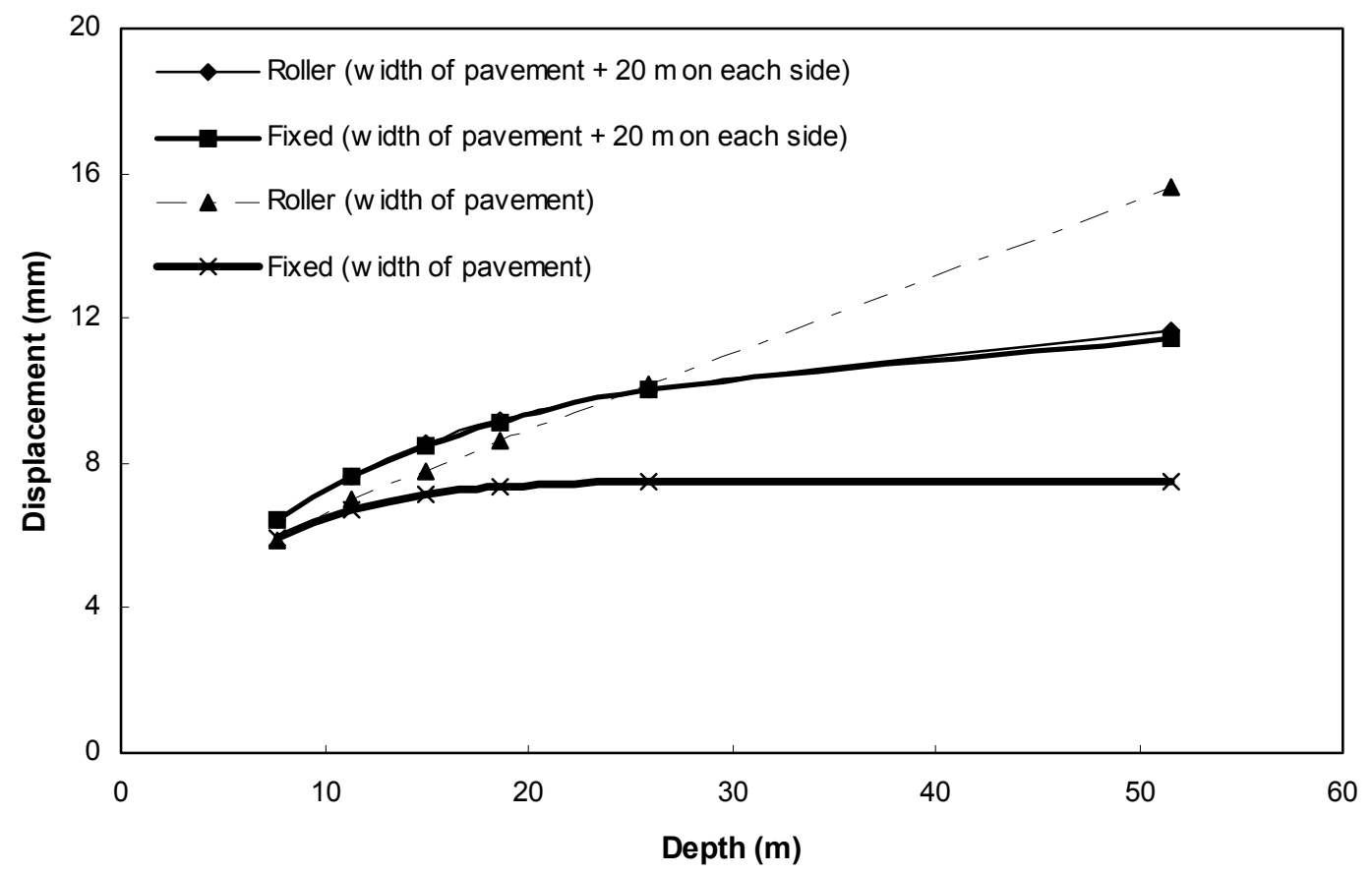

Figure 4.2 The effect of boundary depth and width in plane-strain (2D) analysis 


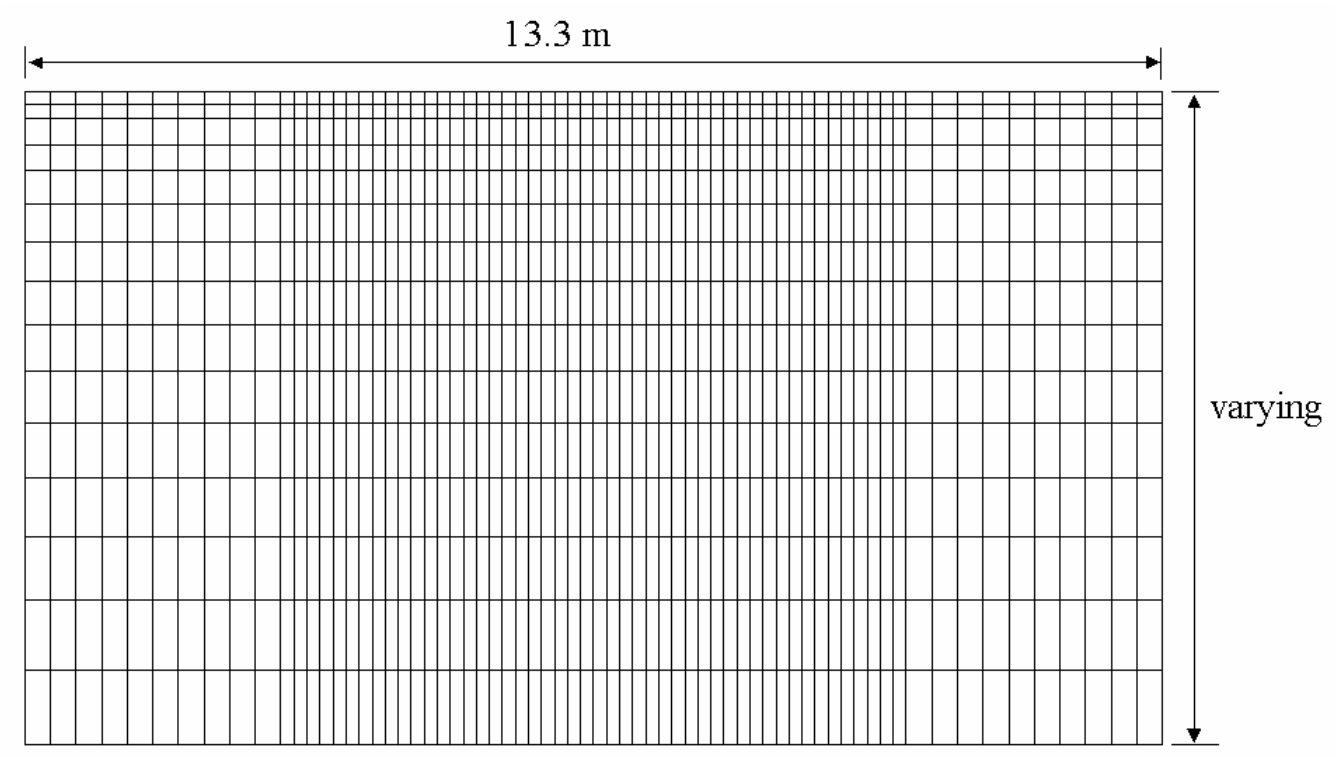

(a)

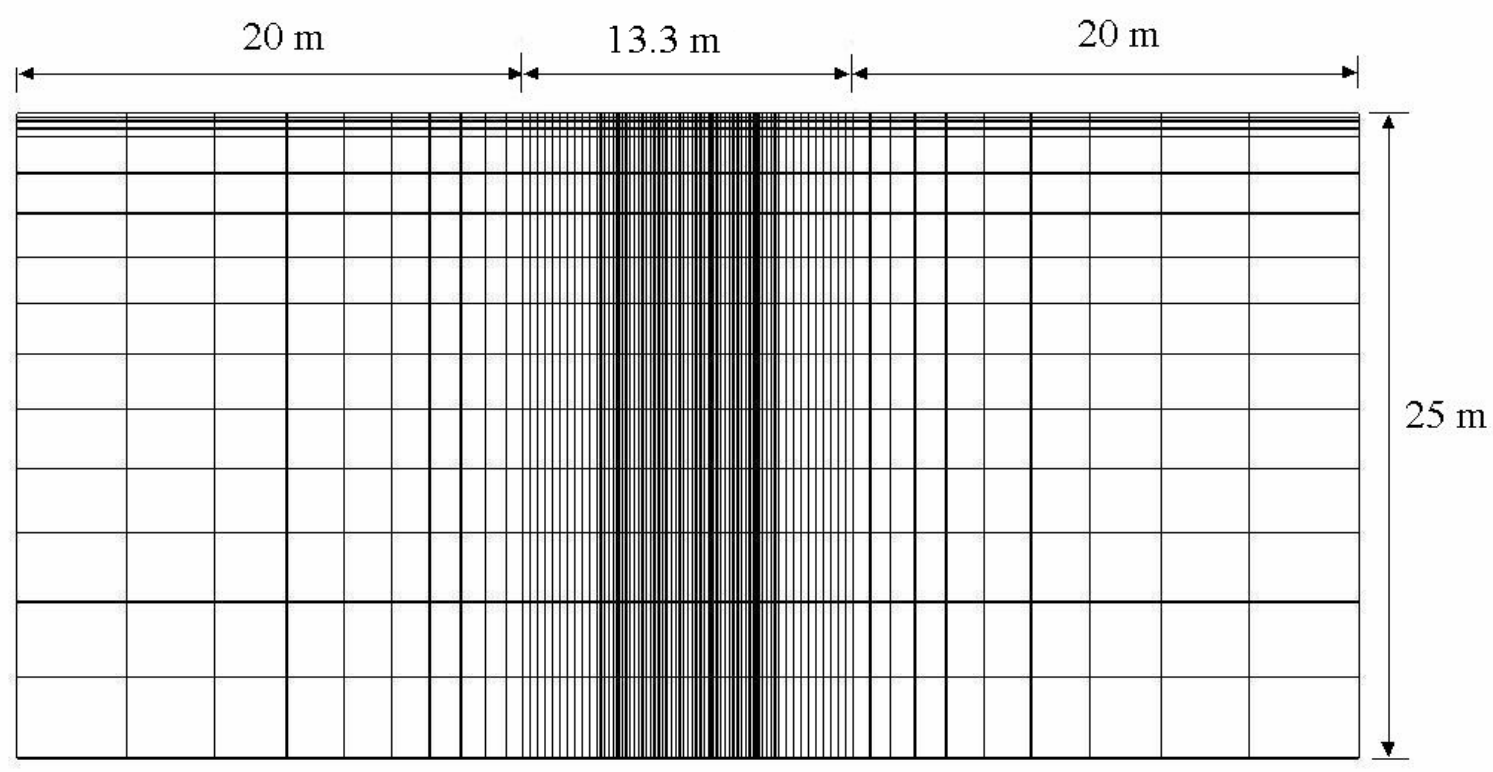

(b) 


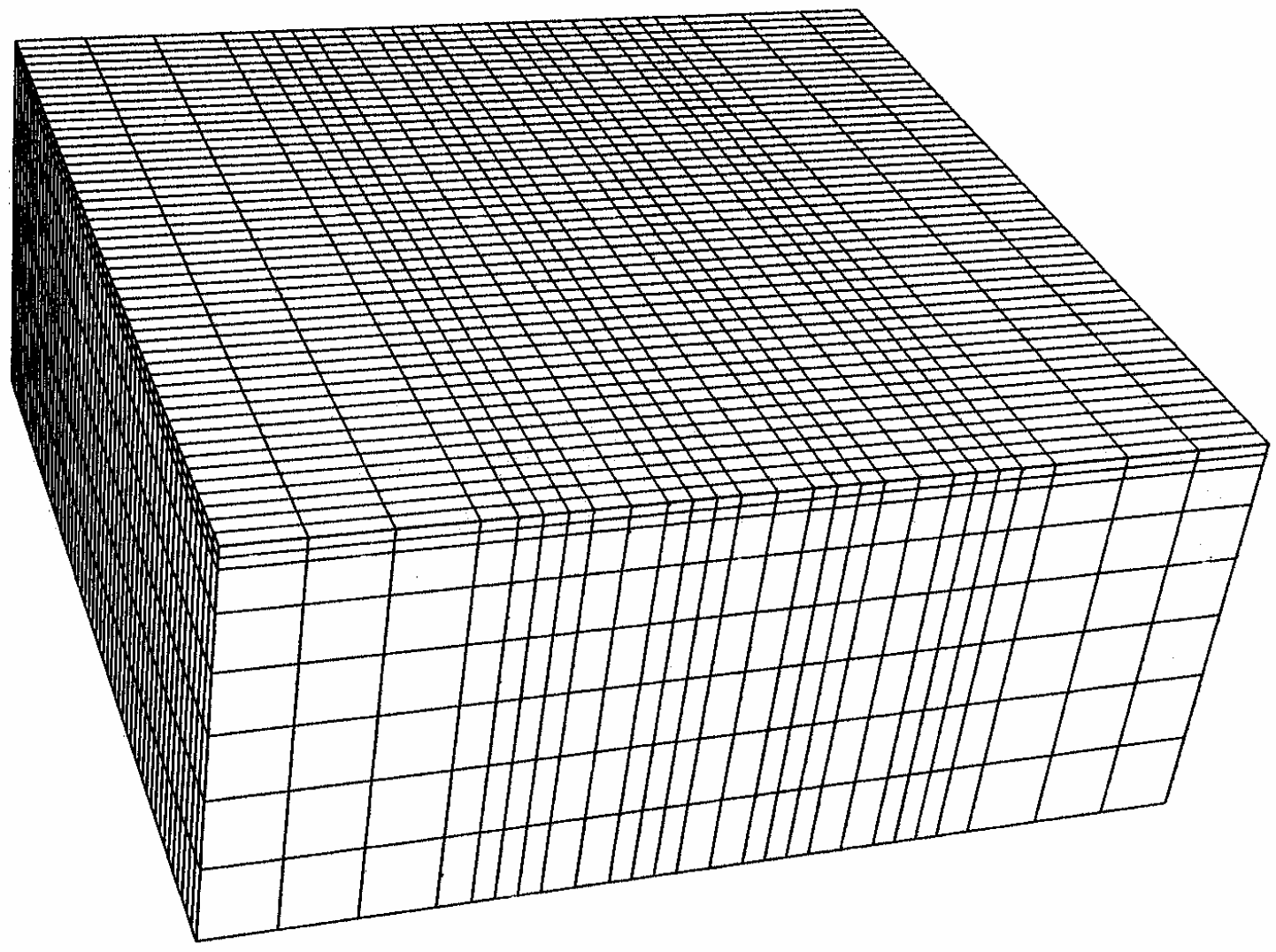

(c)

Figure 4.3 (a) plane-strain (2D) geometry with the cross-section width and typical (b) plane-strain (2D) and (c) 3D finite element geometries 


\subsubsection{Implication of the Nonuniform Contact Stresses Observed for Super-Single Tires}

\subsubsection{Contact Stress in Pavement Design}

The contact stresses of truck tires in pavement design and analysis have mostly been approximated to be a uniform contact stress equal to the inflation pressure, even though it has already been acknowledged that in reality, the contact stresses of tires are nonuniform due to the inclined road surface and the structural characteristic of tires. Multi-layered elastic theory assumes that the contact stress is only composed of a uniform circular vertical stress equal to the tire inflation pressure of tires. Most pavement design methods are also based on the same assumption, and do not account for other contact stress components such as transverse and longitudinal shear stresses. However, recent research done by De Beer et al. (1997), Tielking ( 1994), Meyer et al. (1999), Sebbaly (1989) indicate that super-single tires induce nonuniform contact stresses on a pavement surface layer. Therefore, consideration of the contact stress distribution will be important in analysis.

\subsubsection{Equivalent Nodal Force in FEM}

Since recent research has given insight into the contact stress distribution of supersingle tires, their effects can be investigated. In this section, the implication of contact stress distribution of super-single tires is investigated using finite element modeling. In the finite element method, equivalent nodal forces corresponding to the distributed loads applied to an element can be formulated as follows:

$$
F=\int_{V} N^{T} \Phi d V+\int_{S} N^{T} T d S+N^{T} P
$$


where $\mathrm{N}=$ shape function, $\Phi=$ body force, $\mathrm{T}=$ surface traction, and $\mathrm{P}=$ concentrated load, respectively. The equivalent nodal force formulation is based on the requirement that the work done by the nodal forces $\mathrm{F}$ for given nodal displacements $\mathrm{d}$ be equal to the work done by the distributed loads $\Phi$ and $\mathrm{T}$ for the displacement field related to $\mathrm{d}$ through the shape functions $\mathrm{N}$ (Cook et al. 1989).

It is useful to first examine a two dimensional eight node solid element in which traction is only applied on top of the element. Figures 4.4 and 4.5 are examples of a distributed load and associated equivalent nodal forces in a two dimensional solid element. As seen in Figure 4.4, the traction force is acting vertically on the element. Thus, in this case, neglecting body force, equation (4.1) is simplified to

$$
F=\int_{S} N^{T} T d S=\int_{-l / 2}^{l / 2} N^{T} w d S
$$

where:

$$
\begin{aligned}
& N_{1}=\frac{2 x^{2}}{l^{2}}-\frac{x}{l} \\
& N_{2}=\frac{2 x^{2}}{l^{2}}+\frac{x}{l} \\
& N_{3}=1-\frac{4 x^{2}}{l}
\end{aligned}
$$




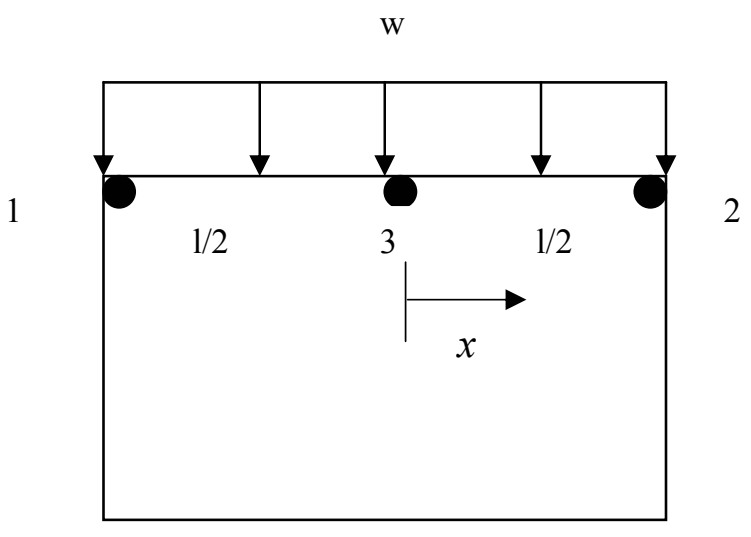

Figure 4.4 Uniform vertical contact stress in one 2D eight-node element

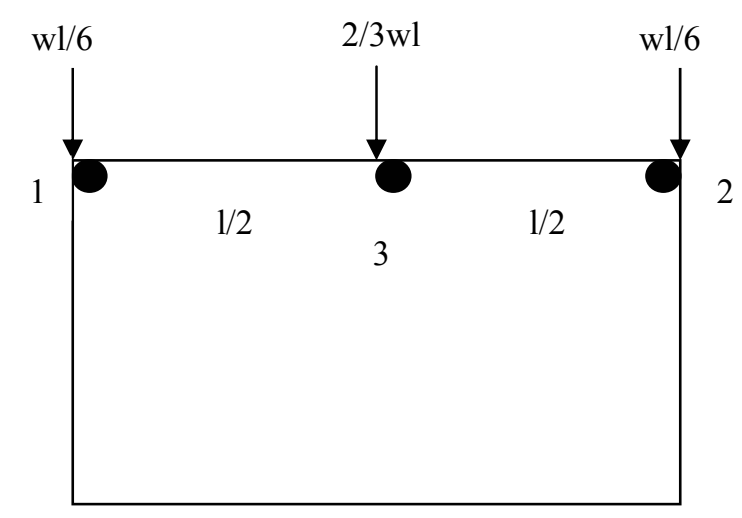

Figure 4.5 Equivalent nodal forces in one 2D eight-node element

For a three-dimensional element, Figures 4.6 and 4.7 illustrate the uniform vertical stress and corresponding equivalent nodal forces. The next step is to expand the concept of the equivalent nodal force to a nonuniform contact stress. Figure 4.8 illustrates the typical configuration of nonuniform vertical contact stresses for a super-single tire. 
Figure 4.7 shows the corresponding equivalent nodal forces in the $\xi-\eta$ coordinate system shown in Figure 4.9, where $\xi$ and $\eta$ are the transformed coordinates that are determined by the mapping from $\mathrm{x}$ and $\mathrm{y}(-1 \leq \xi \leq 1,-1 \leq \eta \leq 1)$. Only if traction forces or vertical contact stresses as shown in Figure 4.8 are applied to a three dimensional quadratic 20-node element in a nonuniform configuration, can the equation (4.1) be written as follows.

$$
F=\int_{-1}^{1} \int_{-1}^{1} N^{T} w 1 d \xi d \eta+\int_{-1}^{1} \int_{-1}^{1} N^{T} w 2 d \xi d \eta+\int_{-1}^{1} \int_{-1}^{1} N^{T} w 3 d \xi d \eta
$$

where:

$$
\begin{aligned}
& N_{1}=\frac{1}{4}(1-\xi)(1-\eta)-\frac{1}{2}\left(N_{8}+N_{5}\right) \\
& N_{2}=\frac{1}{4}(1+\xi)(1-\eta)-\frac{1}{2}\left(N_{5}+N_{6}\right) \\
& N_{3}=\frac{1}{4}(1+\xi)(1+\eta)-\frac{1}{2}\left(N_{6}+N_{7}\right) \\
& N_{4}=\frac{1}{4}(1-\xi)(1+\eta)-\frac{1}{2}\left(N_{7}+N_{8}\right) \\
& N_{5}=\frac{1}{2}\left(1-\xi^{2}\right)(1-\eta) \\
& N_{6}=\frac{1}{2}(1+\xi)\left(1-\eta^{2}\right) \\
& N_{7}=\frac{1}{2}\left(1-\xi^{2}\right)(1+\eta) \\
& N_{8}=\frac{1}{2}(1-\xi)\left(1-\eta^{2}\right)
\end{aligned}
$$




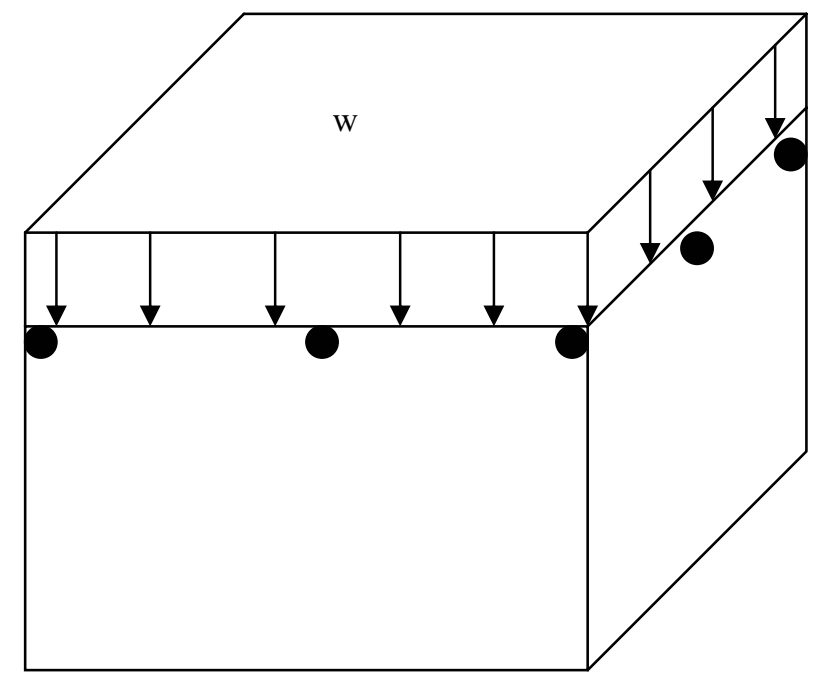

Figure 4.6 Uniform vertical stress in one 3D 20-node element

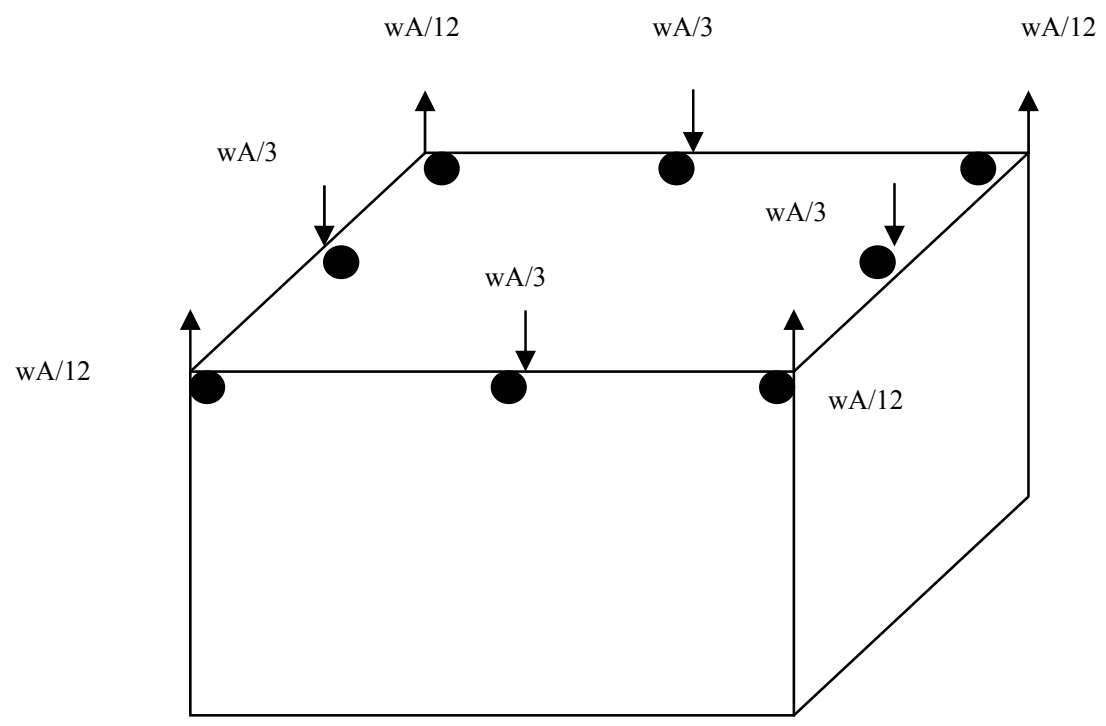

Figure 4.7 Equivalent nodal force in one 3D 20-node element 


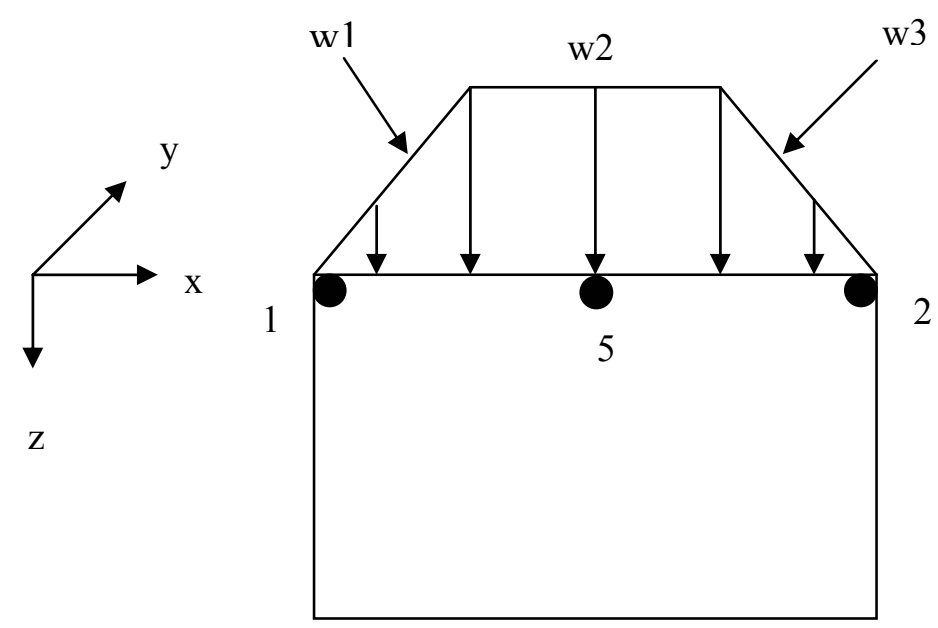

Figure 4.8 Nonuniform contact stress in $\mathrm{x}-\mathrm{z}$ plane

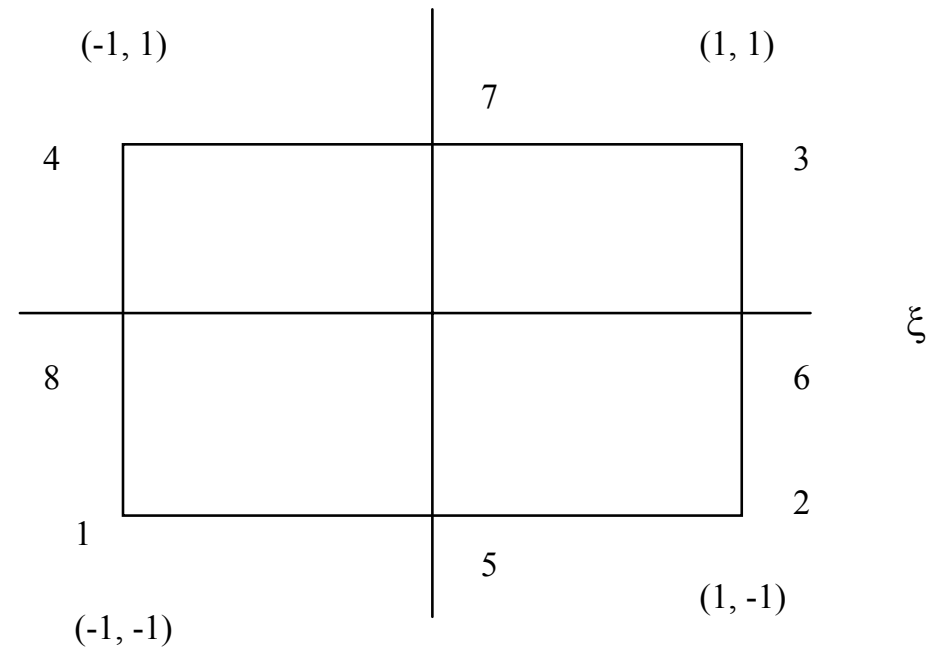

Figure $4.9 \xi-\eta$ Coordinate system 


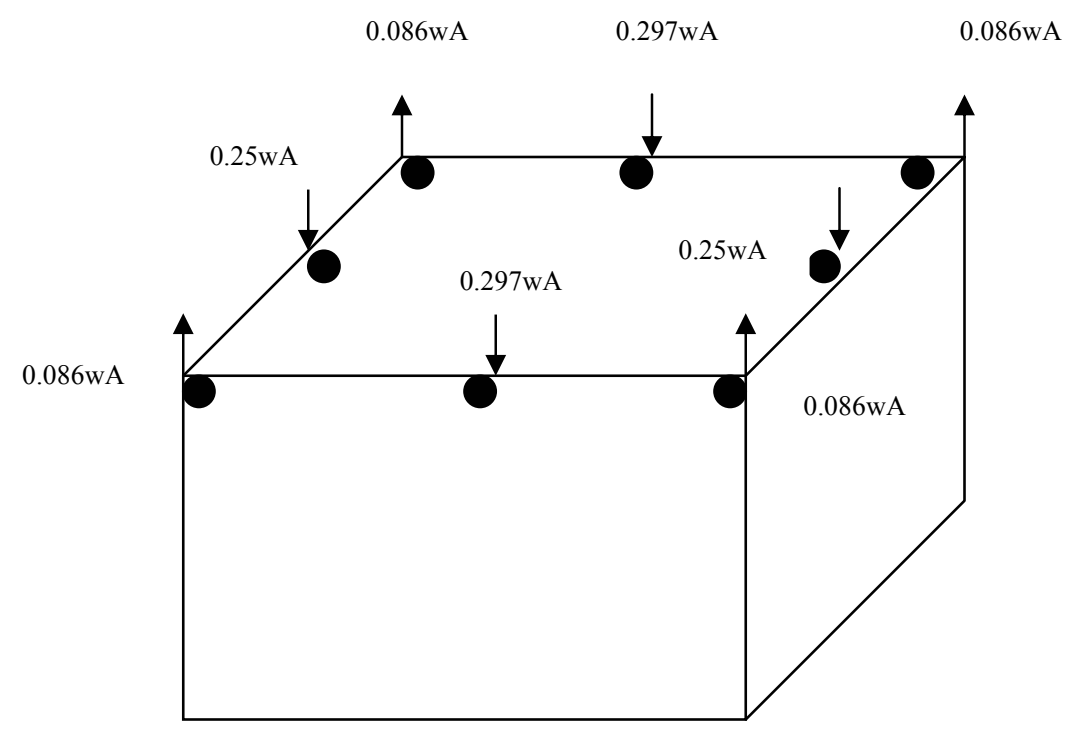

Figure 4.10 Equivalent nodal forces corresponding to nonuniform vertical stresses in one3D element

As seen from Figures $4.4-4.10$, any contact stress distributions can be expressed using equivalent nodal force formulation in FEM.

\subsubsection{Possible Contact Stress Distribution of Super-Single Tires}

As mentioned previously, the tire loading imposes vertical, transverse and longitudinal stresses on top of the pavement. A few analytical studies have accounted for the variation of normal and shear contact stress within the loaded area in the estimation of horizontal strain (Tielking and Roberts 1994, Perdomo and Nokes 1993). The study of Perdomo and Nokes showed that inclusion of contact shear stresses is very important. They computed an increase in horizontal strain by a factor as large as 6 when contact shear stresses are considered. However, Siddaharthan et al. (1998) argued that Perdomo 
and Nokes used circular loaded areas and a contact stress distribution that conformed to radial symmetry. The loaded area and contact stress distribution associated with widebase tires do not conform to the load description used by Perdomo and Nokes. Secondly, Perdomo and Nokes applied a substantially higher radial shear stress distribution in which the maximum radial shear stress was as much as $56 \%$ of the maximum normal stress. In contrast, the maximum longitudinal and transverse shear stresses used in the Siddaharthan et al. (1998) study were only 12 and 16\% of the maximum normal stress, based on the data obtained by De Beer et al. (1997). According to Siddaharthan et al. (1998), it is believed that the shear stress distribution adopted in their study is more realistic, as it is based on comprehensive field measurements made by the Council of Scientific and Industrial Research using state of the art technology. Siddharthan et al. (1998) reported that the impact of contact shear stresses on tensile strains at the bottom of the asphalt layer were insignificant. Accordingly, in the FE analysis presented here, transverse and longitudinal shear stress components are neglected.

It is worth noting that the contact stresses of tires are dependent on the tire types (Weissman 1993, Tielking 1994). In order to account for various possible contact stress distributions of super-single tires, several linear elastic analyses assuming typical parameters were done to assess the contact stress distributions that would be most adverse to the performance of the pavement system. In these analyses, as mentioned before, the tire load, inflation pressure, maximum vertical contact stress obtained from the equation (2.12), and the ratio of the contact area are 11,400 lbs, 125 psi, 233 psi, and $1: 0.85$, respectively. Note that the total tire load and the maximum vertical contact stress 
remain the same in all the cases; only contact areas and stress distributions used in the FEM change in each case.

\subsubsection{Interpretation of Effects of Possible Contact Stress Distributions}

The six distributions considered for super-single tires are the following.

- Uniform (square): uniform contact stress equal to the inflation pressure over the square contact area (width and length $=24.26 \mathrm{~cm}$ );

- Uniform (equivalent): uniform contact stress equal to the inflation pressure over the equivalent contact area (width $=20.13 \mathrm{~cm}$, length $=29.23 \mathrm{~cm}$ ) obtained from $(2.12)$ (see Figure 2.5(right));

- Uniform (maximum): uniform contact stress equal to the maximum vertical contact stress over the contact area with the ratio 1:0.85 (width $=19.27 \mathrm{~cm}$, length $=16.38 \mathrm{~cm}$ );

- Trapezoidal (10\%): trapezoidal contact stress shape with the maximum vertical contact stress acting on the middle $10 \%$ of the contact area with the ratio $1: 0.85$ (width $=25.98$ $\mathrm{cm}$, length $=22.09 \mathrm{~cm}$ ). This means the smaller base of the trapezoid is only $10 \%$ of the larger base (see Figure 4.8);

- Trapezoidal (30\%): trapezoidal contact stress shape with the maximum vertical contact stress acting on the middle $30 \%$ of the contact area with the ratio $1: 0.85$ (width $=23.90$ $\mathrm{cm}$, length $=20.32 \mathrm{~cm})($ see Figure 4.8$)$;

- Trapezoidal (50\%): trapezoidal contact stress shape with the maximum vertical contact stress acting on the middle $50 \%$ of the contact area with the ratio 1:0.85 (width $=22.25$ $\mathrm{cm}$, length $=18.91 \mathrm{~cm})($ see Figure 4.8$)$; 
Figures $4.11-4.13$ show the vertical displacements and vertical strains on top of the subgrade and the horizontal strains at the bottom of the asphalt layer induced by the various shapes of contact stress distributions. A comparison of the uniform (square) case with the uniform (equivalent) case shows a very slight difference in vertical and horizontal strains. It is also seen in Figure 4.12 that the smallest vertical strain is observed in the case of the uniform (equivalent) case. These results suggest that current pavement design methods assuming the contact stress equal to the inflation pressure, and using the uniform circular type of contact stress, appear to be unconservative for pavement systems subjected to super-single tire loadings. The largest vertical strain occurs in the case of the uniform (maximum) case, which is only slightly larger than that resulting from the trapezoidal (30\%) case.

Conventional dual tires typically induce the maximum horizontal strain at the bottom of the asphalt layer in the longitudinal direction (Siddharthan and Sebaaly 1998). However, it is worth noting that, except for the uniform (square) case and the uniform (equivalent) case, the maximum horizontal strains occurred in the transverse direction. This indicates that the maximum horizontal strain may be related to the shape of the contact area of a tire. As Siddharthan and Sebaaly (1998) indicated, this would imply that wider tires initiate fatigue cracking in the longitudinal direction.

As seen in Figures 4.12 and 4.13, the greatest vertical and horizontal strains are not generated for the trapezoidal cases but for the uniform distribution with stress equal to the maximum vertical stress. This implies that, as the maximum vertical contact stresses act on a larger portion of the contact area, higher strains occur in the pavement layers. Therefore, an analysis that considers the uniform maximum vertical contact stress can be 
conservative for the increased contact stresses of super-single tires. Based on this condition, the uniform maximum vertical contact stress is used as the contact stress for super-single tires in the following FE analysis.

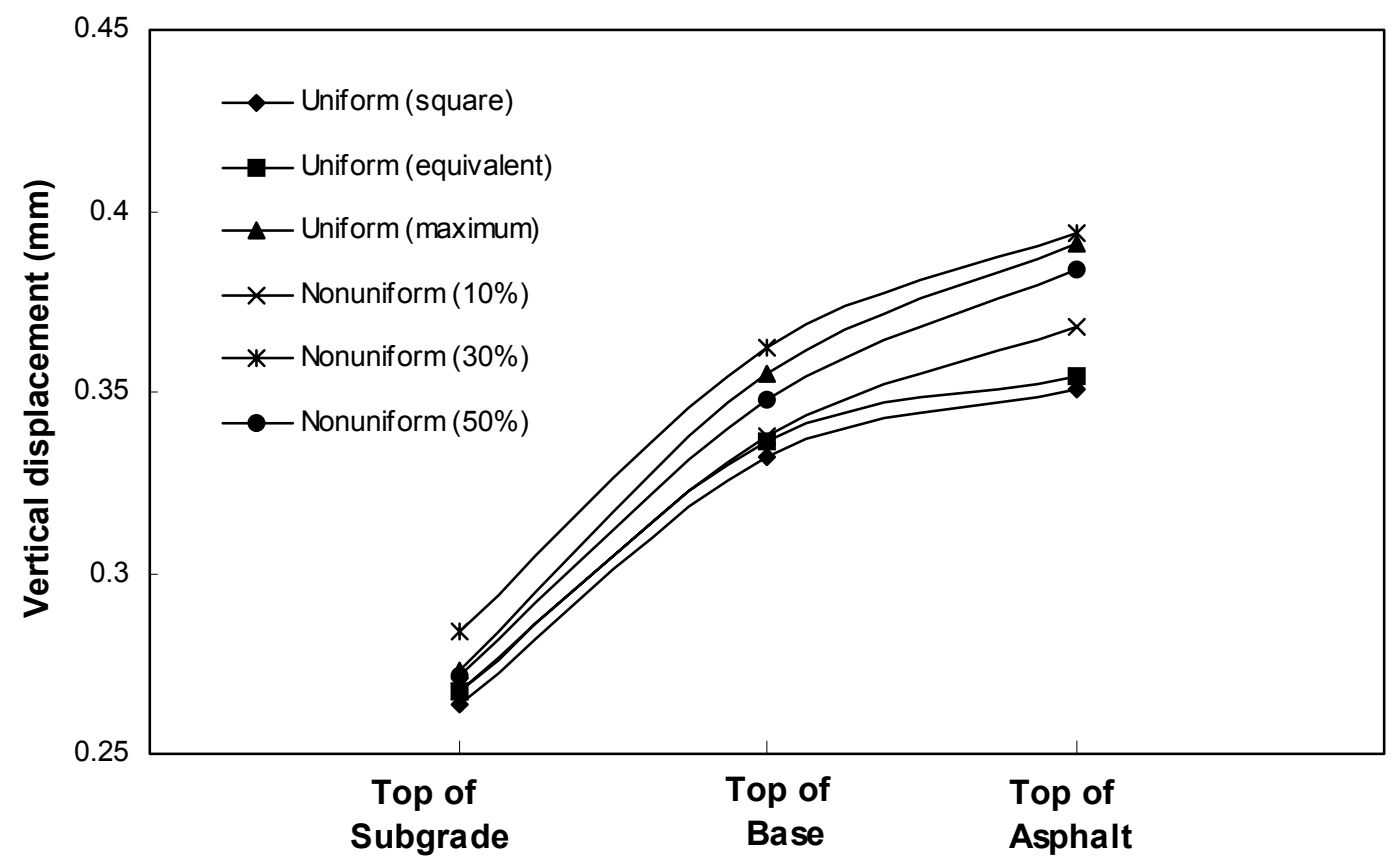

Figure 4.11 Vertical displacements of various contact stresses 


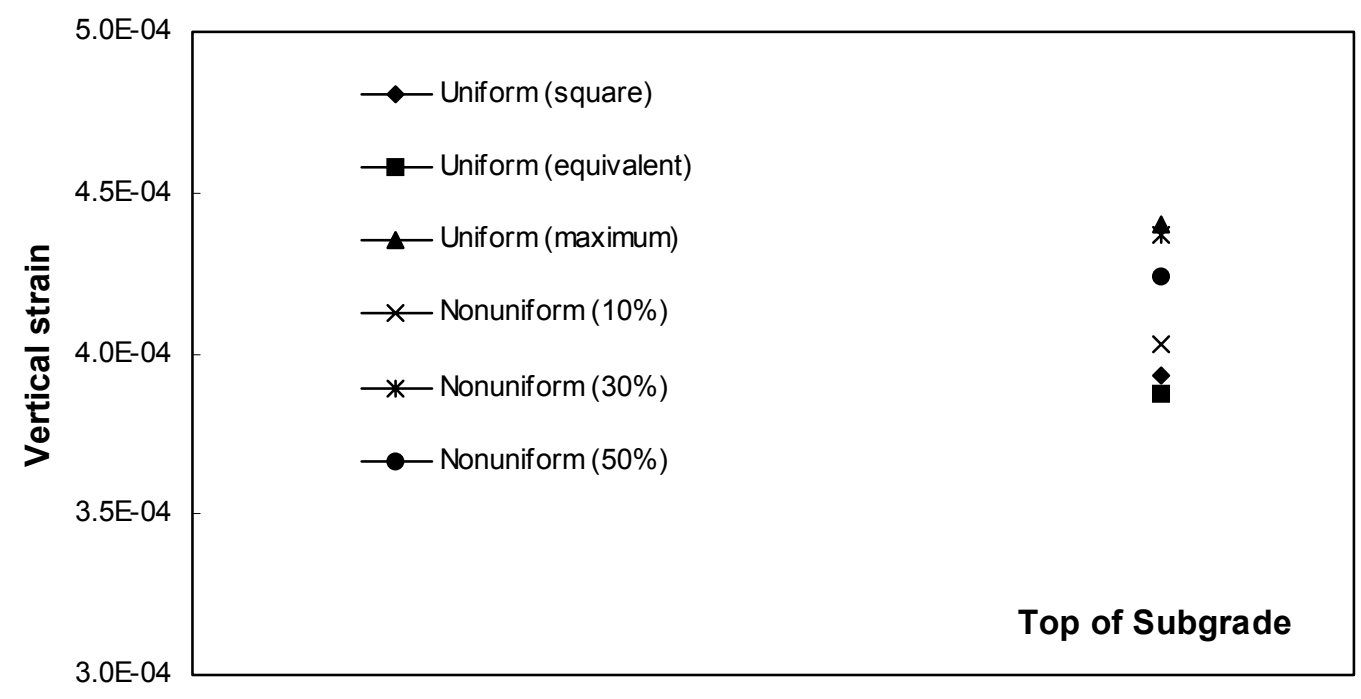

Figure 4.12 Vertical strains of various contact stresses on top of the subgrade layer

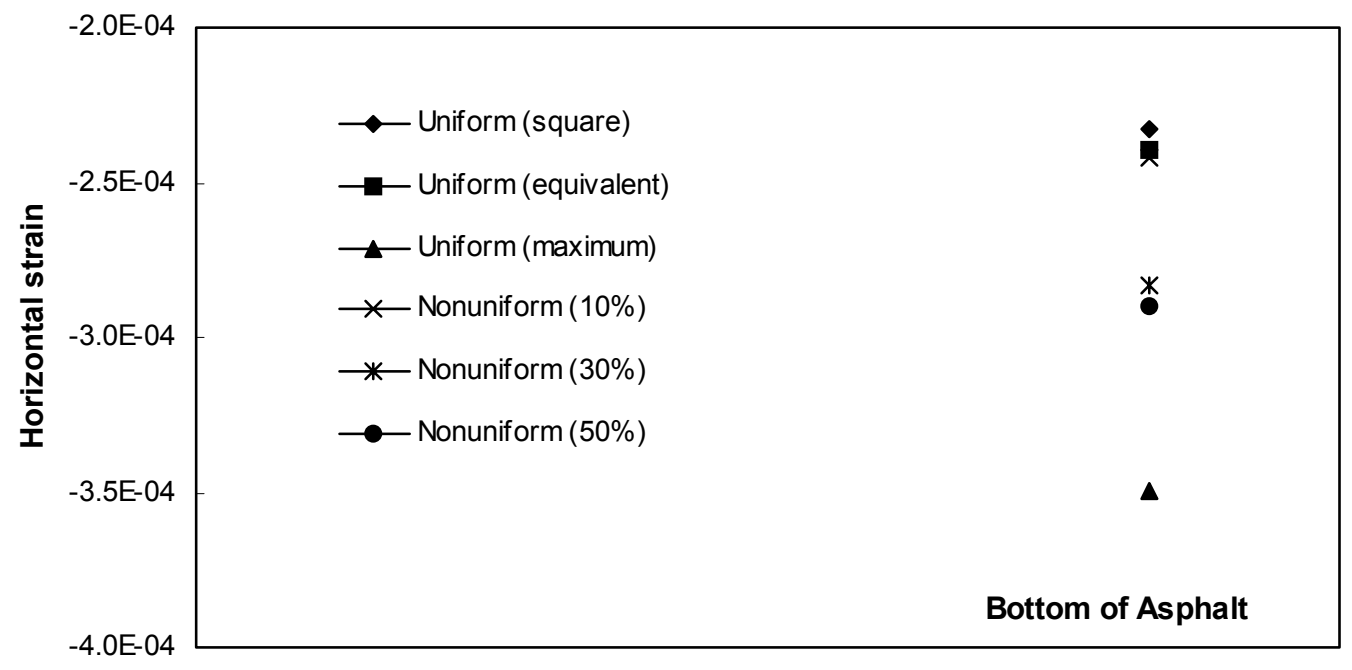

Figure 4.13 Horizontal strains of various contact stresses at the bottom of the asphalt layer 


\subsection{Analysis Parameters used in FEM}

The first step in performing the analysis was to select reasonable values for the mechanical parameters of each layer. For the asphalt and base layers, the values of Young's modulus of Zaghloul and White (1994) and Poisson's ratio values obtained from Jaky's equation were used (see Table 4.1). The shear strength parameters $\mathrm{c}$ and $\phi$ for the asphalt layer were taken from the results obtained by Goetz (1957). Values of $\mathrm{c}$ and $\phi$ for the base layer were taken from typical values reported by Zaghloul and White (1994). The values of Feng (1999) for Young's modulus, c and $\phi$ were used for the HMA base layer. The values of $\mathrm{K}_{0}$ were determined using $K_{0}(N C)=1-\sin \phi^{\prime}$ (Jaky's equation), and the value of $v^{\prime}$ was found from $v^{\prime}=\frac{K_{0}}{1+K_{0}}$. Finally, assuming a value for $\mathrm{E}^{\prime}$ for the asphalt layer or base layer, values for $\mathrm{G}^{\prime}$ or $\mathrm{G}_{\mathrm{u}}$ can be found using

$$
\begin{gathered}
G^{\prime}=\frac{E^{\prime}}{2\left(1+v^{\prime}\right)} \text { for drained } \\
\text { and } \\
G_{u}=\frac{E_{u}}{2\left(1+v_{u}\right)} \quad \text { for undrained loading }
\end{gathered}
$$

For undrained conditions, because $\mathrm{G}_{\mathrm{u}}=\mathrm{G}^{\prime}$ and $v_{u}=0.5$, Young's modulus is given by:

$$
E_{u}=\frac{3 E^{\prime}}{2\left(1+v^{\prime}\right)}
$$

For a sand subgrade, in order to estimate shear modulus more realistically, the properties of Ticino sand (Salgado 1993, Salgado et al. 1999) were used, and Young's modulus was calculated using eqs. (4.5) and (4.6). The shear modulus was calculated using the empirical equation of Hardin and Black (1968). 


$$
\frac{G_{0}}{p_{a}}=C_{g} \frac{\left(e_{g}-e_{0}\right)^{2}}{1+e_{0}}\left(\frac{\sigma_{m}^{\prime}}{p_{a}}\right)^{n_{g}}
$$

where $\mathrm{C}_{\mathrm{g}}, \mathrm{e}_{\mathrm{g}}$, and $\mathrm{n}_{\mathrm{g}}=$ material constants that depend only on the nature of the soil; $\mathrm{e}_{0}=$ initial void ratio; $\mathrm{p}_{\mathrm{a}}=$ reference pressure $=100 \mathrm{kpa} \approx 1 \mathrm{kgf} / \mathrm{cm}^{2} \approx 2000 \mathrm{psf} \approx 14.5 \mathrm{psi}$; and $\sigma_{\mathrm{m}}^{\prime}=$ initial mean effective stress in the same unit as $\mathrm{p}_{\mathrm{a}}$.

For a clay subgrade, the shear modulus was calculated using the equation of Hardin and Drnevich (1972), which takes into account the overconsolidation ratio of the clay. Their empirical equation is given by:

$$
\frac{G_{0}}{p_{a}}=323 \frac{\left(2.973-e_{0}\right)^{2}}{\left(1+e_{0}\right)}(\text { OCR })^{k}\left(\frac{\sigma_{m}^{\prime}}{p_{a}}\right)^{n_{g}}
$$

where $\mathrm{k}$ depends on the plasticity index (PI).

The analyses in this study were done in terms of small-strain values. This allows the analyses to retain consistency throughout, but leads to subgrade deformations that are slightly less than would be observed if modulus degradation were allowed, particularly where purely elastic analyses were done.

The $\mathrm{K}_{0}$ of overconsolidated soil was calculated using:

$$
K_{0}(O C)=K_{0}(N C) \sqrt{O C R}
$$

The undrained shear strength $\left(\mathrm{s}_{\mathrm{u}}\right)$ was estimated using the following relationship (Wroth 1984):

$$
\frac{s_{u}}{\sigma_{v}^{\prime}}=\frac{\phi^{\prime}}{100}=0.28
$$

for a $\phi^{\prime}$ of $28^{\circ}$. 
The undrained shear strength of OC clays was estimated using the following correlation suggested by Ladd et al. (1977).

$$
\frac{\left(\frac{S_{u}}{\sigma_{v}^{\prime}}\right)_{O C}}{\left(\frac{S_{u}}{\sigma_{v}^{\prime}}\right)_{N C}}=O C R^{0.8}
$$

Tables 4.1 and 4.2 represent the material parameters used in the FE analysis.

Table 4.1 Material parameters for asphalt and base layers

\begin{tabular}{|c|c|c|c|c|c|c|c|c|}
\hline \multirow{2}{*}{ Material } & \multicolumn{2}{|c|}{ Young's Modulus } & \multicolumn{2}{c|}{$\begin{array}{c}\text { Poisson's } \\
\text { Ratio }\end{array}$} & \multicolumn{2}{c|}{ Cohesion } & \multicolumn{2}{c|}{ Friction Angle } \\
\cline { 2 - 9 } & $\begin{array}{c}E^{\prime} \\
(\mathrm{kPa})\end{array}$ & $\begin{array}{c}E_{u} \\
(\mathrm{kPa})\end{array}$ & $v^{\prime}$ & $v_{u}$ & $\begin{array}{c}\mathrm{c}^{\prime} \\
(\mathrm{kPa})\end{array}$ & $\begin{array}{c}\mathrm{c}_{\mathrm{u}} \\
(\mathrm{kPa})\end{array}$ & $\begin{array}{c}\phi^{\prime} \\
(\mathrm{Deg})\end{array}$ & $\begin{array}{c}\phi_{\mathrm{u}} \\
(\mathrm{Deg})\end{array}$ \\
\hline $\begin{array}{c}\text { Asphalt } \\
\text { layer }\end{array}$ & $2,068,000$ & $2,068,000$ & 0.32 & 0.32 & 207 & 207 & 32.5 & 32.5 \\
\hline $\begin{array}{c}\text { HMA } \\
\text { Base }\end{array}$ & 222,600 & 270,000 & 0.32 & 0.499 & 90 & 90 & 50 & 50 \\
\hline $\begin{array}{c}\text { Base } \\
\text { layer }\end{array}$ & 344,000 & 404,000 & 0.28 & 0.499 & 0.1 & 0.1 & 38 & 38 \\
\hline
\end{tabular}


Table 4.2 Material parameters for sand and clay layers

\begin{tabular}{|c|c|c|c|c|c|c|c|c|}
\hline Material & \multicolumn{2}{|c|}{ Young's Modulus } & \multicolumn{2}{|c|}{ Poisson's Ratio } & \multicolumn{2}{c|}{ Cohesion } & \multicolumn{2}{c|}{ Friction Angle } \\
\hline & $E^{\prime}(\mathrm{kPa})$ & $E_{u}(\mathrm{kPa})$ & $v^{\prime}$ & $v_{u}$ & $\mathrm{c}^{\prime}(\mathrm{kPa})$ & $\mathrm{c}_{\mathrm{u}}(\mathrm{kPa})$ & $\phi^{\prime}(\mathrm{Deg})$ & $\phi_{\mathrm{u}}(\mathrm{Deg})$ \\
\hline Sand & 173,000 & 198,000 & 0.31 & 0.499 & 0.1 & 0.1 & 33 & 33 \\
\hline Clay (NC) & 60,000 & 66,000 & 0.35 & 0.499 & 2.6 & 6 & 13 & 0 \\
\hline Clay (OCR = 3) & 103,000 & 114,000 & 0.35 & 0.499 & 8.4 & 14 & 13 & 0 \\
\hline Clay (OCR = 5) & 134,000 & 148,000 & 0.35 & 0.499 & 12.5 & 20 & 13 & 0 \\
\hline Clay (OCR =7) & 160,000 & 177,000 & 0.35 & 0.499 & 17.7 & 27 & 13 & 0 \\
\hline Clay (OCR = 9) & 183,000 & 203,000 & 0.35 & 0.499 & 22.8 & 33 & 13 & 0 \\
\hline Clay (OCR = 15) & 242,000 & 268,000 & 0.35 & 0.499 & 32.4 & 49 & 13 & 0 \\
\hline
\end{tabular}




\subsection{Static Finite Element Analysis}

Although it is true that a pavement structure undergoes a moving traffic loading, static analysis has been generally used instead of dynamic analysis due to the theoretical and practical difficulties involved in dynamic analysis. In this section, plane-strain (2D) and 3D static analyses are performed.

\subsubsection{Plane-Strain (2D), Elastic, Static Analysis}

Most studies on super-single tires done to date focus on comparing the effects on the pavement structure of super-single tires with those of dual tires both in their standard $18,000 \mathrm{lb}$ axle load configuration and with a load consistent with the recommended maximum tire load for super-single tires. We follow the same approach here. Three configurations (shown in Figure (4.14)) were analyzed: 18,000 lb dual tires, 22,800 lb dual tires and 22,800 lb single tires. The inflation pressures for all types of axle loads are assumed to be 125 psi.

As seen in Figure 4.15, super-single tires induce comparatively large horizontal stresses at the bottom of the asphalt layer, which can be a significant cause of fatigue failure when repeated many times. The horizontal stresses are highest immediately below the center of the tires, regardless of the tire configurations. Figure 4.16 represents the vertical stresses generated on top of the subgrade with three types of configurations. As expected, super-single tires produce the highest vertical stress increases, which are approximately $20 \%$ larger than in conventional dual tires. Therefore, the change from 
dual tires to super-single causes a pavement structure to experience more severe loading. In addition, from Figures 4.17 - 4.19, it can be concluded that super-single tires induce higher stresses, strains and larger displacements than do conventional dual tires in a pavement structure. 


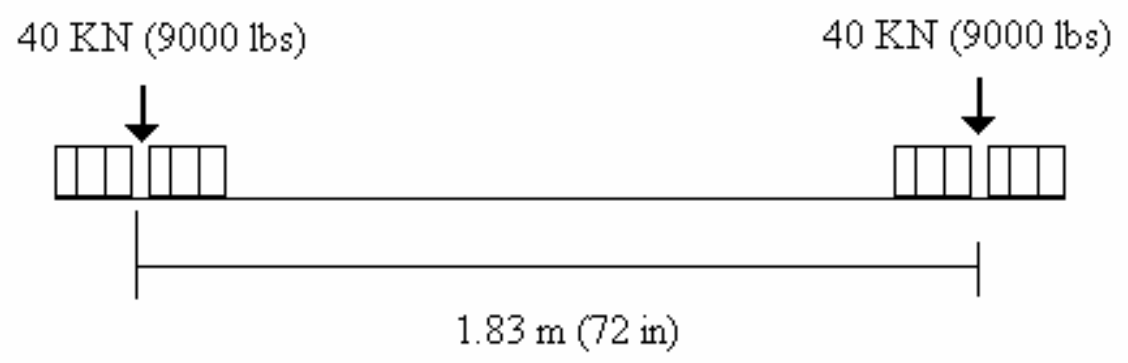

(a)

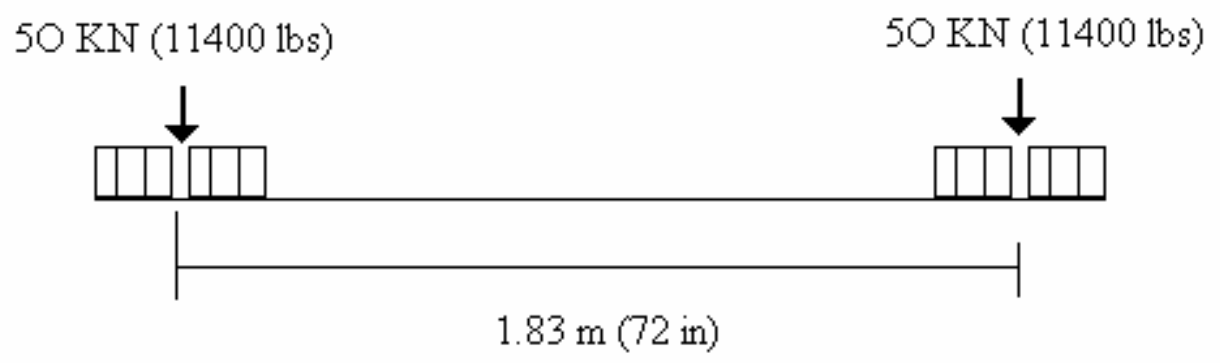

(b)

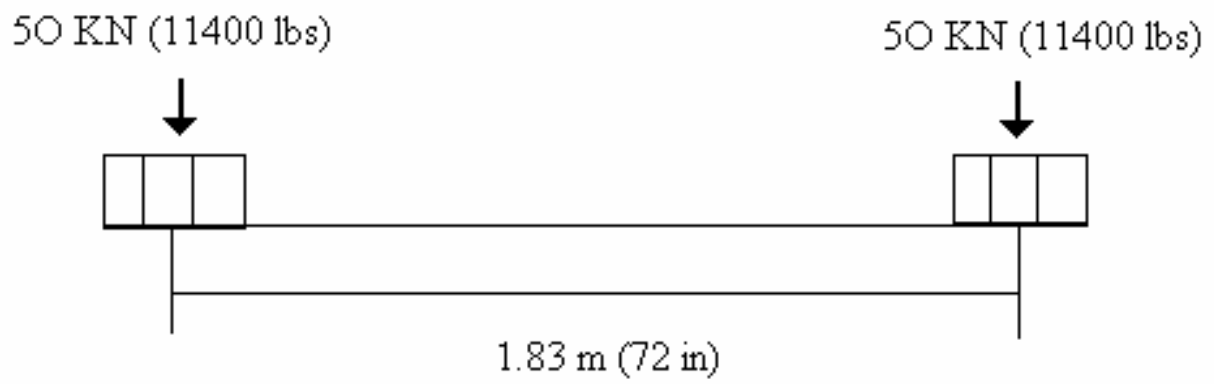

(c)

Figure 4.14 (a) 18,000 lb. single axle and (b) 22,800 lb. single axle with dual tires and 22,800 lb. single axle with super-single tires 


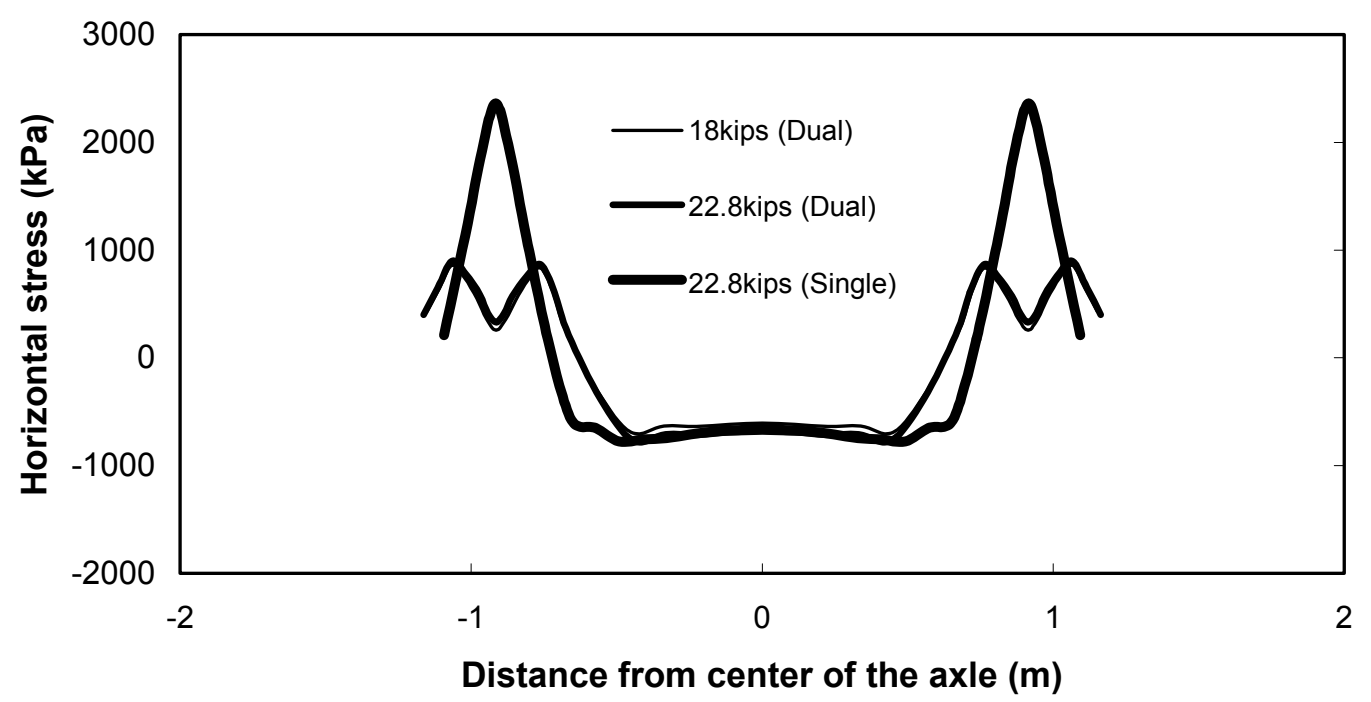

Figure 4.15 Horizontal stresses at the bottom of the asphalt layer

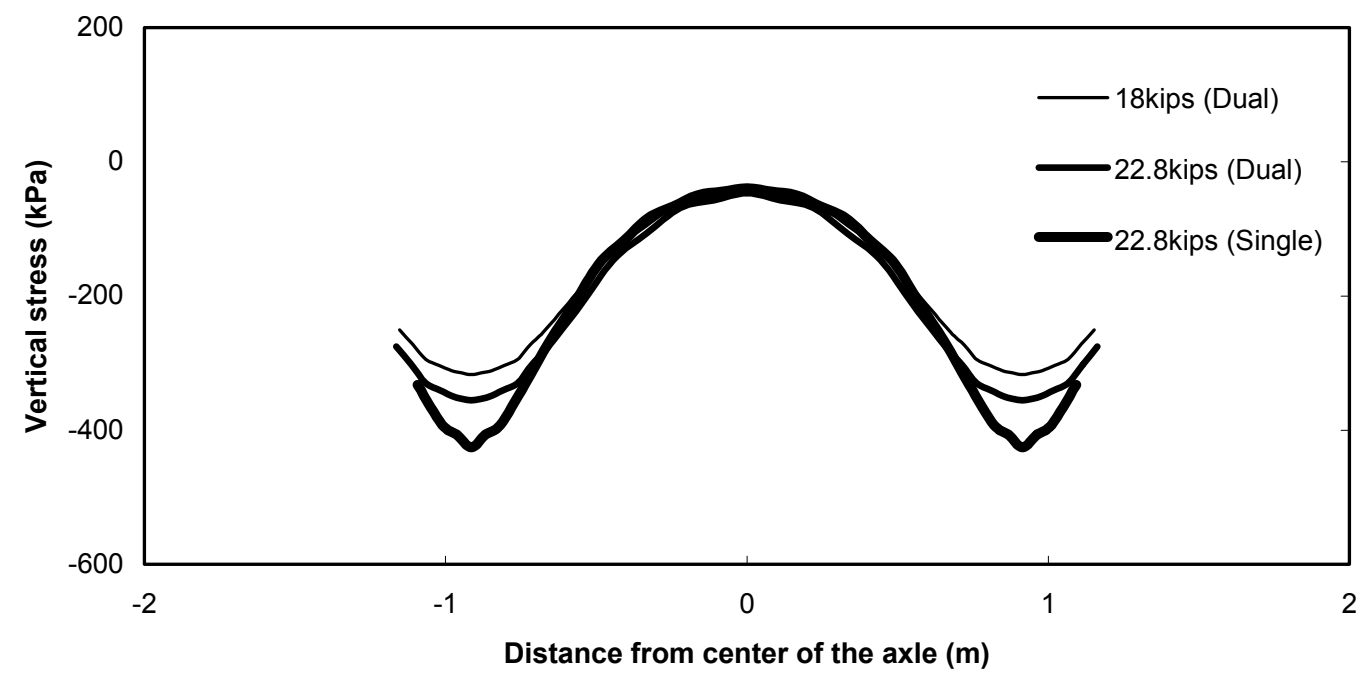

Figure 4.16 Vertical stresses on the top of the subgrade layer 


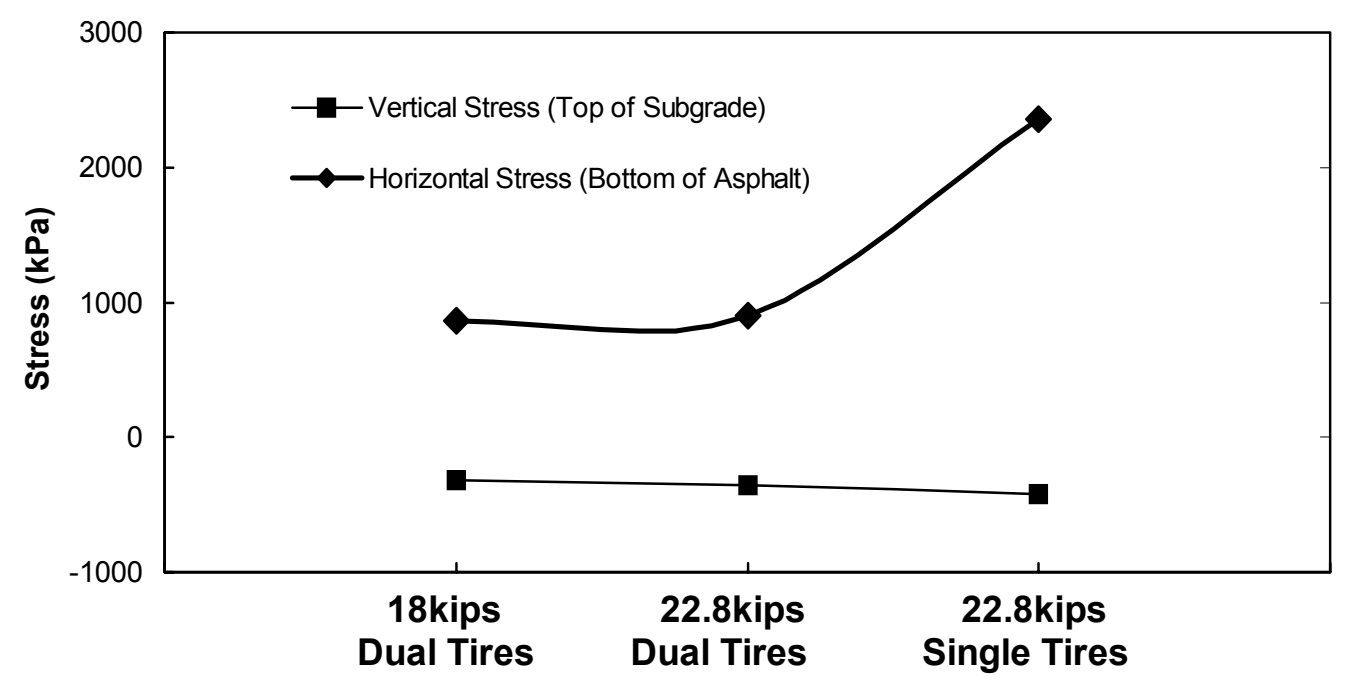

Figure 4.17 Comparison of stresses for the tire configurations

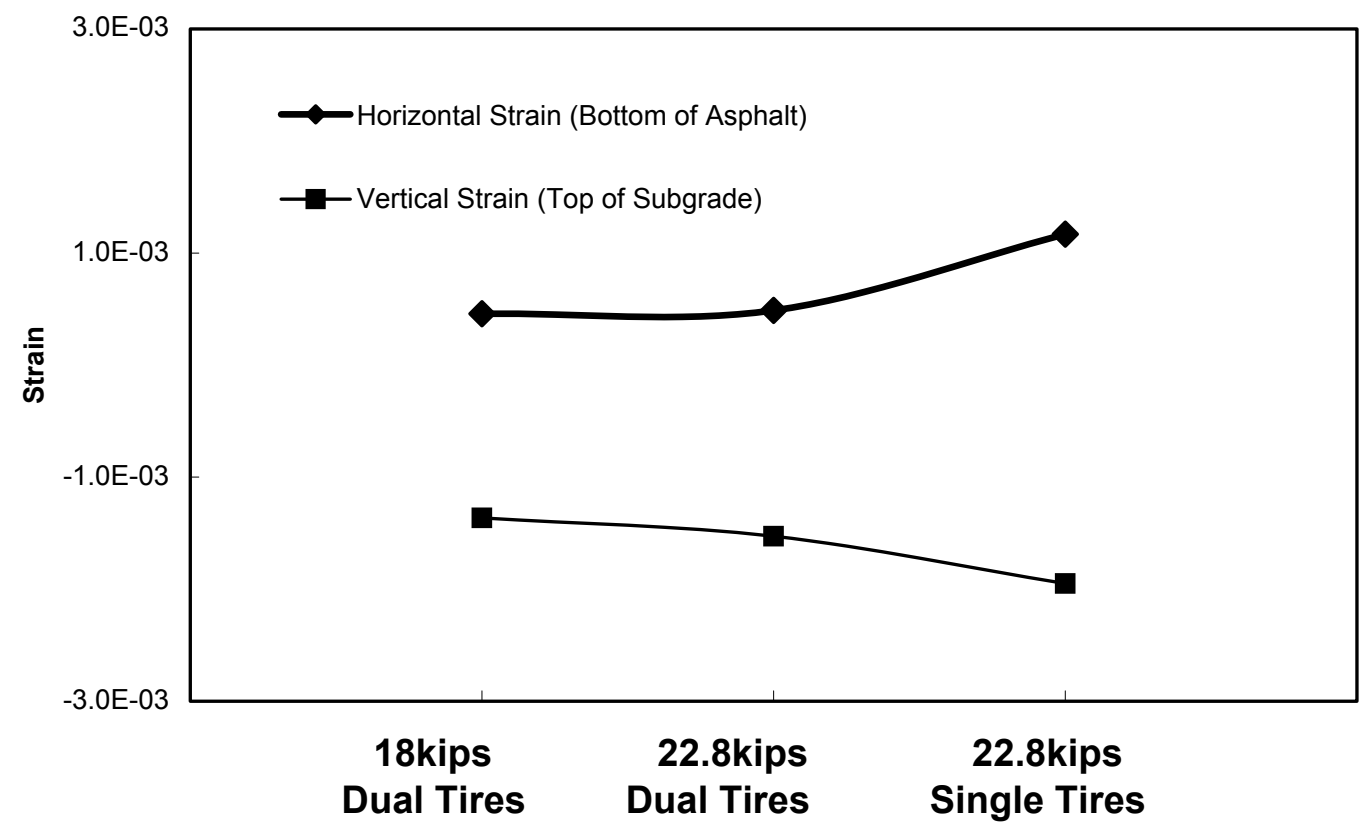

Figure 4.18 Comparison of strains for the tire configurations 


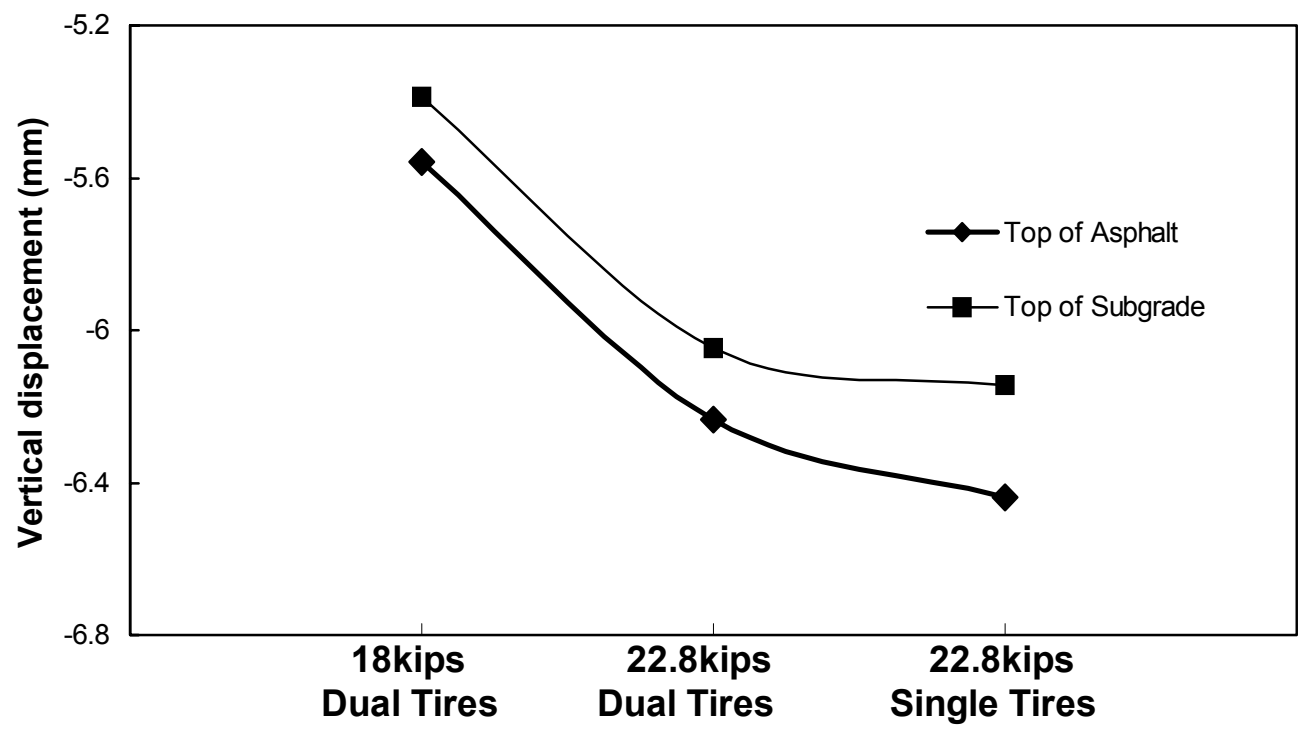

Figure 4.19 Comparison of vertical displacements for the tire configurations

\subsubsection{D Elastic, Static Analysis}

Based on the boundary conditions determined previously, analyses were done using 3D loading conditions. As in two-dimensional analysis, comparisons were made in three dimensions of the effects of two conventional dual tire configurations with supersingle tires. As seen in Figures 4.20 - 4.22, the trends observed in the three dimensional results were similar to those observed under plane strain conditions, but the magnitudes of stresses, strains, and displacements were considerably different. 


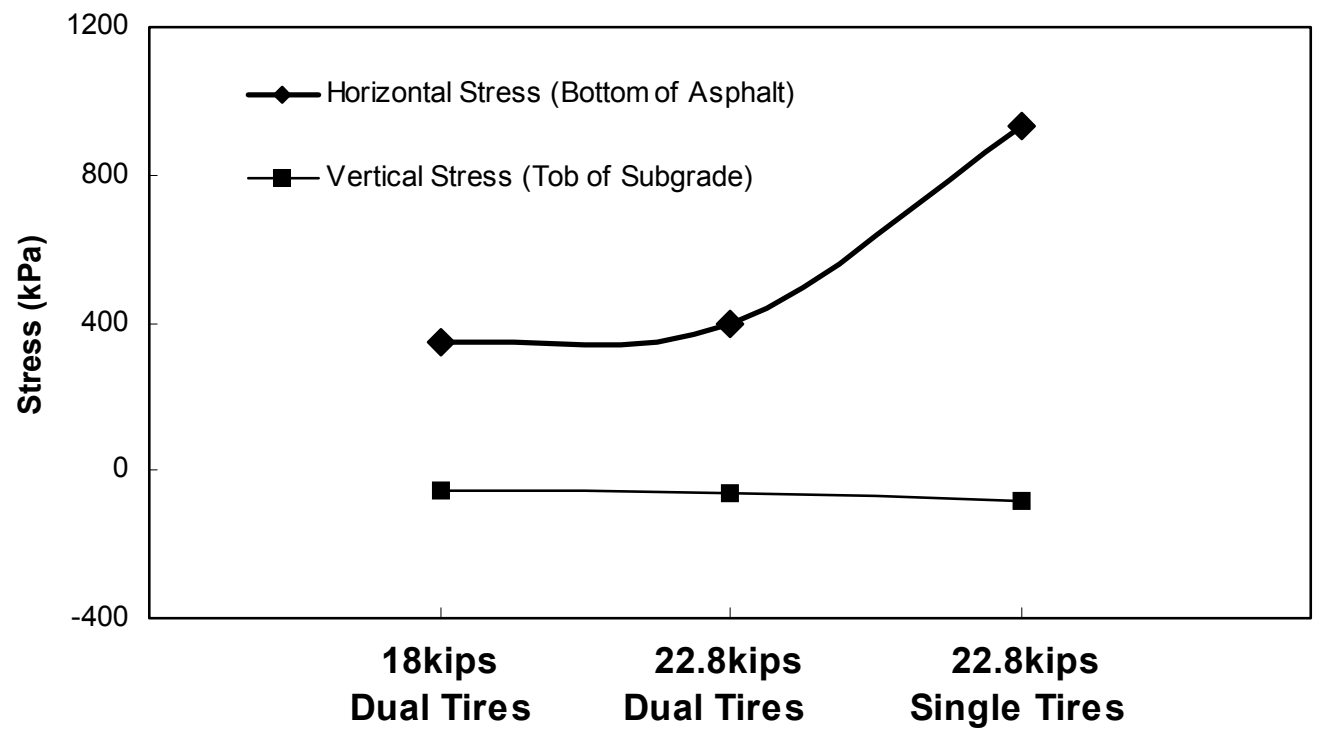

Figure 4.20 Comparison of stresses for the tire configurations

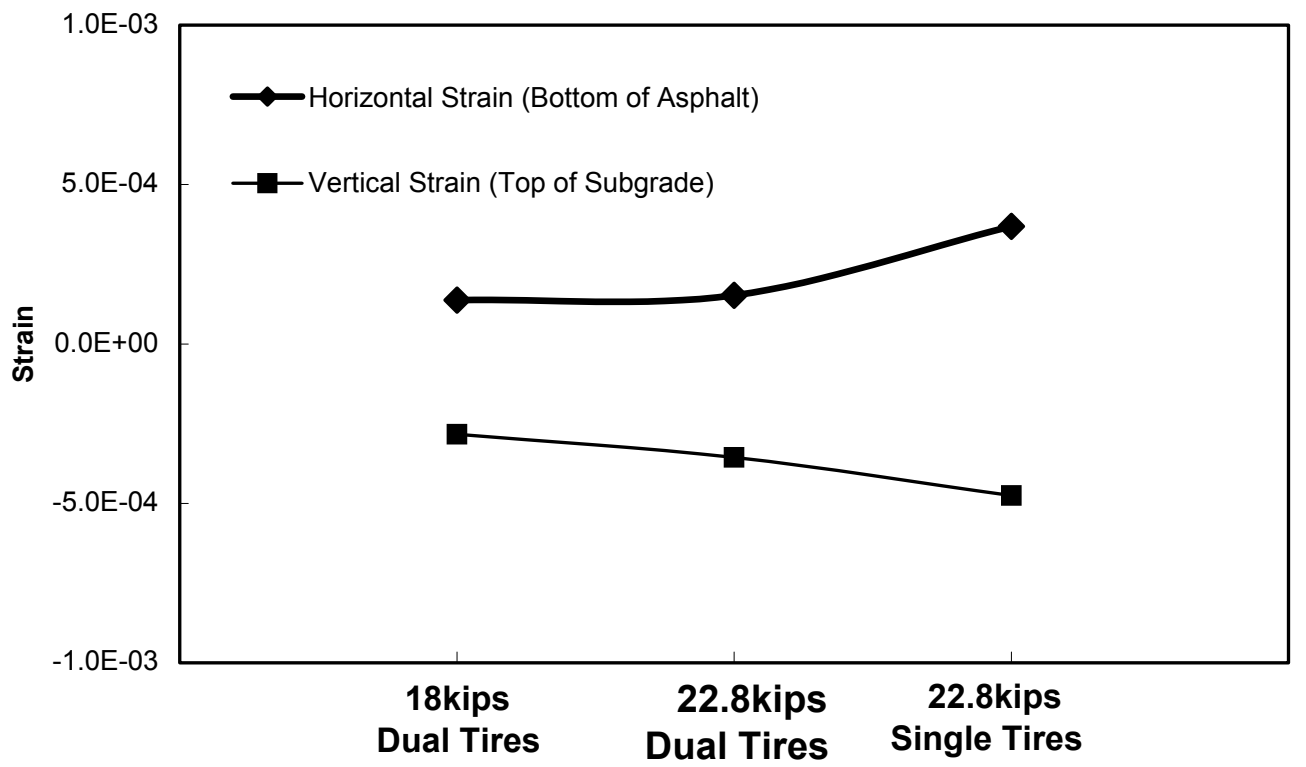

Figure 4.21 Comparison of strains for the tire configurations 


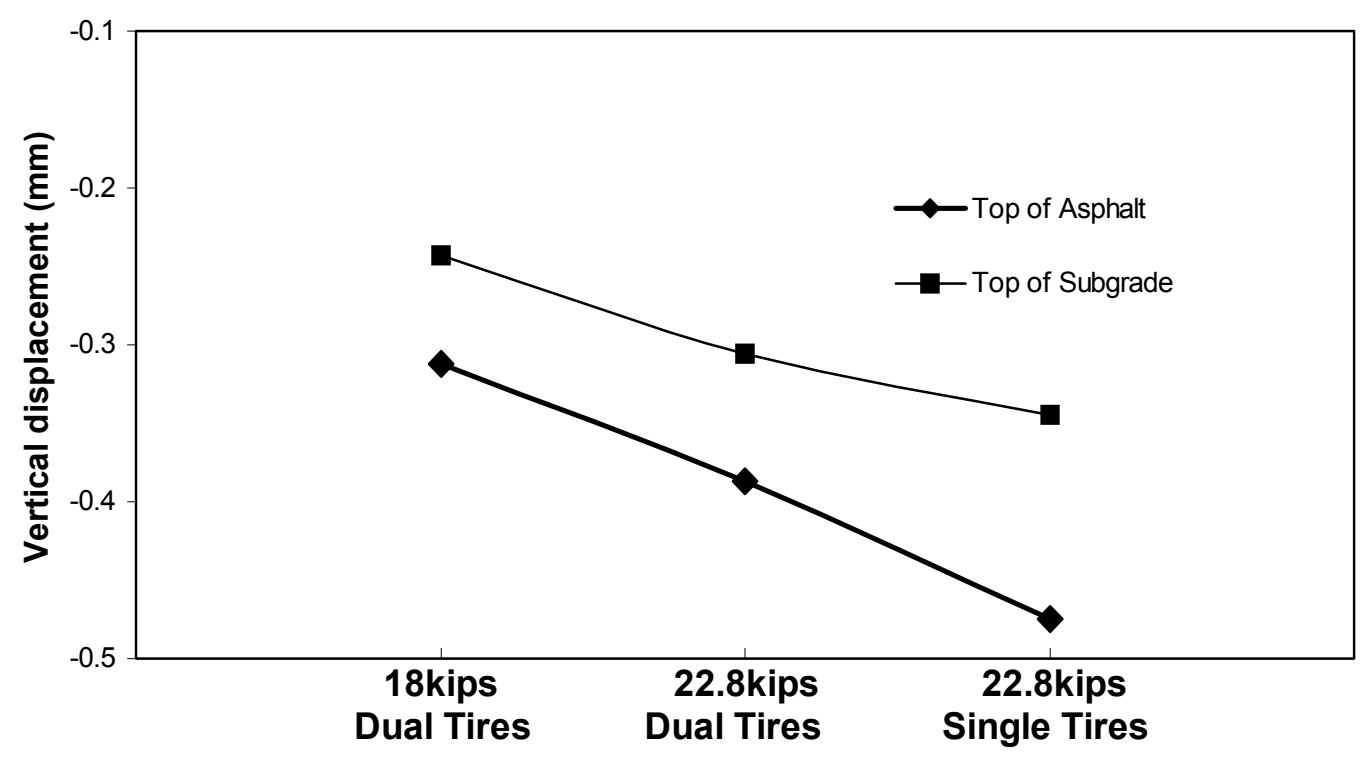

Figure 4.22 Comparison of vertical displacements for the tire configurations

\subsubsection{Comparison of Plane-Strain (2D) and 3D Elastic Results}

In order to assess the applicability of two analysis methods (plane-strain (2D) and 3D analysis), stresses, strains and vertical displacements from each analysis are compared. Three-dimensional modeling is more realistic than plane strain modeling, in which a load extending to infinity in the traffic direction is applied on top of the pavement. In $3 \mathrm{D}$ modeling, the loading is applied to the limited number of elements corresponding to the tire contact area. Figures $4.23-4.25$ show that the plane-strain (2D) modeling induces higher stresses, strains and displacements than 3D modeling. This means that plane-strain (2D) analysis is much more conservative than $3 \mathrm{D}$ analysis of the pavement. 


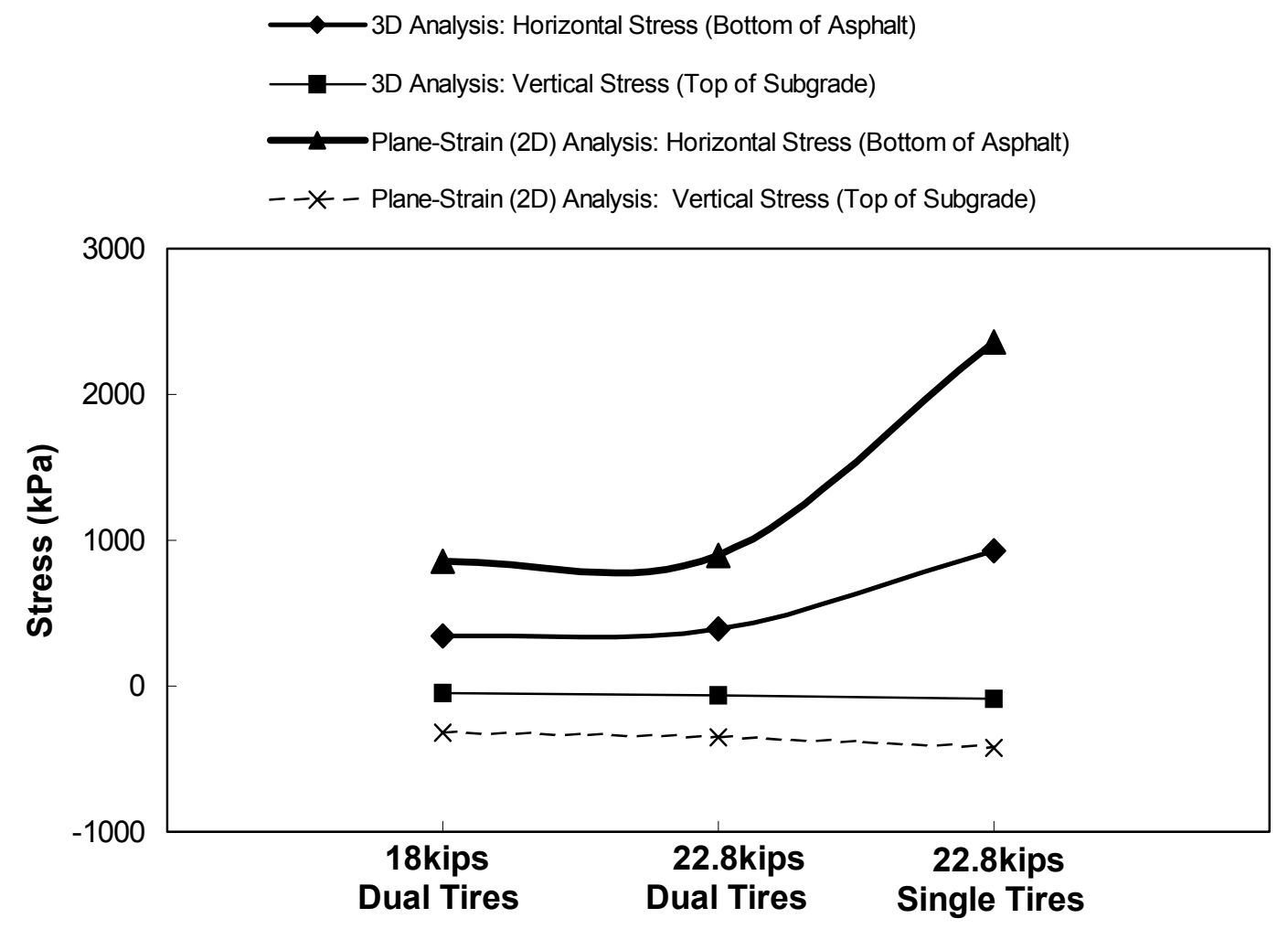

Figure 4.23 Comparison of plane-strain (2D) and 3D stresses 


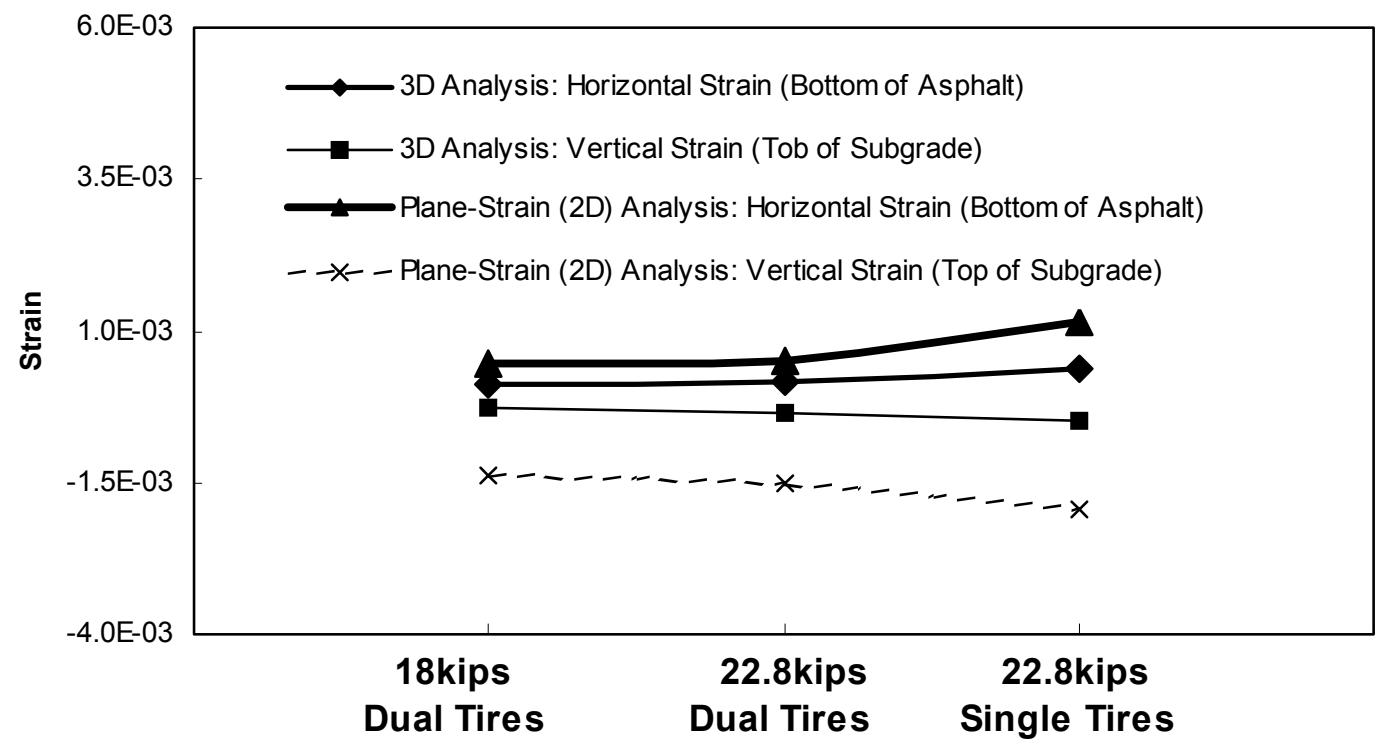

Figure 4.24 Comparison of plane-strain (2D) and 3D strains

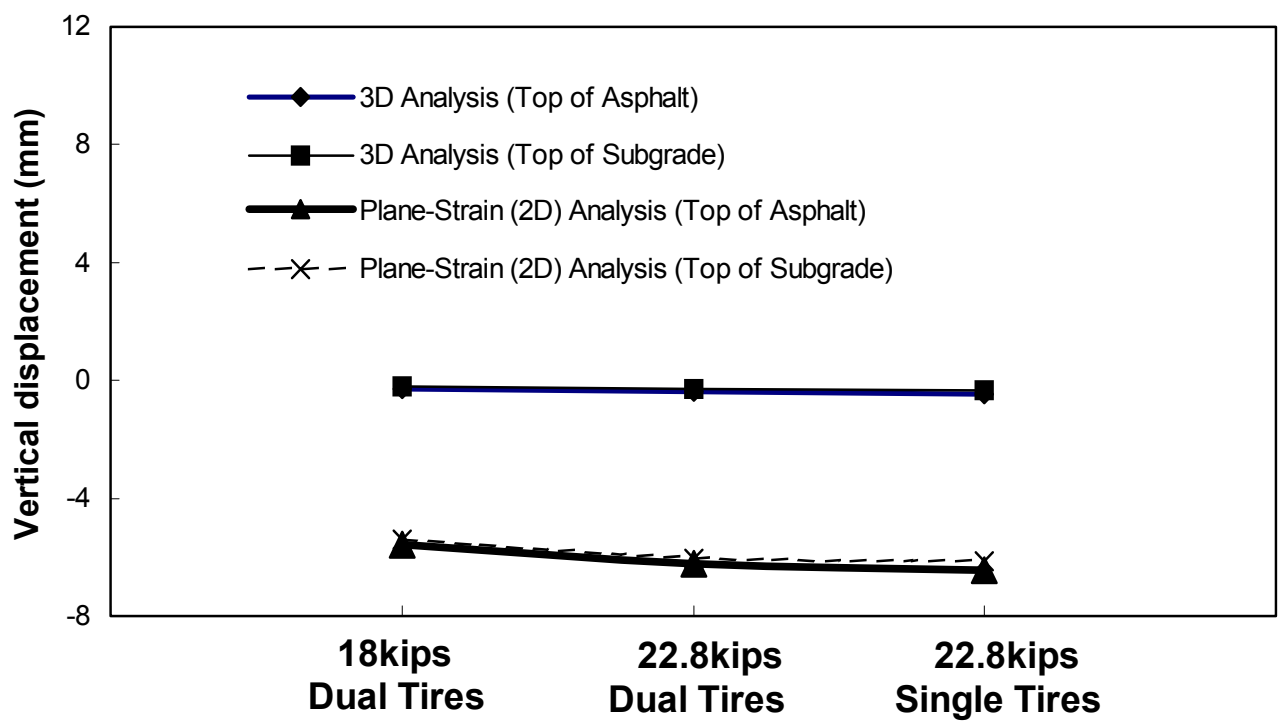

Figure 4.25 Comparison of plane-strain (2D) and 3D displacements 


\subsubsection{Comparison of 3D and Multi-Layered Elastic Results}

Elsym5 is one of the widely used linear-elastic programs in pavement engineering. This program assumes that the contact stress is equal to the inflation pressure. The program was developed based on the solution of Burmister (1943) for the problem of a multi-layered elastic medium subjected to circular tire loadings. Figures 4.26 - 4.28 show that the results of Elsym5 and of the 3D analysis are in good agreement for dual tires, but differ slightly for super-single tires. This small difference for super-single tires can be explained by the fact that, in Elsym5, the contact stress equal to the inflation pressure is applied to the surface of the pavement, while in the FE analysis, the maximum vertical contact stress (approximately equal to 1.9 times the inflation pressure) is considered.

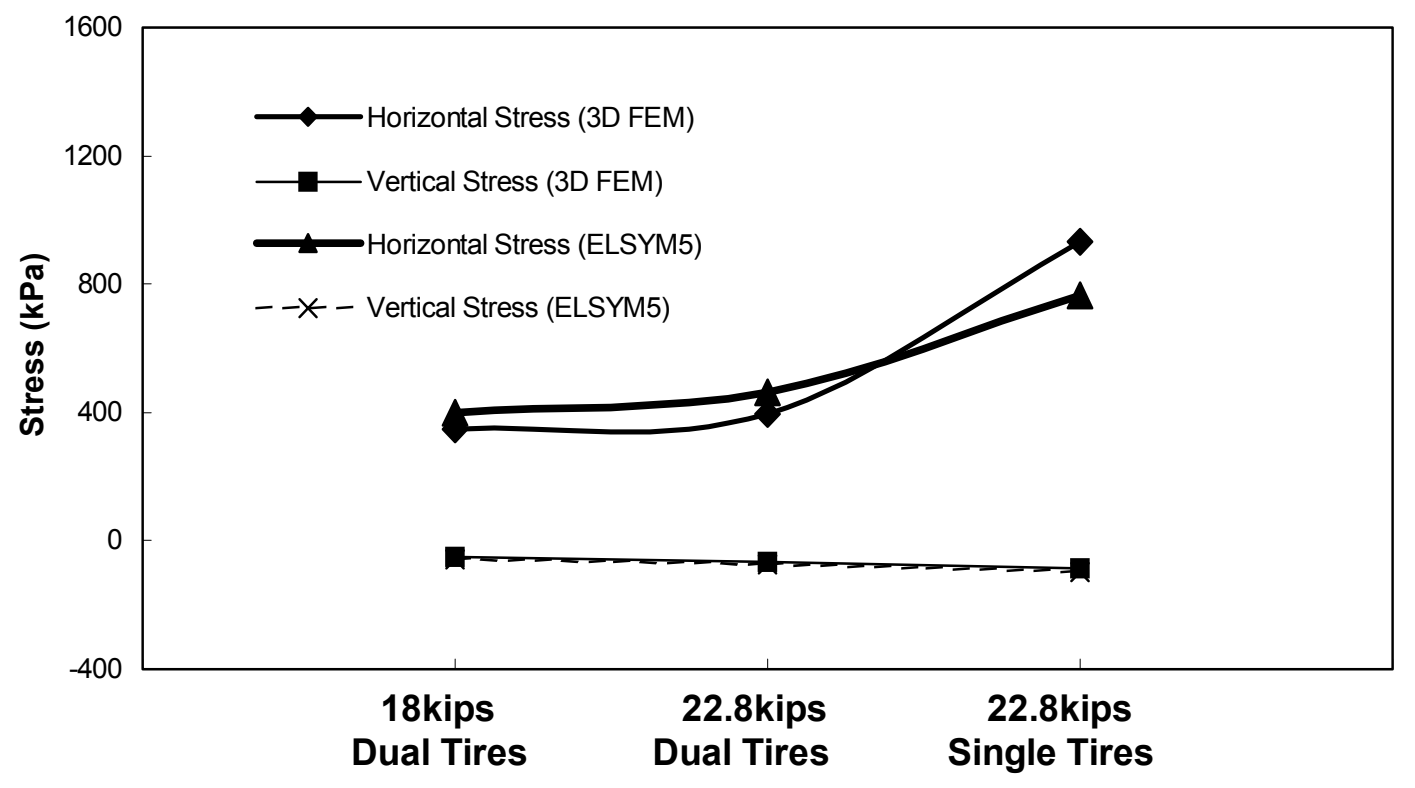

Figure 4.26 Comparison of stresses (3DFEM and ELSYM5) 


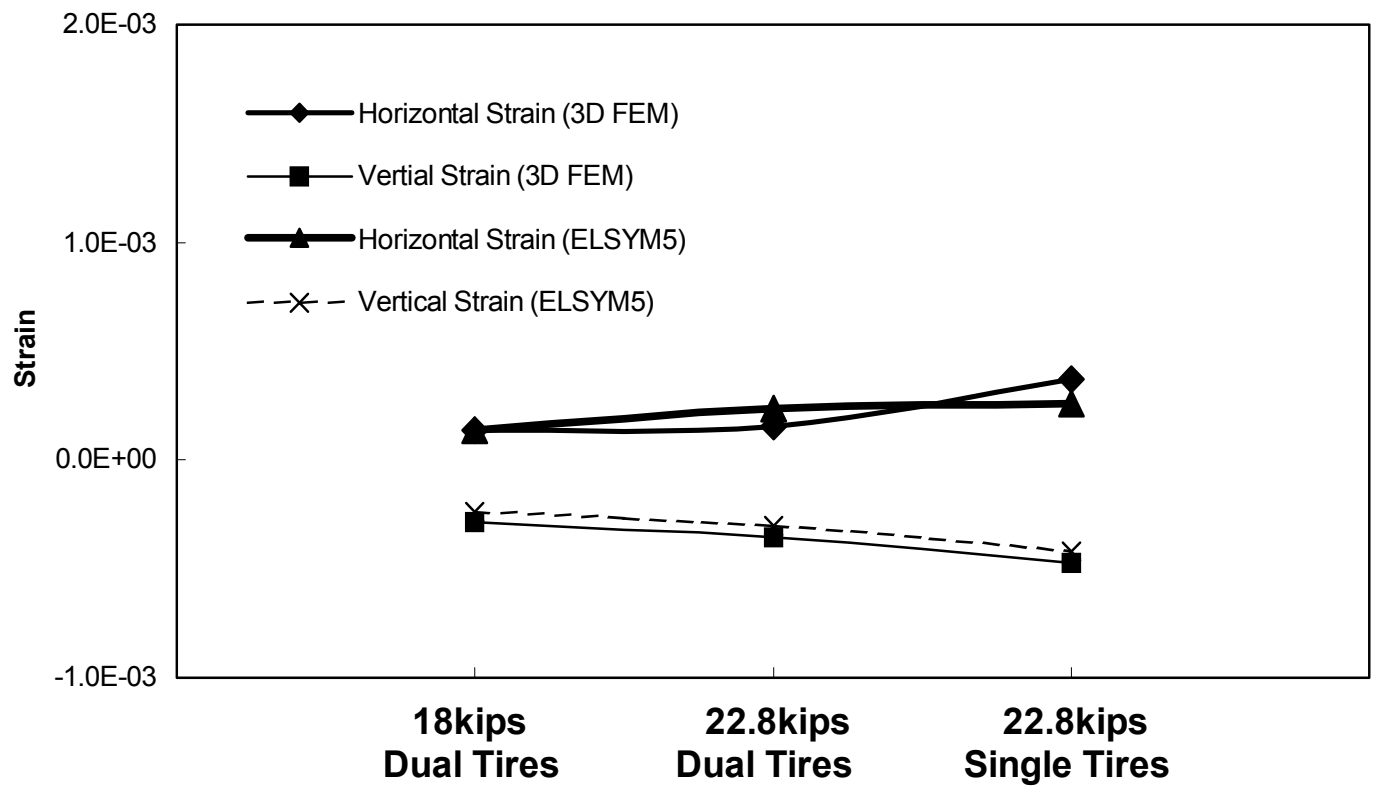

Figure 4.27 Comparison of strains (3DFEM and ELSYM5)

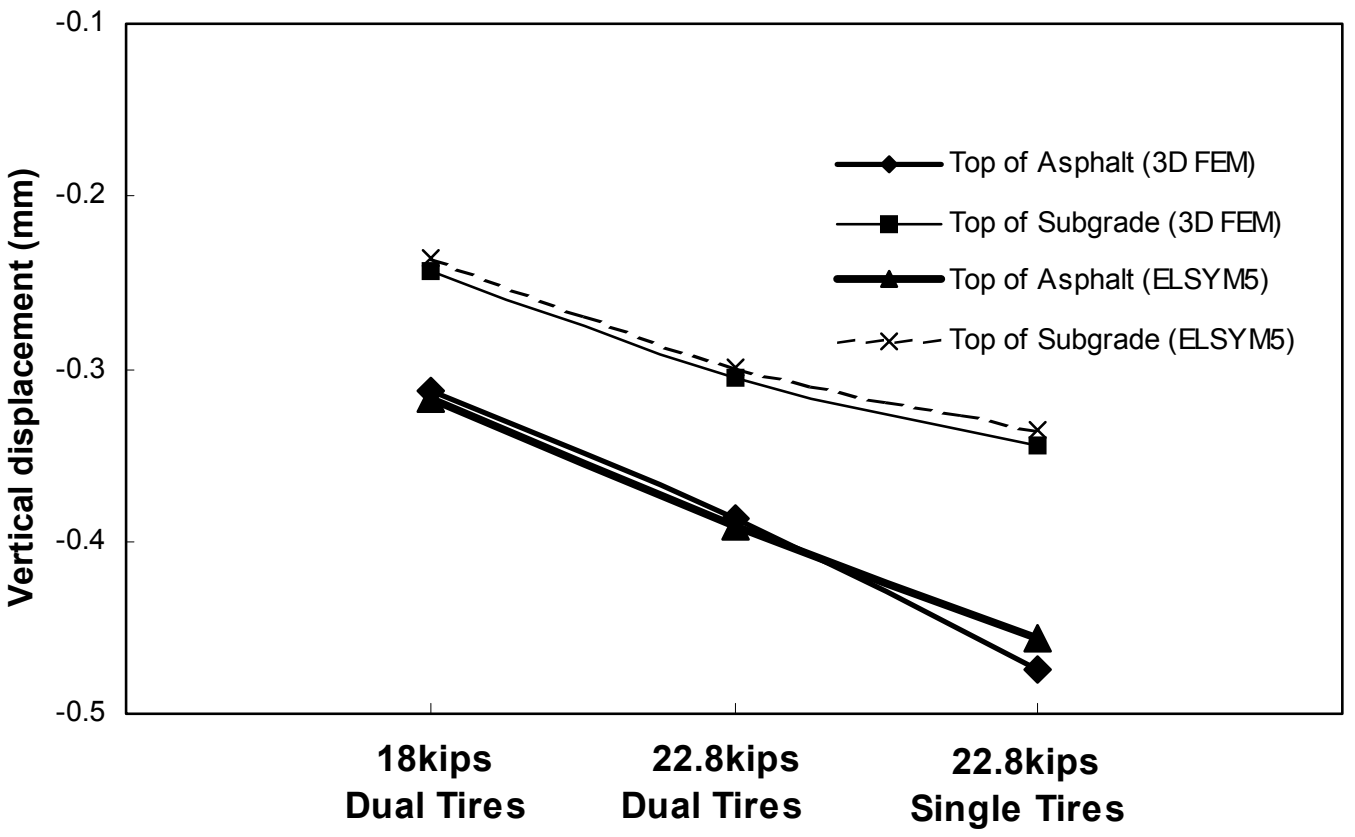

Figure 4.28 Comparison of vertical displacements (3DFEM and ELSYM5) 


\subsubsection{D Elastic-Plastic, Static Analysis}

The model of a pavement structure in the FE analysis is composed of three layers: the asphalt layer, base layer and subgrade layer. The model is modeled as saturated from the top of the base layer to the bottom of the subgrade layer in order to capture the most critical drainage condition expected to happen during the pavement design life.

Most past research has focused on the behavior of the asphalt and base layer than on the subgrade. Researchers have often neglected some important geotechnical facts when modeling subgrade layers. Such geotechnical considerations might include the existence of geostatic stress states resulting from $\mathrm{K}_{\mathrm{o}}$ and the generation of porewater pressures. Research that considers these necessary components in FE analysis is lacking. Keeping these geotechnical considerations in mind, the FE analysis is performed. In the FE analysis, subgrade soils are modeled using the Drucker-Prager model. As described in chapter 3, for clays, a cap is used, but not for sands.

\subsubsection{Implication of Drainage Conditions}

As mentioned before, the static analysis done using FEM is to look into the behavior of pavement structure subjected to super-single tires at any one moment of the pavement life. The subgrade is modeled as saturated, so that tire loadings applied to the pavement surface generate porewater pressures within the subgrade. The generation of porewater pressures is dependent on the nature of the soil (sand or clay), drainage conditions, its hydraulic conductivity, and its overconsolidation ratio (OCR). For the clay subgrade, undrained conditions may be assumed since there is not enough time for the excess porewater pressures to dissipate. For the sand subgrade, drainage conditions 
depend on the hydraulic conductivity of the soil and of the materials above it. Both effective stress analysis and total stress analysis were done for undrained conditions; the parameters used in the total stress analysis are $\mathrm{E}_{\mathrm{u}}$ (undrained Young's modulus) and $v_{\mathrm{u}}$ (undrained Poisson's ratio), while the effective stress analyses were performed using an effective Young's modulus E' and an effective Poisson's ratio v'.

\subsubsection{Effective Stress Analysis}

In the effective stress analyses of clayey subgrades, the soil was modeled using the Drucker-Prager model with cap. This model can account for two types of failure: shear failure and yield resulting from excessive mean stress. An initial cap is set based on the preconsolidation pressure. Figures 4.29 - 4.31 show typical results for normally consolidated and over-consolidated cohesive soils. The higher the OCR is, the smaller the displacement. As the OCR increases, the displacement decreases due to the increase in soil stiffness. For OCR $>7$, the rate of reduction of the vertical plastic strains decreases with increasing OCR. Positive pore pressures are generated in cohesive soil with OCR less than 5. Negative pore pressures are generated for OCR $>6$. 


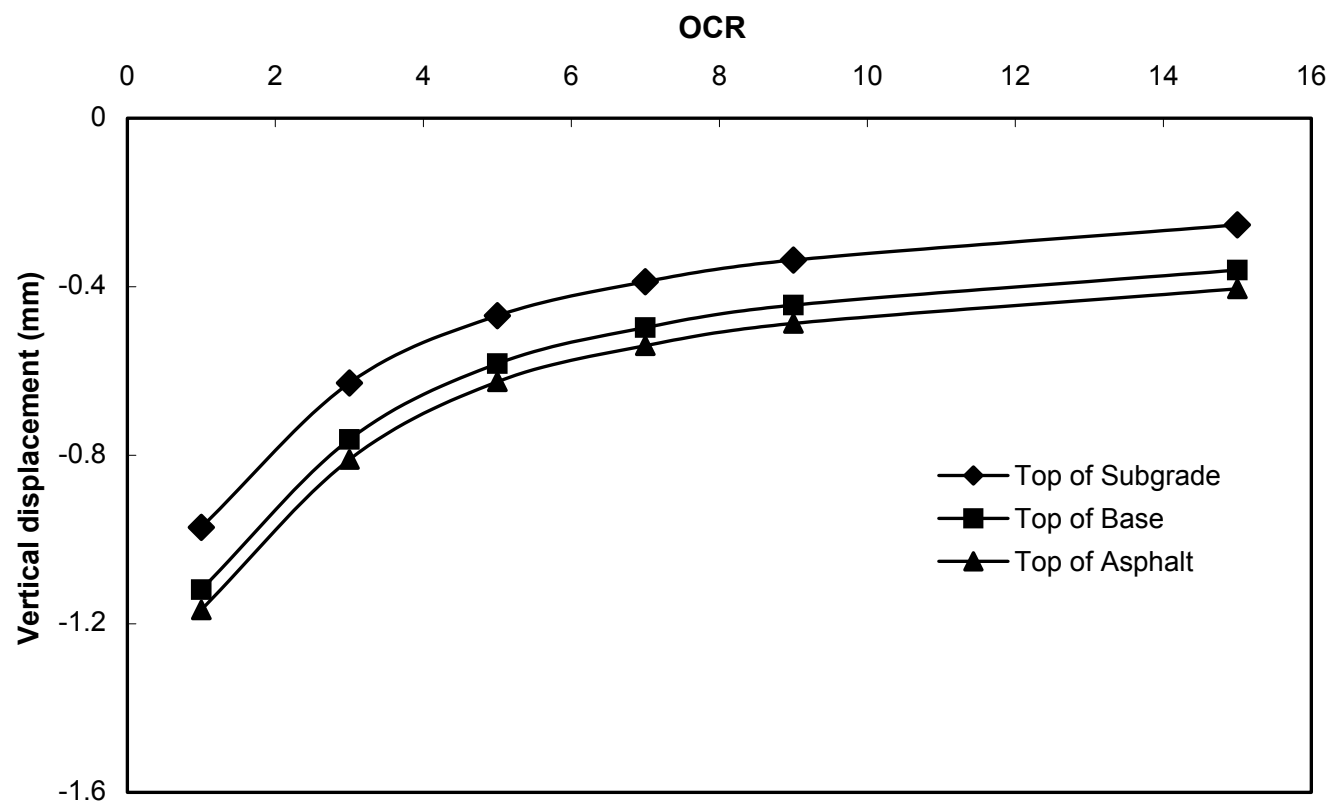

Figure 4.29 Displacements vs. OCRs

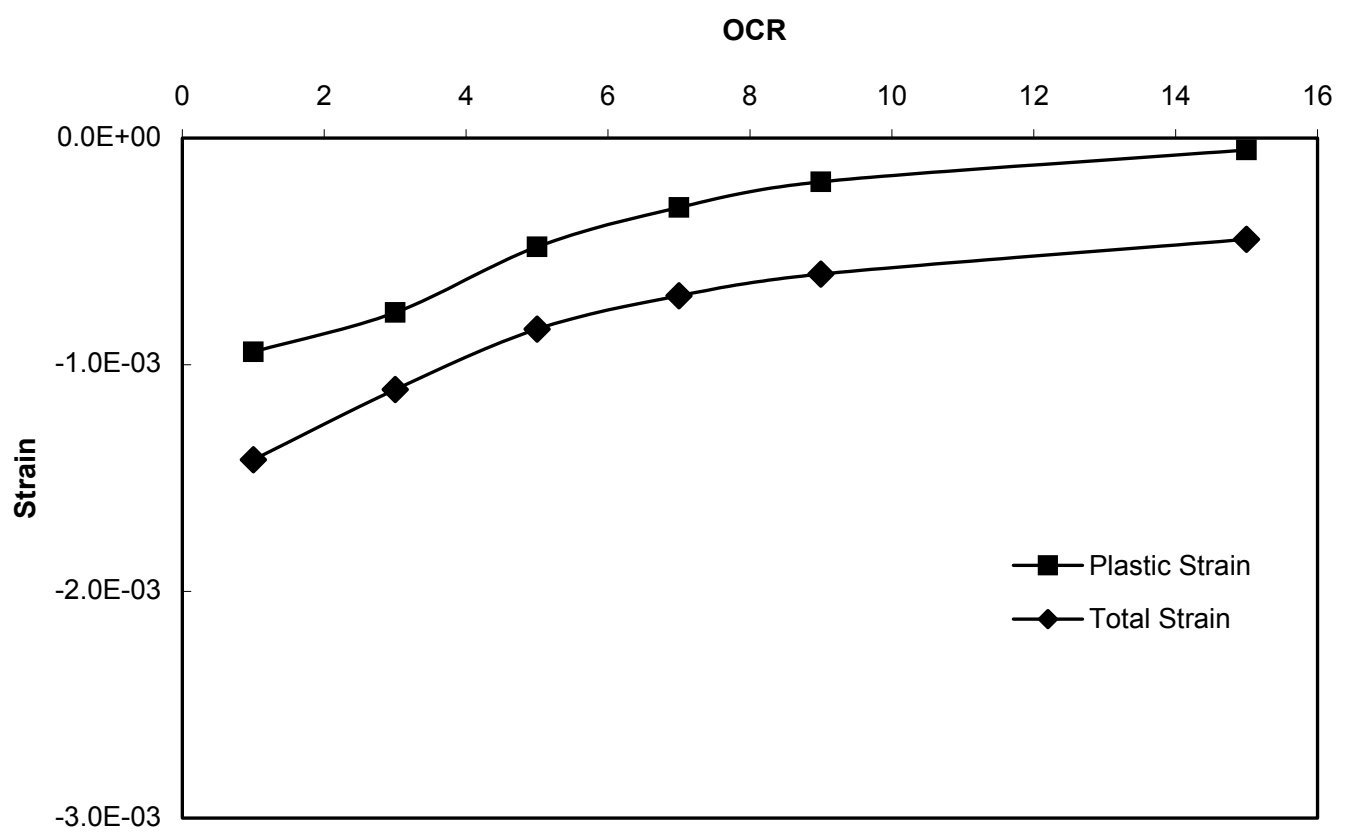

Figure 4.30 Vertical strains vs. OCRs 


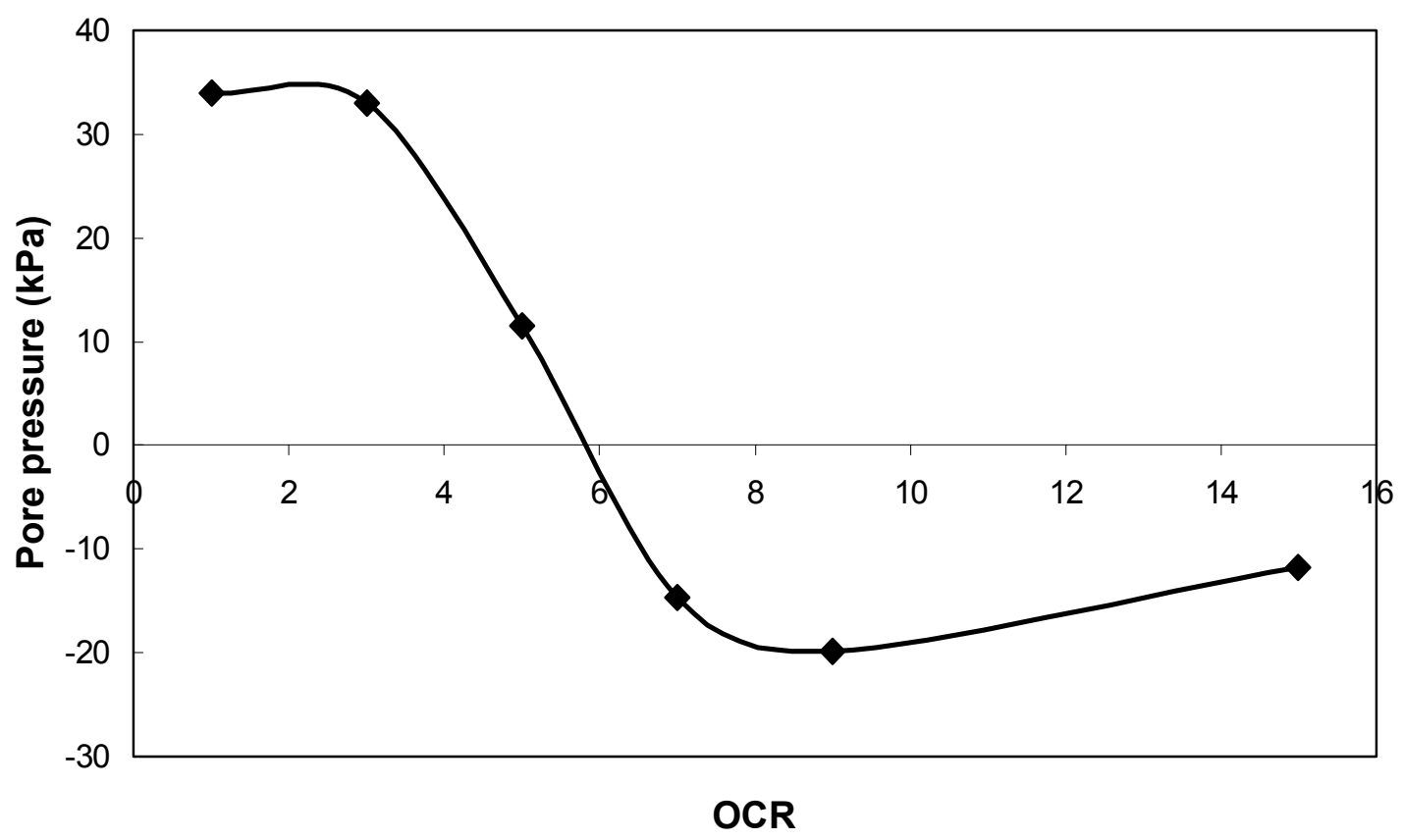

Figure 4.31 OCRs vs. pore pressures

\subsubsection{Total Stress Analysis}

As Figures 4.32 - 4.35 indicate, due to the increase in the soil stiffness with increasing OCR, vertical displacements and strain decrease. As the results of the effective stress analysis, these results also indicate that the soil does enter the plastic range for super-single tire loadings. These results imply that an improvement of subgrades to increase the shear strength might be necessary to avoid excessive permanent damage. 


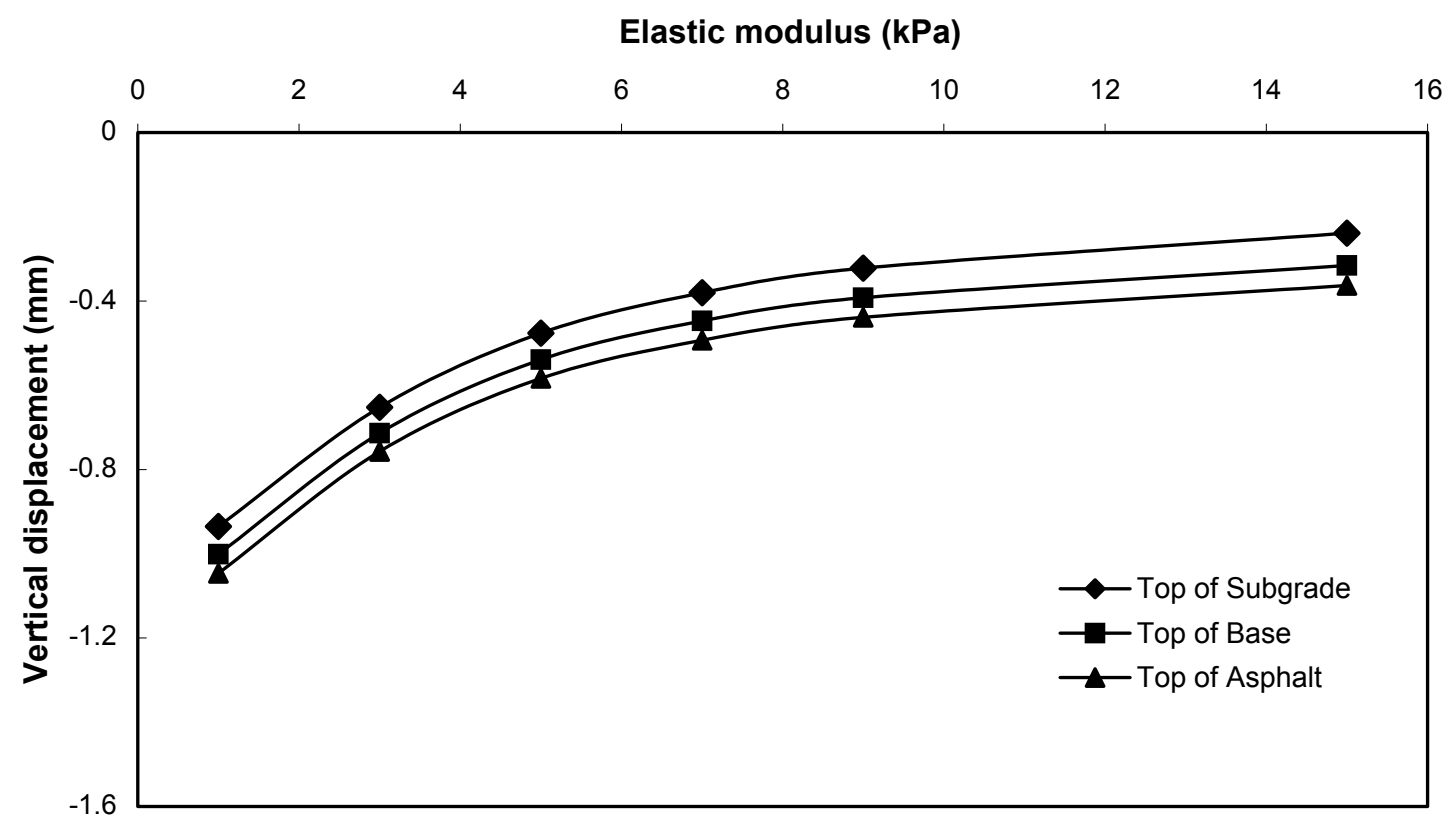

Figure 4.32 Displacements vs. OCR

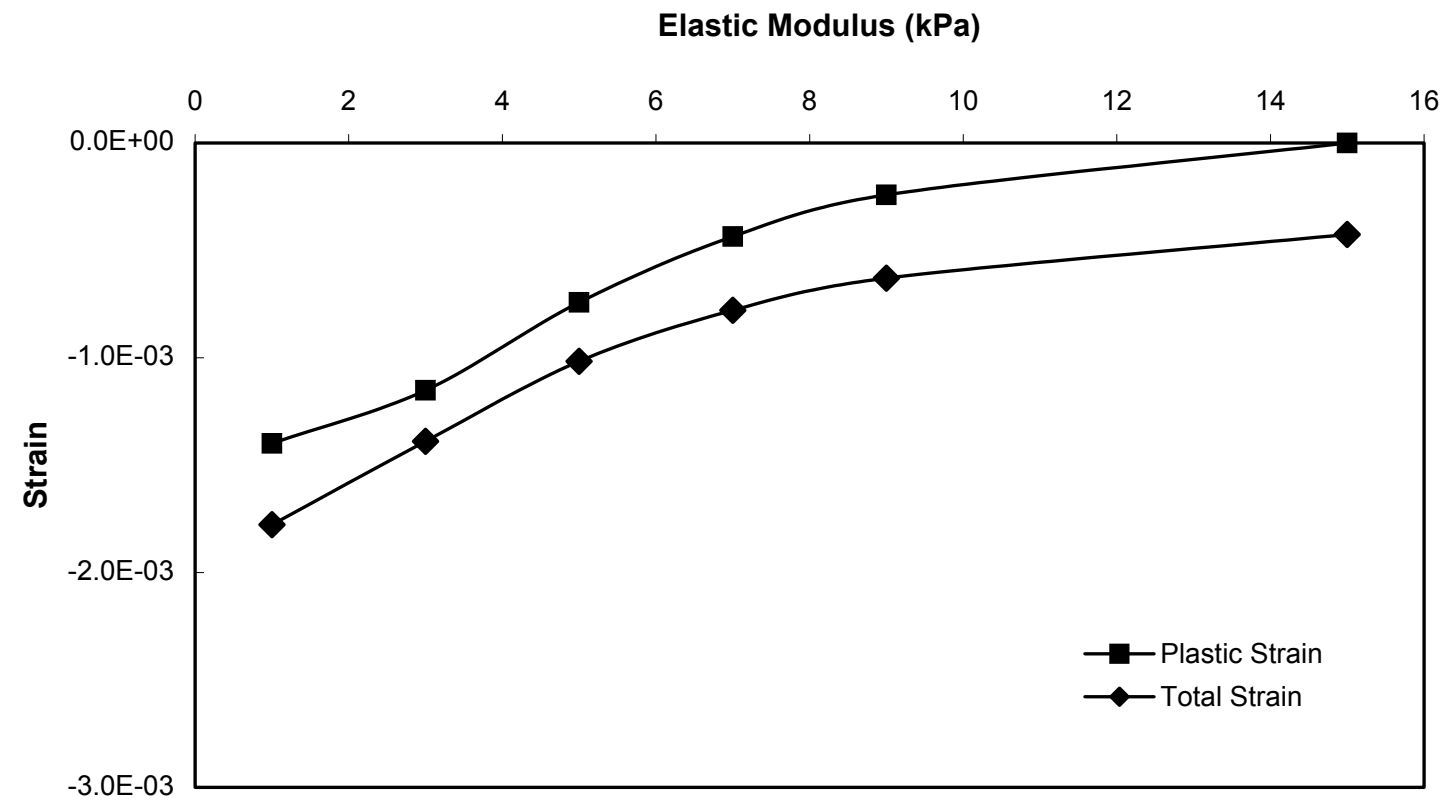

Figure 4.33 Strains vs. OCRs 


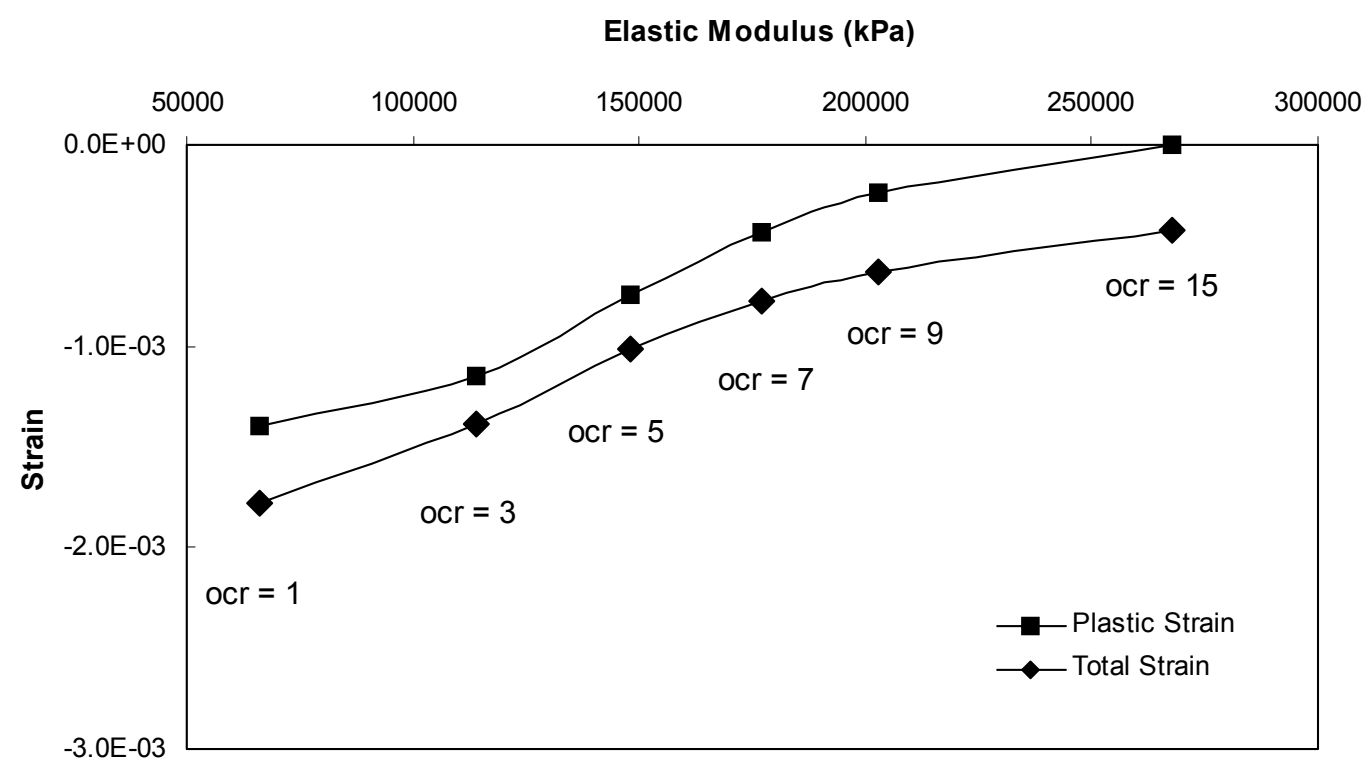

Figure 4.34 Strains vs. elastic moduli depending on OCR

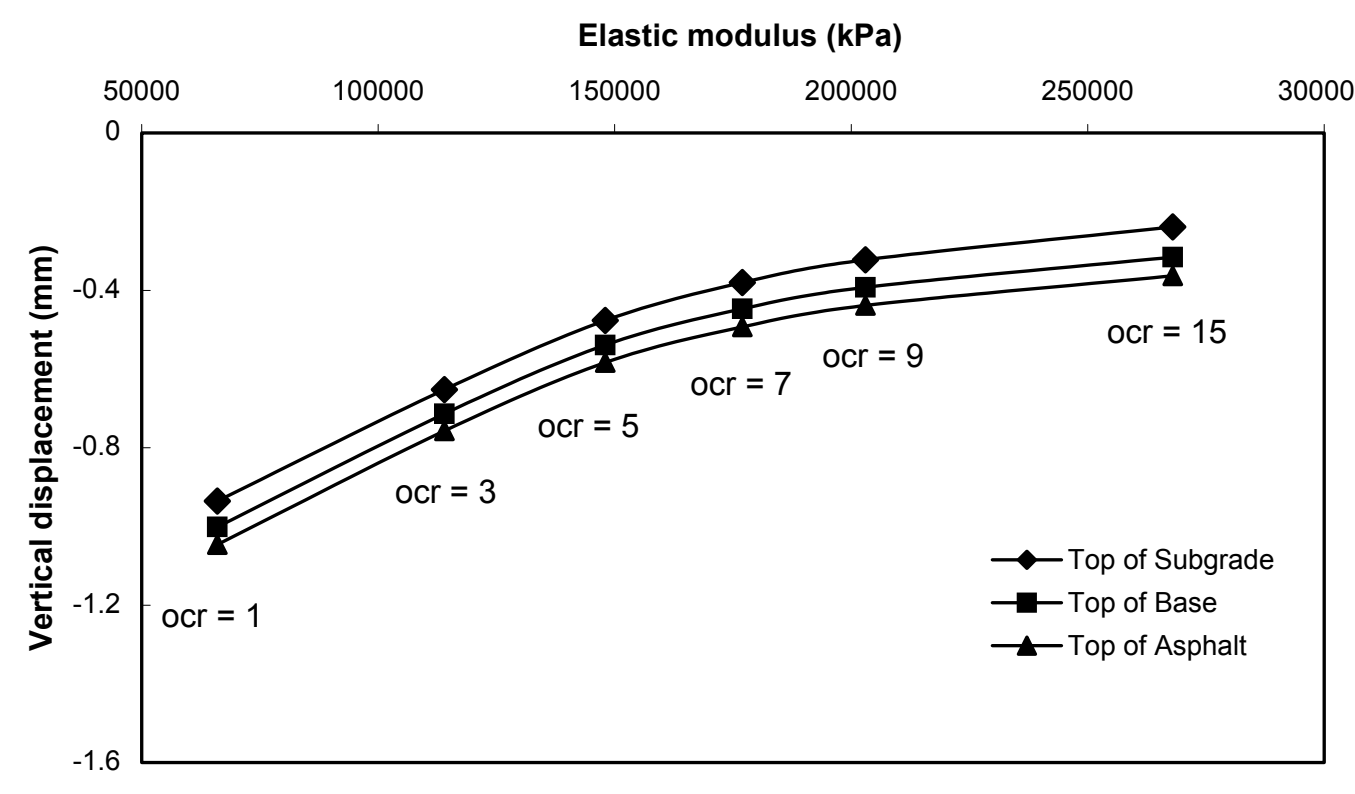

Figure 4.35 Displacements vs. elastic moduli depending on OCR 


\subsubsection{Pore Pressure Generation in Sand and Clay Subgrades}

It is meaningful to compare the generation of pore pressure in subgrades depending on whether the soil is modeled as elastic or elastic-plastic, since the prediction of the behavior of subgrades subject to super-single tire loadings might be quite different from what happens in the observed subgrades. Figure 4.36 shows the generation of porewater pressures for a dense subgrade using linear elasticity. The elements shown in Figure 4.36 are located immediately below the super single tires. For a dense subgrade, if a soil is modeled as an elastic material, only positive pore pressures are observed in the soil as a result of traffic loading. However, this result does not appear realistic for a typical dense sand, for which dilatancy would likely generate negative pore pressures.

Figure 4.37 illustrates the generation of pore pressures in a dense sand subgrade based on elastic-plastic behavior. In contrast with the results from linear-elasticity, negative pore pressures are generated both in the base layer and in the subgrade. If we take a closer look, negative pore pressures are being generated in the upper part of the subgrade, while positive pore pressures are being generated at greater depths into the subgrade. Therefore, for an accurate estimation of pore water pressures, elastic-plastic analysis must be done.

Figure 4.38 shows the pore pressures in the normally consolidated clay subgrade.

The pore pressure trends in the base layer are similar to those observed in Figure 4.37 because the same material properties were used for the base layer as for the sand subgrade. Differently from the sand subgrade, positive pore pressures are produced in the NC clay subgrade. As already seen in Figure 4.31, negative pore pressures are generated in overconsolidated clay subgrades. 
The generation of porewater pressures affects the shear strength of the subgrade. Positive pore pressures in the subgrade will decrease its shear strength due to the reduction of the effective stresses. In the pavement subjected to repeated tire loadings, as the number of repetitions of the loadings increases, pore pressure build-up is expected, further degrading the strength of the subgrade. In contrast, negative pore pressures in the subgrade will increase the effective stresses, resulting in increasing shear strength. Therefore, for the NC clay subgrade, an appropriate way to decrease the build-up of the positive pore pressures may be required. 


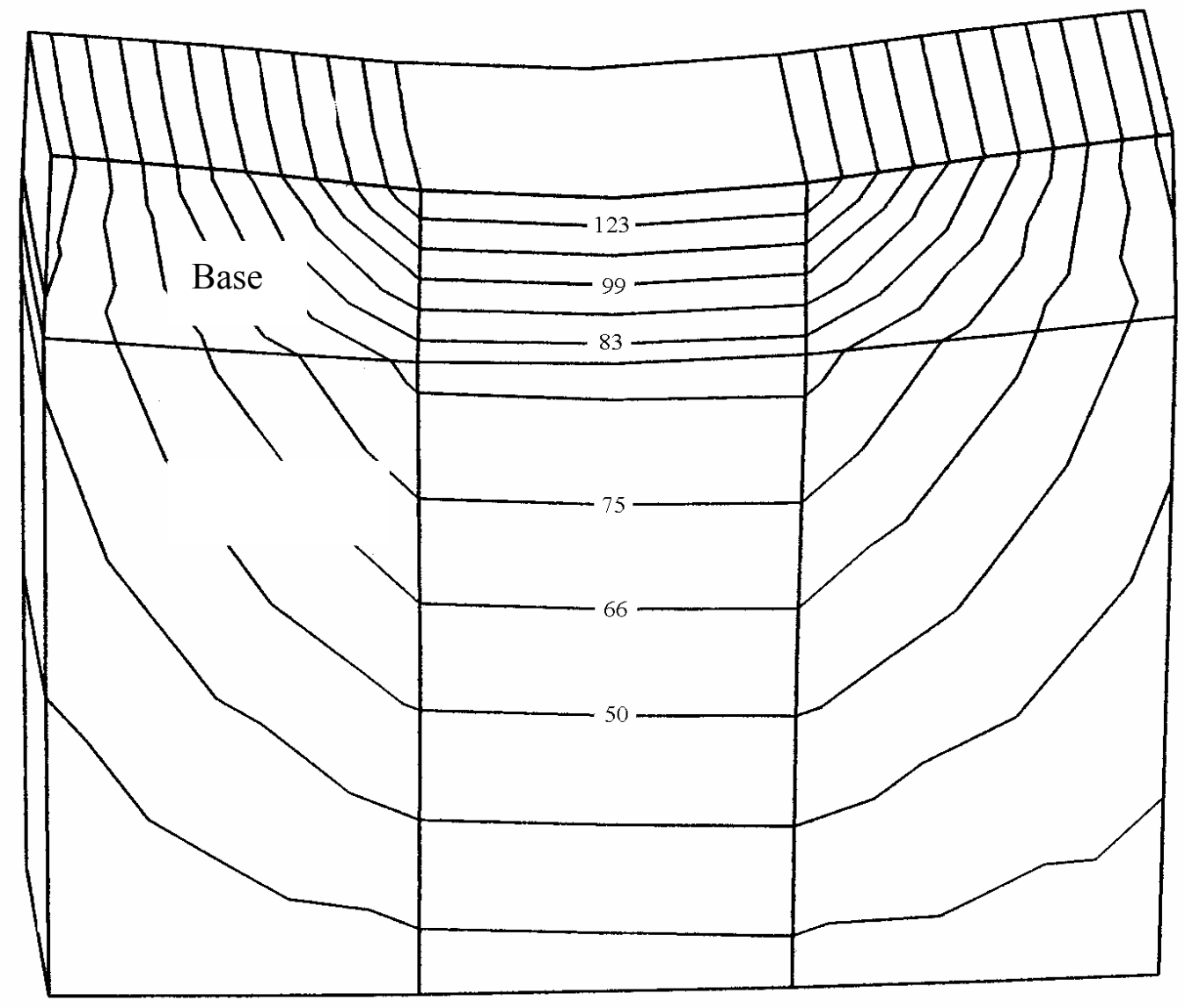

Figure 4.36 Pore pressures (unit: $\mathrm{kPa}$ ) in sand subgrade analyzed by linear-elasticity 


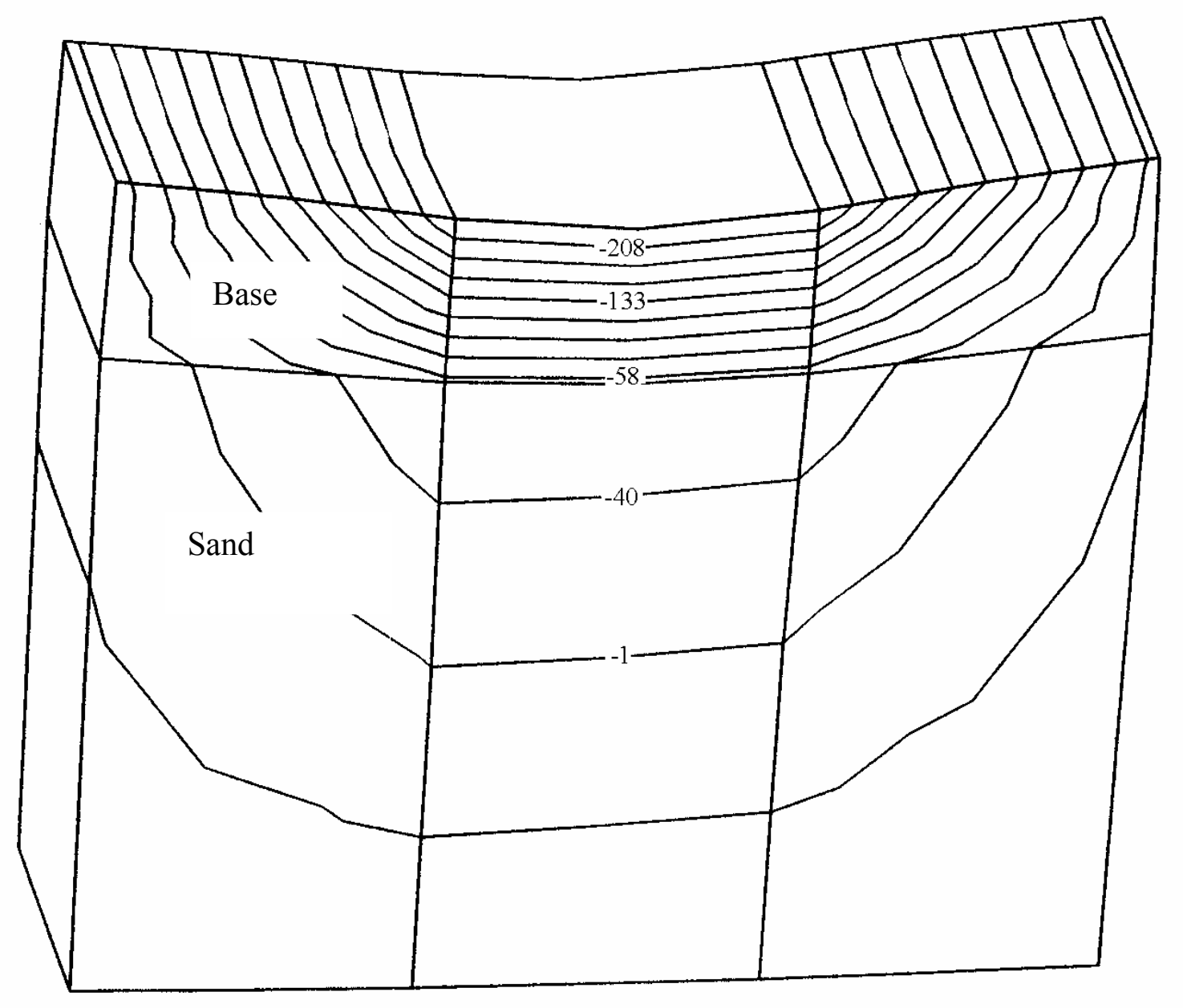

Figure 4.37 Pore pressures (unit: $\mathrm{kPa}$ ) in sand subgrade analyzed by elastic-plasticity 


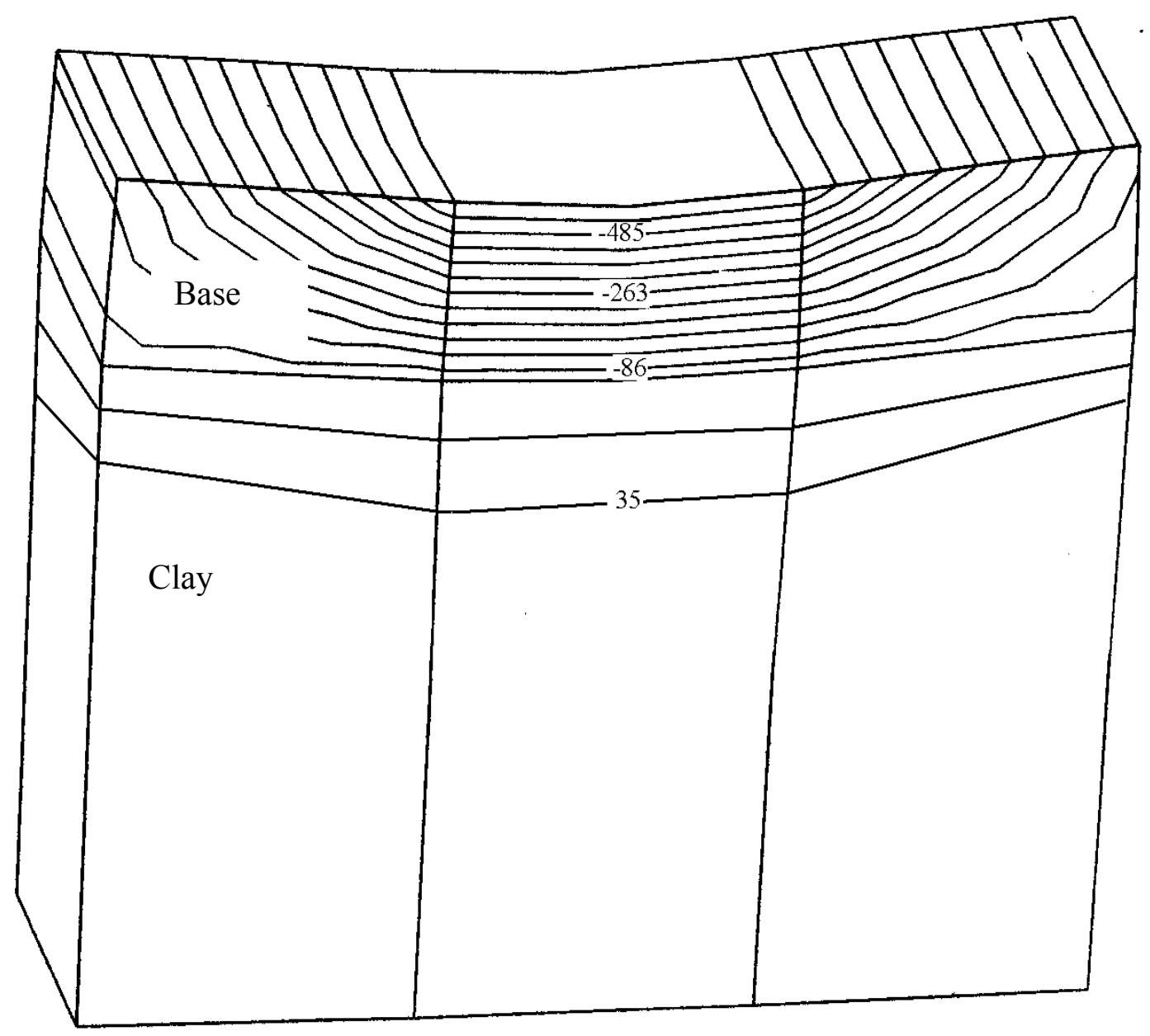

Figure 4.38 Pore pressures (unit: $\mathrm{kPa}$ ) in normally consolidated subgrade analyzed by elastic-plasticity 


\subsubsection{Static Load Equivalency Factors using 3D Elastic, Static Analysis}

There are two major flexible pavement design methods: the Asphalt Institute method (AI method) and the AASHTO method. Both methods employ the concept of Load Equivalent Factor (LEF) and the Equivalent Single Axle Load (ESAL). LEF is defined as the number of equivalent $80 \mathrm{kN}(18,000 \mathrm{lbs}$.) single axle load applications causing the same amount of damage by one passage of an axle. ESAL is defined as the LEF $\times$ number of passages of an axle. However, neither of these two methods accounts for the LEF of axles with super-single tires. Due to this limitation, many researchers have focused on obtaining LEF values in their research.

Using the empirical failure criteria discussed in Chapter 2, the load equivalency factors and the number of passages to cause fatigue failure and rutting failure using linear elastic results were obtained for each type of tire configuration. For clarification, the equations are shown as follows.

$$
\begin{gathered}
\log N_{f}(10 \%)=15.947-3.291 \log \left(\frac{\varepsilon_{t}}{10^{-6}}\right)-0.854 \log \left(\frac{E}{6.895 \times 10^{3}}\right) \\
\log N_{f}(45 \%)=16.086-3.291 \log \left(\frac{\varepsilon_{t}}{10^{-6}}\right)-0.854 \log \left(\frac{E}{6.895 \times 10^{3}}\right) \\
N_{d}=1.365 \times 10^{-9}\left(\varepsilon_{v}\right)^{-4.477}
\end{gathered}
$$

The value of Young's modulus used in the equations (4.12) and (4.13) was 2,068,000 $\mathrm{kPa}$, as shown in Table 4.1.

Table 4.3 shows the number of passages for $10 \%$ and $45 \%$ fatigue failure obtained from the horizontal strain at the bottom of the asphalt layer using equations (4.12) and (4.13). The number of passages to induce $13 \mathrm{~mm}$ rutting, suggested by the Asphalt 
Institute, was obtained from the vertical strain on top of the subgrade using equation (4.14). As seen in Table 4.3, the number of repetitions needed to reach fatigue failure and rutting failure is much smaller for super-single tires than for dual tires. Based only on this data, cross-section 1 performs better than cross-section 2. This result occurs because the value of Young's modulus for cross-section 2 is lower than for cross-section 1. Since cross-section 2 includes a HMA base layer, it has a higher cohesion value than cross-section 1 as shown in Table 4.1. It will be shown later that cross-section 2 performs better than cross-section 1 due to the higher cohesion value in elastic-plastic analysis. 
Table 4.3 Number of fatigue and rutting failure using empirical equations

\begin{tabular}{|c|c|c|c|c|c|c|c|}
\hline Tire type & $\begin{array}{c}\text { Axle Load } \\
\text { (lbs) }\end{array}$ & $\begin{array}{c}\text { Horizontal } \\
\text { strain }\end{array}$ & $\begin{array}{c}\text { Vertical } \\
\text { Strain }\end{array}$ & $\begin{array}{l}\mathrm{N}_{\mathrm{f}} 10 \% \\
\text { (fatigue) }\end{array}$ & $\begin{array}{l}\mathrm{N}_{\mathrm{f}} 45 \% \\
\text { (fatigue) }\end{array}$ & $\begin{array}{c}\mathrm{N}_{\mathrm{d}} \\
\text { (rutting) }\end{array}$ & $\begin{array}{l}\text { Cross- } \\
\text { Section }\end{array}$ \\
\hline Dual & 18,000 & 0.0001716 & 0.0002863 & $3,007,706$ & $4,163,607$ & $9,958,987$ & 1 \\
\hline Dual & 22,800 & 0.0001989 & 0.0003579 & $1,847,229$ & $2,557,522$ & $3,663,424$ & 1 \\
\hline Super-single & 22,800 & 0.0003692 & 0.0004754 & 241,519 & 334,594 & 1,027871 & 1 \\
\hline Super-single & 22,800 & 0.000415 & 0.0004831 & 164,293 & 227,634 & 955,999 & 2 \\
\hline Super-single & 22,800 & 0.0004546 & 0.0005534 & 121,683 & 168,612 & 520,482 & 3 \\
\hline Super-single & 22,800 & 0.0005227 & 0.0005798 & 76,857 & 106,512 & 445,597 & 4 \\
\hline
\end{tabular}


Table 4.4 shows the Load Equivalent Factors obtained from $\mathrm{N}_{\mathrm{f}}(18,000 \mathrm{lb}$ standard axle) $/ \mathrm{N}_{\mathrm{f}}(22,8000 \mathrm{lb}$ axle $)$ and $\mathrm{N}_{\mathrm{d}}(18,000 \mathrm{lb}$ standard axle $) / \mathrm{N}_{\mathrm{d}}(22,8000 \mathrm{lb}$ axle $)$. In order to assess the relative damage between dual tires and single tires for the same load (22, $800 \mathrm{lbs})$, fatigue and rutting damage factors were calculated from the ratio LEF (22,800 lb single tires) / LEF (22,800 lb dual tires). Table 4.4 shows that super- single tires cause fatigue failure and rutting failure to occur approximately 8 and 4 times earlier than dual tires for the same load, respectively. Therefore, it can be shown with a static analysis that super-single tires cause considerably more damage than the corresponding dual tires.

Table 4.4 Load equivalency factors by linear elastic FE results for cross-section 1

\begin{tabular}{|c|c|c|c|c|c|}
\hline Tire type & Axle Load & LEF (Fatigue) & Damage & LEF (rutting) & Damage \\
\hline Dual & $18,000 \mathrm{lbs}$ & 1 & (fatigue) & 1 & (fatigue) \\
\hline Dual & $22,800 \mathrm{lbs}$ & 1.63 & 1 & 2.72 & 1 \\
\hline Super-single & $22,800 \mathrm{lbs}$ & 12.4 & 7.6 & 9.69 & 3.6 \\
\hline
\end{tabular}




\subsection{D Dynamic Finite Element Analyses}

\subsubsection{Simulation of Moving Load}

Since the super-single tire imposes a moving load on a given road, a dynamic simulation of this load is the most appropriate treatment of the problem. Figure 4.39 illustrates the simulation of a moving load as it passes by an element. The moving load can be modeled as a trapezoidal step load. As the tire load enters a certain element, the load in the element increases linearly $\left(\mathrm{T}_{0} \sim \mathrm{T}_{1}\right)$. The load then reaches a plateau $\left(\mathrm{T}_{1} \sim\right.$ $\mathrm{T}_{2}$ ), during which the load is constant for some time. Then, as the tire load exits the element, the load in the element decreases linearly to zero $\left(T_{2} \sim T_{3}\right)$. If the length of the tire load is 2 times the length of the element, because the tire loading is assumed to be moving at constant speed, the time for the tire loading to move across the element can be expressed as 3 times the length of the element as shown in Figure 4.39. 


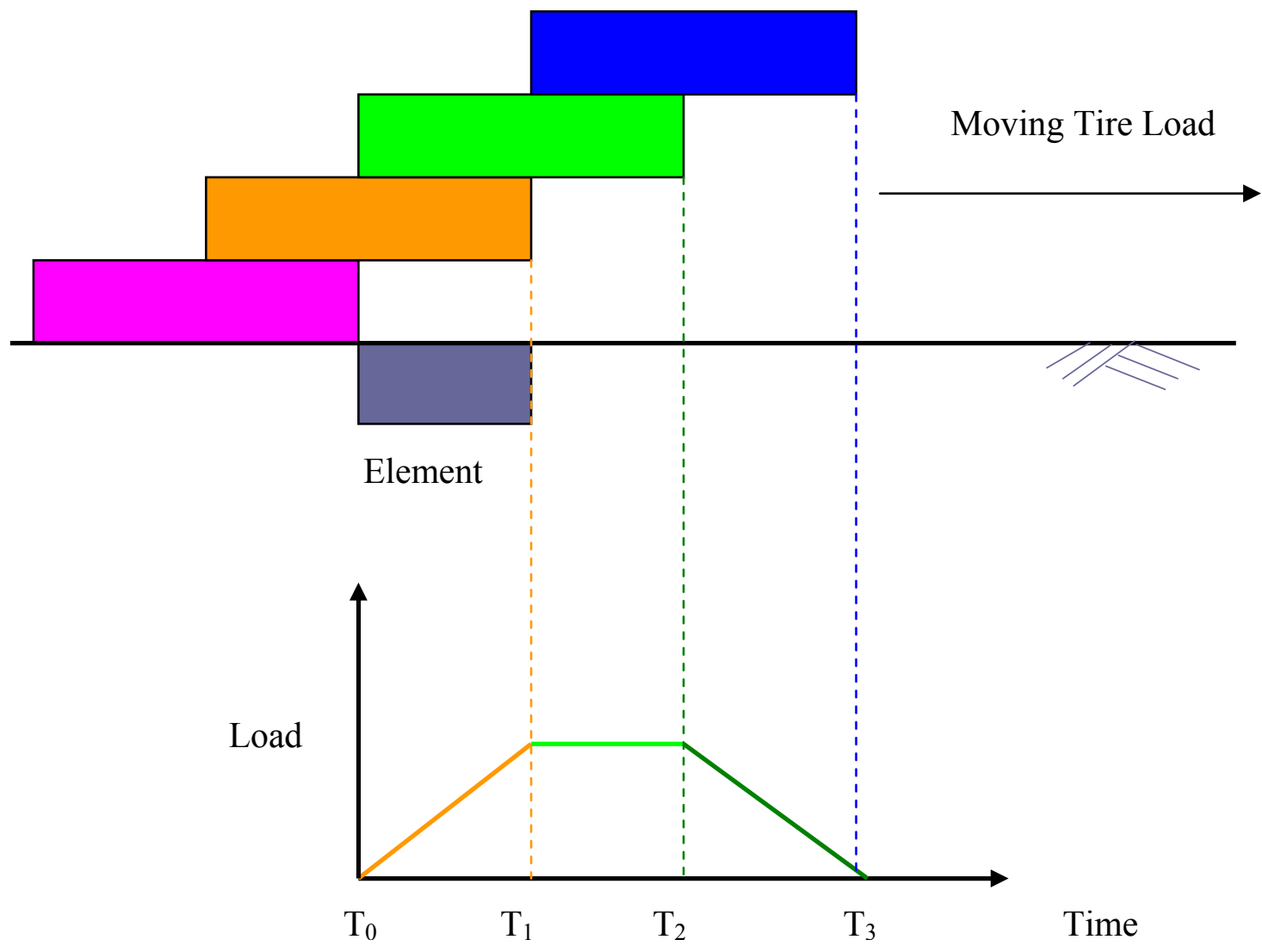

Figure 4.39 Simulation of moving load 


\subsubsection{Determination of Appropriate Number of Moving Load Elements}

An appropriate number of elements to simulate moving tire load should be selected to satisfy both accuracy and economy. In order to determine the number of elements where the load travels, the load to travel over a number of elements ranging from one to fifty was considered. Figure 4.40 shows examples of cases with number of elements. During passage of the load, the response of the central elements of the mesh for every layer of the pavement, including the subgrade was observed. It was concluded that there was no significant difference in the response of these elements whether the load was made to travel over one or fifty elements. Therefore, to keep computation time economical, all calculations were made for the case in which the load travels across the central top element of the mesh.

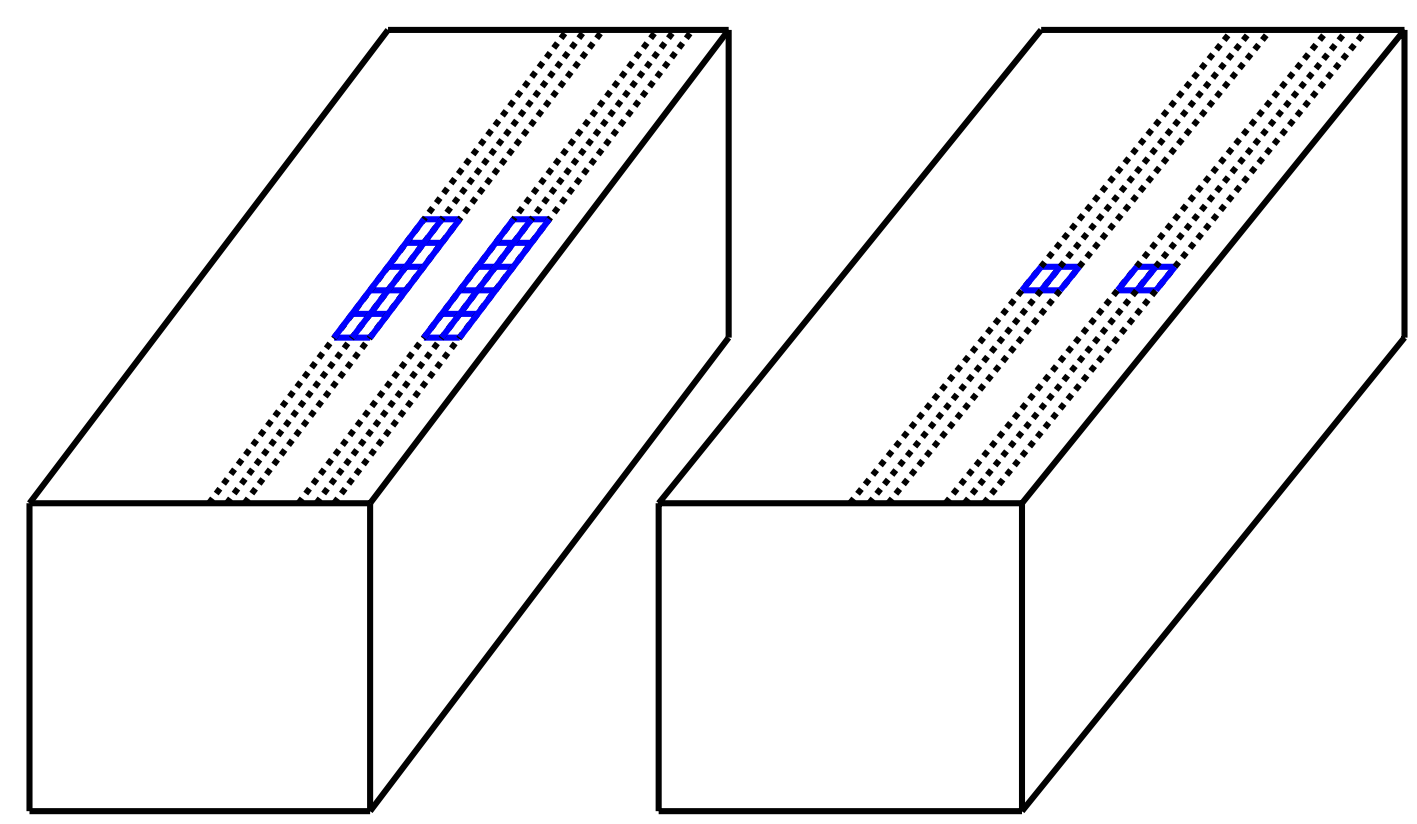

Figure 4.40 Determination of appropriate element number of moving tire loads 


\subsubsection{Effects of Moving Load Speed}

Figure 4.41 is an illustration of the displacements resulting from different truck speeds. The lower the truck speed, the larger the displacements. This implies that at lower speeds, trucks can do more damage to road systems. As seen in this figure, the difference in displacements between a speed of $60 \mathrm{~km} / \mathrm{hr}$ and $10 \mathrm{~km} / \mathrm{hr}$ is not large. At high speed $(100 \mathrm{~km} / \mathrm{hr})$, a considerable decrease in displacement is observed. In the following work, a speed of $60 \mathrm{~km} / \mathrm{hr}$ is used.

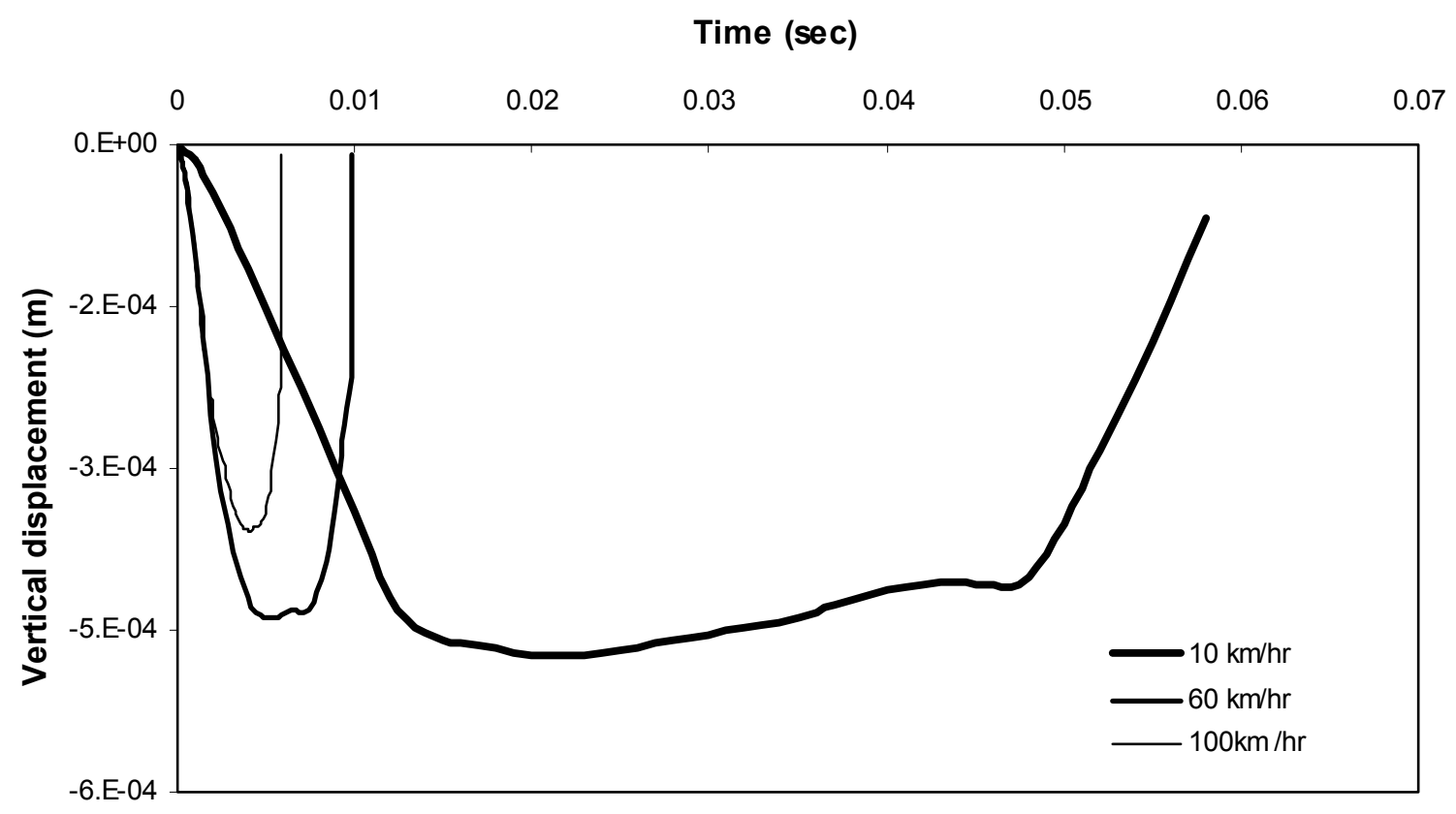

Figure 4.41 Vertical deformations on top of subgrade with various speeds 


\subsubsection{Effects of Repeated Moving Loads}

Figure 4.42 shows the permanent displacements of each pavement layer. The horizontal axis represents the time required for a tire loading to pass the given element for which the displacement is plotted. The figure shows that as the moving tire load enters the element being analyzed, the pavement structure starts to deform. After the tire loading is out of the element, only permanent, plastic deformations remain. It can be seen that permanent deformations occur in every pavement layer, but are particularly large in the subgrade layer.

As mentioned previously, the permanent strain on top of the subgrade is the basis for rutting criteria. Figure 4.43 shows the evaluation of permanent vertical strains due to five passages of moving super-single tires over the element. The permanent strains initially increase sharply, and then stabilize. Figure 4.44 shows the predicted permanent strains by FEM from zero to five repetitions, as well as those by the predictive model of Diyaljee and Raymond (1983). As seen in Figure 4.44, the results of FEM and the permanent strain model of Diyaljee and Raymond are in good agreement in the zero to five load repetition range. The time required for FE analysis for a large number of repetitions is prohibitive, so extrapolation of the FE results by a relationship such as that of Diyaljee and Raymond (1983) is necessary. As the number of passages of a supersingle tire increases, the permanent deformations clearly increase, if such a model is deemed satisfactory for repetitions beyond 5 . 


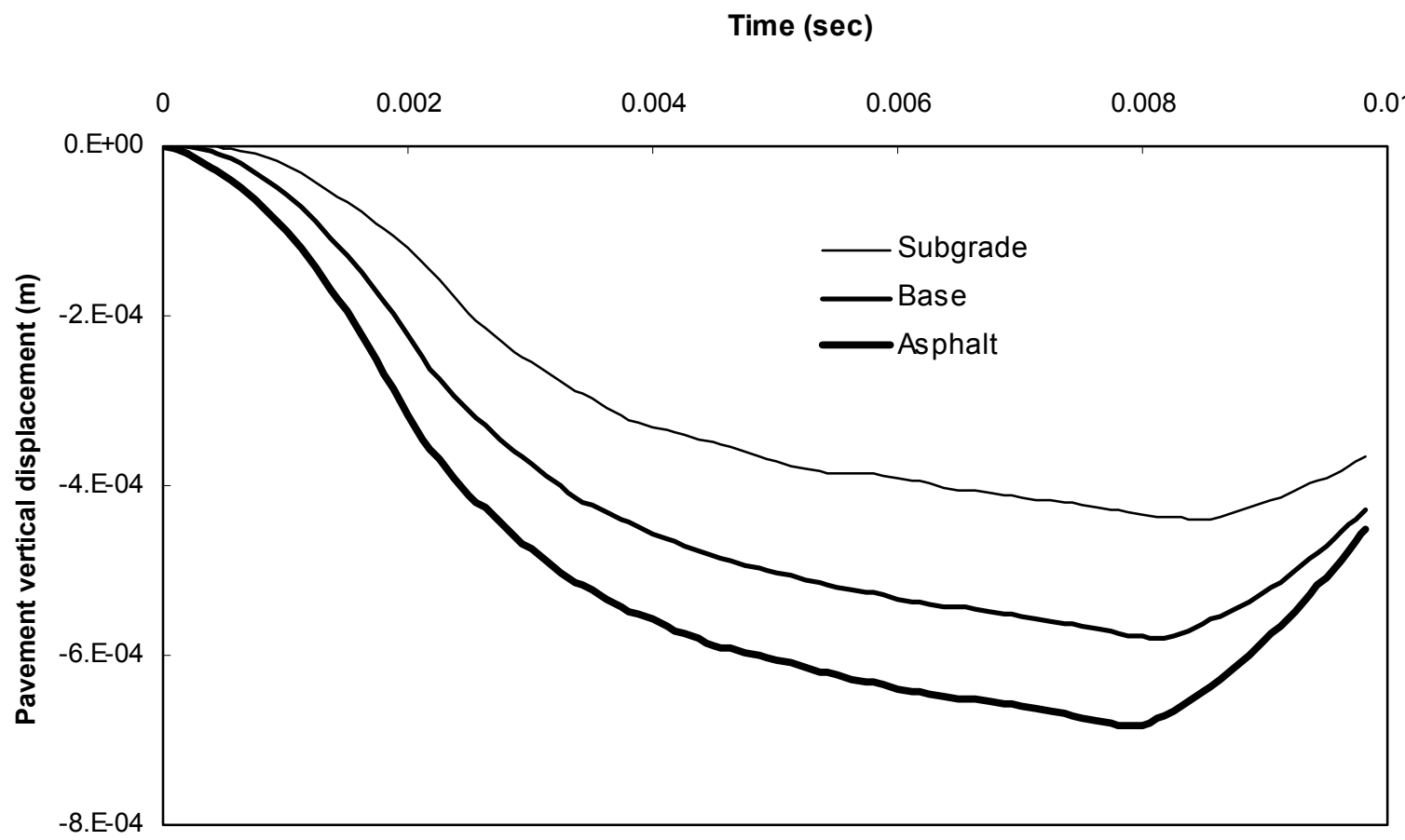

Figure 4.42 Permanent vertical deformations of each layer 


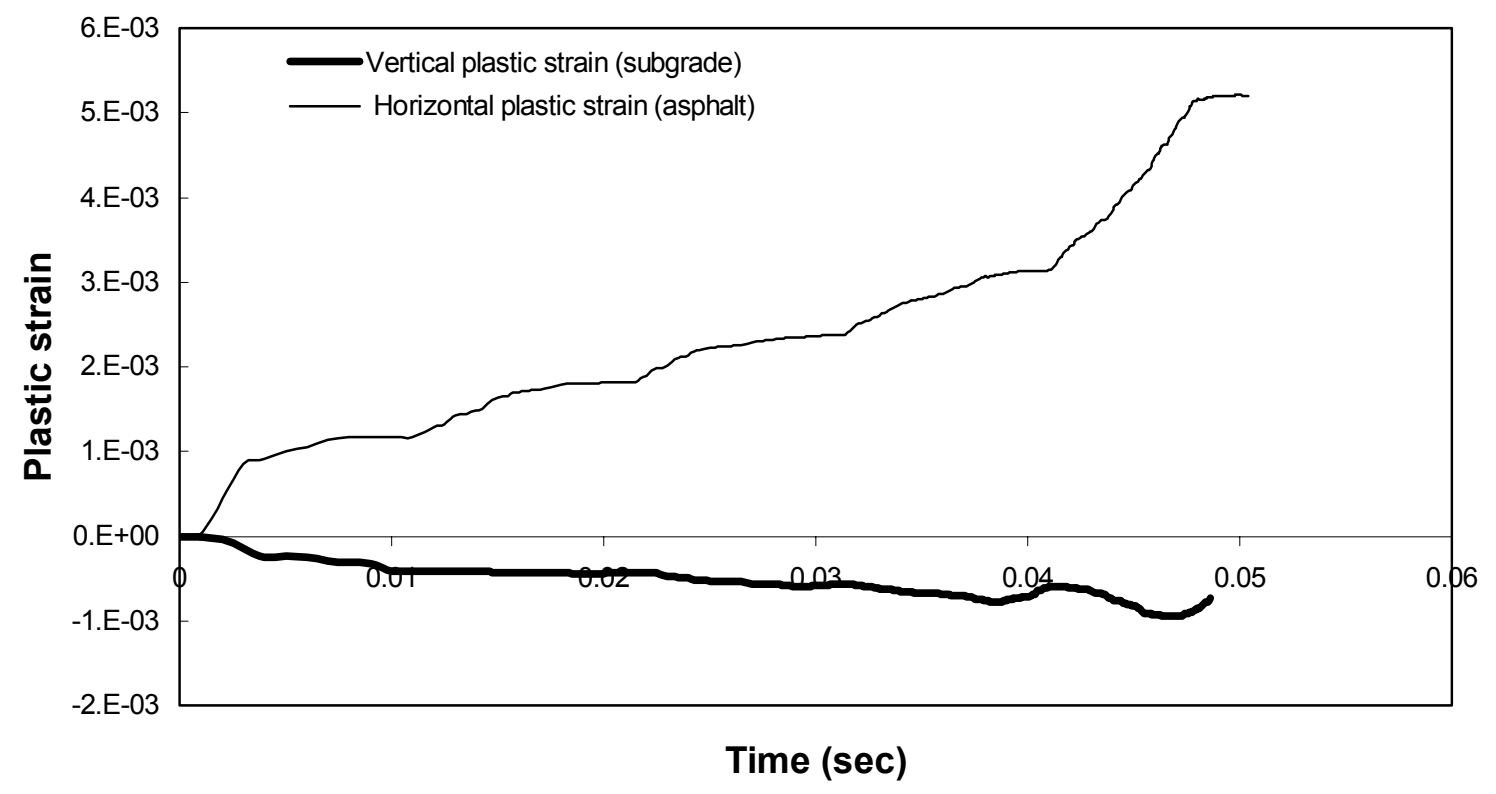

Figure 4.43 Permanent strains due to the repeated moving loads

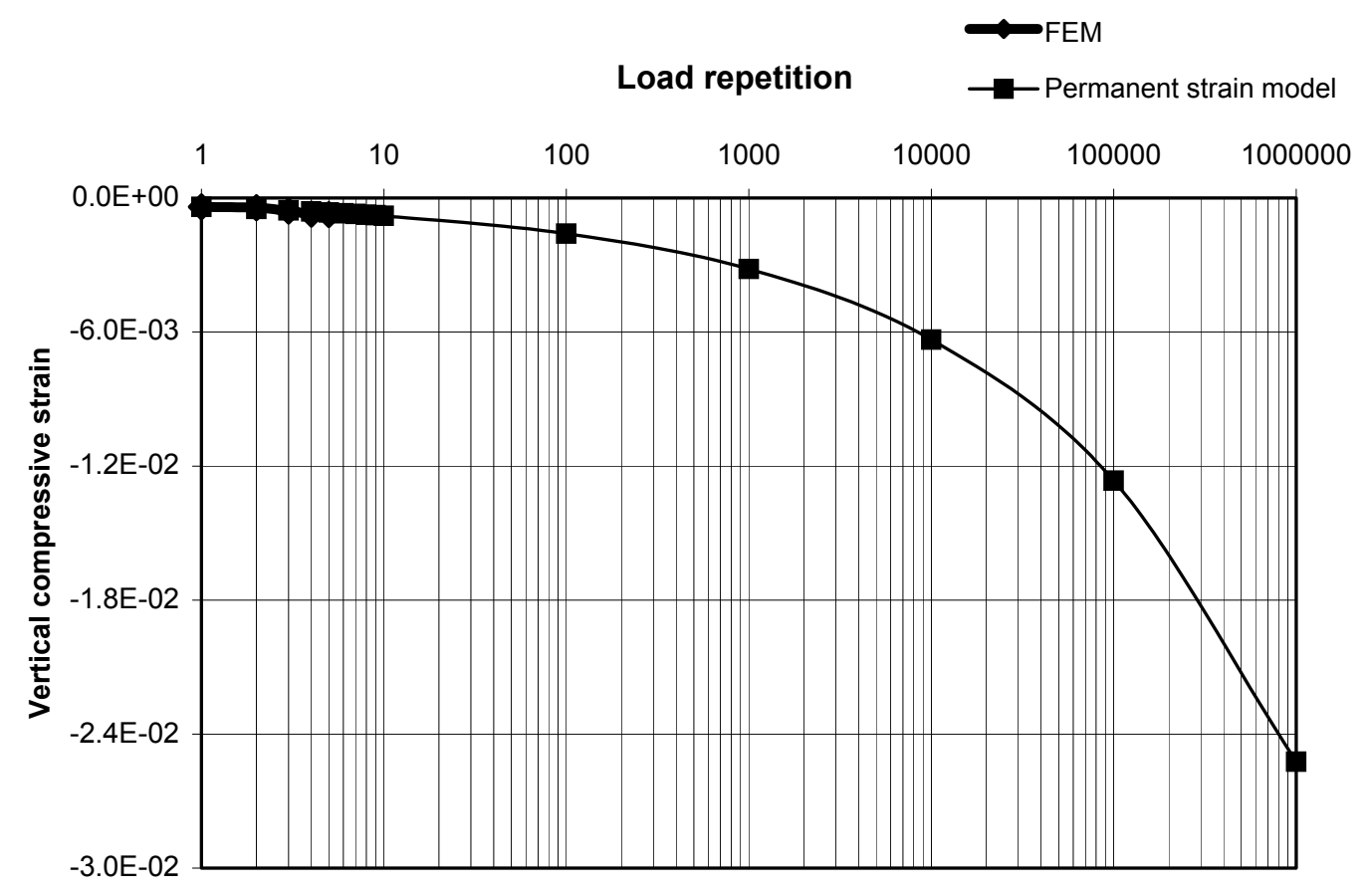

Figure 4.44 Load Repetitions vs. vertical permanent strains 


\subsection{Dynamic Load Equivalency Factors}

In order to obtain the dynamic load equivalent factors, the $18,000 \mathrm{lb}$ single axle load was repeatedly applied up to 20 times. The LEF for rutting was obtained from the permanent vertical strains on top of the subgrade layer, while the LEF for fatigue was determined from the permanent horizontal strains at the bottom of the asphalt layer. The number of repetitions of the $18,000 \mathrm{lb}$ single axle was obtained from the magnitude of the permanent vertical strains on top of the subgrade and the permanent horizontal strains at the bottom of the asphalt layer. These strains are created by one passage of a moving super-single tire loading. As seen in Table 4.5, one passage of the super-single tire generates the same damage as about four passages of dual tires.

Table 4.5 Dynamic load equivalent factors using elastic-plastic, dynamic analysis

\begin{tabular}{|c|c|c|c|c|c|}
\hline Tire type & Axle Load & $\begin{array}{c}\text { LEF } \\
\text { (Fatigue) }\end{array}$ & \multirow[t]{2}{*}{$\begin{array}{l}\text { Damage } \\
\text { (Fatigue) }\end{array}$} & $\begin{array}{c}\text { LEF } \\
\text { (rutting) }\end{array}$ & \multirow[t]{2}{*}{$\begin{array}{l}\text { Damage } \\
\text { (Rutting) }\end{array}$} \\
\hline Dual & $18,000 \mathrm{lbs}$ & 1 & & 1 & \\
\hline Dual & $22,800 \mathrm{lbs}$ & 1.27 & 1 & 1.22 & 1 \\
\hline Super-single & $22,800 \mathrm{lbs}$ & 6.23 & 4.9 & 4.37 & 3.5 \\
\hline
\end{tabular}


4.7 Comparison of Damage Factor between Linear-elastic and Elastic-plastic Dynamic $\underline{\text { Analyses for Dual and Super-Single Tires }}$

Table 4.6 shows the damage factors obtained from empirical equations using linear elastic analysis and those from repeated moving loads using elastic-plastic dynamic analysis. The obtained values for the rutting damage factor is in good agreement, with values ranging from 3.5 to 3.6. Fatigue damage factors range from 4.9 to 7.6. Therefore, in the design of a pavement structure, these results can be used as relative damage factors for super-single tires.

Table 4.6 Comparison of damage factors between linear-elastic and elastic plastic, dynamic analysis

\begin{tabular}{|c|c|c|c|c|c|}
\hline \multirow{2}{*}{ Tire type } & \multirow{2}{*}{ Axle load } & \multicolumn{2}{|c|}{$\begin{array}{c}\text { Damage factor } \\
\text { (linear-elastic) }\end{array}$} & \multicolumn{2}{c|}{$\begin{array}{c}\text { Damage Factor } \\
\text { (elastic-plastic, dynamic) }\end{array}$} \\
\cline { 3 - 6 } & & Fatigue & Rutting & Fatigue & Rutting \\
\hline Dual & $22,800 \mathrm{lbs}$ & 1 & 1 & 1 & 1 \\
\hline Super-Single & $22,800 \mathrm{lbs}$ & 7.6 & 3.6 & 4.9 & 3.5 \\
\hline
\end{tabular}




\subsection{Effects of Axle Configurations}

Figure 4.46 compares the effects of different axle configurations. It shows that single tires induce higher vertical plastic strains than dual tires. Super-single tires with a single axle produce the highest vertical plastic strains. This confirms the findings of Kilareski (1992) and Jooste and Fernando (1995). Although the total loads for tandem and tridem axles are larger than the total load for single axles, the distance between the two or three axles in these configurations is large enough and hence there is little superposition of effects. Therefore, the single axle with super-single tires is more adverse to pavement systems than tandem axles and tridem axles with super-single tires. This result is due to the higher second deviatoric tensor $\mathrm{J}_{2}$ produced by the single axle with super-single tires, as observed also in the study done by Jooste and Fernando (1995).

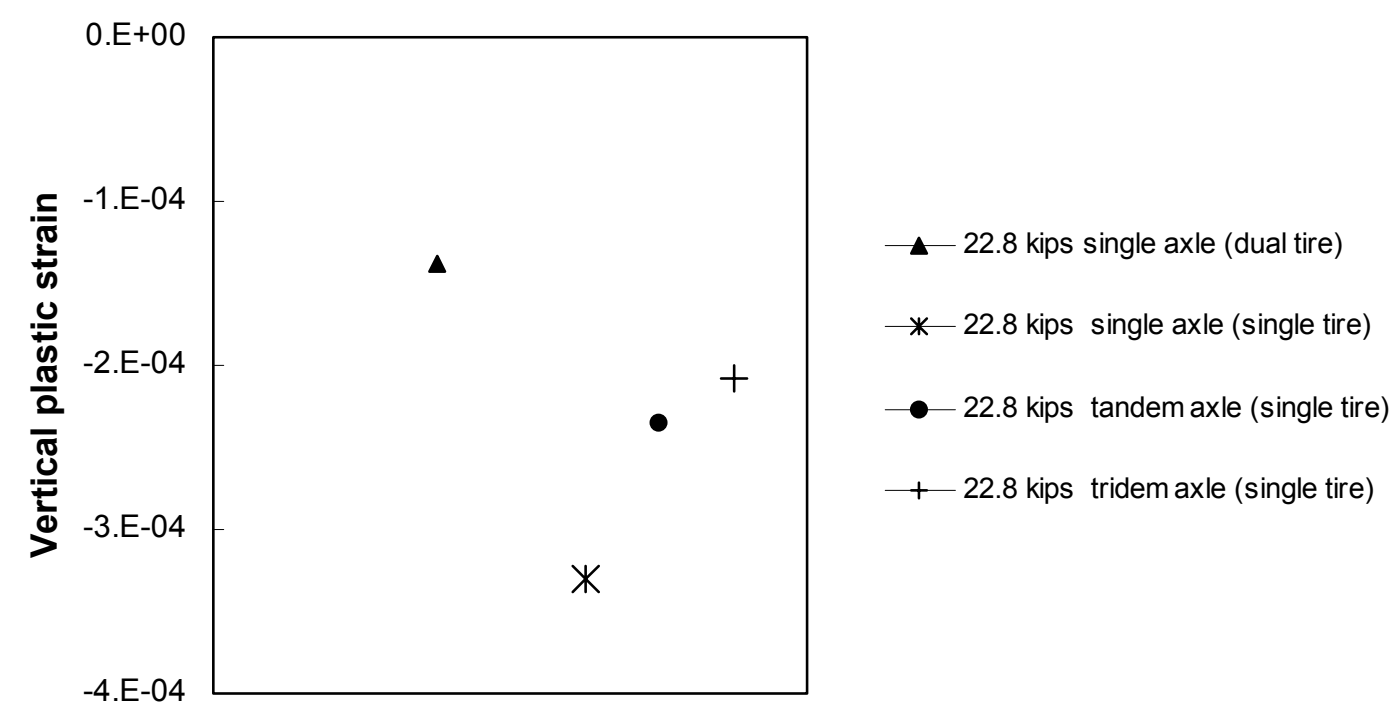

Axle configuration

Figure 4.45 Axle configurations vs. vertical plastic strains. 


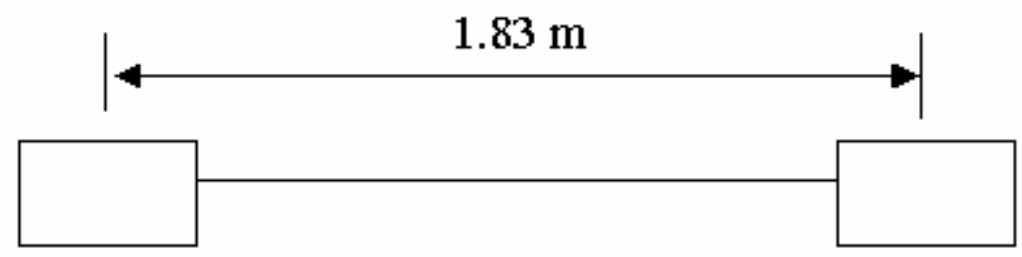

(a)

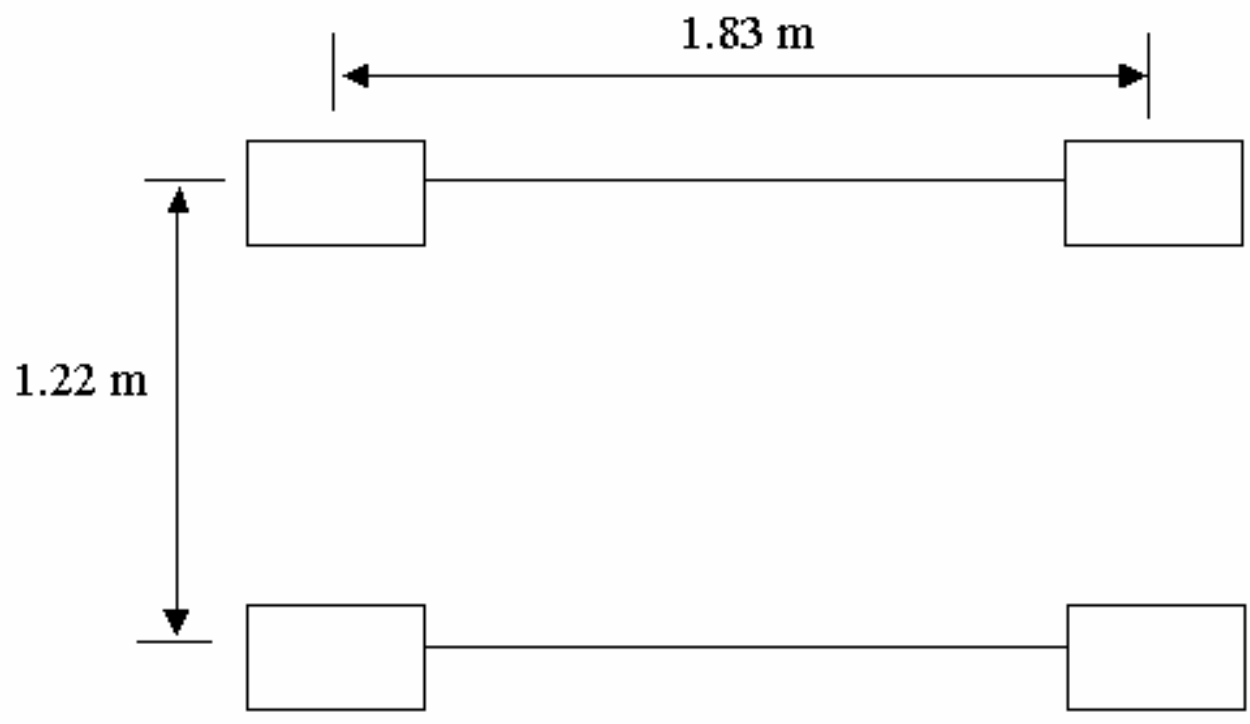

(b)

Figure 4.46 (a) Single axle (b) Tandem axle (c) Tridem axle with super-single tires 


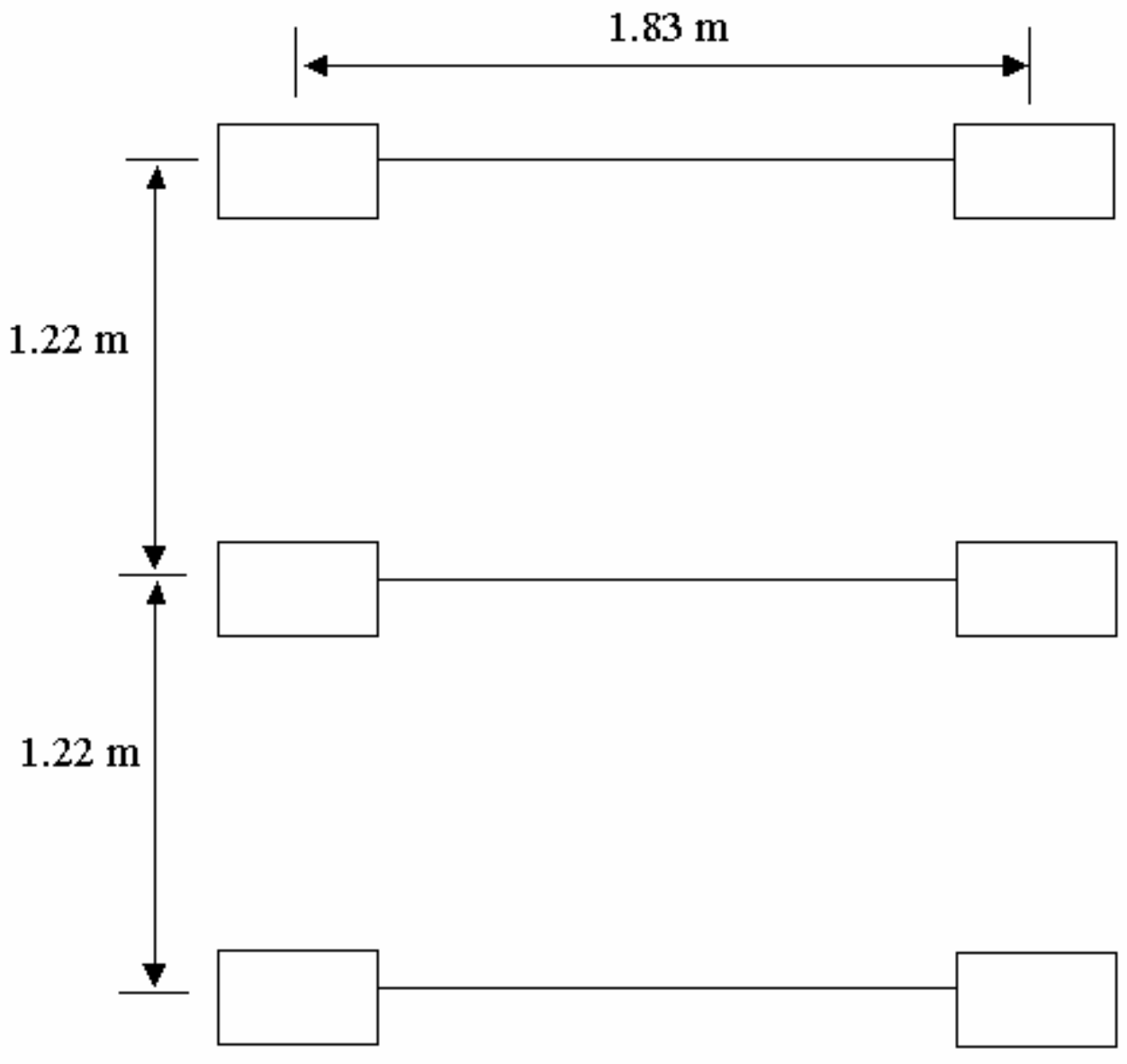

(c)

Figure 4.46 continued (a) Single axle (b) Tandem axle (c) Tridem axle with super-single tires 


\subsection{Comparison of the subgrade type}

Table 4.7 shows that larger displacements and larger plastic strains take place in the clay subgrade than in the sand subgrade. The data for clay shown in Table 4.7 are for cross-section 1 . A clay with OCR $=9$ experiences a similar magnitude of plastic strains as the sand subgrade. As a result, since the generation of pore water pressures in the subgrade and the performance of the subgrade are quite different depending on soil conditions, an appropriate evaluation of the subgrade soils is important in the design of pavements.

\subsection{Effects of the type of cross-section}

As shown in Table 4.7, cross-section 2, which has an asphalt base layer, performs better than cross-section 1, which has an aggregate base, in terms of vertical plastic strains and displacements on top of the subgrade. When the subgrades are composed of sand in all the cross-sections, cross-section 2 has the lowest negative pore pressure. This result occurs because the asphalt base layer, which has low hydraulic conductivity, is located right above the sand subgrade. 
Table 4. 7 Effects of types of cross-sections and nature of subgrade on response to supersingle tires loadings

\begin{tabular}{|c|c|c|c|}
\hline & $\begin{array}{c}\text { Vertical plastic strain } \\
\text { (on top of subgrade) }\end{array}$ & $\begin{array}{c}\text { Displacement (mm) } \\
\text { (on top of subgrade) }\end{array}$ & $\begin{array}{c}\text { Pore pressure } \\
(\mathrm{kPa})\end{array}$ \\
\hline Cross-Section 1 & 0.0001106 & 0.3205 & -35 \\
\hline Cross-Section 2 & 0.0000915 & 0.2924 & -38 \\
\hline Cross-Section 3 & 0.0001617 & 0.3655 & -40 \\
\hline Cross-Section 4 & 0.0001514 & 0.3554 & 35 \\
\hline OCR 1 & 0.0009431 & 0.9709 & 12 \\
\hline OCR 3 & 0.0007691 & 0.6283 & -15 \\
\hline OCR 5 & 0.0004800 & 0.4685 & -19 \\
\hline OCR 7 & 0.0003059 & 0.3879 & -12 \\
\hline OCR 9 & 0.0001932 & 0.3364 & \\
\hline OCR 15 & 0.0000526 & 0.2531 & \\
\hline
\end{tabular}




\subsection{Summary}

As a result of the trend in the trucking industry of relying more on trucks using super-single tires, the effects of the loading imposed by these tires on pavements require careful study. In this chapter, this problem was studied through extensive finite element analyses using both elastic and elastic-plastic models, considering both plane-strain (2D) and $3 \mathrm{D}$ conditions. The difference in results using 2D FEA and 3D FEA shows that 2D modeling can be excessively conservative in designing pavements due to the infinite loading condition which is not true for the tire loading acting on the limited tire contact area. Therefore, it would be desirable to do 3D modeling in order to achieve more realistic results although it requires much more computation effort. Multi-layered elastic analysis is mostly used in design of pavements. However, as subgrade soils show nonlinear and elastic-plastic behavior, it would be more reasonable to do plastic analysis than to do elastic analysis. The main findings of the study are as follows:

- It was found that the orientation of the maximum tensile stress is dependent on the shape of the contact stress distribution and that the maximum tensile strain occurring in the transverse direction is larger than that in the longitudinal direction.

- Plane-strain modeling of the pavement is much more conservative than $3 \mathrm{D}$ modeling. Although the computation effort is much larger for 3D analyses, the more realistic results justify the use of these analyses where greater accuracy is required.

- According to the comparison of conventional and super-single tires under elastic-plastic conditions, super-single tires induce larger permanent strains in the pavement layers than 
conventional tires. Therefore, design of a pavement using LEF values for dual tires leads to overestimation of the pavement design life.

- Single axle loadings with super-single tires induce the largest vertical plastic strains on top of the subgrade of all the axle configurations considered.

- The analysis done for moving loads shows that the higher the speed of the truck, the less the load on the subgrade.

- For clay subgrades, the higher the OCR, the less deformation occurs.

- Positive pore pressures are generated in normally consolidated clay subgrades, while negative pore pressures are typically generated within heavily overconsolidated clays. Therefore, in a NC clayey subgrade, the shear strength is reduced as a result of traffic loadings.

- The estimation of vertical permanent deformations using FEM shows good agreement with the permanent strain model for 0 to 5 load repetitions. FE analysis is prohibitive for a large number of load repetitions, making the use of a simplified model a necessity.

- Repeated super-single tire loadings increase vertical permanent strains in the subgrade for existing roads. This implies that either mitigation of permanent strains in the subgrade must be pursued or the number of passages of super-single tires must be limited by appropriate regulation.

- Rutting damage factors for super-single tires compared with dual tires range from 3.5 to 3.6. Fatigue damage factors range from 4.9 to 7.6. Therefore, in the design of a pavement structure, these results can be used as relative damage factors for super-single tires compared with dual tires for the same load. 


\section{CHAPTER 5 OVERLAY AND SUBGRADE IMPROVEMENT}

\subsection{Introduction}

In the FE analyses described in chapter 4, super-single tires were shown to cause higher permanent strains in the subgrade than conventional dual tires for typical pavement cross-sections. If super-single tire prevail in highway use, existing pavements designed using current methods will deteriorate much earlier than their expected design life. As a result, methods to relieve the permanent strains in subgrades should be devised. Such methods may be either placing an overlay or improving the strength of each layer.

Pavement design is generally performed based on the LEF or ESAL obtained from the axle with dual tires. Therefore, in this chapter, the overlay addition and subgrade improvement will be investigated by comparing the strains in the subgrade induced by super-single tires for the modified cross-section with those induced by dual tires for the same load for the original cross-section. The primary objective of this investigation is to identify how much overlay and subgrade improvement are needed for the super-single tires to produce lower strain levels than dual tires induce in the subgrade for the original pavement cross-section. The methods of overlay and typical subgrade improvement will 
be reviewed. The quantity of overlay and soil improvement will also be investigated through FE analyses.

\section{$5.2 \underline{\text { Overlay }}$}

Since a pavement is not a permanent structure, maintenance is needed at appropriate times during the pavement life in service. Usually, when a pavement structure is deteriorated by fatigue cracking and rutting, some form of rehabilitation is required. Depending on the situation, these types of treatments can range from simple maintenance to complete reconstruction of the pavement. For pavements subjected to heavy traffic, the most prevalent treatment is to place an overlay on the exiting pavement. The following are four types of overlay: HMA overlays on asphalt pavements, HMA overlays on PCC pavement, PCC overlays on asphalt pavements, and PCC overlays on PCC pavements (Huang 1993).

\subsubsection{Overview of Overlay Methods}

For an existing asphalt pavement, HMA overlay on the asphalt layer is the typical method. A variety of agencies utilize diverse methods for the design of overlays. Generally, the procedure for the design of the overlay is similar to that of a new pavement, with the difference that it should take into consideration the condition or remaining life of the existing pavement at the time of overlay. Three methods used for overlay design are the (a) effective thickness method, (b) the deflection method, and (c) the mechanistic-empirical method. 
The fundamental principle of the effective thickness method is that the necessary thickness of the overlay is the difference between the thickness required for the new pavement and the effective thickness of the existing pavement. This procedure assumes that as the pavement deteriorates and uses part of its total life, it behaves as if it were an increasingly thinner pavement, i.e., its effective thickness accounts for the expended portion of the total life (growing smaller over time).

The basic concept of the deflection method is that larger pavement surface deflections imply a weaker pavement and subgrade, requiring thicker overlays. The overlay must be thick enough to reduce the deflection to a tolerable amount. Only the maximum deflection directly under the load is typically considered. The deflection method is based on the empirical relationship between pavement deflection and overlay thickness and has been used by the Asphalt Institute (1983)

The mechanistic-empirical approach is similar to the design of new pavements. This method requires the determination of critical stress, strain, or deflection in the pavement by mechanistic methods and the prediction of the resulting damages by some empirical failure criteria. Based on the pavement condition or remaining design life, the thickness of the overlay is determined so that the damage in either the existing pavement or new overlay will be within the allowable limits. This method has been used by the Portland Cement Association (PCA).

Two major overlay design methods are the Asphalt Institute method and the AASHTO method. In the Asphalt Institute method, two available procedures are the effective thickness and the deflection method. The effective thickness method is based on an assessment of the condition of the existing pavement at the time of overlay without 
conducting deflection tests. In order to determine the effective thickness of the existing pavement in terms of HMA thickness, based on the Present Service Index (PSI) and the condition of each layer, one or more conversion factors obtained from figures and tables should be found. The deflection method is based on the pavement deflections measured with a Benkelman beam using a rebound test procedure. The overlay thickness is determined by the evaluation of the deflection before and after overlay considering remaining life, current ESAL and additional ESAL.

The AASHTO overlay design procedure is based on the remaining life and can be applied to any type of overlay. The existing pavement has an initial pavement serviceability and structural capacity. As the number of load applications increases, the pavement gradually deteriorates resulting in its reduction of serviceability and structural capacity. Finally, the pavement reaches its serviceability limit, requiring an overlay.

More detailed design procedures are well explained in the manuals of the AI method and the AASHTO design method. In summary, as a pavement deteriorates by cracking or rutting, and experiences its designed ESAL, an overlay can be added to it to extend its life and enhance serviceability. In order to perform an overlay design, a comprehensive assessment of the existing pavement structure should be performed.

\subsubsection{Effects of Overlay}

In this section, FE analyses with respect to the thickness of overlay were done to assess the effects of the overlay on vertical strains on top of the subgrade. For existing pavements, comparisons of the strains by super-single tires with those by dual tires were made. Then the amount of overlay required for the current pavement structure by the 
super-single tire was investigated. The procedure is as follows. First, the strains on top of the subgrade are obtained for super-single tires and dual tires, allowing the difference between the magnitudes of these strains to be estimated. By increasing the thickness of the asphalt layer, this difference can be shrunk down to zero.

Figures 5.1 and 5.2 show the effect of overlay thickness on the vertical strains on top of the subgrade obtained from elastic analyses for cross-section 1 and cross-section 2, respectively. In these analyses, the thickness of overlay was increased with the Young's modulus kept constant. The results are for dual tires and super-single tires with an axle load of 22,800 lbs. As seen from these figures, the vertical strains induced by the supersingle tires are much higher in the existing pavement. As the overlay increases, the vertical strains decrease. Around 45 to $50 \mathrm{~mm}$ overlay above the asphalt layer allows the vertical strains induced by super-single tires on top of the subgrade to be of the same magnitude as those induced by dual tires in the existing pavement. 


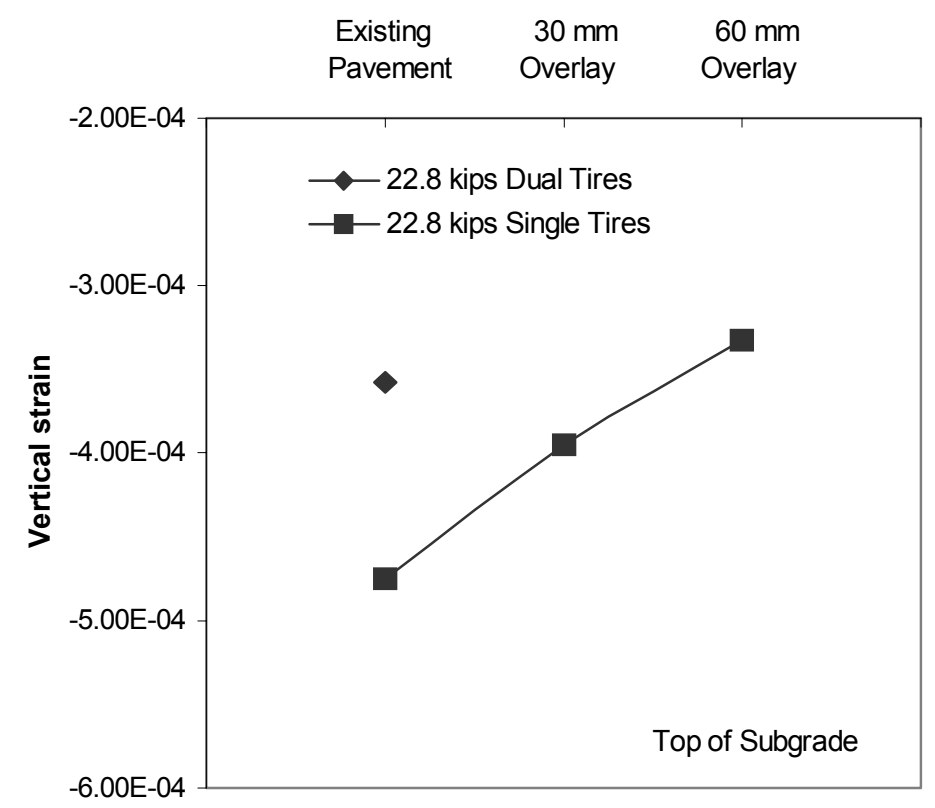

Figure 5.1 Effect of overlay on vertical strain on top of subgrade for cross-section 1 (elastic analysis)

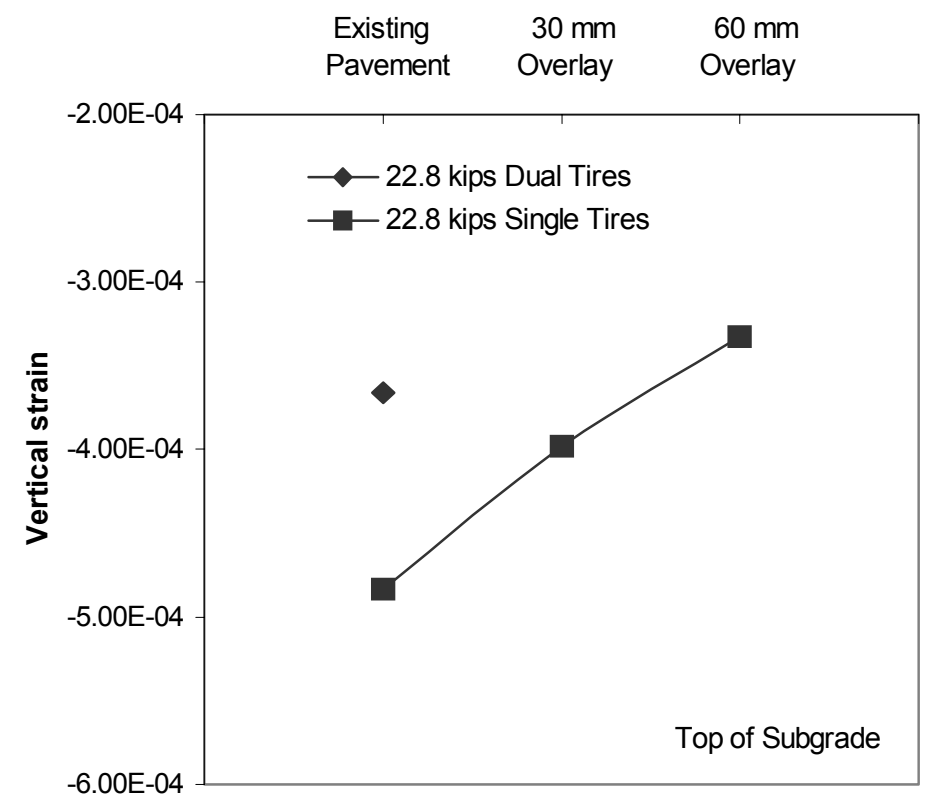

Figure 5.2 Effect of overlay on vertical strain in subgrade for cross-section 2 (elastic analysis) 
Figures 5.3 and 5.4 show the effect of overlay on the vertical strains on top of the subgrade obtained from elastic plastic analyses for cross-section 1 and cross-section 2 , respectively. The thicker the overlay, the smaller the vertical plastic strains on top of the subgrade. The range of the overlay thickness needed to mitigate the vertical strains by super-single tires is 50 to $60 \mathrm{~mm}$. This thickness may be appropriate to decrease the vertical strains on top of the subgrade if the super-single tires become dominant on highways.

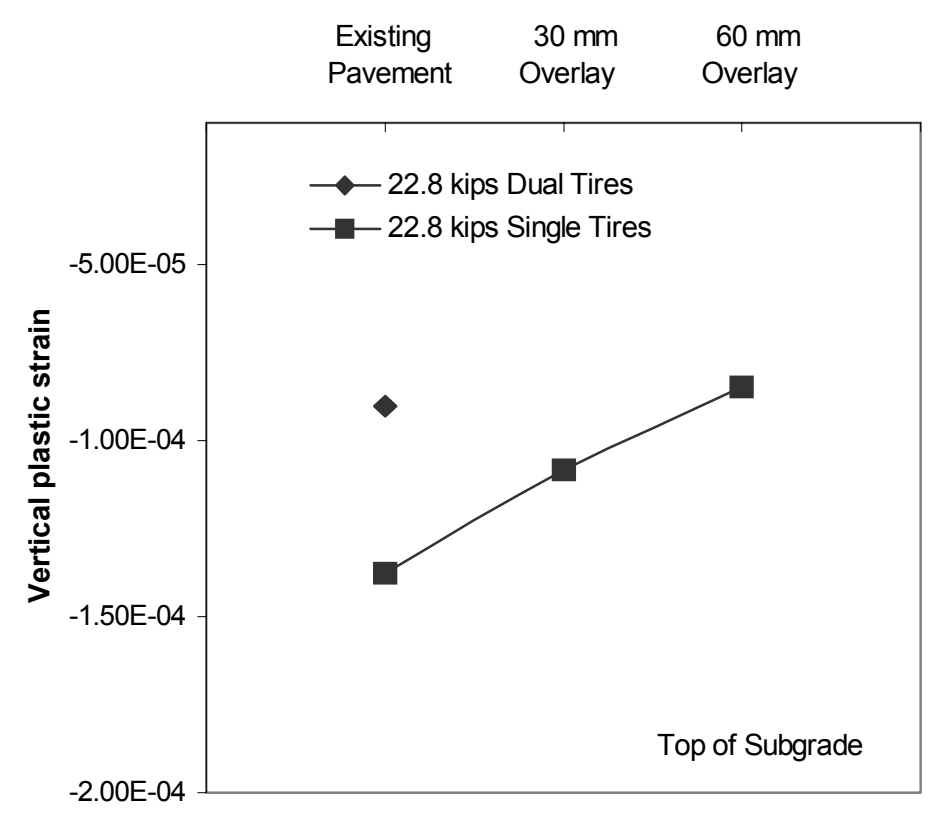

Figure 5.3 Effect of overlay on vertical plastic strain in subgrade for cross-section 1 (elastic-plastic analysis) 


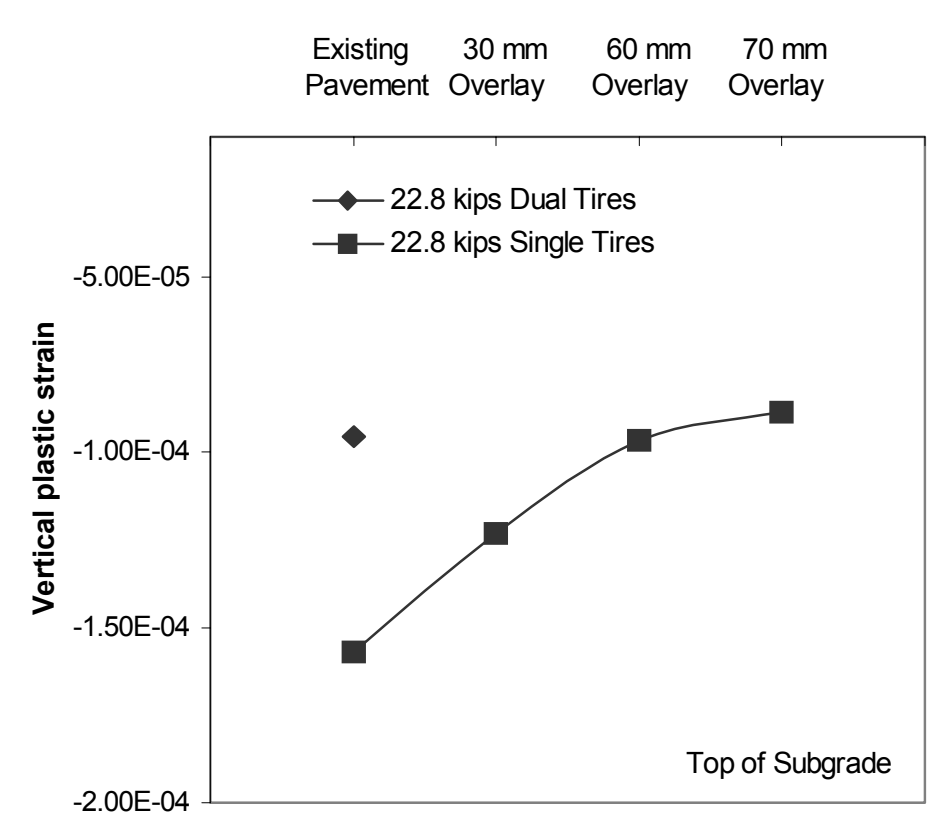

Figure 5.4 Effect of overlay on vertical plastic strain in subgrade for cross-section 2 (elastic-plastic analysis)

Figures 5.5 and 5.6 show the effect of overlay thickness on the horizontal strains at the bottom of the asphalt, obtained from elastic and elastic-plastic analyses, respectively. As observed from Figures 5.1 - 5.4, when a 40 to $60 \mathrm{~mm}$ overlay is used, the vertical strains induced by the super-single tires decreased into the targeted ranges (lower than the strains by dual tires). However, as seen in Figures 5.5 and 5.6, horizontal strains are still higher than the strains induced by dual tires. Figure 5.7 shows the effect of increase in Young's modulus of the asphalt layer on the horizontal strains. This result indicates that mitigation of the horizontal strains may be more effectively accomplished by the increase in the stiffness of the asphalt layer than increase of the overlay thickness. 


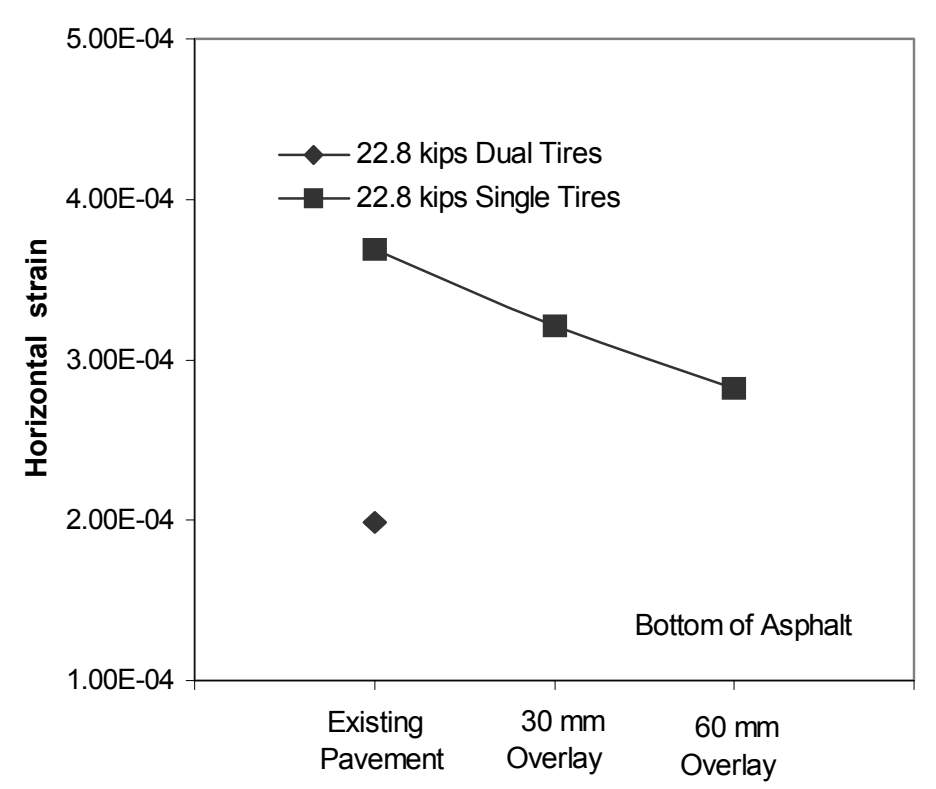

Figure 5.5 Effect of overlay on horizontal strain at the bottom of asphalt layer for crosssection 1 (elastic analysis)

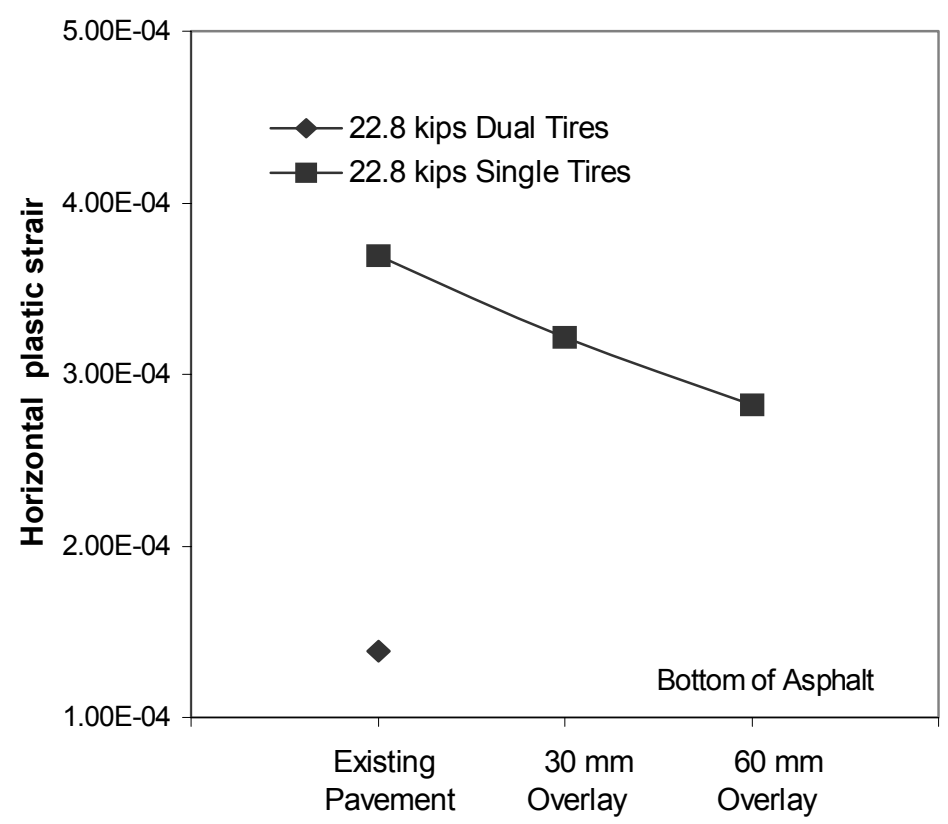

Figure 5.6 Effect of overlay on horizontal strain at the bottom of asphalt layer for crosssection 1 (elastic-plastic analysis) 


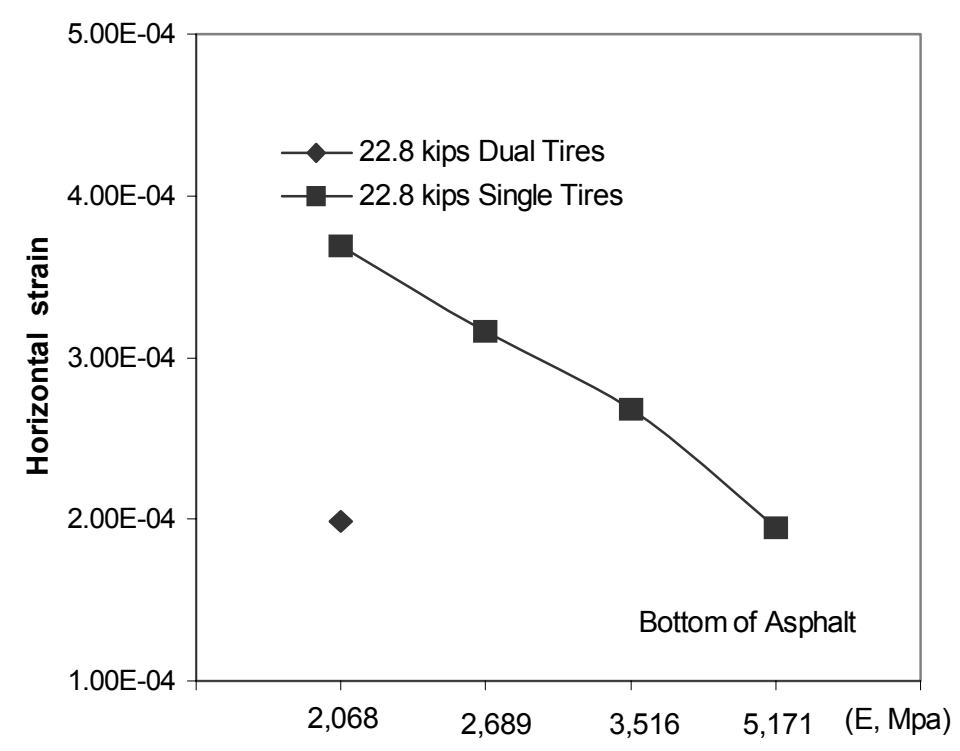

Figure 5.7 Effect of increase in Young's modulus of asphalt layer on horizontal strain for cross-section 1 (elastic-plastic analysis)

Tables 5.1 and 5.2 show the number of repetitions required to cause fatigue failure and rutting failure with respect to the thickness of overlay. As the thickness of overlay increases, the number of repetitions for failure increases. This result means that the overlay can reduce rutting failure resulting from the accumulation of vertical strains in a certain design period. Table 5.3 shows that the number of repetitions for fatigue failure is increased due to the increase in Young's modulus of the asphalt layer. Therefore, a decision to decrease the vertical strains or horizontal strains would be more effectively made based on the given conditions where either rutting or fatigue failure is prevalent. 
Table 5.1 Effect of overlay on the number of repetitions needed for fatigue and rutting failure (cross-section 1)

\begin{tabular}{|c|c|c|c|c|c|c|c|c|c|}
\hline Tire type & Load & Horizontal & Vertical & $\mathrm{N}_{\mathrm{f}} 10 \%$ & $\mathrm{~N}_{\mathrm{f}} 45 \%$ & LEF & $\mathrm{N}_{\mathrm{d}}$ & LEF \\
(frain & Strain & (fatigue) & (fatigue) & (fatigue) & (rutting) & (Rutting) & pavement \\
\hline Dual & 18,000 & 0.0001716 & 0.0002863 & $3,007,706$ & $4,163,607$ & 1 & $9,958,987$ & 1 & existing \\
\hline Dual & 22,800 & 0.0001989 & 0.0003579 & $1,847,229$ & $2,557,522$ & 1.63 & $3,663,424$ & 2.72 & existing \\
\hline Super-single & 22,800 & 0.0003692 & 0.0004754 & 241,519 & 334,594 & 12.44 & 1,027871 & 9.69 & existing \\
\hline Super-single & 22,800 & 0.0003212 & 0.0003952 & 381,822 & 528,893 & 7.87 & $2,351,157$ & 4.24 & $3 \mathrm{~cm}$ overlay \\
\hline Super-single & 22,800 & 0.0002818 & 0.0003329 & 587,299 & 813,409 & 5.12 & 506,6800 & 1.97 & $6 \mathrm{~cm}$ overlay \\
\hline
\end{tabular}


Table 5.2 Effect of overlay on the number of repetitions needed for fatigue and rutting failure (cross-section 2)

\begin{tabular}{|c|c|c|c|c|c|c|c|c|c|}
\hline Tire type & Load & Horizontal & Vertical & $\mathrm{N}_{\mathrm{f}} 10 \%$ & $\mathrm{~N}_{\mathrm{f}} 45 \%$ & LEF & $\mathrm{N}_{\mathrm{d}}$ & LEF \\
& $(\mathrm{lbs})$ & strain & Strain & (fatigue) & (fatigue) & (fatigue) & (rutting) & (Rutting) & pavement \\
\hline Dual & 18,000 & 0.0001982 & 0.0002927 & $1,871,266$ & $2,590,792$ & 1 & $9,016,221$ & 1 & existing \\
\hline Dual & 22,800 & 0.0002313 & 0.0003661 & $1,125,378$ & $1,558,342$ & 1.66 & $3,309,974$ & 2.72 & existing \\
\hline Super-single & 22,800 & 0.0004150 & 0.0004832 & 164,293 & 227,634 & 11.38 & 955,999 & 9.43 & existing \\
\hline Super-single & 22,800 & 0.0003529 & 0.0003979 & 280,061 & 387,972 & 6.68 & $2,280,822$ & 3.95 & $3 \mathrm{~cm}$ overlay \\
\hline Super-single & 22,800 & 0.0003044 & 0.0003321 & 455,566 & 631,008 & 4.11 & $5,079,084$ & 1.78 & $6 \mathrm{~cm}$ overlay \\
\hline
\end{tabular}


Table 5.3 Effect of increase in Young's modulus of the asphalt layer on the number of repetitions for fatigue and rutting failure (cross-section 1)

\begin{tabular}{|c|c|c|c|c|c|c|c|c|c|}
\hline Tire type & Load & Horizontal & Vertical & $\mathrm{N}_{\mathrm{f}} 10 \%$ & $\mathrm{~N}_{\mathrm{f}} 45 \%$ & LEF & $\mathrm{N}_{\mathrm{d}}$ & LEF \\
& $(\mathrm{lbs})$ & strain & Strain & (fatigue) & (fatigue) & (fatigue) & (rutting) & (Rutting) & Pavement \\
\hline Dual & 18,000 & 0.0001716 & 0.0002863 & $3,007,706$ & $4,163,607$ & 1 & $9,958,987$ & 1 & existing \\
\hline Dual & 22,800 & 0.0001989 & 0.0003579 & $1,847,229$ & $2,557,522$ & 1.63 & $3,663,424$ & 2.72 & existing \\
\hline Super-single & 22,800 & 0.0003692 & 0.0004754 & 241,519 & 334,594 & 12.44 & 1,027871 & 9.69 & existing \\
\hline Super-single & 22,800 & 0.0003158 & 0.0004392 & 322,644 & 446,940 & 9.3 & $1,465,472$ & 6.8 & $30 \%$ increase \\
\hline Super-single & 22,800 & 0.0002678 & 0.0004022 & 441,359 & 611,251 & 6.8 & $2,172,445$ & 4.6 & $70 \%$ increase \\
\hline Super-single & 22,800 & 0.0001946 & 0.0003499 & 908,404 & $1,257,674$ & 3.3 & $4,052,037$ & 2.5 & $150 \%$ increase \\
\hline
\end{tabular}




\subsection{Subgrade Improvement}

Indiana specification (1999) for subgrades requires that the first $150 \mathrm{~mm}$ (6 in) below the top of the subgrade shall be compacted to at least $100 \%$ of the maximum dry density as determined in accordance with AASHTO T 99. Also, it requires that soft, loose, or otherwise unsuitable material that cannot be compacted satisfactorily shall be removed if corrective measures are not effective. So, once the road has been constructed and is in use, the subgrade can be regarded to be in good condition. In this section, the methodology of subgrade improvement is briefly discussed. The focus is on how much subgrade improvement is needed to achieve performance requirements for super-single tires.

\subsubsection{Overview of Subgrade Improvement Methods}

When a soil is too poor to pass specifications, one way to improve it is to blend it with other natural materials (Hausmann 1990). Lime and cement treatment has been extensively used for road construction purposes resulting in increased bearing capacities in soft subgrades, enabling a reduction of base layer thicknesses (Bergado et al. 1996, Croney et al. 1998). The asphalt or base layer would have to be thicker if the subgrade had a very low strength in a pavement structure. The thickness of the asphalt or base layer can be reduced if the subgrade soil is appropriately treated. This judgment of treatment is accompanied by whether the improvement is economic. 
The cement-treated method is a commonly used way for subgrade improvement in the construction of roads. The reaction of cement and water produces cementitious calcium silicate and aluminate hydrates, resulting in the bond of soil particles together. Hydration allows slaked lime, $\mathrm{Ca}(\mathrm{OH})_{2}$, to be discharged and to successively react with clay minerals. During the hydration occurring immediately on the contact of cement and water, secondary reactions occur gradually and may continue for several months, similar to soil-lime interaction. Because the major reaction, hydration, is independent of the soil type, cement improvement is useful for a wide range of soils. However, there are limits of applicability imposed by the difficulty of mixing with wet, highly plastic clays (liquid limit $\geq 40 \%$ ). In this case, improvement with quicklime could be more advantageous.

Major advantages from the cement treatment of soils are increased strength and stiffness, better volume stability (less moisture sensitivity, control frost heave), and increased durability. Cement contents in soil improvement typically range from 2 to $10 \%$. Too little cement content may lead to spotty in consistent mixing with the soil, while too much cement can cause shrinkage and cracking. Hausmann (1990) reported that cement treatment might slightly increase the Proctor maximum dry density of sands and highly plastic clays, but that of silt may be decreased; small changes of the optimum moisture content also occur. The strength after improvement would be an important consideration. The strength of cement-treated soil is related to density, the time elapsed between mixing and compaction, length of curing time, temperature, and humidity. The strength of cement-treated cohesionless subgrade increases with higher densities. For cohesionless soils with and without cement, water content and method of compaction are also important as mentioned previously. Elastic properties are of particular interest to 
pavement design with cement treated soils. Typically the modulus for a granular soil can be increased through cement treatment from 200 to $2,000 \mathrm{MPa}$ or 400 to $20,000 \mathrm{MPa}$ (Hausmann 1990).

In subgrade improvement using lime, either quicklime $(\mathrm{CaO})$ or hydrated lime, $\left(\mathrm{Ca}(\mathrm{OH})_{2}\right)$ is generally used. Quicklime (calcium oxide) is applied as a coarse-grained powder with a bulk density of 8.3 to $10.3 \mathrm{kN} / \mathrm{m}^{3}$. Lime is primarily used for the treatment of clayey soils. Lime reacts rapidly with the porewater of the soil, producing hydrated or slaked lime, generating considerable heat, and causing a volume increase: $\mathrm{CaO}+\mathrm{H}_{2} \mathrm{O} \rightarrow$ $\mathrm{Ca}(\mathrm{OH})_{2}+65.3 \mathrm{kj} / \mathrm{mol}$. The short-term soil-lime reactions are hydration and flocculation (ion exchange). The long-term reactions are related to cementation and carbonation. Quicklime reacts with water very quickly in the soil. This drying action is particularly beneficial in the treatment of moist clays. When lime is mixed with clay, sodium and other cations absorbed to the clay mineral surfaces are exchanged with calcium. This change in the cation exchange affects the way the structural components of the clay minerals are linked together. Lime causes clay to coagulate, aggregate, or flocculate. The plasticity of clay is reduced, making it more easily workable and potentially increasing its stiffness and strength. Cementation is the main contributor to the strength of the stabilized soil. The higher the surface area of the soil, the more effective is this process; note that lime is not suitable for improving clean sands or gravels. Practical lime admixtures range from 2 to $8 \%$. Lime has some advantages in clay subgrade stabilization, which increases strength of clay soils and permeability, and reduces shrinkage and swelling. 


\subsubsection{Effects of Subgrade Improvement}

The previous FEM analyses revealed that the super-single tires create larger deformations, and higher strains than do dual tires. If super-single tires were predominantly used on current pavement structures, the pavement structures would be deteriorated in a shorter period of time than the expected design life. As a result, appropriate treatments to cope with the shortened pavement's life should be made. Action to be taken regarding existing pavement structures can be to restrict the number of trucks equipped with super-single tires or improve the subgrade in highways. However, it would be practically very difficult or cumbersome for the number of trucks to be limited if it is the prevalent trend to change from dual tires to single tires. It would be a more persuasive approach to improve subgrades to maintain the originally expected pavement life. For newly designed pavement structures, enough improvement should be considered for decreasing the relative damage. Therefore, comparison of the damage induced by supersingle tires and dual tires for the same axle load are made. Then, the amount of subgrade improvement actually needed to mitigate the relative damage by the two types of tires can be assessed. The investigation of the effects of subgrade on vertical plastic strain on top of subgrade is done in terms of increases in cohesion, friction angle and Young's modulus of subgrade.

Figures 5.8 and 5.9 illustrate the effects of an increase in Young's modulus of the subgrade using elastic and elastic-plastic analyses, respectively. Vertical strains in elastic analysis and vertical plastic strains in elastic-plastic were obtained. The value of Young's modulus for the existing pavement is $1,720,000 \mathrm{kPa}$, as shown earlier. An elastic-plastic material requires a higher increase in Young's modulus to obtain the targeted strains. 
This difference is due to the fact that the influence of other factors (c, $\phi)$ are involved in elastic-plastic analysis.

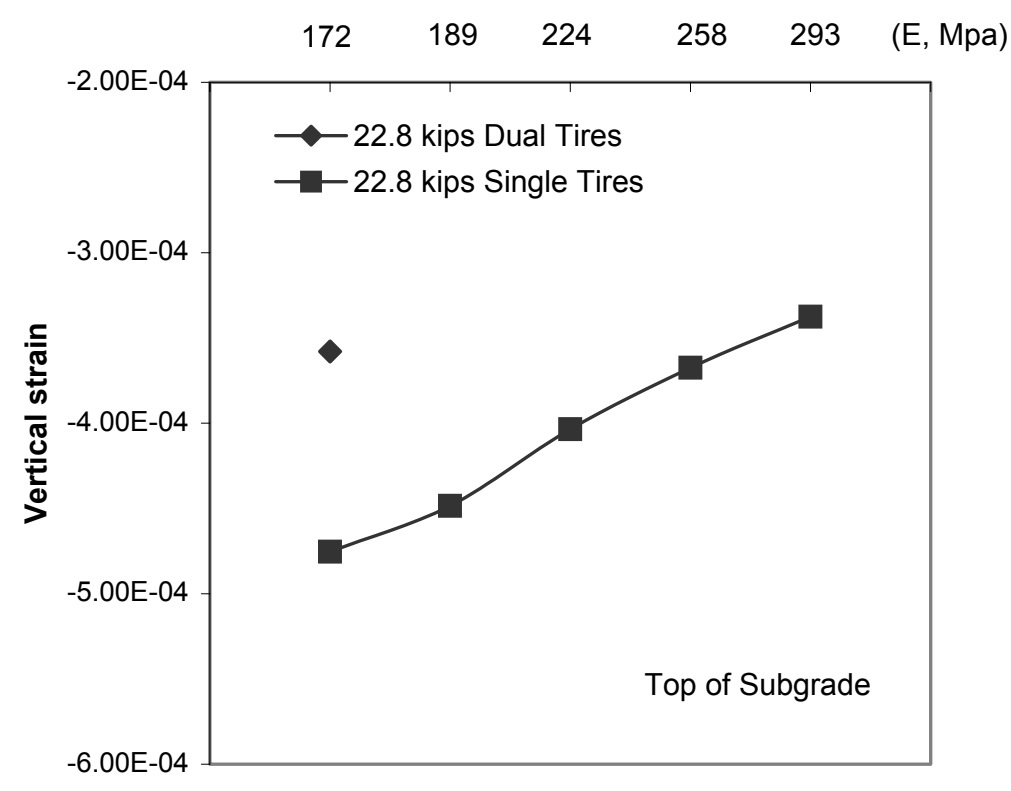

Figure 5.8 Effect of increase in Young's modulus of subgrade on vertical plastic strain for cross-section 1 (elastic analysis) 


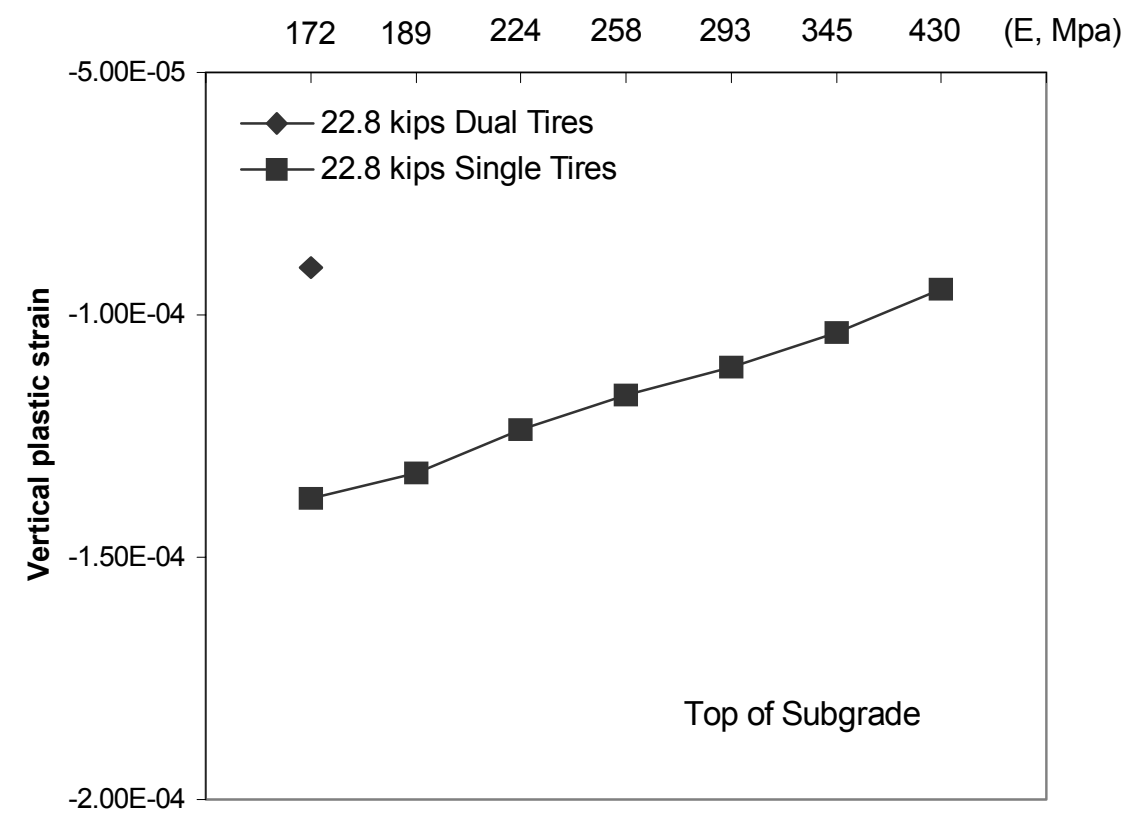

Figure 5.9 Effect of increase Young's modulus of subgrade on vertical plastic strain for cross-section 1 (elastic-plastic analysis)

Figures 5.10 and 5.11 show the effects of the increase in cohesion and friction angle of the subgrade. Figure 5.10 suggests that an increase of $20 \mathrm{kPa}$ in the cohesion value of the subgrade will decrease the vertical plastic strains to the level of plastic strains that dual tires produce. Figure 5.11 indicates that around $7^{\circ}$ to $8^{\circ}$ increase in friction angle of the subgrade allows the subgrade to reach the equivalent strain levels to dual tires. 


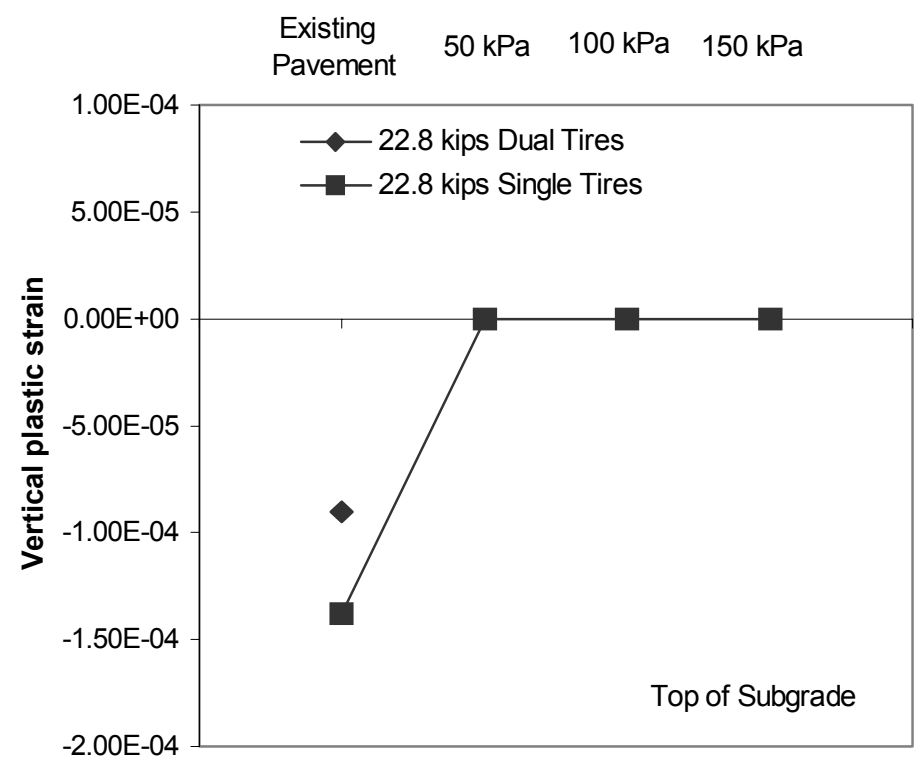

Figure 5.10 Effect of increase in cohesion of subgrade on vertical plastic strain for crosssection 1 (elastic-plastic analysis)

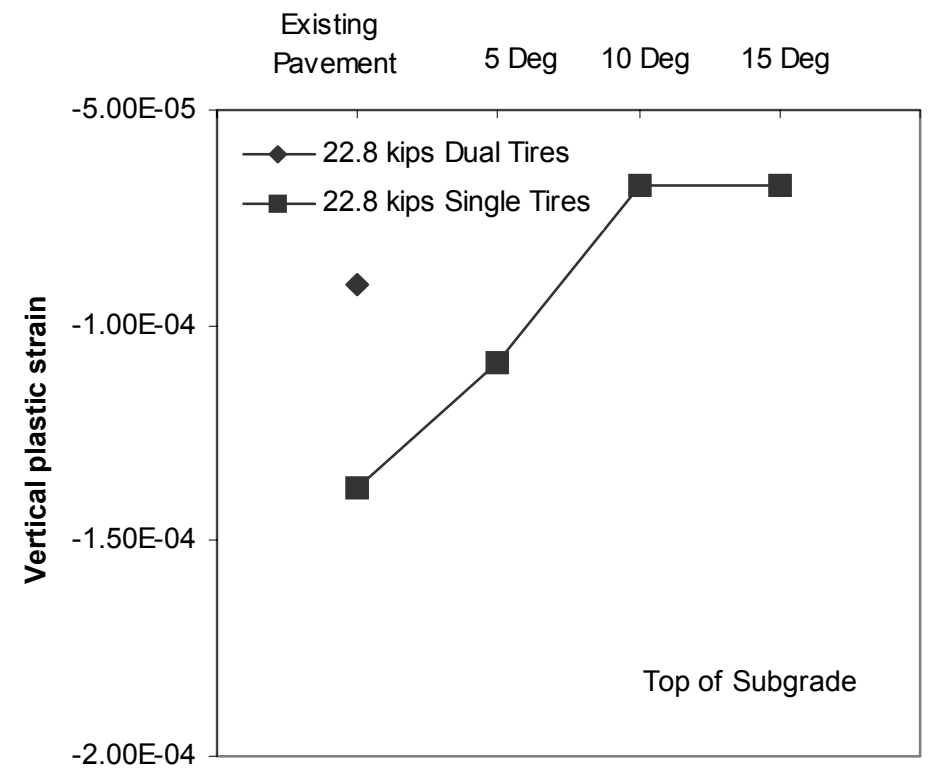

Figure 5.11 Effect of increase in friction angle of subgrade on vertical plastic strain for cross-section 1 (elastic-plastic analysis) 


\subsection{Summary}

In this chapter, in order to deal with the higher strains on top of subgrades generated by super-single tires, the effects of overlays and subgrade improvement were investigated. This investigation was done under the assumption that the strains induced by super-single tires should be reduced to the strain level induced by conventional dual tires.

The required thickness of overlay to mitigate vertical strains on top of the subgrade is around 50 to $60 \mathrm{~mm}$. This range of overlay enables the pavement structure to accommodate the increased contact stresses of super-single tires. However, a 50 to 60 mm overlay will not reduce the horizontal strains satisfactorily. An alternative way to reduce the horizontal strains at the bottom of the asphalt layer could be the increase in the stiffness of the asphalt layer. The preferred method to decrease the strains may be determined considering the circumstances for which rutting or fatigue cracking is prevalent.

Subgrade improvement was briefly investigated in terms of increase in the stiffness, cohesion and friction angle. Around 70 to 150 percent of the increase in Young' modulus effectively mitigates the vertical plastic strains. A small increase in the cohesion value (approximately $20 \mathrm{kPa}$ ) enables the pavement to reduce vertical plastic strains. About $7^{\circ}$ to $8^{\circ}$ increase in friction angle of subgrade improves the strength required to generate the desired strain levels. 


\section{CHAPTER 6 SUPER-HEAVY LOAD MOVE IN TEXAS}

\subsection{Introduction}

Super-heavy loads caused much concern in Texas during the early to middle 1990s. These super-heavy loads, which were much higher than the typical truck loads, appeared in some parts of Texas. The trailers were built with both multiple tires and multiple axles to distribute the super-heavy loads. In this chapter, in order to assess the performance of typical pavements for super-heavy loads, several FE analyses are done by applying the super-heavy loads to the typical Indiana pavements using elastic-plastic analyses. The main objective of this investigation is to evaluate how much plastic strain occurs in the subgrade and asphalt layers compared with the super-single tire loadings.

\subsection{Typical Super Heavy Loads in Texas}

Since a limited number of wheel load passages are expected, the super heavy loads may not induce fatigue and rutting failures in pavements due to repetition. Despite the possibility that even more than one super heavy load move may occur in short succession over the same pavement, the number of super-heavy wheel loads that are expected is 
unlikely to be more than forty per one move (Jooste and Fernando 1995). Table 6.1 shows some data measured during the study done by Jooste and Fernando (1995). As seen in Table 6.1, the super heavy loads would not involve long-term failure, but rather a rapid succession of higher than normal wheel loads. Therefore, static elastic-plastic finite element analyses would be reasonable to evaluate the effects of the super-heavy load on the subgrades.

Table 6.1 Details of ten superheavy loads monitored in Texas (Jooste and Fernando 1995)

\begin{tabular}{|c|c|c|c|}
\hline Date Moved & Location & $\begin{array}{c}\text { Total number of } \\
\text { axles }\end{array}$ & $\begin{array}{c}\text { Maximum wheel } \\
\text { load }(\mathrm{kN})\end{array}$ \\
\hline $12 / 08 / 92$ & Victoria, Texas & 13 & 28.0 \\
\hline $12 / 10 / 92$ & Victoria, Texas & 18 & 33.0 \\
\hline $02 / 21 / 93$ & Beaumont, Texas & 23 & 38.1 \\
\hline $03 / 14 / 93$ & Beaumont, Texas & 23 & 38.1 \\
\hline $04 / 23 / 93$ & Beaumont, Texas & 16 & 38.8 \\
\hline $08 / 01 / 94$ & Freeport, Texas & 22 & 38.1 \\
\hline $08 / 22 / 94$ & Freeport, Texas & 15 & 21.4 \\
\hline $04 / 05 / 93$ & Henderson, Texas & 9 & 27.0 \\
\hline $04 / 16 / 93$ & Henderson, Texas & 9 & 28.1 \\
\hline $04 / 21 / 93$ & Henderson, Texas & 15 & \\
\hline
\end{tabular}




\subsubsection{Super-heavy load Move}

During the early to middle 1990s, the Texas Department of Transportation (TXDOT) received as many as 75 to 100 super-heavy load permit applications a year. Such applications were typically accompanied by diagrams of the proposed route as well as of the load configurations (Jooste and Fernado 1995). Before a permit to move superheavy loads was issued, TXDOT needed to determine whether the proposed route was structurally adequate to sustain the super-heavy load. Therefore, they conducted research to investigate the movement of super-heavy loads over the state highway system (Jooste and Fernando 1994).

\subsubsection{Typical super heavy load configuration}

Three basic configurations used by super-heavy load hauler were observed in their study. As shown in Figure 6.1, the first configuration uses conventional truck and trailer combinations. This configuration is normally used on super heavy loads close to the limits for being classified as super-heavy (i.e., $1112 \mathrm{kN}$ ). Figure 6.2 shows another configuration with a tractor-trailer combination. In this case, a specialized tractor is connected with a trailer that is composed of up to 12 wheels per axle and as many as 20 axles. This configuration has generally been used for most of the heavier super-heavy load moves, which have more than $8000 \mathrm{kN}$ gross vehicle weight. Figure 6.3 describes the third configuration, a specialized vehicle with self-propelled multiple axle trailer.

An investigation of the load configurations during their study suggested that a variety of axle and wheel spacings could be used on the same type of load moving vehicle. They summarized the axle and wheel spacings encountered on each type of load 
moving vehicle. Figure 6.4 and Table 6.2 show the summary of the some of the load configurations encountered during their study. 

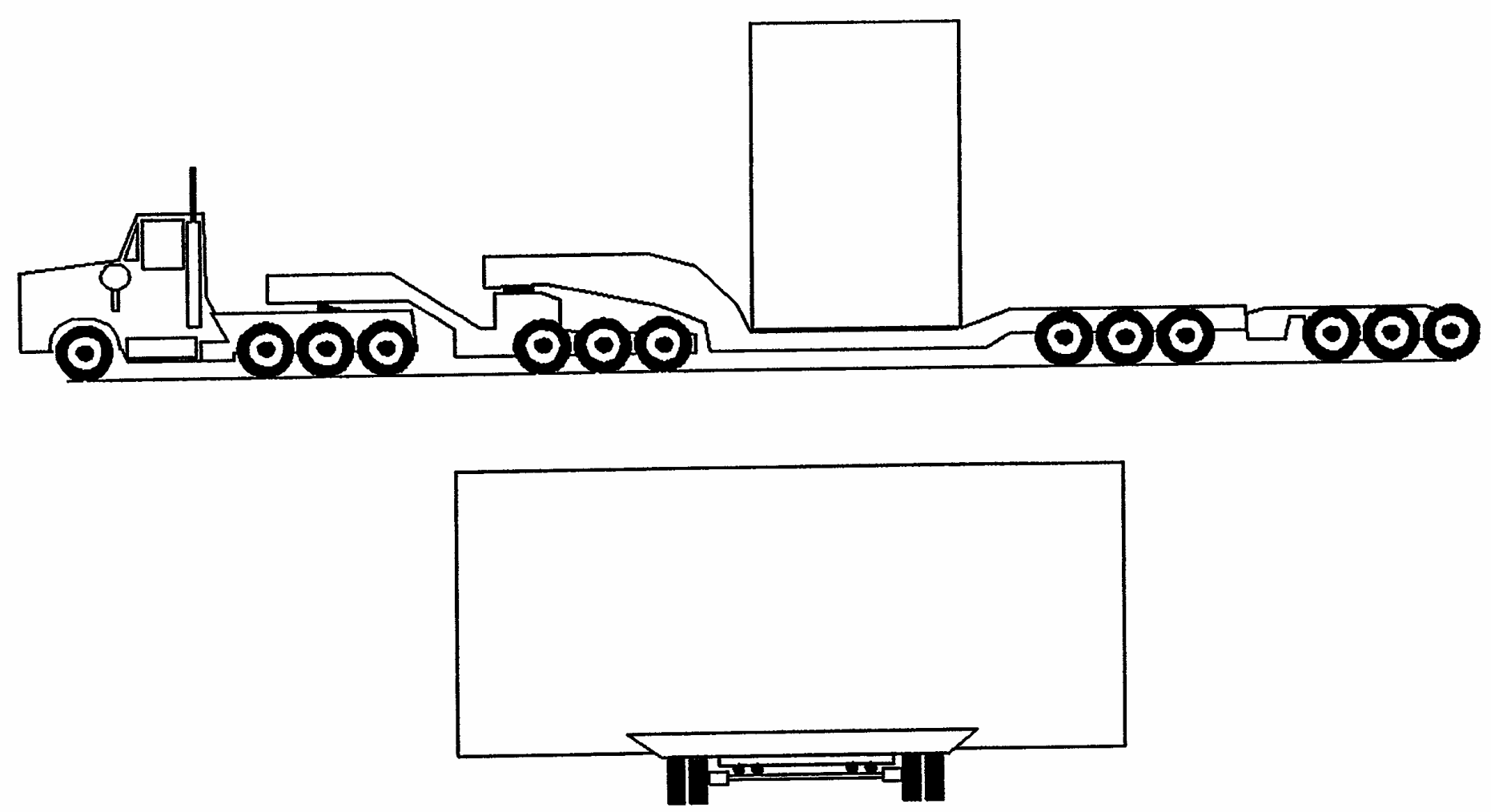

Figure 6.1 Example of a conventional truck and trailer combination (Jooste and Fernado 1995) 

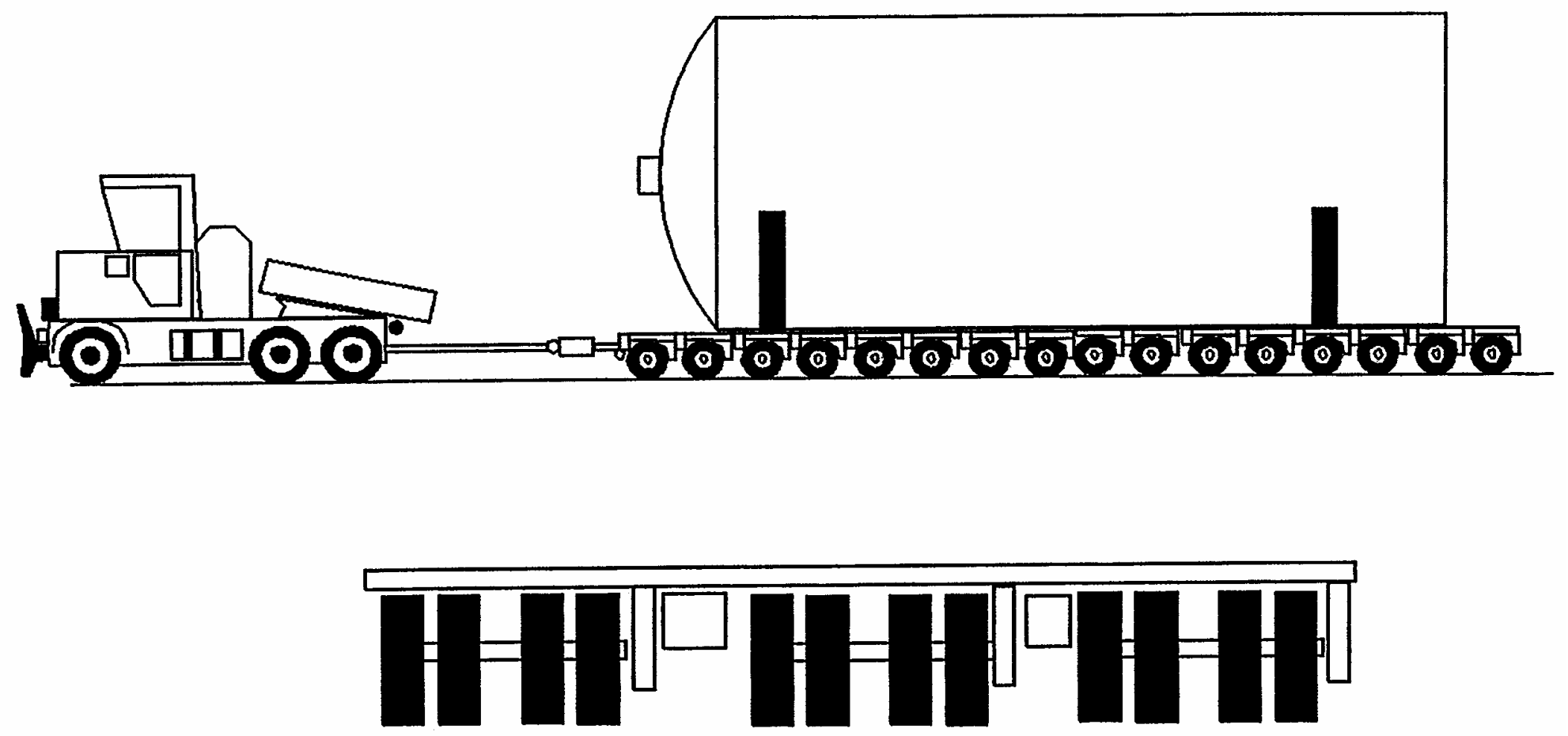

Figure 6.2 Example of a specialized tractor-trailer combination (Jooste and Fernando 1995) 

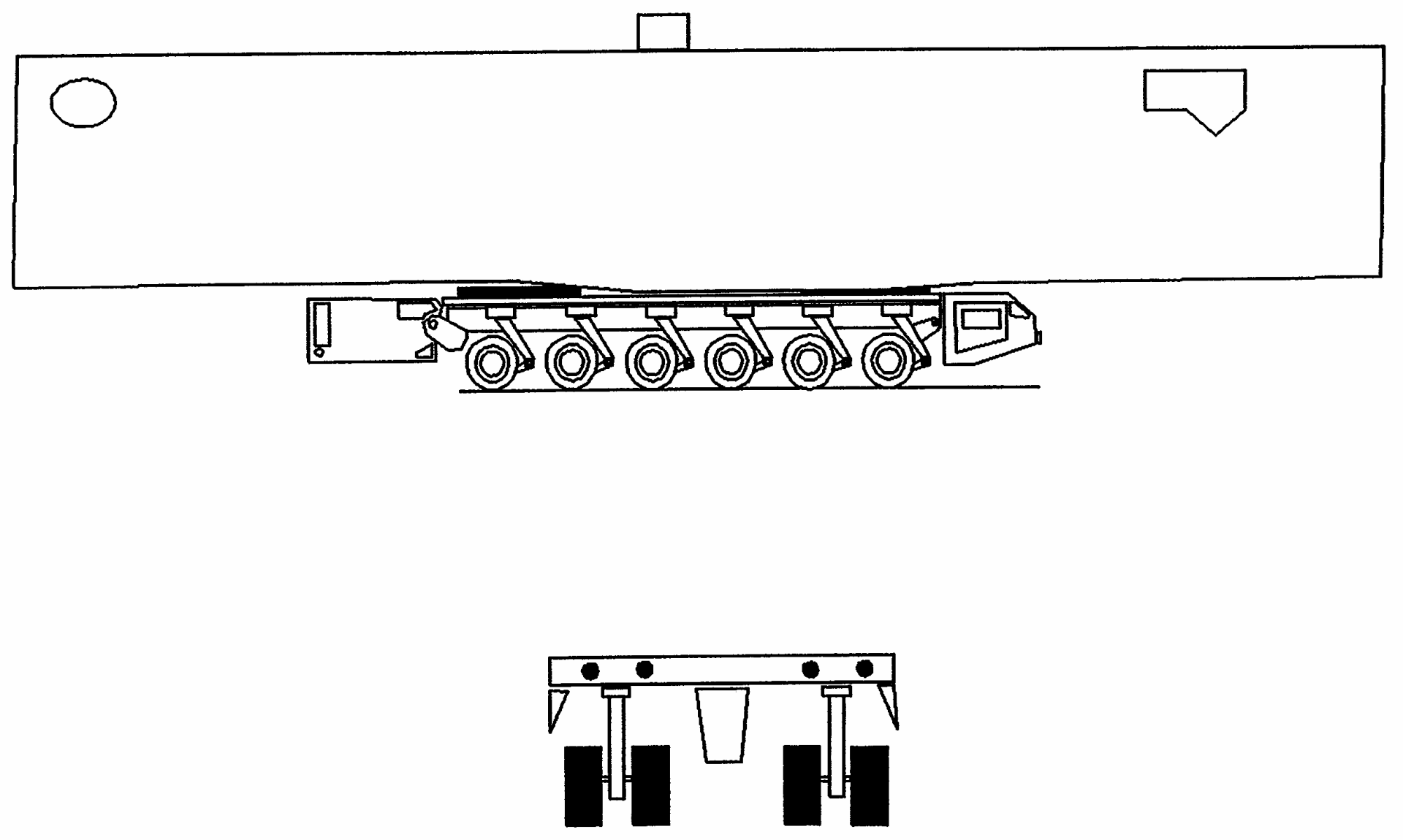

Figure 6.3 Example of a self-propelled multiple axle tirailer (Jooste and Fernando 1995) 


VEHICLE TYPE
$\begin{aligned} & \text { CONYENTIONAL } \\ & \text { TRAILER }\end{aligned}$
$\begin{aligned} & \text { CONVENTIONAL } \\ & \text { TRACTOR }\end{aligned}$
$\begin{aligned} & \text { SPECIALIZED } \\ & \text { TRALER }\end{aligned}$
$\begin{aligned} & \text { SPECIALIZED } \\ & \text { TRACTOR }\end{aligned}$

SELF

PROPELED

MULTIPLE AXLE

TRAILER
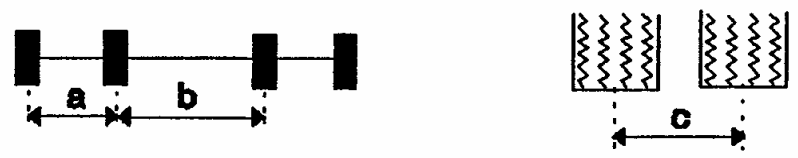

Figure 6.4 Typical load configuration used on superheavy load vehicles (Jooste and Fernando 1995) 
Table 6.2 Approximate axle and wheel spacings used on superheavy load vehicle (Jooste and Fernando 1995)

\begin{tabular}{|c|c|c|c|c|}
\hline \multirow[t]{2}{*}{ Vehicle type } & \multirow{2}{*}{$\begin{array}{c}\text { Approximate } \\
\text { axle spacing } \\
(\mathrm{mm})\end{array}$} & \multicolumn{2}{|c|}{$\begin{array}{l}\text { Approximate wheel } \\
\text { spacing }\end{array}$} & \multirow{2}{*}{$\begin{array}{c}\text { Approximate } \\
\text { wheel load } \\
(\mathrm{kN})\end{array}$} \\
\hline & & Reference & Spacing $(\mathrm{mm})$ & \\
\hline $\begin{array}{l}\text { Conventional and } \\
\text { trailer (rear) }\end{array}$ & 1220 & $\begin{array}{l}a \\
b\end{array}$ & $\begin{array}{c}1830 \\
320 \sim 330\end{array}$ & 33.4 \\
\hline $\begin{array}{l}\text { Conventional and } \\
\text { trailer (steering) }\end{array}$ & N/A & $\mathrm{a}$ & $1960 \sim 2060$ & 32.0 \\
\hline Specialized trailer & $1370 \sim 1520$ & $\begin{array}{l}\mathrm{a} \\
\mathrm{b} \\
\mathrm{c}\end{array}$ & $\begin{array}{c}380 \sim 1020 \\
1120 \sim 1220 \\
270 \sim 325\end{array}$ & $18.7 \sim 31.7$ \\
\hline Specialized tractor & 1830 & $\mathrm{a}$ & 2130 & 34.7 \\
\hline $\begin{array}{c}\text { Self-propelled } \\
\text { multiple axle trailer }\end{array}$ & 1400 & $\begin{array}{l}\mathrm{a} \\
\mathrm{b} \\
\mathrm{c}\end{array}$ & $\begin{array}{l}620 \\
860 \\
620\end{array}$ & 40.0 \\
\hline
\end{tabular}

Note: spacing refers to rear tandem axle of tractor

\subsubsection{Modeling of the super heavy loads}

Jooste and Fernando (1995) used a typical load configuration in order to study the effects of the different load configurations. The load configuration they chose was approximately that of the special trailer as well as that of the self-propelled multiple axle trailer. In order to model the multiple axle loads, they used three simplified load models using multi-layered elastic theory. Figures 6.5 - 6.7 illustrate the schematic load models used. Figure 6.5 was considered as the most accurate load representation and was used as 
the standard against which the accuracy of the more simplified load models were evaluated. The loads shown as dotted ellipses in Figures 6.6 and 6.7 were not modeled and are shown only to illustrate the relationship between the simplified load configuration and the three-axle configuration shown in Figure 6.5. Figure 6.8 shows the pavement sections adopted in their analysis.

In their analysis, Jooste and Fernando concluded that simplifying a multiple axle load configuration into a single axle or even a dual wheel load leads to a more conservative prediction. Of the three load configurations analyzed, the single axle generally resulted in the most conservative prediction of failure potential. In those examples where the triple axle or dual wheel loads resulted in a more conservative prediction, the differences between the three predicted yield function were considerably small. They finally concluded that there does not seem to be any advantage to modeling all wheels on an axle as opposed to modeling only the two wheels that are closest together. This observation was also made in their earlier study (Jooste and Fernando 1994). The load configurations used are shown in Figure 6.10. In their study, a single axle model was easier to use for evaluating the potential for pavement damage under super heavy loads and the results obtained were more conservative. 


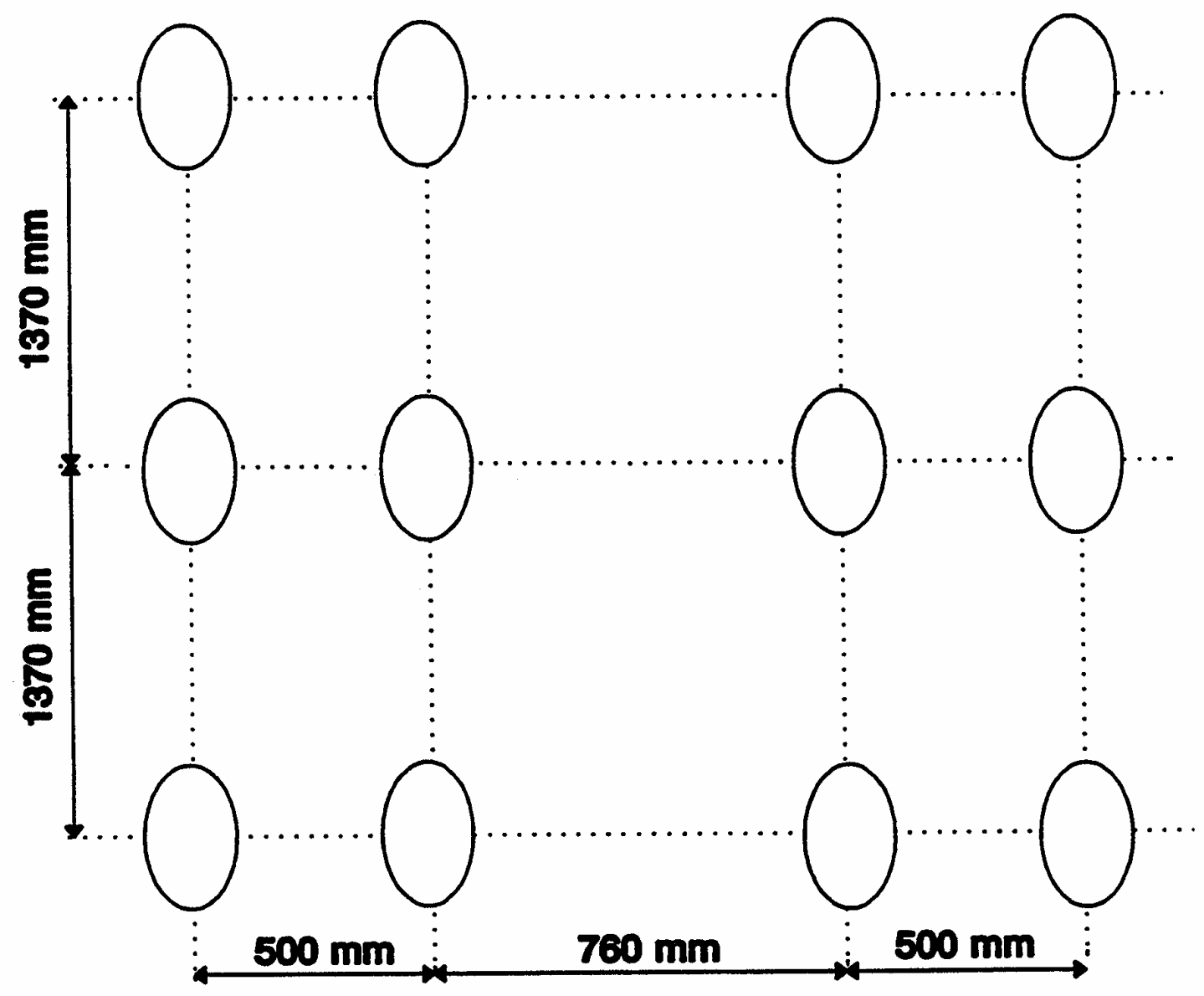

Figure 6.5 Triple axle load used in analysis (Jooste and Fernando 1995) 


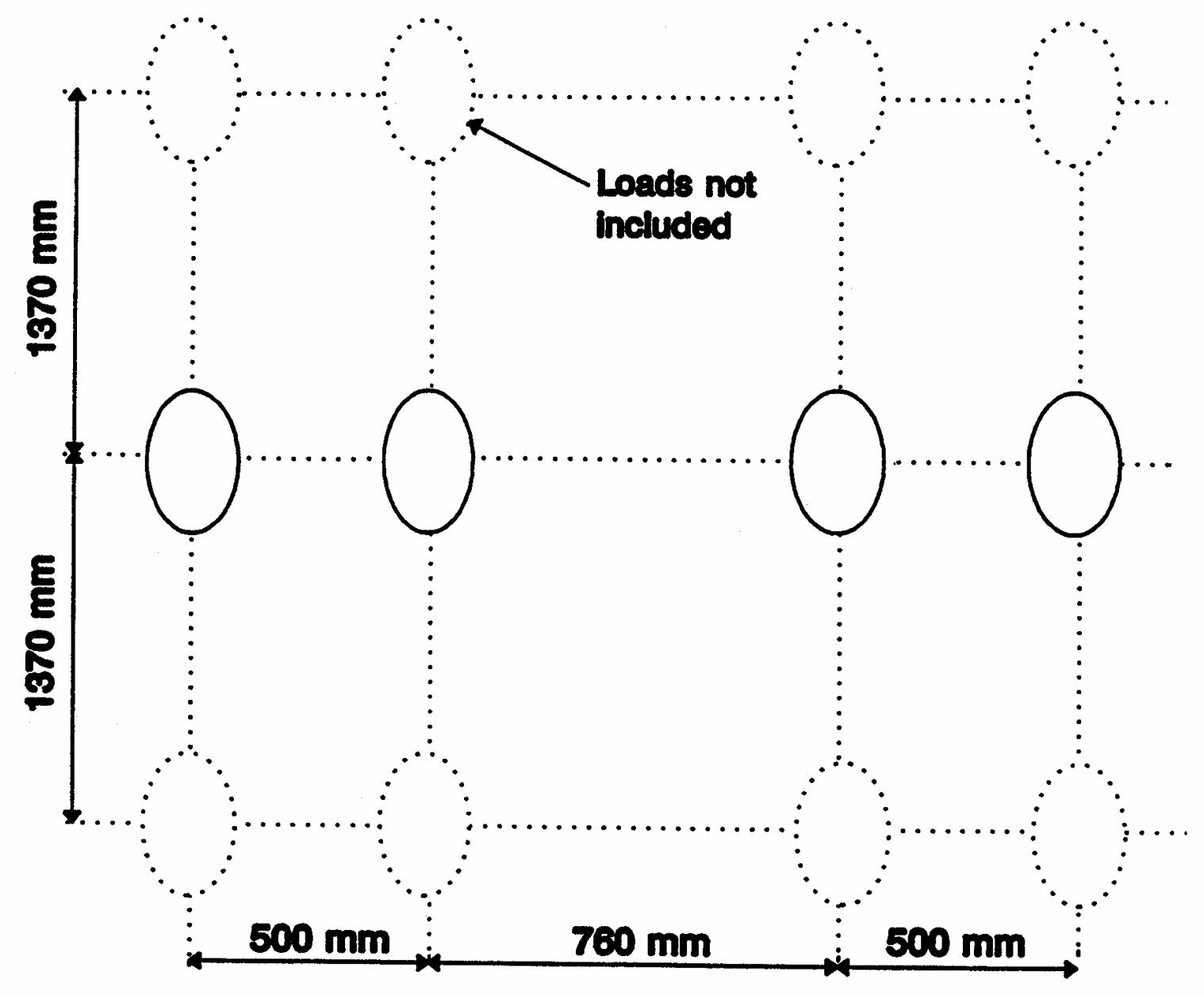

Figure 6.6 single axle load used in analysis (Jooste and Fernando 1995) 


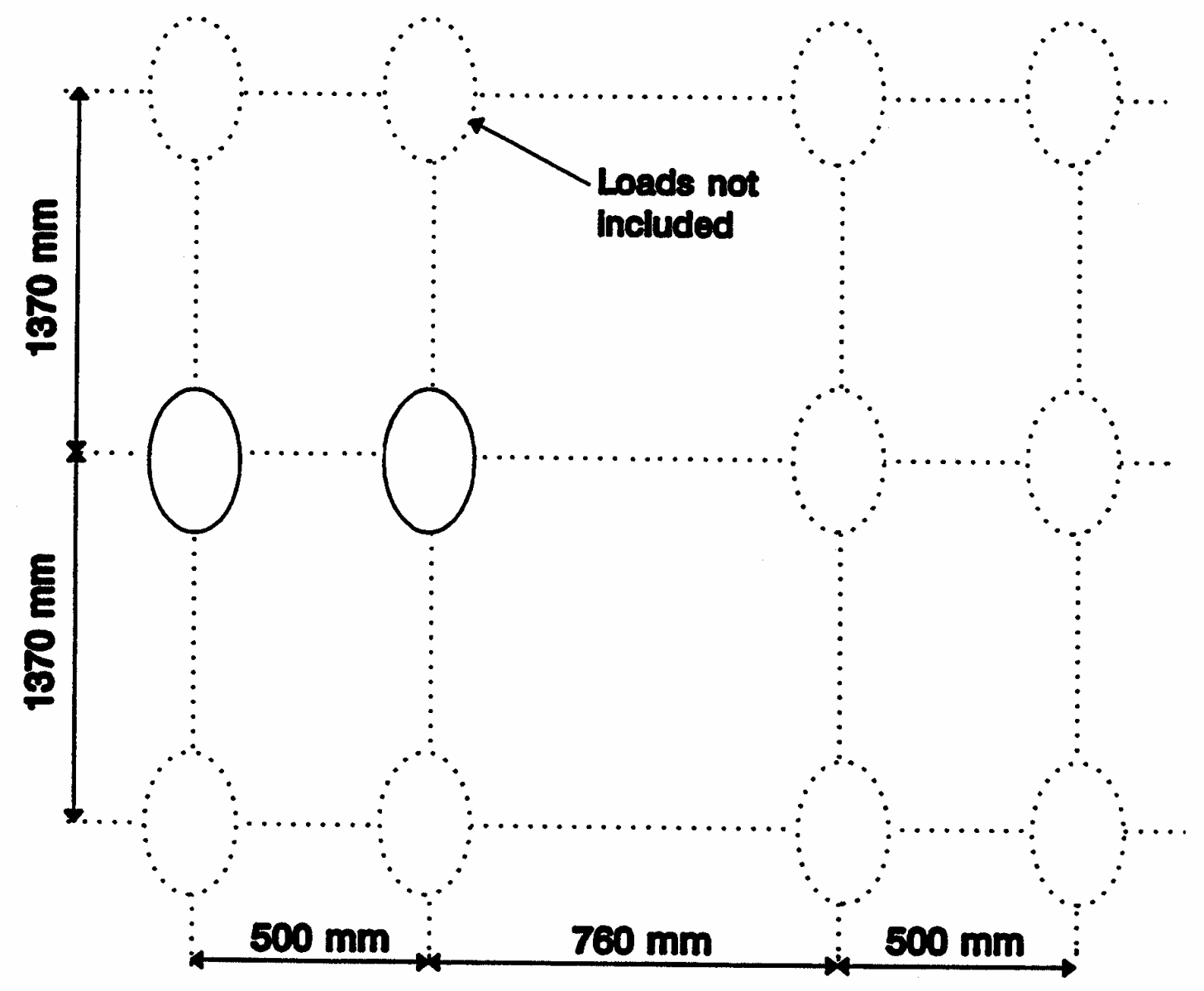

Figure 6.7 Dual wheel load used in analysis (Jooste and Fernando 1995) 
40.0 kN LOAD OVER $127 \mathrm{~mm}$ RADIUS

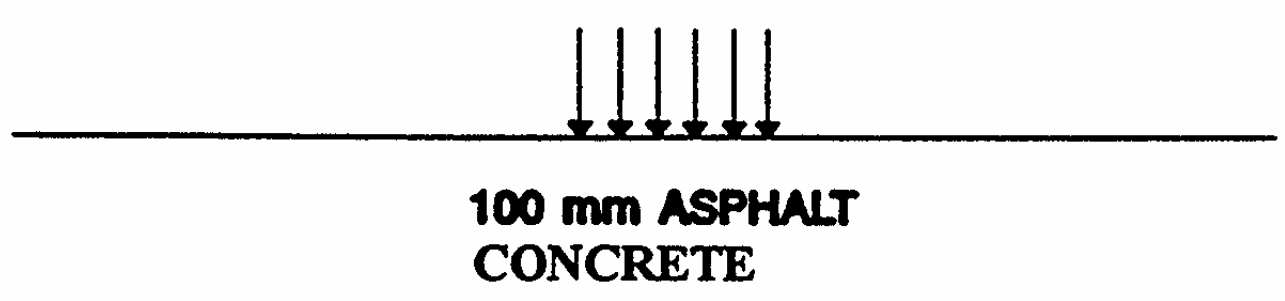

$200 \mathrm{~mm}$ CRUSHED

STONE

CLAY SUBCRADE (1.47 $m$ TO EQUNALENT STIFF LAYER)

Figure 6.8 Pavement section in analysis (Jooste and Fernando 1995)

\subsection{Effects of Typical Heavier Truck Move in Indiana}

In this section, the typical super heavy loads were modeled for Indiana roads. The objective of this investigation is to assess how large vertical strains occur in the subgrade when the typical super-heavy load moves over the Indiana highway system. The three types of load configuration models were analyzed using finite element analyses. The two models are the same as Figure 6.5 (tridem axle model) and 6.6 (single axle model). The 
final configuration was modeled as a tandem axle for the purpose of finding the effects of axle types. In the FE analyses, the tire load and the inflation pressure were $9000 \mathrm{lbs}$ (40 $\mathrm{kN})$ and $125 \mathrm{psi}(862 \mathrm{kPa})$, respectively. It should be noted that the tire load for supersingle tire was 11,400 lbs $(51 \mathrm{kN})$. In Jooste and Fernando's study, the tire load shown in Figure 6.8 was applied on a circular contact area, and a particular tire type was not mentioned. Therefore, the contact area was calculated by the general equation (2.12). Figure 6.9 shows the FE mesh for tridem axle configuration.

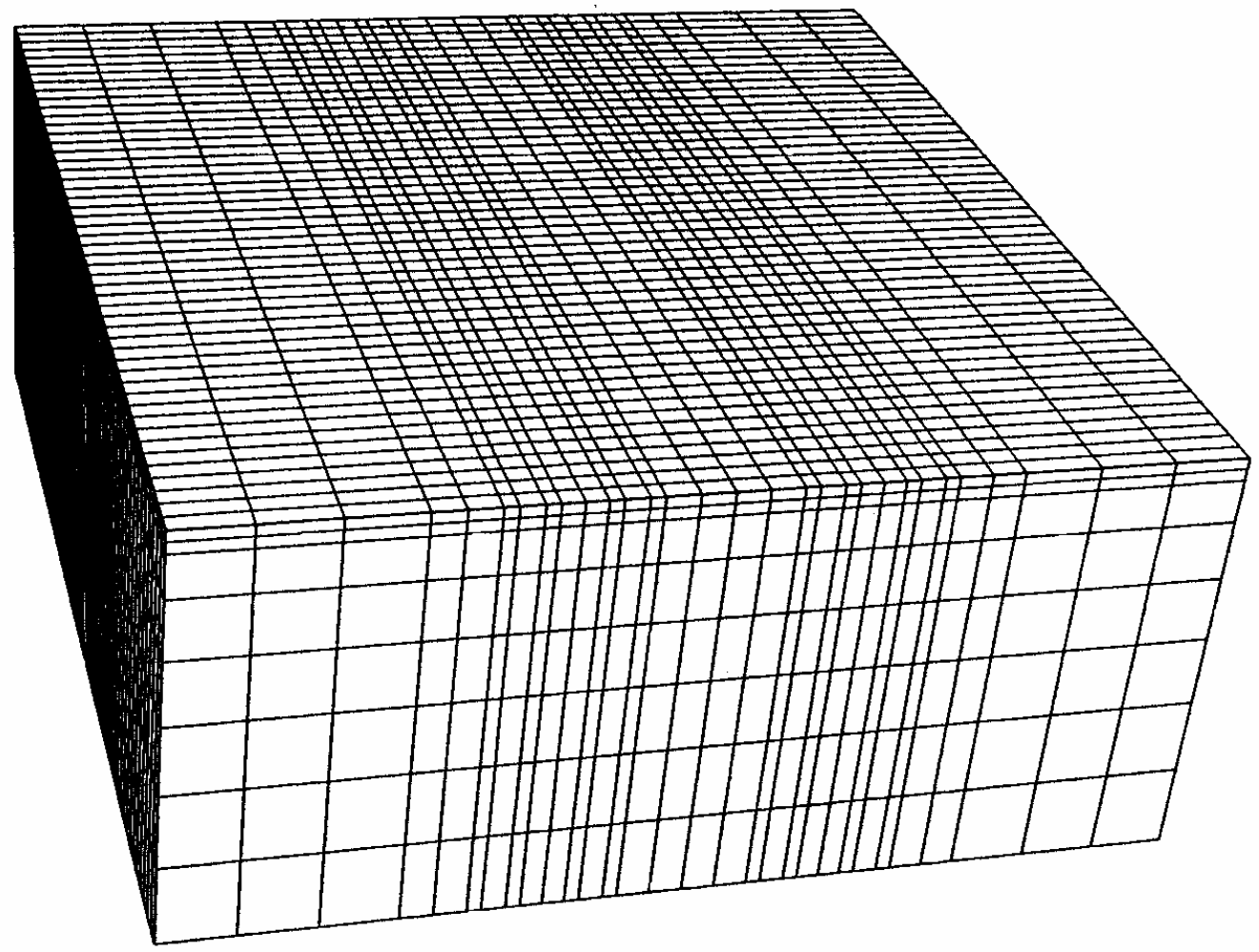

Figure 6.9 FE Mesh for tridem axle configuration for super-heavy load in Texas 
Figures 6.10 and 6.11 compare the vertical plastic strains on top of the subgrade for different types of super-heavy loads with those induced by super-single tires. Among the three models, the single axle model induces the highest vertical plastic strains. This is due to the higher second deviatoric tensor $\mathrm{J}_{2}$, as discussed earlier in chapter 4 . Because the difference in strains between the three models is also not large, super-heavy load can be modeled with the single axle model, which is conservative. Figure 6.12 and 6.13 compares the horizontal strains at the bottom of the asphalt layer. The single axle model also induces the highest horizontal plastic strains. Figures $6.10-6.13$ show that the single axle with super-single tires induce higher vertical and horizontal strains than the superheavy loads. This is due to the higher tire load and higher vertical contact stress of supersingle tires compared with those of super-heavy loads. This implies that although superheavy loads are much higher than the typical truck loads, they have multiple tires to distribute the higher total load, resulting in less tire load and in less damage to the pavement layers. Therefore, it can be concluded that the super-heavy load moves which occurred in Texas are less severe to the typical pavements than super-single tire loadings. 


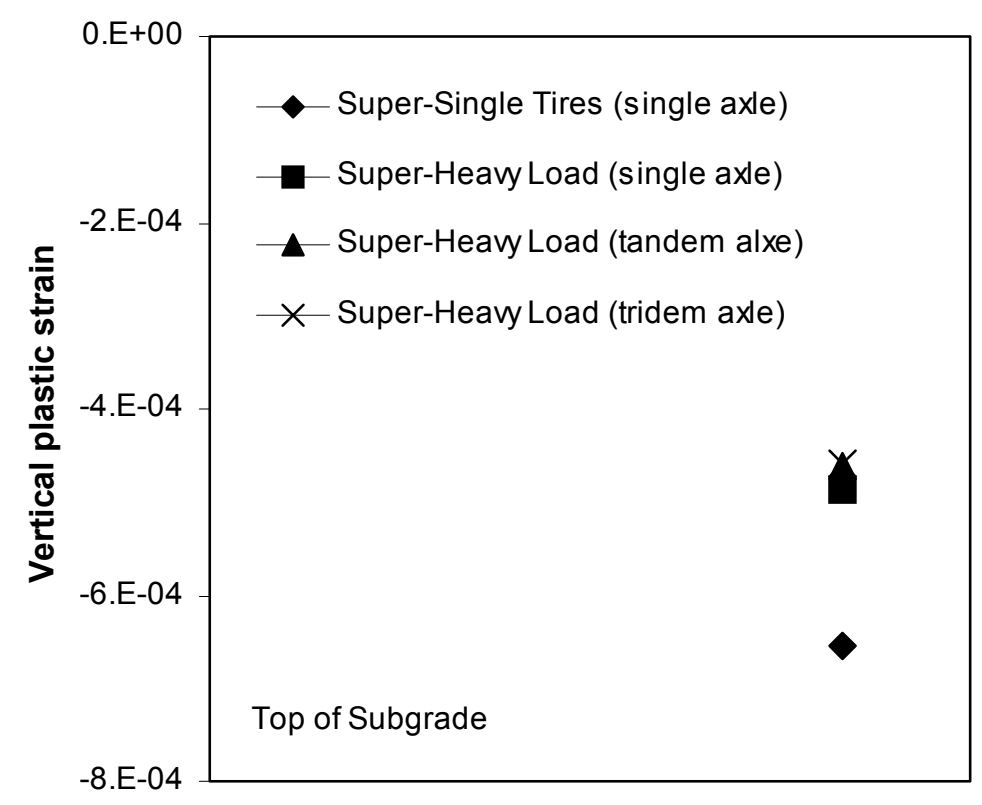

Figure 6.10 Vertical plastic strains on top of the subgrade by super-heavy load (crosssection 1)

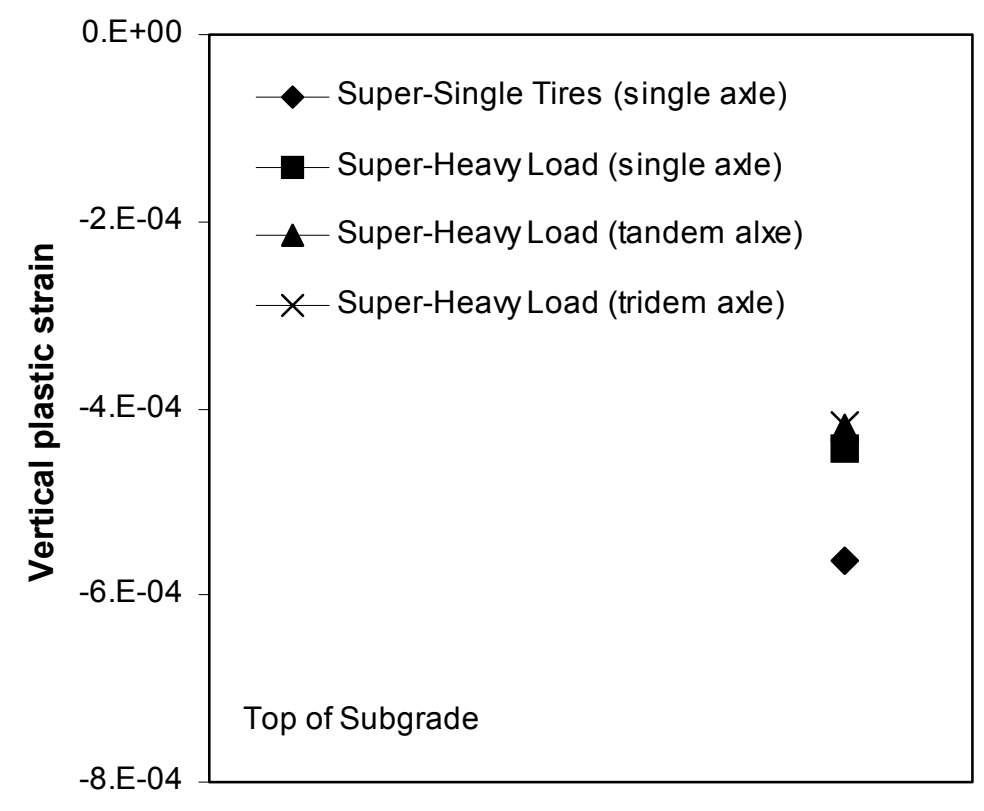

Figure 6.11Vertical plastic strains on top of the subgrade by super-heavy load (crosssection 2) 


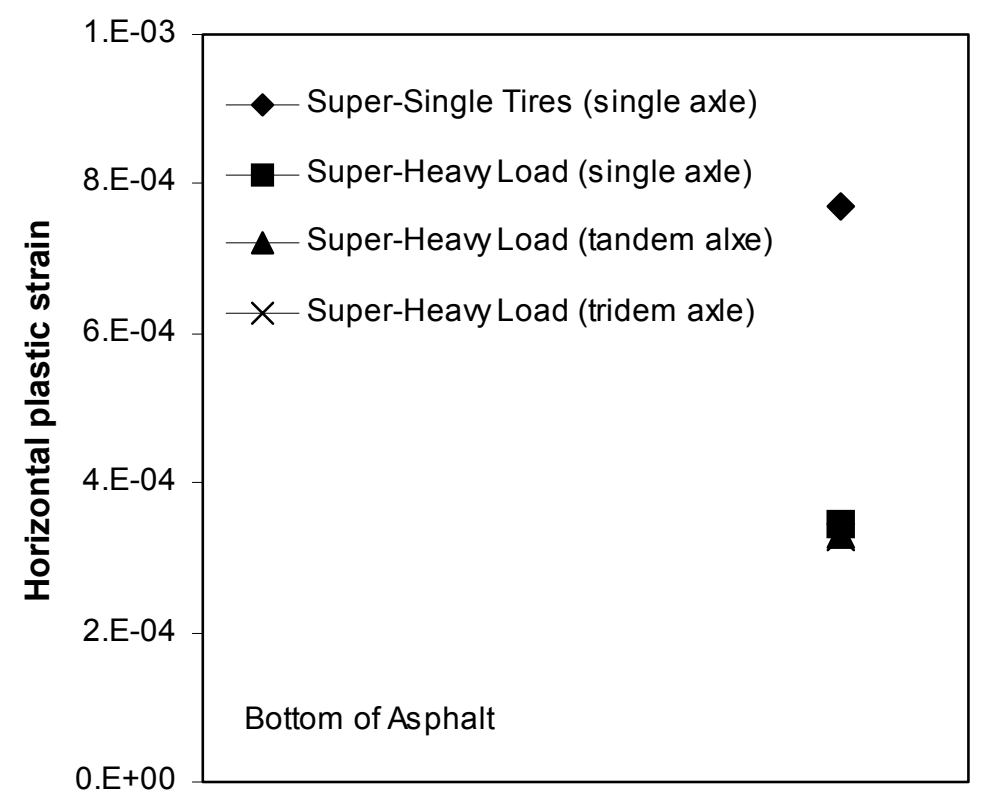

Figure 6.12 Horizontal strains at the bottom of the asphalt layer by super-heavy load (cross-section 1)

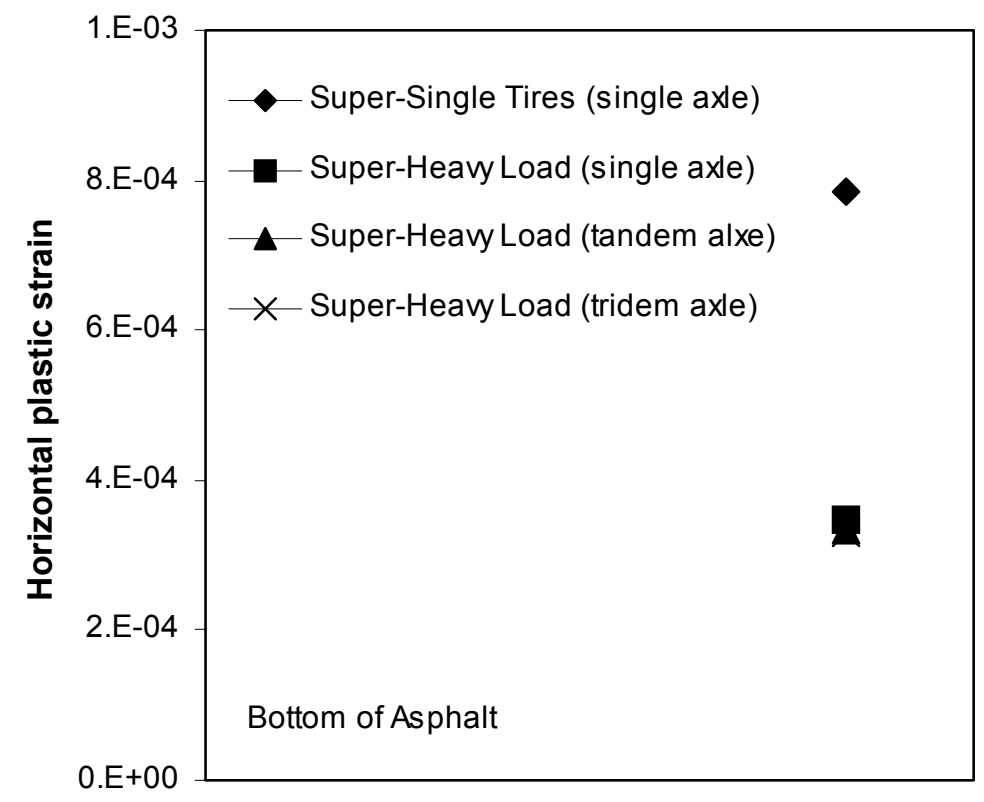

Figure 6.13 Horizontal strains at the bottom of the asphalt layer by super-heavy load (cross-section 2) 


\subsection{Summary}

During the design life of pavements, pavements might experience heavy truck loads such as super-heavy loads as well as super-single tire loadings. In this chapter, the super-heavy loads that were moved in Texas during the 1990s' were applied to the typical cross-sections in Indiana using FE analyses. Unlike typical truck loads, the super-heavy loads have larger number of axles and higher total traffic load. In FE analyses, this superheavy load was modeled using a single axle model, tandem axle model, and tridem axle model. The single axle model induces the highest plastic strains both on top of the subgrade and at the bottom of asphalt layers due to the higher second deviatoric tensor $\mathrm{J}_{2}$. This single axle model can be used for modeling the super-heavy load, and is conservative. Compared with the super-heavy load, super-single tires are more severe to pavement systems. This suggests that as the total load of trucks becomes heavier, a larger number of tires and axles would be more favorable to the pavement's performance. 


\section{CHAPTER 7 SUMMARY AND CONCLUSIONS}

\section{1 $\underline{\text { Summary }}$}

Multi-layered elastic theory assumes that the contact stress is equal to the inflation pressure and that contact area is circular. According to recent studies, these assumptions fail to appropriately represent the real contact stresses induced by increased inflation pressures, especially for the super-single tires.

Super-single tires are replacing conventional dual tires in the trucking industry due to the reduced fuel consumption and the smaller total contact area compared to conventional dual tires. The contact area of super-single tires is in reality almost rectangular and larger in the transverse direction compared with conventional dual tires. Super-single tires, however, induce higher contact stresses, resulting in more adverse effects on the pavement structure in any layer. The contact stress might be 1.9 times the inflation pressures. This higher contact stress reaches deeper in the pavement, and is more likely to damage the subgrade layer. In this study, in order to reasonably model the vertical contact stress generated by typical super-single tires, the maximum vertical contact stress for the recommended tire load was determined using De Beer et al.'s 
equation. A reasonable contact area ratio $(1: 0.85)$ for super-single tires was also determined.

The subgrade resilient modulus is affected by the following factors: deviator stress, confining pressure, degree of saturation, aggregate gradation, method of compaction, compaction water content and dry density, thixotropy, degree of saturation, and freezethaw. Permanent subgrade deformations are affected by the following factors: stress level, dry unit weight, moisture content, stress history, thixotropy, load frequency, freethaw, and overconsolidation ratio. The mechanical behavior of subgrade soils is related to various factors. It might be difficult to represent the subgrade behavior completely due to such factors. The models to estimate resilient modulus and permanent strain have limitations that apply to all types of subgrades since the models that are available are based on specific soils for each model. In the FE analysis, the Drucker-Prager model was used for modeling yield of sands and clays.

In order to ascertain the severity of the potential effects of the use of super-single tires on the subgrades, the effects of super-single tires on subgrades for typical road cross-sections were investigated using plane-strain (2D) and 3D static and dynamic finite element analysis. The analysis focused on the sand and clay subgrades rather than on asphalt and base layers. The subgrades were modeled as saturated in order to investigate the effects of porewater pressures under the most severe conditions.

The effects of overlay and subgrade improvement were investigated in order to deal with the higher strains on top of subgrade generated by super-single tires. These investigations were done by comparing the strains in the subgrade induced by super- 
single tires with those induced by dual tires for the same load and by focusing on decreasing the difference in those strains.

Several FE analyses were done by applying super-heavy loads (those which occurred in Texas during the 1990s) to the typical Indiana pavements using elastic-plastic analyses in order to assess the performance of the typical pavements under the superheavy loads. The main objective of this investigation is to evaluate how much plastic strains occur in the subgrade and asphalt layers compared with the super-single tire loadings.

\section{2 $\underline{\text { Conclusions }}$}

Based on the findings of the present study, the conclusions listed below are drawn.

(1) It was found that the direction of the maximum tensile stress is dependent on the shape of the contact stress distribution and that the maximum tensile strain occurring in the transverse direction is larger than that in the longitudinal direction.

(2) Plane-strain modeling of the pavement is much more conservative than $3 \mathrm{D}$ modeling. Although the computation effort is much larger for 3D analyses, the more realistic results justify the use of these analyses where greater accuracy is required.

(3) According to the comparison of conventional and super-single tires under elasticplastic conditions, super-single tires induce larger permanent strains in the pavement layers than conventional tires. Therefore, design of a pavement using LEF values for dual tires leads to overestimation of the pavement design life. 
(4) Single axle loadings with super-single tires induce the largest vertical plastic strains on top of the subgrade of all the axle configurations considered.

(5) The analysis done for moving loads shows that the higher the speed of the truck, the less the load on the subgrade.

(6) For clay subgrades, the higher the over consolidation ratio (OCR), the less deformation occurs.

(7) Positive pore pressures are generated in normally consolidated clay subgrades, while negative pore pressures are typically generated within heavily overconsolidated clays. Therefore, in a normally consolidated clay (NC) subgrade, the shear strength is reduced as a result of traffic loadings.

(8) The estimation of vertical permanent deformations using FEM shows good agreement with the permanent strain model for 0 to 5 load repetitions. FE analysis is prohibitive for a large number of load repetitions, making the use of a simplified model a necessity.

(9) Repeated super-single tire loadings increase vertical permanent strains in the subgrade for existing roads. This implies that either mitigation of permanent strains in the subgrade must be pursued or the number of passages of super-single tires must be limited by appropriate regulation.

(10) Rutting damage factors for super-single tires compared with dual tires range from 3.5 to 3.6. Fatigue damage factors range from 4.9 to 7.6 . Therefore, in the design of a pavement structure, these results can be used as relative damage factors for supersingle tires compared with dual tires for the same load. 
(11) The required thickness of overlay to mitigate vertical strains on top of the subgrade is around 50 to $60 \mathrm{~mm}$. This range of overlay enables the pavement structure to accommodate the increased contact stresses of super-single tires. However, 50 to 60 mm overlay does not reduce the horizontal strains far enough.

(12) Around 70 to 150 percent of increase in the Young' modulus of the subgrade achieves the desired mitigation of the vertical plastic strains. A small cohesion value increase (approximately $20 \mathrm{kPa}$ ) enables the pavement to reduce vertical plastic strains down to the level associated with dual tires. The same is accomplished with $7^{\circ}$ to $8^{\circ}$ increase in the friction angle of the subgrade. These conclusions on the subgrade improvement are obtained from how much subgrade improvement is needed for super-single tire loadings when those tires are dominantly used.

(13) Compared with super-heavy loads, super-single tires impose more severe conditions to the pavement systems. This is due to the larger number of tires and axles used to transport these loads.

\subsection{Design Examples}

In this section, simple design examples are provided in order to describe how to consider the effects of super-single tires on the subgrades in design practice. Two examples, an in-service pavement and a newly constructed pavement are discussed under the AASHTO design procedure. 


\section{Example 1: In-service pavement}

An in-service pavement was constructed 10 years ago with 20 year design life. Its overall condition is pretty acceptable. The pavement was designed with the design ESALs obtained from traffic analysis at the time of design. The number of design ESALs for the pavement was 2,000,000. The value of ESALs was calculated following the AASHTO design procedure. Through traffic investigation and analysis, the pavement has been subjected to 1,000,000 ESALs since it was opened for use, and thus the value of remaining ESALs is $1,000,000$. However, the pavement is expected to be subjected to a number of trucks with super-single tires, which was unexpected when designed. For example, $30 \%$ of axles use super-single tires and $70 \%$ of axles use conventional dual tires. Estimate the allowable remaining number of repetitions to maintain the pavement's design life.

For simplification, we consider only one type of axle load and its Load Equivalency Factors (LEF) for typical axles with the conventional dual tires and corresponding supersingle tires are used as 2.72 and 9.43, respectively, as shown in Table 4.4. In order to calculate the allowable remaining number of passages, we simply divide remaining ESALs by Load Equivalent Factors. The remaining number of repetitions, in the cases of the use of $100 \%$ dual tires and $100 \%$ super-single tires would be 367,647 and 106,044 , respectively. In the case of the use of $70 \%$ dual tires and $30 \%$ super-single tires in the given problem, the allowable remaining number of repetitions can be calculated using: 
- Allowable remaining number of repetitions = total remaining ESALs/ $(0.7 \times \mathrm{LEF}$ for dual tires $+0.3 \times$ LEF for super-single tires)

As a result, the allowable remaining number of repetitions is 211,282.

- Estimated remaining pavement life $($ year) $=$ (remaining design life $\times$ allowable remaining number of repetitions)/ (remaining number of repetitions for $100 \%$ dual tires)

An estimated remaining life of 5.7 year can be obtained from the above equation. Compared with the 10 year remaining design life, 4.3 year would be shortened due to the increase of the use of single tires. If the pavement is not to be modified with an overlay, the pavement should be rehabilitated 4.3 year earlier than expected. This is a simple example for use of the results of this study. As indicated, the allowable remaining number of repetitions may be different depending on the portions of trucks using different tire types, such as dual tires and super-single tires. Therefore, engineers need to collect reliable information through traffic analysis and use it in pavement analysis.

\section{Example 2: Newly constructed pavement}

For a newly constructed pavement, it would be advisable to account for the effects of super-single tires on subgrade in designing pavements. A newly constructed pavement can be designed as follows. 
Step 1: Through traffic analysis, investigate how many axles with super-single tires per day or year will be used in a pavement and how the trend will change;

Step 2: In calculating ESALs for super-single tires, use damage factors obtained from this study (i.e. $3.5-3.6$ for rutting and $4.9-7.6$ for fatigue). For subgrade evaluation, use rutting damage factors of $3.5-3.6$;

If the pavement is designed following AASHTO design procedure, use AASHTO load equivalency factors for dual tires and obtain the load equivalency factors for the corresponding super-single tires by the following relationship.

- Load Equivalency factors for super-single tires for a given axle load = AASHTO load equivalency factor for the axle load $\times$ damage factor obtained from this study

Step 3: Complete design the pavement under current specifications and procedures.

\subsection{Recommendations}

Analysis results for the typical cross-sections encountered in Indiana showed that the use of super-single tires requires engineers to review current Indiana pavement design procedure and to prepare for the general use of super-single tires. Based on the analysis results, followings are recommended. 
1) As shown previously, super-single tires have more severe influence on typical subgrades than dual tires. This severity might be overcome by use of subgrade improvement methods, such as lime and cement treatment methods, leading to considerable expense. The decision on whether or not subgrade treatment methods are used should be made by significant considerations on the various conditions including economy. However, consideration of improvement of the untreated subgrade in Indiana would be advisable in preparation for the general use of supersingle tires in highways.

2) In order to evaluate the effects of super-single tire loadings on the subgrades in Indiana, this study was conducted for typical subgrades composed of clays or sands, not for various types of subgrade treatments. However, the INDOT specification on subgrade has recently been upgraded to reflect the common use of different types of subgrade treatments in practice (i.e. Type A, B, C, D and E). These types of subgrade treatments are generally used for dehydrating the soils with higher water contents (i.e. due to heavy rain) that do not meet criteria of water contents under a given specification in order to facilitate construction process, as well as improving poor subgrades. It appears that more improved subgrades, such as new specified subgrade types could possibly sustain the heavy truck loadings. However, in order to account for various behavior of each subgrade type, more rigorous analysis in the future is necessary to quantify the effects of heavy truck loadings on those subgrade treatments as an alternative in place of general subgrade compaction. 
3) In the design of new pavements, design engineers needs to collect reliable information on traffic analysis and to use it for considering the effects of super-single tires on pavements as discussed in design examples. The Load Equivalent factors for super-single tires can be used following the procedures shown in the design examples.

4) For the pavements in use, the pavement design life would be shortened due to the use of super-single tires. The reduction of the pavement life will vary with the degree of use of super-single tires. It may be necessary either to limit the repetitions of supersingle tires or to prepare for earlier rehabilitation than expected. This should also be followed by enough consideration on traffic and axle numbers with super-single tires. 


\section{LIST OF REFERENCES}

"The AASHO Road Test". (1962). Report 7, American Association of State High Officials, Washington, D.C.

Akram, T., Scullion, T., Smith, R. E. and Fernando, E. G. (1992). "Estimating Damage Effects of Dual Versus Wide Base Tires with Multidepth Deflectometers", Transportation Research Record, 1355, TRB, National Research Council, Washington, D.C., pp. 59-66.

Barenberg, E. J. and Thompson, M. R. (1992). "Calibrated Mechanistic Structural Analysis Procedures for Pavements, Phase 2 of NCHRP Project 1-26", NCHRP, TRB, Washington, D.C.

Bell, C. A., Randhaw, S. and Xu, Z. K. (1996). "Impact of High-Pressures and SingleTired Axles in Oregon", Transportation Research Record, 1540, TRB, National Research Council, Washington, D.C., pp. 132-141.

Bergado D. T., Anderson, L. R., Miura, N. and Balasubramaniam, A. S. (1996). "Soft Ground Improvement in Lowland and Other Environments", ASCE, New York.

Bonaquist, R. (1992). "An assessment of the increased damage potential of wide base single tires", Proc., $7^{\text {th }}$ international conference on Asphalt Pavements, Vol. 3, pp 1-16.

Burmister, D. M. (1943). "The Theory of Stresses and Displacements in Layered Systems and Applications to the Design of Airport Runways", Proceedings, Highway Research Board, Vol. 23, pp. 126-144.

Chen, W. F. and Saleeb, A. F. (1994). "Constitutive Equations for Engineering Materials", Vol. 2, Elsevier Science B.V, Amsterdam, The Netherlands.

Cook, R. D., Malkus, D. S. and Plesha, M. E. (1989). "Concepts and Applications of Finite Element Analysis, $3^{\text {rd }}$ edition, John Wiley \& Sons.

Croney, D. and Croney, D. (1997). "Design and Performance of Road Pavements", $3^{\text {rd }}$ edition, McGraw-Hill Publishing Company.

Deacon, J. (1969). "Load Equivalency in Flexible Pavements", Proceedings Association of Asphalt Paving Technology, Vol. 38. 
De Beer, M., Fisher, C. and Jooste, F. J. (1997). "Determination of Pneumatic Tire/Pavement Interface Contact Stresses under Moving Loads and Some Effects on Pavements with Thin Asphalt Surfacing Layers", Proceedings of the $8^{\text {th }}$ International Conference on Asphalt Pavements, University of Washington, 1997, pp. 179-227.

Desai, C. C. and Siriwardane, H. J. (1984). "Constitutive Laws for Engineering Materials with Emphasis on Geological Materials, Prentice-Hall, Englewood Cliffs, New Jersey.

Diyaljee, V. A. and Raymond, G. P. (1983). "Repetitive Load Deformation of Cohesionless Soil", Journal of Geotechnical and Engineering, ASCE, Vol. 108, No. 10, pp. 1215-1229.

Drumm, E. C., Boateng-Poku, Y. and Pierce, T. J. (1990). "Estimation of Subgrade Resilient Modulus from Standard Tests." Journal of Geotechnical Engineering, ASCE, Vol. 116, No. 5, pp. 774-789.

Drumm, E. C., Reeves, J. S., Madgett, M.R. and Trolinger, W. D. (1997). "Subgrade Resilient Modulus Correction for Saturation Effects." Journal of Geotechnical and Geoenvironmental Engineering, ASCE, Vol. 123, No. 7, pp. 663-670.

Elliott, R. P., and Thornton, S. I. (1988). "Resilient Modulus and AASHTO Pavement Design." Transportation Research Record, 1196, TRB, National Research Council, Washington, D.C., pp. 116-124.

Elliott, R. P., Dennis, N. and Qiu, Y. (1999). "Permanent Deformation of Subgrade Soils, Phase II: Repeated Load Testing of Four Soils." Report No. MBTC FR-1089, Final Report, National Technical Information Service, Springfiled, VA, pp.1-85.

Feng, A. (1999). "Flexible Pavement Drainage Monitoring, Performance and Stability", Ph.D. Thesis, Purdue Univ., Westlafayette, Indiana.

Finn, F. N., Saraf, C. L., Kulkarni, R., Nair, K., Smith, W. and Abdullah, A. (1986). "Development of Pavement Structural Subsystems", NCHRP NO. 291, TRB, Nation Research Council, Washington, D.C.

Ford, T. L. and Yap, P. (1990). "Truck Tire/Pavement Interface", Proc., The Promise of New Technology in the Automotive Industry: XXIII FISITA Congress, Torino, Italy, pp. 333-340.

Gaskin, P. N., Raymond, G. P. and Addo-Abedi, F. Y. (1979). "Repeated Compressive Loading of a Sand". Canadian Geotechnical Journal, National Research Council of Canada, Vol. 16, pp. 798-802.

Ghazzaly, O. and Ha, H. (1975). "Pore Pressures and Strains After Repeated Loading of Saturated Clay: Discussion." Canadian Geotechnical Journal. National Research Council of Canada, Vol. 12, pp. 265-267. 
Gillespie T. D., Karamihas, S. M., Sayers, M. W., Nasim, M. A., Hansen, W. and Ehsan, N. (1993). "Effect of Heavy Vehicle Characteristics on Pavement Response and Performance", NCHRP Report 353, TRB, National Research Council, Washington, D. C.

Goez, W. H., Mclaughlin, J. H., and Wood, L. E. (1957). "The Strength of a Thin Layer of Bituminous Concrete", Proc., of the Association of Asphalt Paving Technologists, Vol. 26, pp. 237-296.

Hall, D. K. and Thompson, M. R. (1994). "Soil-Property-Based Subgrade Resilient Modulus Estimation for Flexible Pavement Design." Transportation Research Record, 1449, TRB, National Research Council, Washington, D.C., pp. 30-38.

Hallin, J. P., Sharma, J. and Mahoney, J. P. (1983). "Development of Rigid and Flexible Pavement Load Equivalency Factors for Various Widths of Single Tires", Transportation Research Record 949, TRB, National Research Council, Washington, D.C., pp. 4-13.

Hardin, B. O. and Black, W. L (1968). "Vibration Modulus of Normally Consolidted Clay", Journal of Soil Mechanics and Foundation Engineering Division, ASCE, 94(SM2), pp. 353-369.

Hardin, B. O. and Drnevich, V. P. (1972). "Shear Modulus and Damping in soils; Design Equations and Curves", Journal of Soil Mechanics and Foundations Divisions, ASCE, 98(7), pp. 667-692.

Hausmann, M. R. (1990). "Engineering Principles of Ground Modification”, McGrawHill Publishing Company.

Hicks, R. G., and Monismith, C. L. (1971). "Factors Influencing the Resilient Response of Granular Materials". Highway Research Record 345, Highway Research Board, Washington, D.C., pp. 15-31.

Huang, Y. H. (1993). "Pavement Analysis and Design”, Prentice Hall, Englewood Cliffs, N.J.

Huhtala, M., Philajamaki, J. and Pienimaki, M. (1989). "Effects of Tires and Tire Pressures on Road Pavements", Transportation Research Record, 1227, TRB, National Research Council, Washington, D.C., pp. 107-114.

Hyde, A. F. L. (1974). "Repeated load triaxial testing of soils".. Ph.D. Thesis, University of Notingham, U.K..

Indiana State. (1999). “Indiana Specification”. 
Jooste, F. J. and Fernando, E. G. (1995). "Development of a Procedure for the Structural Evaluation of Super-Heavy Load Routes", Researh Report 1335-3F, Texas Transportation Institute, Texas.

Kilareski, W. (1992). "Heavy Vehicle Evaluation for Overload Permits", Transportation Research Record, 1227, TRB, National Research Council, Washington, D.C., pp.194204.

Ladd, C. C., Foote, R., Ishihara, K., Schlosser, F. and Poulos, H. G. (1977). "Stress Deformation and Strength Characteristics", Proc., of $9^{\text {th }}$ International Conference on Soil Mechanics and Foundation Engineering, Tokyo, Vol. 2, pp. 421-494.

Lee, W. (1993). "Evaluation of In-Service Subgrade Resilient Modulus with Consideration of Seasonal Effects", Ph.D. Thesis, Purdue University, West Lafayette, IN.

Lee, W. J., Bohra, N. C., Altschaeffl, A. G. and White, T. D. (1997). "Resilient Modulus of Cohesive Soils", Journal of Geotechnical and Geoenvironmental Engineering, ASCE, Vol. 123, No. 2, pp. 131-136.

Lee, W., Bohra, N. C. and Altschaeffl, A.G. (1995). "Resilient Characteristics of Dune Sand", Journal of Transportation Engineering, ASCE, Vol. 121, No. 6, pp. 502-506.

Lekarp, F., Isacsson, U. and Dawson, A. (2000). "State of The Art. I: Resilient Response of Unbound Aggregates", Journal of Transportation Engineering, Vol. 126, pp.66-75.

Lekarp, F. and Dawson, A. (1998). "Modeling Permanent Deformation Behavior of Unbound Granular Materials", Construction and Building Materials, Elsevier Science Ltd, Vol. 12, No. 1, pp. 9-18.

Lekarp, F., Isacsson, U. and Dawson, A. (2000). "State of The Art. II: Permanent Strain of Unbound Aggregates", Journal of Transportation Engineering, Vol. 126, pp.76-83.

Lentz, R.W. and Baladi, G.Y. (1981). "Constitutive Equation for Permanent Strain of Sand Subjected to Cyclic Loading." Pumphrey, N.D. Jr., and Lentz, R.W.. "Deformation Analyses of Florida Highway Subgrade Sand Subjectd to Repeated Load Triaxial Tests", Transportation Research Record, 810, TRB, National Research Council, Washington, D.C., 1986, pp. 50-54.

Marshek, K. M., Chen, H. H., Conell, R. B. and Hudson, R. W. (1986). "Experimental Determination of Pressure Distribution of Truck Tire-Pavement Contact", Transportation Research Record, 1070, TRB, National Research Council, Washington, D.C., pp. 9-13.

Michelin, Inc. (1997). "Michelin Truck Tire Characteristics May 1997”. 
Mohammad, L. N., Titi, H. H. and Herath, A. (1999). "Evaluation of Resilient Modulus of Subgrade Soil by Cone Penetration Test", Transportation Research Record, 1652, TRB, National Research Council, Washington, D.C., pp. 236-245.

Mohammad, L. N., Puppala, A. J. and Alavilli, P. (1995). "Resilient Properties of Laboratory Compacted Subgrade Soils", Transportation Research Record, 1196, TRB, National Research Council, Washington, D.C., pp. 87-102.

Monismith, C. L., Ogawa, N. and Freeme, C.R. (1975). "Permanent Deformation Characteristics of Subgrade Soils Due to Repeated Loading", Transportation Research Record, 537, TRB, National Research Council, Washington, D.C., pp. 1-17.

Muhanna, A. S., Rahman, M. S., and Lambe, P. C. (1998). "Model for Resilient Modulus and Permanent Strain of Subgrade Soils", Transportation Research Record, 1619, TRB, National Research Council, Washington, D.C., pp. 85-93.

Mrad, N., El-Gindy, N. and Kenis, W. (1998). "Effects of Wheel-Load Spatial Repeatability on Road Damage. A Literature Review", Federal Highway Admistration, Report No. FHWA-RD-97-036, McLean, VA.

Myers, L. A., Roque, R., Ruth, B. E. and Drakos, C. (1999). "Measurement of Contact Stresses for Different Truck Tire Types to Evaluate Their Influence on Near-Surface Cracking and Rutting." Transportation Research Record, 1655, TRB, National Research Council, Washington, D.C., pp. 175-184.

Odermat, N., Janoo, V. and Magnusson, R. (1999). "Analysis of Pavement Deformation in Subgrade Material Using a Heavy Vehicle Simulator", Proceedings, Conference on Accelerated Pavement Testing, Reno, Nevada.

Perdomo, Dario. and Nokes , Bill (1993). " Theoretical Analysis of the Effects of Super single Tires on Flexible Pavements using Circly", Transportation Research Record, 1388, TRB, National Research Council, Washington, D.C., pp. 108-119.

Pezo, R. F., Kim, D., Stokoe, K. H. II. and Hudson, W. R. (1991). "A Reliable Resilient Modulus Testing System", Transportation Research Record, 1307, TRB, National Research Council, Washington, D.C., 1990, pp. 90-98.

Pezo, R. and Hudson, W. R. (1994). "Prediction Models of Resilient Modulus for Nongranular Materials", Geotechnical Testing Journal, Vol. 17, No. 3, pp. 349-355.

Poulsen, J. and Stubstad, R. N. (1978). "Laboratory Testing of Cohesive Subgrades: Results and Implications Relative to Structural Pavement Design and Distress Models", Transportation Research Record, 671, TRB, National Research Council, Washington, D.C., pp. 84-91. 
Pumphrey, N. D. Jr. and Lentz, R. W. (1986). "Deformation Analyses of Florida Highway Subgrade Sand Subjectd to Repeated Load Triaxial Tests", Transportation Research Record, 1089, TRB, National Research Council, Washington, D.C., pp. 49-56.

Puppala, A. J., Mohammad, L. N. and Allen, A. (1996). "Non-Linear Models for Resilient Modulus Characterization of Granular Soils", Proceedings of Engr. Mechanics, ASCE, New York, N.Y., USA, Vol. 1, pp. 559-562.

Raad, L. and Zeid, B.A. (1990). "Repeated Load Model for Subgrade Soils: Model Development", Transportation Research Record, 1278, TRB, National Research Council, Washington, D.C., pp. 72-82.

Raymond, G. P., Gaskin, P. N. and Addo-Abedi, F. Y. (1979). "Repeated Compressive Loading of Leda Clay", Canadian Geotechnical Journal. National Research Council of Canada, Vol. 16, pp. 1-10.

Salgado, R. (1995). “Analysis of Penetration Resistance in Sand”, Ph.D. Thesis, Univ. of California, Berkeley, California.

Salgado, R., Bandini, P. and Karim, A. (1999). "Stiffness and Strength of Silty Sand", Journal of Geotechnical and Geoenvironmental Engineering, ASCE, 126(5), pp. 451-462.

Sebaaly, P. and Tabatabaee, N. (1989). "Effect of Tire Pressure and Type on Response of Flexible Pavement." Transportation Research Record, 1227, TRB, National Research Council, Washington, D.C., pp. 115-127.

Sebaaly, P. and Tabatabaee, N. (1992). "Effect of Tire Parameters on Pavement Damage and Load-Equivalency Factors." Journal of Transportation Engineering, Vol. 118, No. 6, pp. 115-127.

Seed, H. B. and Chan, C.K. (1959). "Structure and Strength Characteristics of Compacted Clays", Journal of Soil Mechanics and Foundation Engineering Division, ASCE, Vol. 85, No. 5, pp. 87-128.

Seed, H. B. and Chan, C.K. (1957). "Thixotropic Characteristics of Compacted Clays", Journal of Soil Mechanics and Foundation Engineering Division, ASCE, Vol. 83, No. 6, pp. 31-47.

Seed, H. B., and Chan, C. K. (1958). "Effect of Stress History and Frequency of Stress Application on Deformation of Clay Subgrades Under Repeated Loading", Proc., Highway Research Record, Vol. 37, Highway Research Board, Washington, D.C., pp. $555-575$. 
Siddharthan, R.V. and Sebaaly, P. (1999). "Investigation of Asphalt Concrete Layer Strains from Wide-Base Tires”, Transportation Research Record, 1655, TRB, National Research Council, Washington, D.C., pp. 168-174.

Siddharthan, R. V., Yao, J. and Sebaaly, P. (1998). "Pavement Strain From Moving Dynamic 3D Load Distribution", Journal of Transportation Engineering. Vol. 124, No. 6, pp. 557-565.

The Asphalt Institute. (1982). "Research and Development of the Asphalt Institute's Thickness Design Manual (MS-1)", $9^{\text {th }}$ edition, Research Report 82-1, College Park, Maryland.

The Asphalt Institute. (1983). “Asphalt Overlays for Highway and Street Rehabilitation”, Manual series No. 15.

Thompson, M. R. and Robnett, Q.L. (1979). "Resilient Properties of Subgrade Soils." Journal of Transportation Engineering, ASCE, Vol. 105, No. 1, pp. 71-89.

Tielking, J. T. (1994). "Force Transmissibility of Heavy Truck Tires", Tire Science and Technology, Vol. 22, No. 1, pp. 60-74.

Weissman, S. L. (1999). "Influence of Tire-Pavement Contact Stress Distribution on Devlopment of Distress Mechanisms in Pavements", Transportation Research Record, 1655, TRB, National Research Council, Washington, D.C., pp. 161-167.

Wilson, B. E., Sargand, S. M., Hazen, G. A., and Green, R. (1990). "Multiaxial Testing of Subgrade", Transportation Research Record, 1278, TRB, National Research Council, Washington, D.C., pp. 91-95.

Wilson, N. E., and Greenwood, J. R. (1974). "Pore Pressures and Strains After Repeated Loading of Saturated Clay." Canadian Geotechnical Journal, National Research Council of Canada, Vol. 11, pp. 269-277.

Yap, P. (1988). "A Comparative Study of the Effect of Truck Tire Types on Road Contact Pressures", Paper 881846, Society of Automotive Engineers, Inc., pp. 53-59.

Zaghoul, S. and White, T. D. (1994). "Guidelines for Permitting Overloads-Part 1: Effect of Overloaded Vehicles on the Iniana Highway Network, FHWA/IN/JHRP-93-5, Purdue University, West Lafayette, Indiana. 